Universidad Nacional de La Plata

Facultad de Ciencias Naturales y Museo

Tesis Doctoral

\title{
PALEOBIOLOGÍA DE LA ASOCIACIÓN FAUNÍSTICA DE CALEUFÚ (LA PAMPA, FORMACIÓN CERRO AZUL, MIOCENO SUPERIOR - PLIOCENO INFERIOR), A TRAVÉS DE ANÁLISIS TAFONÓMICOS
}

\author{
Por Claudia Inés Montalvo \\ Directora Dra. María Guiomar Vucetich \\ Codirector Dr. Silvio A. Casadío
}




\section{$\underline{\text { Indice }}$}

Índice

Resumen.

Agradecimientos

Capítulo 1 Introducción.

Introducción

Marco teórico.

Antecedentes estratigráficos y paleontológicos

Objetivos, hipótesis y estructuración del trabajo.

Materiales y métodos.

Capítulo 2 Asociación faunística de la Formación Cerro Azul en Caleufú

Antecedentes.

Situación geográfica del área de estudio.

Contexto geomorfológico del afloramiento de la Formación Cerro Azul en Caleufú.

Estratigrafía.

Análisis taxonómico.

Comparación de la asociación faunística de Caleufú con otras de la Formación Cerro Azul.

Capítulo 3 Representación anatómica y taxonómica de los restos recuperados...........

Cálculo del número de restos (NR).

Cálculo del número de especímenes identificados por taxón (NEIT)

Cálculo del número mínimo de elementos esqueléticos (NME) y número mínimo de individuos (NMI)

NMI y masa corporal estimada.

Diversidad y abundancia relativa de los componentes anatómicos representados en la asociación y en cada taxón.

Análisis de la representación anatómica y taxonómica de los microvertebrados......

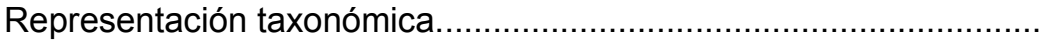

Espectro de edad

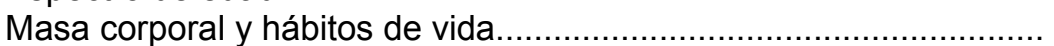

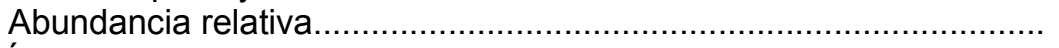

Índices.

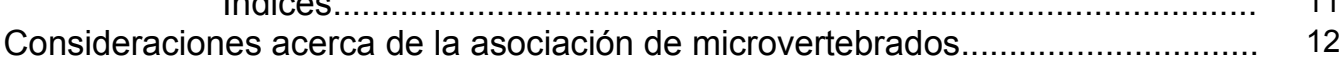

Capítulo 4 Otros atributos tafonómicos ..................................................................... 122

Grado de biodegradación.............................................................................. 123

Asociación de microvertebrados............................................. 126

Coprolitos...................................................................... 131

Coprolitos enteros................................................... 131

Fragmentos de coprolitos.................................................. 134

Fragmentos óseos asociados con muy fuerte grado de digestión que indicaría que estuvieron incluidos en un coprolito.

Grado de bioerosión.

Atributos bioerosivos relacionados con la actividad de los depredadores sobre los elementos esqueléticos en el momento de la muerte de la presa..

Marcas de dientes.

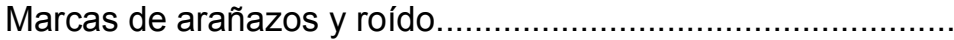

Corrosión sobre los restos

Señales producidas por el crecimiento de raíces.

Corrosiones provocadas por hongos y bacterias y ácidos propios del sustrato.

Corrosiones producidas por el desarrollo de líquenes sobre la superficie. 
Elementos esqueléticos enteros

Rotura de elementos postcraneanos en la asociación de microvertebrados...

Tipo de rotura de hemimandíbulas...................................... 163

Tipo de rotura de cráneos............................................. 167

Índice de fragmentación.............................................. 167

Coprolitos

Pérdida de dientes y dientes aislados............................... 169

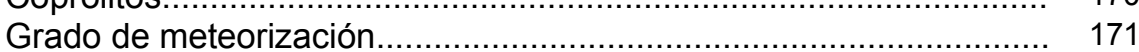

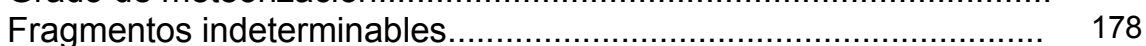

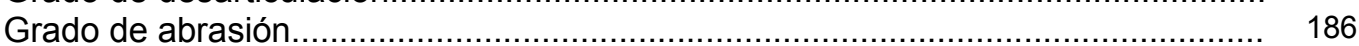

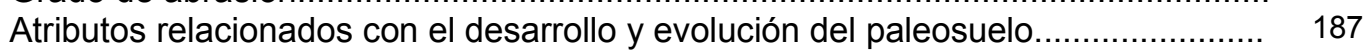

Grados de encostramiento, desarrollo de concreciones calcáreas y relleno sedimentario....................................................... 188

Impregnaciones por óxidos de manganeso.............................. 197

Grado de dispersión.

Grado de reagrupamiento................................................................. 202

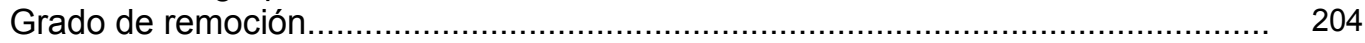

\section{Capítulo 5 Discusión}

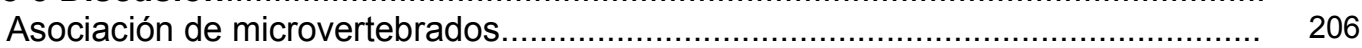

Consideraciones acerca de los depredadores........................... 208

Mamíferos candidatos a ocupar el papel de depredador................. 213

Otros atributos de la etapa bioestratinómica.................................. 215

Asociación de mamíferos de mayor talla corporal.............................................. 218

Desarrollo del suelo e interpretación de los atributos adquiridos después del enterramiento

Historia tafonómica de la asociación faunística de Caleufú................................ 224

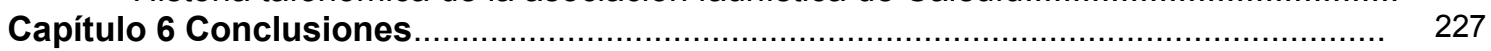

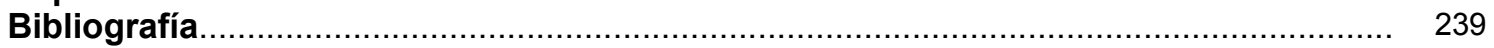




\section{$\underline{\text { Resumen }}$}

Se realizaron estudios detallados de la asociación faunística proveniente de niveles de la Formación Cerro Azul (Mioceno superior - Plioceno inferior) aflorantes en Caleufú, al Norte de la provincia de La Pampa. Los mismos incluyen la descripción de los niveles portadores, la revisión sistemática de los taxa presentes y el análisis tafonómico de los restos recuperados y de la asociación en conjunto. Se planteó una investigación en la que la información tafonómica aporta datos significativos a la investigación taxonómica y estratigráfica.

Los niveles de la Formación Cerro Azul en Caleufú son limolitas loessoides con evidencias de pedogénesis y diagénesis. La asociación faunística está constituida por reptiles de la Familia Teiidae y la Superfamilia Colubroidea, aves indeterminadas y mamíferos de los órdenes Xenarthra (Dasypodidae, Glyptodontidae y Mylodontidae), Didelphimorphia (Didelphidae, Sparassocynidae), Orden indet. (Argyrolagidae), Rodentia (Echimyidae, Octodontidae, Chinchillidae, Dinomyidae, Caviidae y Muridae Sigmodontinae), Notoungulata (Hegetotheriidae, Mesotheriidae), Litopterna (Proterotheriidae) y Carnivora. Se registraron 11 taxa de mamíferos atribuibles a la Edad mamífero Huayqueriense y 6 taxa indicadores de mayor modernidad, por lo que esta asociación puede ser ubicada en el Mioceno tardío - Plioceno temprano, cercana aunque algo más antigua que la Edad mamífero Montehermosense.

Los especímenes recuperados fueron agrupados en dos categorías, de acuerdo con la presencia de ciertos atributos tafonómicos y a su masa corporal estimada: los microvertebrados (menos de $5 \mathrm{~kg}$ ) y los mamíferos de mayor talla corporal (más de $5 \mathrm{~kg}$ ).

El análisis de los microvertebrados, basado en la representación taxonómica, el espectro de edad, la abundancia relativa de los elementos esqueléticos, los tipos de rotura tanto en elementos craneanos como en postcraneanos, las evidencias de digestión y las marcas de dientes y rasguños, sugiere que su acumulación se produjo como resultado de la actividad de depredadores, probablemente mamíferos carnívoros.

El grupo de los macromamíferos tiene una diversidad taxonómica alta, con al menos 15 taxa y presenta bajo número mínimo de elementos esqueléticos y 
también de individuos. Los especímenes de esta categoría tienen alto grado de meteorización, desarticulación y rotura. Se interpretó, de acuerdo con estos atributos, que los restos se originaron a partir de la mortalidad natural de individuos de comunidades sucesivas que vivieron en el área y que estuvieron sujetos a factores destructivos que actuaron previo al enterramiento.

Se encontraron además 66 coprolitos de tamaño pequeño. Presentan una alta densidad de fragmentos óseos, que tienen un grado fuerte o extremo de digestión y marcas de dientes o de mordida. Se determinaron algunos restos incluidos en los coprolitos que, coincidentemente, son representantes de los taxa más frecuentes de la asociación de microvertebrados. De acuerdo al grado de digestión, marcas de dientes y tipos de rotura de los elementos óseos, estos coprolitos podrían ser asignados a mamíferos carnívoros. La presencia de representantes de la asociación de microvertebrados entre los restos óseos incluidos en los coprolitos avalaría su sincronismo con aquella asociación y sugeriría, además, que los productores de los coprolitos y los de la asociación de microvertebrados podrían ser los mismos.

La incorporación de especímenes al suelo fue un proceso gradual, aunque los restos de microvertebrados acumulados en un período breve durante el desarrollo de ese suelo presentan caracteres que indican que su enterramiento fue rápido. Para los representantes de la asociación de macromamíferos, el proceso de incorporación implicó un tiempo mayor que estaría relacionado con el lapso de estabilidad que permitió la formación y desarrollo del suelo. De este modo, la asociación de Caleufú sería una asociación condensada en la que los restos de microvertebrados y los de macromamíferos representan diferentes intervalos temporales.

Los especímenes que se incorporaron al suelo fueron rápidamente encostrados, cementados e incluidos en concreciones calcáreas. Estas características evitaron que fueran afectados por agentes destructivos que actuaban en el suelo y permiten explicar, también, la preservación de un porcentaje muy elevado de elementos asignados a juveniles de tamaño muy pequeño que, de otro modo, sin estas estructuras protectoras, deberían haber sido destruidos en el ambiente en el que se encontraban enterrados. Si bien el 
ambiente de depositación era básico, de tipo incrustante, a escala menor, el microambiente del suelo que rodeó a algunos especímenes pudo haber tenido, en diferentes momentos, un $\mathrm{pH}$ más bajo, ya que sobre los restos hay diferentes evidencias de corrosión por agentes propios del suelo, crecimiento de raíces y hongos. Por otro lado, ciertos procesos pedoturbadores pueden haber favorecido la movilidad horizontal y vertical de los fósiles en el área. Este proceso puede ser el responsable de parte de la reelaboración observada, verificada mediante la presencia de marcas de líquenes y de roído. 


\section{Agradecimientos}

Expreso mi agradecimiento a Guiomar Vucetich quien orientó mi trabajo de investigación durante muchos años y me alentó para la realización de esta tesis.

A Silvio Casadío, quien ayudó a la concreción de este trabajo, alentándome, pero a la vez discutiendo y corrigiendo mis escritos, incansablemente.

A Sixto Fernández López y a Yolanda Fernández Jalvo, quienes me ayudaron a comprender mejor la problemática de esta tesis y respondieron siempre rápidamente a mis consultas.

A Luciano De Santis, Francisco Goin, Alejandra Abello, Graciela Esteban, Norma Nasif y Adriana Albino quienes colaboraron en la determinación de los especímenes.

A Diego Verzi por su colaboración en las distintas etapas de este trabajo.

A Graciela Visconti, quien además de participar en las tareas de campo, realizó parte del análisis estratigráfico.

A Sergio Tiranti y Mariana Rocha, quienes colaboraron en las tareas de campo y posteriormente en las determinaciones taxonómicas.

A Oscar Ruggero y Sergio Sidam por su asistencia para la realización de las figuras y láminas.

A Marcelo Zarate, Ana Parras, Diego Villarreal, Eduardo Mariño, Edsel Brussa y Ricardo Melchor, quienes realizaron en diversas oportunidades valiosas sugerencias. Con Marcelo Zarate he tenido enriquecedoras conversaciones sobre algunos aspectos de esta tesis.

A Graciela Alfonso y Bárbara Corró Molas que se hicieron cargo en muchas oportunidades de mis clases.

A la Facultad de Ciencias Exactas y Naturales de la Universidad Nacional de La Pampa que aportó los fondos para la realización de esta tesis, y en particular a María C. Martín quien los gestionó.

A Enrique, mi marido y a mis hijos que me ayudaron de muchas maneras, siempre.

A todos ellos, mi más sincero agradecimiento 


\section{Capítulo 1 INTRODUCCIÓN}


$\underline{\text { Introducción }}$

Las primeras menciones de vertebrados fósiles de La Pampa corresponden a Ameghino (1904), Rovereto (1914), Kraglievich (1932) y Rusconi (1934) quienes describieron mamíferos hallados al realizar perforaciones para la extracción de agua en la zona central y del Este de la provincia. Posteriormente, Cabrera (1939) describió restos hallados en sedimentitas areno-limosas aflorantes en el Oeste de la provincia de Buenos Aires. Pascual (1961) señaló que los fósiles coleccionados en esa zona y, por extensión, en el Este de La Pampa, eran más modernos que los provenientes de la Formación Arroyo Chasicó (Mioceno superior). En esa oportunidad, los niveles portadores fueron asignados a la "Formación Epecuén". Estas sedimentitas areno-limosas se extienden en una amplia zona del área pampeana, y en la provincia de La Pampa recibieron distintas denominaciones, v.g. "Formación Araucana" (Doering, 1882), "Formación Pampeano" (Stappenbeck, 1926), "Formación Epecuén" (Pascual, 1961 y Pascual y Bocchino, 1963). Actualmente estos depósitos se asignan a la Formación Cerro Azul (sensu Llambías, 1975; Linares et al., 1980 y Goin et al., 2000) y las asociaciones faunísticas recuperadas a las Edades mamífero Chasiquense y Huayqueriense, Mioceno tardío (Verzi, 1999).

En La Pampa, la localidad clásicamente estudiada fue Salinas Grandes de Hidalgo (departamento Atreucó), cuyas barrancas han aportado numerosos restos de mamíferos asignados a Xenarthra, Marsupialia, Litopterna, Notoungulata, Rodentia y Carnivora. Éstos sirvieron como base a los trabajos sistemáticos efectuados por Pascual y Bocchino (1963), Pascual et al. (1965), Ortega Hinojosa (1967) y Zetti (1967, 1972 a y b). También provienen de esa localidad restos de aves (Campbell y Tonni, 1980, 1981; Tambussi, 1987; Vizcaíno y Fariña, 1999) y de hormigueros fósiles (Laza, 1982).

El estudio de las sedimentitas de la Formación Cerro Azul se incrementó en los últimos años y en particular el de los restos fósiles recuperados. Así, se relevaron numerosos afloramientos, se mejoró su conocimiento sedimentológico y litoestratigráfico (Montalvo et al., 1995, 1996; Visconti et al., 1996; Goin et al., 
2000) y se recolectaron abundantes y diversas asociaciones faunísticas, constituidas fundamentalmente por mamíferos (Montalvo y Szelagowski, 1999).

Se describieron, además, nuevos taxa y se reconocieron por primera vez para esta formación especies conocidas para otras áreas del país (Montalvo y Casadío, 1988; Goin y Montalvo, 1988; Verzi et al., 1990, 1991, 1993, 1994, 1995, 1996, 1999 a y b, 2003; Montalvo y Rocha, 2001, 2003; Montalvo y Cerdeño, 2002; Montalvo et al., 1995, 1996, 1998, 1999, 2000 a y b; Rocha y Montalvo, 1999; Goin et al., 1997, 2000; Esteban et al., 1996, 2001, 2003; Cerdeño y Montalvo, 2001, 2002), lo que permitió ampliar los datos para una correlación bioestratigráfica.

El incremento en el conocimiento de la diversidad faunística para la Formación Cerro Azul, permitió detectar diferencias en la composición entre algunas de las asociaciones exhumadas en distintas localidades de la Formación Cerro Azul. Ello, junto con el análisis particular de los caracteres dentarios de algunos taxa, sobre todo de roedores Octodontidae y Echimyidae, facilitó la identificación de procesos anagenéticos que permitieron establecer una propuesta bioestratigráfica para esta formación (Verzi, 1994, 1999, 2002; Verzi et al., 2003, en prensa).

Además de los aspectos estratigráficos y sistemáticos, llamó nuestra atención desde las primeras prospecciones, que en algunos de los afloramientos de la Formación Cerro Azul los restos se presentaban constituyendo concentraciones con particularidades tafonómicas que merecían estudio y valoración contextual. Las características de estos yacimientos mostraban que el análisis de cada asociación y las relaciones paleoecológicas de sus integrantes no podía ser realizado en su conjunto sin tener en cuenta la historia pre y post depositacional de los restos en cada localidad. Por ello y con la finalidad de interpretar la historia de las concentraciones, las asociaciones faunísticas fueron estudiadas utilizando la metodología del análisis tafonómico.

El término tafonomía fue establecido por Efremov (1940) para referirse a la disciplina paleontológica que estudia los procesos de fosilización. La definió como el estudio de la transición de los restos orgánicos desde la biósfera a la litósfera. 
Para el desarrollo de este trabajo de investigación y de acuerdo a las propuestas de Fernández López $(1988,2000)$ se consideró a la tafonomía como un subsistema conceptual de la paleontología "que aspira a explicar cómo se ha producido y qué modificaciones ha experimentado el registro fósil" (Fernández López, 1988:15). Al registro fósil se lo interpreta con naturaleza y dinámica propia, por lo tanto como un sistema organizado capaz de mantener y transmitir información. De este modo, se considera que el proceso de fosilización aumenta la información producida originalmente y la información que aumenta es información tafonómica (Fernández López, 1989, 1991).

Se planteó un tipo de investigación en el que la información tafonómica sume datos a la investigación taxonómica y estratigráfica. De esta forma se ajustaron las interpretaciones surgidas del análisis tafonómico con las paleoambientales y paleoecológicas realizadas sobre la base de la presencia de determinados taxa en cada asociación faunística. Para ello, se prestó especial atención a los aspectos relacionados con la bioestratinomía y con la fosildiagénesis, es decir con aquellos atributos relacionados con las modificaciones ocurridas sobre los elementos esqueléticos antes del enterramiento, en el primer caso, y aquellos ocurridos después del enterramiento inicial en el segundo (Fernández López y Fernández Jalvo, 2002). Los restos producidos por la fauna del pasado recuperados de los afloramientos, son potenciales informadores de las diversas estrategias biológicas, de datos paleoclimatológicos, paleoambientales y paleoecológicos, entre otros. Tal como lo señaló Behrensmeyer (1991), se tuvo en cuenta el contexto estratigráfico ya que, si bien la caracterización sedimentaria debe ser independiente del análisis que se realice sobre el tipo de preservación de los elementos, los procesos sedimentológicos y tafonómicos interactúan entre sí y con los restos depositados.

El análisis tafonómico se orientó a evaluar, en primer lugar, los atributos tafonómicos de los elementos conservados, entendiendo como tales a todos los restos o señales de las entidades biológicas del pasado (Fernández López, 2000). Estos atributos brindaron información sobre los acontecimientos que afectaron a los restos después de la muerte de los animales productores. Por lo tanto, de acuerdo con Blasco Sancho (1995) el hilo conductor de este análisis fue la 
valoración de la asociación a partir de los atributos tafonómicos detectados en los elementos que la forman. Por este medio se descodificó analíticamente la información paleobiológica que fue encriptada durante la fosilización, tal como lo plantearon Palmqvist et al. (1999, 2001), de modo tal que fuera posible poner de manifiesto en la asociación faunística sesgos consecutivos acontecidos durante la etapa bioestratinómica (que pudieron haber afectado la composición original) y sesgos que afectaron a esa asociación una vez que los restos fueron enterrados.

El estudio de los mamíferos fósiles tiene una historia importante en Argentina, si bien su abordaje ha estado clásicamente orientado a temas de identificación taxonómica, filogenia y distribución geográfica y temporal. Son pocos los yacimientos continentales con mamíferos terciarios que fueron objeto de análisis tafonómicos. Entre ellos, se encuentran los estudiados por Bown y Larriestra (1990) y Tauber (1997 a y b) para asociaciones del Mioceno inferior de Patagonia mientras que Peña (1997) hizo lo propio para el Plioceno superior del partido de General Pueyrredón en la provincia de Buenos Aires. Estos análisis ayudaron a mejorar la interpretación ecológica disponible para esas asociaciones.

Este trabajo se centra en el análisis tafonómico de la asociación faunística recuperada de sedimentitas de la Formación Cerro Azul en Caleufú, al Norte de la provincia de La Pampa, asociación que fue recuperada desde su hallazgo con criterios tafonómicos. Este análisis permite reconstruir la historia tafonómica de la misma.

\section{Marco teórico}

Como ya se indicó, esta tesis se realizó de acuerdo a los lineamientos teóricos para la disciplina tafonómica propuestos por Fernández López (2000).

En sentido estricto, la tafonomía es un subsistema conceptual de la paleontología que aspira a explicar cómo se produjo y que modificaciones experimentó el registro fósil.

Los acontecimientos ocurridos desde la muerte de un organismo hasta su descubrimiento se pueden dividir en dos categorías de procesos, los que ocurrieron sobre los elementos antes del enterramiento (bioestratinómicos) y los 
ocurridos después del enterramiento inicial (fosildiagenéticos). Ambos constituyen subsistemas de la tafonomía.

El proceso tafonómico-paleoecológico por el cual, a partir de los organismos se generan las entidades tafonómicas (los fósiles), se denomina producción biogénica. La producción puede o no implicar la muerte del organismo. Cada resto o señal, llamado fósil, pudo haber sido producido al morir un organismo, pero también cuando un organismo del pasado realizaba alguna actividad o a partir de restos preexistentes, por lo que los procesos generadores de los fósiles no necesariamente están relacionados con la muerte. El proceso tafonómico por el que, a partir de entidades tafonómicas se originan nuevas entidades tafonómicas se denomina producción tafogénica. De lo expuesto surge que la tafonomía se ocupa de las modificaciones que han experimentado las entidades tafonómicas desde su producción biogénica o tafogénica hasta la actualidad. Las entidades tafonómicas no son entidades ni biológicas ni paleobiológicas, si bien portan información paleobiológica y fueron generadas directa o indirectamente por organismos del pasado.

Las entidades tafonómicas que son objeto de estudio de la tafonomía van desde el menor nivel de organización, los elementos conservados (cualquier resto o señal de un organismo del pasado), hasta las asociaciones conservadas, los tafosistemas y el registro fósil. La asociación conservada es un grupo de restos y/o señales, generado por representantes de uno o más taxa. De lo expuesto surge el postulado de emergencia: la existencia de sistemas tafonómicos jerárquicamente organizados; éstos sistemas están constituidos por entidades tafonómicas elementales (los elementos conservados) o supraelementales (asociaciones conservadas). Cada entidad tafonómica y su ambiente interactúan entre sí y constituyen un sistema tafonómico particular.

El término acumulación designa al proceso de entrada de información en la litósfera, a partir de la biosfera. La acumulación puede o no estar acompañada de materia y no implica sedimentación. Las asociaciones tafonómicas pueden haber sido afectadas por dos procesos luego de haber sido acumuladas, la resedimentación y la reelaboración. La resedimentación consiste en el desplazamiento sobre el sustrato antes de ser enterrados, de elementos 
previamente acumulados. La reelaboración es el proceso de alteración tafonómica que consiste en el desenterramiento y desplazamiento de restos y señales de organismos pretéritos. Por lo tanto, los distintos estados mecánicos de conservación en que se pueden encontrar los elementos conservados después de su enterramiento final son 3: acumulado, resedimentado y reelaborado. De este modo es posible establecer relaciones espacio-temporales entre los elementos conservados y los cuerpos rocosos en los que se encuentran.

Junto a los postulados de producción y emergencia, cualquier investigación tafonómica debe tener en cuenta un tercero: el postulado de modificación, que indica que las entidades tafonómicas no son inertes o pasivas y que están involucradas en algún proceso. Por eso, la conservación tafonómica es el resultado de las sucesivas modificaciones ocurridas por alteración tafonómica. A este respecto, las modificaciones tafonómicas pueden ser explicadas de acuerdo a dos modelos alternativos de fosilización, según se utilice un planteamiento transformista o evolucionista.

El primer modelo, llamado de modificación paleobiológica y destrucción selectiva, parte de la base de que la fosilización es la transición del estado vivo al fósil, debido a la propia naturaleza de los organismos o a la intervención de agentes que han actuado a modo de filtros sucesivos y han eliminado los restos menos resistentes o preservables. La composición taxonómica de cada yacimiento está determinada por los procesos selectivos que han ocurrido durante su formación. La fosilización implica pérdida y disminución de la información paleobiológica. De acuerdo con este modelo, la fosilización es un proceso en el que diferentes factores ambientales han causado la destrucción selectiva de los restos organógenos del pasado y por el cual ha disminuido la información paleobiológica. Solo algunos organismos del pasado han alcanzado el estado fósil. Persisten los restos o señales más resistentes que no han sido destruidos.

El modelo evolucionista de la fosilización se desarrolla teniendo en cuenta los postulados previamente descriptos de producción, emergencia y modificación. Se parte de que el registro fósil posee un cúmulo de información paleobiológica distinta a la de la biósfera porque es de distinta naturaleza, y se distingue de aquella no sólo por su composición y estructura, sino también por las 
modificaciones que ha experimentado. Se entiende a la fosilización como un proceso no paleobiológico, experimentado por entidades tafonómicas, que no implica pérdida o disminución de la información paleobiológica. Se interpreta a los factores tafonómicos como no necesariamente destructivos y a la fosilización como un proceso capaz de incrementar la información tafonómica.

\section{Antecedentes estratigráficos y paleontológicos}

Tanto en el Oeste de la provincia de Buenos Aires como en el Este de la de La Pampa se conoce desde hace tiempo la presencia de afloramientos fosiliferos asignables al Mioceno superior (Cabrera, 1939; Pascual, 1961; Zetti, 1967). Se trata de sedimentitas limo-arenosas, en general de escasa extensión areal y espesor. La similitud litológica y la fauna exhumada de aquellos afloramientos fue la que tradicionalmente indujo a extrapolar los resultados obtenidos de una a otra área. Esa similitud complicó también la historia nomenclatorial de las unidades formacionales que se describieron (Goin et al., 2000). Los niveles aflorantes en la provincia de La Pampa, y en particular los de las barrancas que bordean a las Salinas Grandes de Hidalgo fueron incluidos por extensión en la "Formación Epecuén" y su fauna asignada al Mioceno tardío, Edad mamífero Huayqueriense (Pascual y Bocchino, 1963; Pascual et al., 1965; Ortega Hinojosa, 1967; Zetti, 1972 a; Campbell y Tonni, 1980; Laza, 1982; Tambussi, 1987). A esa misma edad fue referida la asociación faunística recuperada en el "Valle de General Acha", que corresponde a la que aquí se denomina Laguna Chillhué (Pascual y Bondesio, 1982). Los niveles portadores se interpretaron como Formación Pampeano (según el criterio de Stappenbeck, 1926; Salso, 1966) y si bien Pascual y Bondesio (1982) discutieron esa asignación, queda claro que correlacionaron estos niveles con los de la "Formación Epecuén".

Posteriormente, los niveles portadores se asignaron a la Formación Cerro Azul (sensu Llambías, 1975; Linares et al., 1980). Esta formación fue descripta en un informe inédito por Llambías (1975:31); en ella se incluyeron "...los limos arenosos pardo rosados a rojizos, sin estratificación interna o muy poco visible, con frecuentes clastos de arcilla rojiza del tamaño de una nuez, dispuestos horizontalmente. Presenta forma de erosión tipo loess con barrancas y cañadones 
abruptos. En la parte superior, los sedimentos están reemplazados por tosca...". Esta formación fue descripta formalmente por Linares et al. (1980), de acuerdo a la información proporcionada por Llambías (1975).

Goin et al. (2000: 104 y 106) reconocieron tres asociaciones de facies en la Formación Cerro Azul (Figura 1.1). De base a techo son las siguientes:

Asociación de facies A: Alcanza hasta $8 \mathrm{~m}$ de espesor y está compuesta por rocas pelíticas y areniscas finas de color rojo pálido (10 $R$ 6/2). En este conjunto se presentan arcillitas y limolitas en capas con laminación paralela con muy buena continuidad lateral. En algunas aparece laminación convoluta. En las capas de areniscas finas puede observarse laminación entrecruzada tabular planar, con óndulas simétricas sobreimpuestas que separan las superficies de los "sets". Las evidencias de bioturbación son numerosas, por ejemplo, hormigueros y rizoconcreciones. Las capas de limolitas y arcillitas han sido generadas por decantación suspensiva en un medio ácueo (evidenciados por las laminaciones paralela y convoluta). Las capas de areniscas constituyen depósitos producidos por corrientes unidireccionales sobre las que hubo retrabajo de olas. Esto implica alternancia de condiciones tractivas subácueas seguidas de exposición subaérea. A todo el conjunto se lo interpreta como una acumulación en un ambiente lacustre somero, sobre el que posteriormente actuaron procesos pedogenéticos.

Asociación de facies $B$ : Su espesor máximo es de unos $30 \mathrm{~m}$. Está constituida por una sucesión de limolitas areno-arcillosas entre las que se intercalan areniscas limo-arcillosas tipo loess. Los principales atributos internos son la masividad y las abundantes concreciones calcáreas. A lo largo de los perfiles analizados se identificaron variaciones transicionales verticales, con capas que presentan estratificación difusa y distintos grados de calcretización. Las concreciones calcáreas son cilíndricas, huecas en algunos casos. También aparecen nódulos calcáreos. Hacia el techo ha sido posible identificar paleosuelos. Se la interpreta como una asociación propia de un sistema eólico sobre la cual actuaron procesos pedogenéticos y diagenéticos.

Asociación de facies C: Está constituida por conglomerados en la base, a los que suprayacen areniscas con estratificación entrecruzada en artesa que pasa a tabular planar, por encima de las cuales se depositaron sedimentos pelíticos. 
Estas sedimentitas corresponden a depósitos de un curso fluvial de escasa magnitud. El pasaje entre las facies de esta última asociación es transicional y granodecreciente.

Sólo en los afloramientos de Salinas Grandes de Hidalgo, Laguna Chillhué y Guatraché (Figura 1.2) han sido hallados sedimentos lacustres (asociación de facies A del perfil integrado de la Formación Cerro Azul, véase Montalvo et al., 1995; Goin et al., 2000).

La asociación de facies B es la más conspicua y consiste en depósitos eólicos con niveles con evidencias de pedogénesis (Goin et al., 2000). Estos depósitos tienen una gran representación areal en el centro y Norte de la provincia de La Pampa; muchos de los afloramientos con concentraciones de fósiles presentan características sedimentológicas que permiten su inclusión en esta asociación (por ejemplo los de Telén, Quehué, Loventué, Bajo Giuliani y Caleufú).

Finalmente, la asociación de facies $\mathrm{C}$, con sedimentitas propias de un curso fluvial, se registra solamente en Cerro de la Bota y presenta una asociación faunística cuyos elementos conservados tienen evidentes manifestaciones de reagrupamiento y abrasión producidas probablemente por el régimen fluvial al que estuvieron sometidos.

Por otro lado, el relevamiento de los niveles de la Formación Cerro Azul permitió dar a conocer nuevas localidades fosilíferas (Figura 1.2), de tal modo que hasta el momento son 23 las localidades relevadas (Montalvo y Szelagowski, 1999) de las que se recolectaron más de 17.000 restos de vertebrados continentales, fundamentalmente de mamíferos (Tabla 1.1). 
Paleobiología de la asociación faunística de Caleufú (La Pampa, Formación Cerro Azul, Mioceno superior - Plioceno inferior), a través de análisis tafonómicos 
Paleobiología de la asociación faunística de Caleufú (La Pampa, Formación Cerro Azul, Mioceno superior - Plioceno inferior), a través de análisis tafonómicos 
Paleobiología de la asociación faunística de Caleufú (La Pampa, Formación Cerro Azul, Mioceno superior - Plioceno inferior), a través de análisis tafonómicos

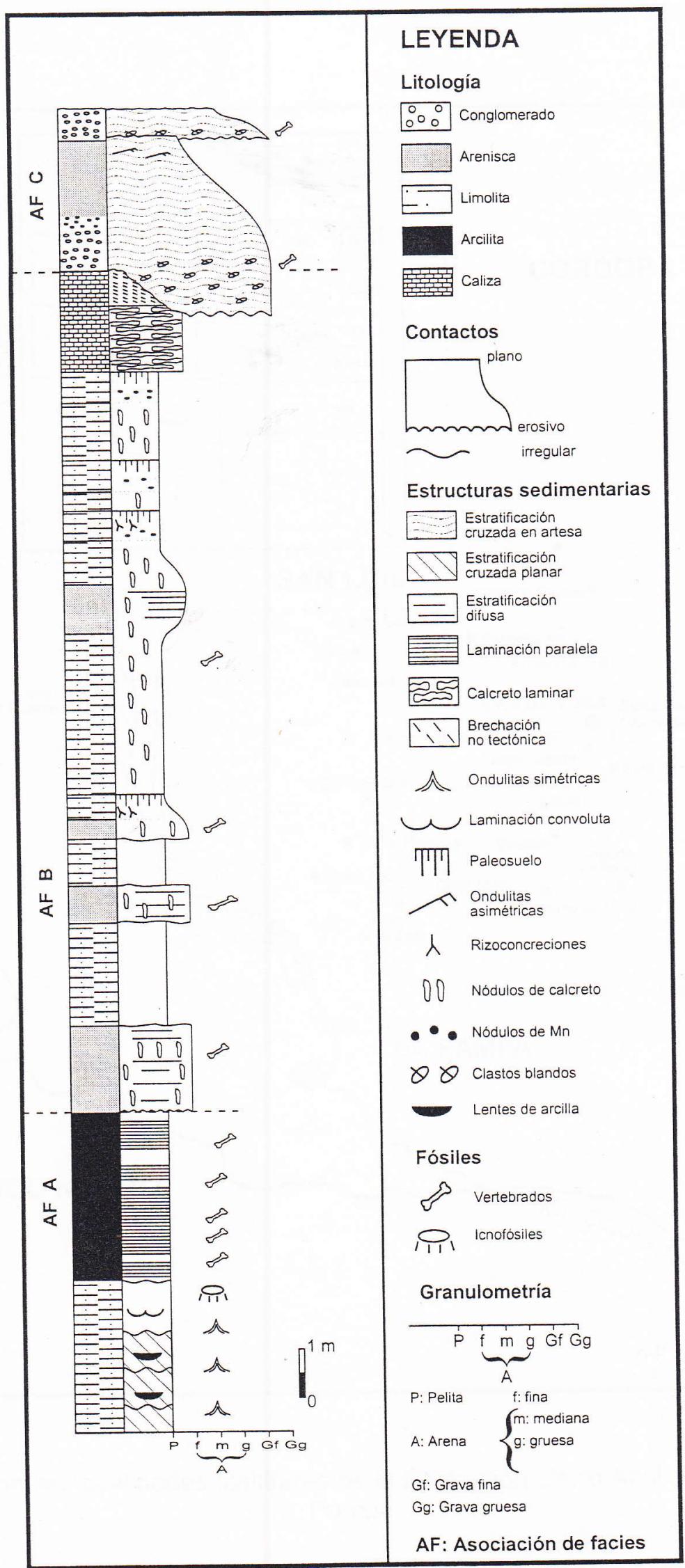

Figura 1.1. Perfil integrado de la Formación Cerro Azul (tomado de Goin et al., 2000) 


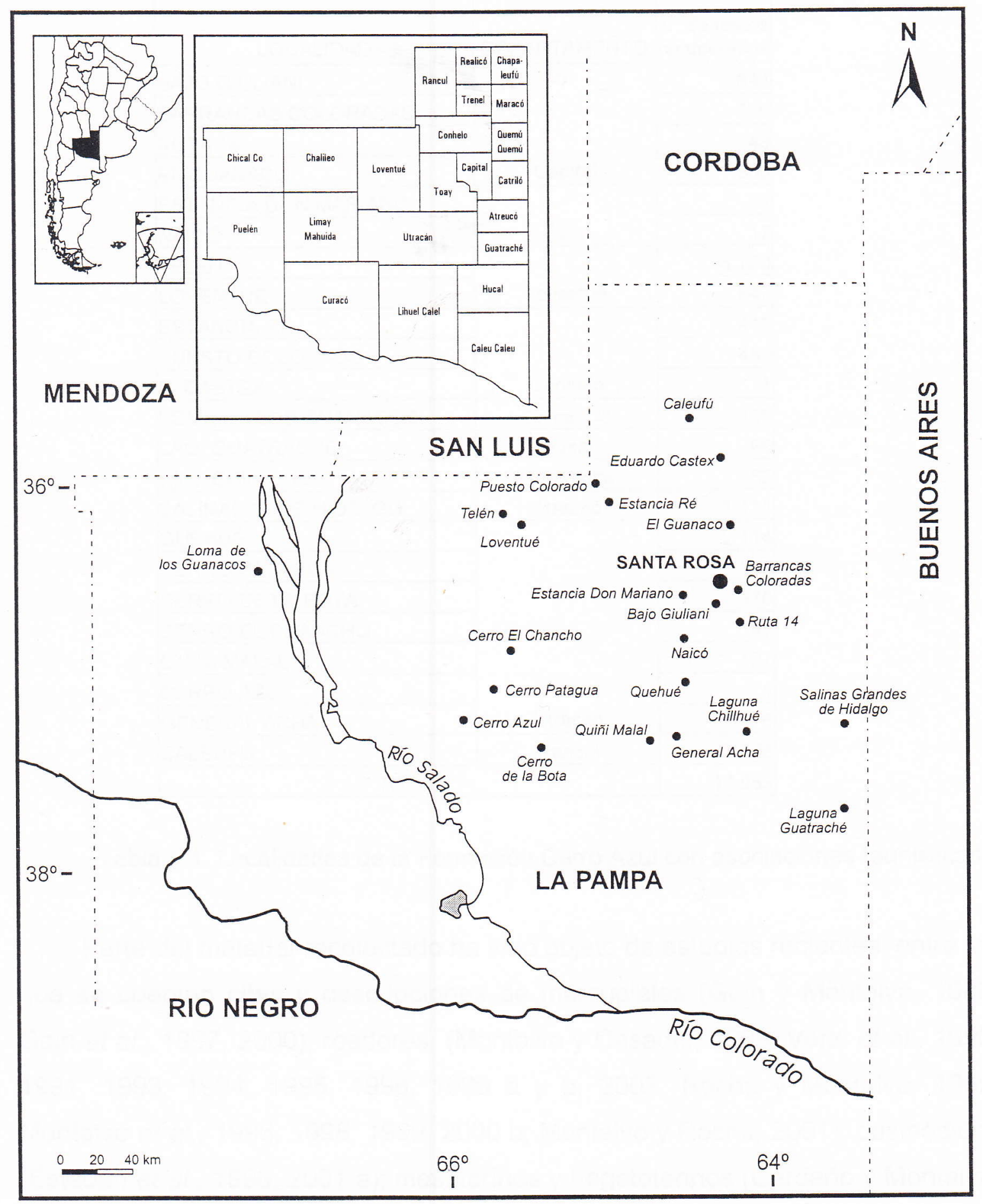

Figura 1.2. Mapa de las localidades fosilíferas de la Formación Cerro Azul en la provincia de La Pampa 


\begin{tabular}{|c|c|c|}
\hline LOCALIDAD & DEPARTAMENTO & $\begin{array}{l}N^{\circ} \text { de restos } \\
\text { recuperados }\end{array}$ \\
\hline BAJO GIULIANI & \multirow[b]{4}{*}{ Capital } & \begin{tabular}{|l|}
1.644 \\
\end{tabular} \\
\hline BARRANCAS COLORADAS & & 256 \\
\hline RUTA 14 & & 43 \\
\hline EL GUANACO & & 300 \\
\hline ESTANCIA DON MARIANO & \multirow[b]{2}{*}{ Toay } & 81 \\
\hline NAICÓ & & 17 \\
\hline TELÉN & \multirow[b]{2}{*}{ Loventué } & 4.730 \\
\hline LOVENTUÉ & & 647 \\
\hline ESTANCIA RÉ & \multirow[b]{3}{*}{ Conhelo } & 413 \\
\hline PUESTO COLORADO & & 489 \\
\hline E. CASTEX & & 1 \\
\hline LOMA DE LOS GUANACOS & Chical-Có & 126 \\
\hline LAG. GUATRACHÉ & Hucal & 86 \\
\hline LAG. CHILLHUÉ & Guatraché & 1.962 \\
\hline SALINAS G. DE HIDALGO & Atreucó & 1.111 \\
\hline QUEHUÉ & \multirow[b]{7}{*}{ Utracán } & 2.114 \\
\hline CERRO PATAGUA & & 123 \\
\hline CERRO DE LA BOTA & & 370 \\
\hline CERRO EL CHANCHO & & 40 \\
\hline QUIÑI MALAL & & 127 \\
\hline CERRO AZUL & & 1 \\
\hline GENERAL ACHA & & 6 \\
\hline CALEUFÚ & Rancul & 3.266 \\
\hline \multicolumn{2}{|c|}{ TOTAL } & 17.953 \\
\hline
\end{tabular}

Tabla 1.1. Localidades de la Formación Cerro Azul con asociaciones faunísticas

Parte del material recolectado ha sido objeto de estudios recientes, entre los que se cuentan citas y descripciones de marsupiales (Goin y Montalvo, 1988, Goin et al., 1997, 2000); roedores (Montalvo y Casadío, 1988; Verzi et al., 1990, 1991, 1993, 1994, 1995, 1996, 1999 a y b, 2003; Rocha y Montalvo, 1999; Montalvo et al., 1996, 1998, 1999, 2000 b; Montalvo y Rocha, 2001); dasipódidos (Esteban et al., 1996, 2001 a); mesoterinos y hegetoterinos (Cerdeño y Montalvo, 2001, 2002; Montalvo y Cerdeño, 2002).

Cada uno de los afloramientos de la Formación Cerro Azul de los que se han recuperado asociaciones faunísticas presenta caracteres propios y particulares. Sin embargo, todos pueden ser ubicados en un lapso breve, en el Mioceno tardío. Por esta razón se puede inferir que las condiciones ambientales bajo las que se 
desarrollaron estas asociaciones fueron similares, si bien ha sido posible, sobre la base de algunos taxa, señalar un deterioro climático hacia el final del Mioceno (Verzi, 1999; Verzi et al., 2003). Se trata de asociaciones desarrolladas en un ambiente terrestre abierto de llanura, bajo un clima árido a semiárido (Pascual y Bondesio, 1982; Pascual et al., 1996; Pascual y Ortiz Jaureguizar, 1990; Ortiz Jaureguizar, 1998).

\section{Objetivos, hipótesis y estructuración del trabajo}

Este trabajo tiene como objetivo el análisis tafonómico de los restos registrados en el afloramiento de la Formación Cerro Azul en Caleufú, provincia de La Pampa. La asociación recuperada fue asignada preliminarmente al Plioceno temprano (Montalvo et al., 2000 a y b), pero luego, análisis más exhaustivos de algunos taxa presentes sugieren su ubicación en el Mioceno más tardío (Montalvo, 2002 b; Abello et al., 2002; Verzi et al., 2003; Montalvo y Rocha, 2003; Esteban et al., 2003), cercana pero algo más antigua que la Edad mamífero Montehermosense (Verzi et al., 2003).

En este trabajo, el afloramiento de Caleufú y su asociación faunística se ha tomado como ejemplo de estudio para aplicar la metodología tafonómica. En la asociación faunística de Caleufú están representados los órdenes de mamíferos presentes en otras asociaciones de la Formación Cerro Azul, destacándose el alto número de restos hallados. Estos tienen, además, características que indican la acción de procesos tafonómicos ocurridos antes y después del enterramiento. Por otro lado, y a diferencia de lo que ocurrió con otros afloramientos con fósiles en La Pampa, la localidad de Caleufú fue abordada desde el primer momento con criterio tafonómico. Por estos motivos, la muestra de Caleufú resulta apropiada para abordar cuestiones sobre el origen de los yacimientos de vertebrados del neógeno del centro de Argentina y los procesos de producción, enterramiento y fosilización, que podrán ser comparadas y contrastadas en el futuro con muestras de otras localidades.

Los niveles de la Formación Cerro Azul en Caleufú están expuestos en superficie y los restos fósiles se encontraron concentrados en un área de 1.590 $\mathrm{m}^{2}$. La asociación faunística está constituida fundamentalmente por 
micromamíferos; sin embargo también están presentes varios taxa de más de 5 $\mathrm{kg}$ de masa corporal estimada.

Las interpretaciones previas realizadas sobre la base del análisis de los caracteres anátomo-funcionales de los taxa registrados en la Formación Cerro Azul sugieren la presencia de amplias llanuras, desarrolladas en un clima árido a semiárido. La información aportada por la sedimentología es coincidente.

Las características de la asociación recuperada en Caleufú permite formular dos hipótesis de trabajo:

1.- En esta localidad la acumulación de restos de microvertebrados corresponde a una concentración producida por depredadores en un suelo bioturbado. Los restos producidos por individuos de pequeño tamaño tuvieron una corta historia previa al enterramiento y los procesos intervinientes en la génesis y desarrollo del suelo fueron los que favorecieron su conservación una vez que se enterraban.

2.- Los restos producidos por mamíferos de más de $5 \mathrm{~kg}$ de masa corporal estimada tuvieron una historia tafonómica diferente a los del grupo anterior, sesgada fundamentalmente por su propio tamaño. Los esqueletos quedaban expuestos durante más tiempo por lo que fueron afectados por procesos relacionados con la superficie del suelo.

En la Figura 1.3 se muestra cómo fue estructurado este trabajo de investigación. 
Paleobiología de la asociación faunística de Caleufú (La Pampa, Formación Cerro Azul, Mioceno superior - Plioceno inferior), a través de análisis tafonómicos 

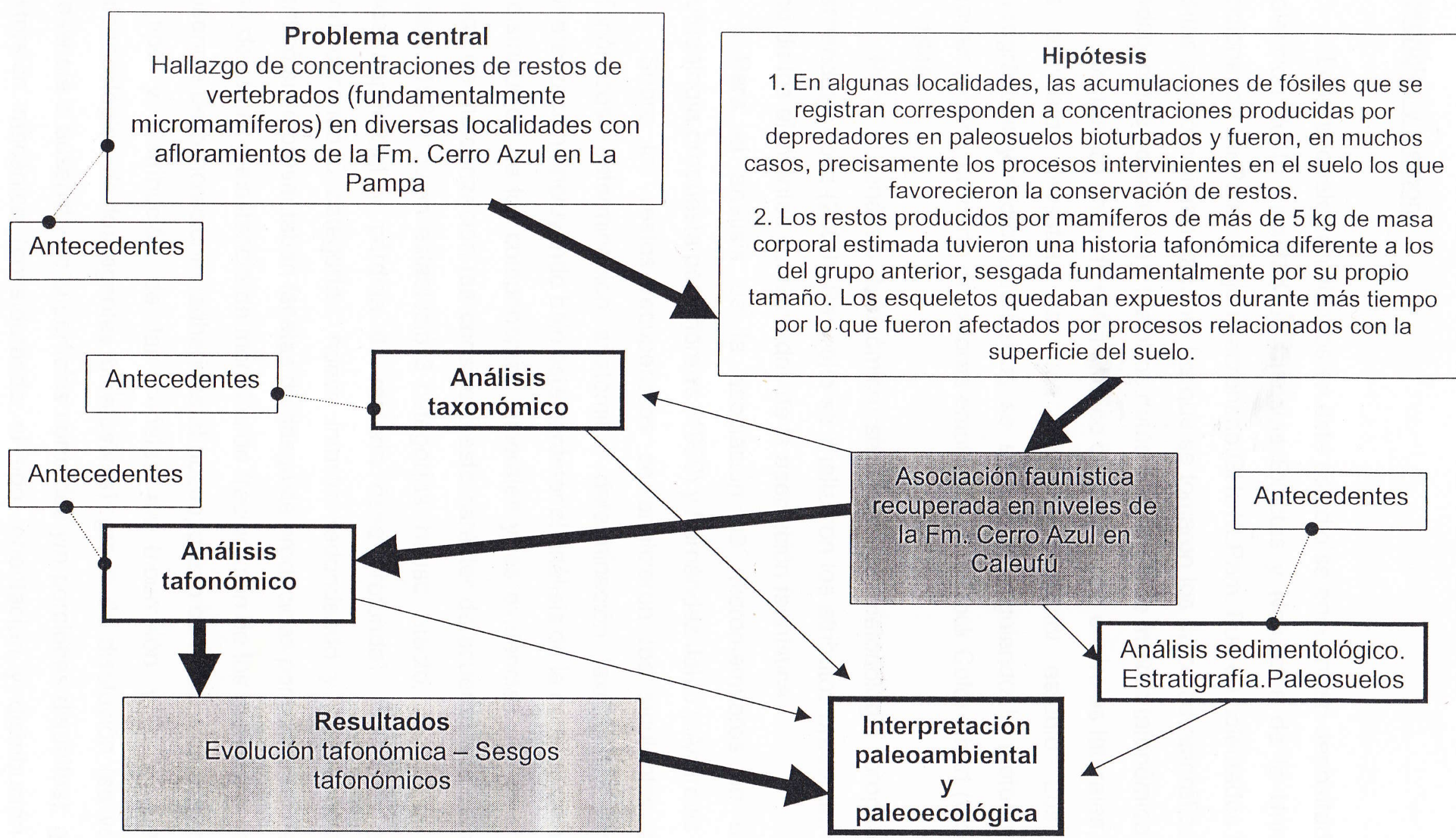

Figura 1.3. Diagrama de flujo de la investigación planteada en este trabajo

\section{Hipótesis}

1. En algunas localidades, las acumulaciones de fósiles que se registran corresponden a concentraciones producidas por depredadores en paleosuelos bioturbados y fueron, en muchos casos, precisamente los procesos intervinientes en el suelo los que favorecieron la conservación de restos.

2. Los restos producidos por mamíferos de más de $5 \mathrm{~kg}$ de masa corporal estimada tuvieron una historia tafonómica diferente a los

del grupo anterior, sesgada fundamentalmente por su propio

tamaño. Los esqueletos quedaban expuestos durante más tiempo

por lo que fueron afectados por procesos relacionados con la superficie del suelo.

\section{leoecológica}




\section{Materiales y métodos}

Los materiales analizados en este estudio se encuentran depositados en la Colección de la Facultad de Ciencias Exactas y Naturales de la Universidad Nacional de La Pampa bajo el acrónimo GHUNLPam. Fueron colectados en cinco visitas al afloramiento, durante las que se tomaron los datos estratigráficos de las sedimentitas portadoras y los otros datos de campo de interés tafonómico.

Se realizó un perfil estratigráfico de detalle con controles laterales, del que se extrajeron muestras de roca para su posterior estudio. Los análisis petrográficos y micromorfológicos se efectuaron siguiendo la metodología de Brewer (1964). La carta de colores empleada es la Rock Color Chart (Goddard et al., 1948).

Para el análisis tafonómico se utilizó la metodología propuesta por Fernández López (2000). Para ello se analizaron los atributos presentes en cada uno de los elementos conservados de la asociación faunística.

Para el análisis de la asociación de micromamíferos se utilizó la metodología propuesta por Andrews (1990) y Fernández Jalvo y Andrews (1992).

Sobre los restos recuperados se analizaron los siguientes atributos tafonómicos: determinación anatómica; determinación taxonómica; grado de mineralización (incluyendo bajo este carácter el análisis de la composición, textura y distribución de los componentes minerales y las evidencias de cementación); grado de meteorización (se consideró este carácter de acuerdo a lo definido por Alcalá (1994) quien estableció 3 categorías: hueso intacto, pérdida de materia ósea superficial y pérdida de materia ósea profunda); grado de abrasión (considerando 3 categorías: hueso intacto, redondeado y pulido; además se verificó si se presentaban facetas de desgaste producidas por el viento o el agua); tipo de rotura y existencia de modelos de fracturación de los huesos; presencia o ausencia de concreciones adheridas al hueso; grado de bioerosión (se consideró el tipo y distribución de las señales de bioerosión y la determinación paleoecológica de los agentes bioerosivos); grado de disolución (se verificó la presencia o ausencia de superficies corroídas y/o porciones disueltas); grado de distorsión mecánica (considerando el tipo, orientación y distribución de las 
deformaciones y las evidencias de compresión); grado de desarticulación (considerándolo como la desconexión o separación de componentes, se verificó además la presencia o ausencia de un patrón de desarticulación); grado de dispersión (evidenciado como la separación y diseminación de los componentes; se analizó bajo este ítem, además, la integridad esquelética, la proporción de componentes pares y el patrón de desintegración); grado de reagrupamiento (se verificó aquí la existencia de un patrón de distribución de los elementos esqueléticos de modo tal de incluir los restos en las siguientes categorías: original/modificado, agrupado/uniforme/al azar); grado de remoción (teniendo en cuenta el estado mecánico de conservación de acuerdo a las categorías acumulado/resedimentado/reelaborado y el grado de autoctonía).

Para la asociación conservada se consideró la situación geográfica del área de estudio y contexto estratigráfico; el número de elementos identificados; el tamaño de la asociación; la diversidad anatómica; diversidad taxonómica; diversidad tafonómica; diversidad morfológica; diversidad paleoecológica y distribución espacial.

La identificación taxonómica de los taxa presentes se realizó por análisis morfológicos y morfométricos, comparando con material de otras localidades de la Formación Cerro Azul depositados en la Colección de la Facultad de Ciencias Exactas y Naturales de la Universidad Nacional de La Pampa y con ejemplares tipo del Museo de La Plata y del Museo Argentino de Ciencias Naturales "B. Rivadavia”. Para el análisis del material se utilizó una lupa Leica MS5, los dibujos se realizaron con la cámara clara de esa lupa y las medidas dentarias se tomaron con un ocular micrométrico o con un calibre mecánico de acuerdo a los casos.

Los ejemplares más significativos se seleccionaron para su posterior estudio con mayor detalle en un microscopio electrónico de barrido (MEB) Jeol 35 CF a $8 \mathrm{KV}$ del CRIBABB (Bahía Blanca).

Se realizaron cortes delgados sobre algunos restos. La técnica utilizada fue el corte de las muestras con sierra de diamante refrigerada con agua. Una vez realizado el corte y limpiada su superficie con agua, se rellenaron los poros con Araldite CY 248. Luego se rebajaron unos $2 \mathrm{~mm}$ con carborundo como abrasivo, utilizando cada vez grano de tamaño menor, limpiando la muestra cada vez que 
se cambió el tamaño del grano. Se pulió con carborundo de grano muy fino, se limpió y se dejó secar. Se pegó esta superficie a un porta de cristal con Araldite CY 248 y se dejó fraguar durante 24 horas. Una vez seco, se volvió a cortar la muestra a algo menos de $2 \mathrm{~mm}$ del porta. Se repitió el proceso de rebajado con carborundo de distinto tamaño de grano, hasta alcanzar aproximadamente los 25$30 \mu$ de espesor. Las muestras se observaron en un microscopio petrográfico Nikon Eclipse E 400 Pol y se fotografiaron con la cámara del mismo microscopio.

A fin de evitar posibles modificaciones sobre los especímenes, estos fueron limpiados con cepillo bajo lupa binocular $y$, sólo se utilizaron técnicas más agresivas en los casos en que fue indispensable para realizar precisiones taxonómicas.

Para la cuantificación de los elementos conservados, de acuerdo a criterios taxonómicos y tafonómicos, se utilizaron diferentes índices que permiten estimar la abundancia de cada taxa en la asociación. En primer lugar, se obtuvo el NR: número de restos recuperados (Blasco Sancho, 1995). En esta categoría se incluyeron tanto los fragmentos óseos indeterminables como cualquier elemento que pudiera ser identificado anatómica y taxonómicamente. Estos últimos elementos fueron calculados de acuerdo al NEIT: número de elementos identificados por taxón (que corresponde al NISP propuesto por Badgley, 1986). Para esta autora, este número es afectado por la fragmentación diferencial de los especímenes y se distorsionan los resultados si se cuentan del mismo modo elementos asociados y aislados. En el caso de la asociación de Caleufú, son muy pocos los elementos articulados, de modo tal que ese problema no modifica la interpretación, pero como es muy alto el grado de rotura de los restos para cada taxón el valor del NEIT es muy alto, y seguramente cada elemento esquelético es contado más de una vez. Este número se obtiene fácilmente ya que se lo calcula a medida que se catalogan los restos. Puede ser actualizado, ya que es aditivo. Otro índice de abundancia taxonómica calculado es el NME: número mínimo de elementos esqueléticos por taxón (este índice corresponde al MNE propuesto por Badgley, 1986). Este valor focaliza su atención en la fragmentación; se determina agrupando todos los fragmentos que se considera pueden derivar de un mismo elemento esquelético, de modo tal que cada uno sea contado una sola vez. En 
general, el valor del NME es intermedio entre el NEIT y el último índice obtenido, el NMI: número mínimo de individuos (que corresponde al MNI propuesto por Badgley, 1986). Se basa en contar solo la parte esquelética más abundante en cada taxón, ya que se pretende conocer mediante este índice el número mínimo de individuos necesarios para aportar todos los elementos esqueléticos identificados en la asociación (Alcalá, 1994; Blasco Sancho, 1992). En la asociación analizada, representada fundamentalmente por mamíferos, son los dientes los elementos más abundantes. De este modo, para obtener el NMI de cada taxón, se eligió el diente más frecuente, excepto en los representantes acorazados del Orden Xenarthra. En algunos grupos fue posible diferenciar dientes de leche y definitivos (por ejemplo en el Notoungulata Paedotherium minor). También se han definido diferentes grados de desgaste, preestablecidos de acuerdo al estado de la superficie oclusal. De este modo, la comparación de estas piezas ha permitido obtener el NMI (Blasco Sancho, 1992). El valor del NMI es poco afectado por la fragmentación (Alcalá, 1994) y sobrevalora en cada asociación a los taxa raros (Badgley, 1986).

Los especímenes asignados a mamíferos fueron agrupados en 3 categorías de edad estimada al momento de la muerte del individuo. Se consideró como muy jóvenes a aquellos con hueso poco conformado y dientes de leche y/o dientes emergentes, jóvenes a aquellos que presentan hueso poco conformado. El resto de los especímenes se catalogó como de adultos.

Los especímenes recuperados fueron agrupados en dos categorías de masa corporal estimada; la asociación de micromamíferos incluye a los taxa de menos de $5 \mathrm{~kg}$ de masa corporal estimada y la asociación de mamíferos de mayor talla corporal a los que superan ese valor. Esta división se realizó tomando como base la estimación de masa corporal de los taxa presentes en Salinas Grandes de Hidalgo, realizada por Vizcaíno y Fariña (1999).

Varios de los atributos tafonómicos fueron evaluados sobre el total de restos, incluyendo los fragmentos indeterminables (NR), por ejemplo las marcas de raíces, la corrosión por líquenes y otras señales bioerosivas.

Las abreviaturas usadas son: $p$, premolar inferior; $P$, premolar superior; $d p$, premolar inferior deciduo, DP, premolar superior deciduo, m, molar inferior; $\mathrm{M}$, 
molar superior; DAP, diámetro ántero posterior; DTA, diámetro transverso anterior; DTP diámetro transverso posterior; L, largo; A, ancho; AP ántero posterior; TA transverso anterior; TP transverso posterior; pr., prisma; a. mand., altura mandibular. 


\section{Capítulo 2 \\ ASOCIACIÓN FAUNÍSTICA DE LA \\ FORMACIÓN CERRO AZUL EN CALEUFÚ}




\section{Antecedentes}

A fines de 1999 se encontró un nuevo afloramiento de la Formación Cerro Azul en el Norte de la provincia de La Pampa, cercano a la ciudad de Caleufú (ver Figura 1.2), con una abundante y diversa asociación faunística, constituida fundamentalmente por micromamíferos. Algunos de los taxa presentes en la asociación indican para esta fauna una antigüedad menor que la de otras asociaciones faunísticas de la Formación Cerro Azul. Montalvo et al. (2000 a y b) asignaron estos niveles al Plioceno temprano. Sin embargo, análisis más exhaustivos de algunos de los grupos presentes en esta asociación (marsupiales, xenartros dasipódidos y roedores octodontidos y cávidos) señalan que su antigüedad podría corresponder al Mioceno tardío (Abello et al., 2002; Esteban et al., 2003; Verzi et al., 2003; Montalvo y Rocha, 2003).

Los restos recuperados en este afloramiento se hallaron en una superficie de aproximadamente $1.590 \mathrm{~m}^{2}$. Desde el primer momento fueron observadas particularidades que están fundamentalmente relacionadas con atributos de los elementos conservados y de la asociación.

Como ejemplos de las características observadas se pueden citar:

$\checkmark$ Distribución al azar de los elementos conservados en un área relativamente pequeña.

$\checkmark$ Ausencia de esqueletos completos y/o articulados. Alto grado de desarticulación de los elementos conservados.

$\checkmark$ Alto grado de fracturación de los elementos conservados.

$\checkmark$ Preponderancia de fragmentos mandibulares y maxilares con dientes o dientes aislados sobre cualquier otro resto postcraneano.

$\checkmark$ Alta frecuencia de elementos producidos por micromamíferos sobre los de macromamíferos.

$\checkmark$ Alto grado de meteorización y desgaste de los elementos producidos por macromamíferos.

$\checkmark$ Diferencias en la frecuencia de hallazgos de varios taxa con respecto a otros afloramientos de la Formación Cerro Azul. 
$\checkmark$ Abundancia de elementos conservados producidos por individuos de un mismo taxón mostrando diferentes estadíos del desarrollo.

$\checkmark$ Relación entre la concentración de elementos producidos por micromamíferos con facies que evidencian procesos pedogenéticos.

$\checkmark$ Elementos conservados con diferentes grados de impregnación por óxidos de manganeso.

$\checkmark$ Elementos conservados con diferentes grados de encostramiento e inclusión en concreciones calcáreas.

$\checkmark$ Evidencias del accionar de agentes bioerosivos sobre algunos elementos conservados (por ejemplo señales de crecimiento de raíces, acción de líquenes y otros tipos de corrosiones).

Si bien muchas de las características que se han mencionado se pueden reconocer en asociaciones faunísticas de otros afloramientos de la Formación Cerro Azul, este sitio fue elegido para este estudio por presentar un alto número de restos concentrados en un área relativamente pequeña. Además, desde su hallazgo las prospecciones se realizaron utilizando metodologías tafonómicas.

Análisis tafonómicos preliminares indicaron que en la formación de la concentración de micromamíferos recuperada de este afloramiento de la Formación Cerro Azul habrían intervenido depredadores (Montalvo, 2001, 2002 b).

\section{Situación geográfica del área de estudio}

Esta localidad está ubicada $10 \mathrm{~km}$ al Sudoeste de la ciudad de Caleufú (35 $41^{\prime} 37^{\prime \prime}$ S, 64 40' 8' O) en el departamento Rancul al Norte de La Pampa.

\section{Contexto geomorfológico del afloramiento de la Formación Cerro Azul en Caleufú}

El afloramiento de la Formación Cerro Azul en Caleufú se encuentra en la subregión de las acumulaciones arenosas combinadas con mesetas residuales en la región fisiográfica central (Cano, 1980). El paisaje del área se ha formado por acción eólica; el material característico es la arena, cuyo espesor no supera los 6 m. En el área de estudio, las arenas recientes cubren directamente a los niveles de la Formación Cerro Azul. La cota a la que se encuentra el afloramiento es de 
190 m y los niveles aflorantes están expuestos en una cárcava producida por un drenaje muy suave de NO a SE que culmina en un bajo cercano al afloramiento cuya cota es de 189 m (Lámina 2.1).

\section{Estratigrafía}

Se transcribe a continuación el análisis sedimentológico detallado de los niveles expuestos de la Formación Cerro Azul de Caleufú (Montalvo et al., en preparación). Estos niveles (Figura 2.1) presentan aproximadamente 1,80 m de espesor y pueden diferenciarse tres capas, con una litología de limolitas loessoides, cementadas por carbonatos.

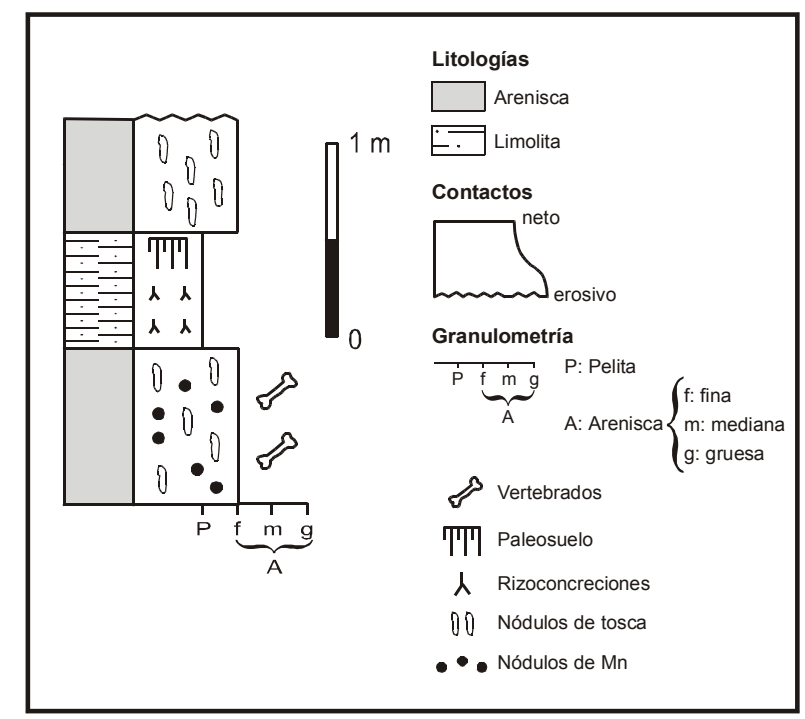

Figura 2.1. Perfil estratigráfico de la Formación Cerro Azul en Caleufú

Capa inferior: Limolita arenosa de $80 \mathrm{~cm}$ a $1 \mathrm{~m}$ de espesor, color rosa anaranjado pálido (5 YR 7/2), con estratificación difusa, sin orientación preferencial. Presenta abundantes concreciones calcáreas dispersas, algunas alargadas verticalmente (con dimensiones variables entre $10 \mathrm{~cm}$ de largo y $5 \mathrm{~cm}$ de diámetro) y otras amorfas. También se encuentran nódulos de manganeso redondeados, de 2 a 4 $\mathrm{mm}$ de diámetro. Los fósiles se hallan dispersos en todo el espesor de la capa, si bien son más abundantes hacia el techo. Sobre la base del estudio micromorfológico se constató que los granos esqueletarios forman parte del $45 \%$ 

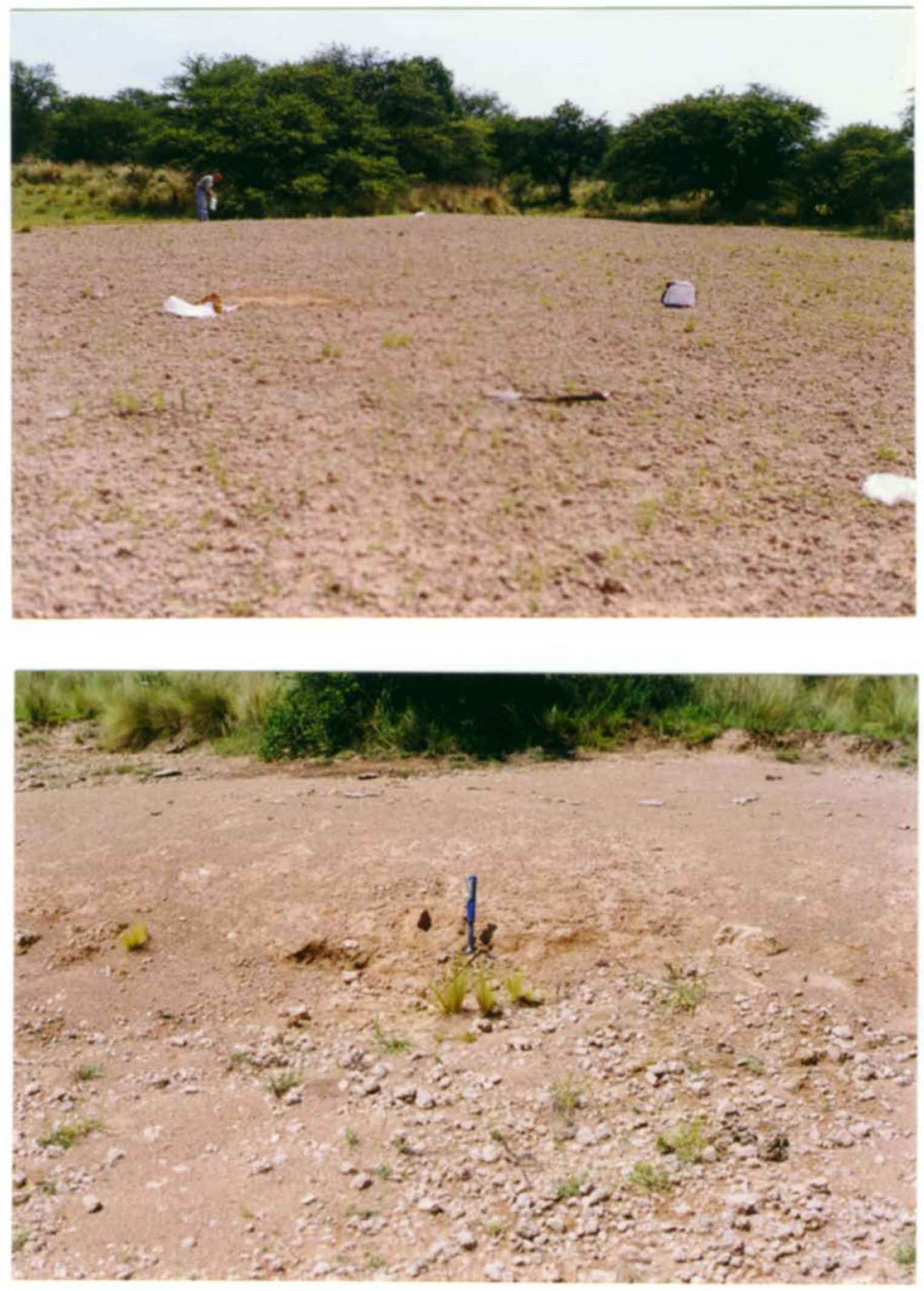

Lámina 2.1. Dos vistas del afloramiento de la Formación Cerro Azul en Caleufú 
Lámina 2.1. Dos vistas del afloramiento de la Formación Cerro Azul en Caleufú 
de la muestra, con formas anhedrales, subangulosos y de baja esfericidad. Las especies minerales determinadas son las siguientes: cuarzo monocristalino (15 $\%)$, feldespato potásico (10\%), plagioclasas (27\%), líticos volcánicos (16\%), vidrio volcánico (30\%), opacos y pesados (2\%). El plasma ocupa el $50 \%$, y está constituido principalmente por arcilla, aunque en algunos sectores se concentra cemento micrítico. La matriz $S$ es del tipo mosépica, es decir formada por un agrupamiento de escamillas orientadas, separadas por áreas reducidas de plasma sin orientación definida. Los huecos ocupan el $5 \%$ restante, con poros alargados y vesículas irregulares, rellenas con micrita. Entre los rasgos pedológicos se observan cutanes de grano y de poro, del tipo argillan y pápulas formadas por restos de argillanes con contornos cerrados y de óxidos de manganeso de contornos abiertos.

Capa media: Limolita arcillosa de $50 \mathrm{~cm}$ de espesor, del mismo color que la anterior, con contactos superior e inferior netos. Presenta estructura blocosa prismática, con caras superiores planas, los prismas son de aproximadamente 3 $\mathrm{cm}$ de largo, $2 \mathrm{~cm}$ de ancho y $2 \mathrm{~cm}$ de espesor. Aparecen escasos moldes de rizolitos axiales (menos del $2 \%$ ), cilíndricos y alargados verticalmente, de $5 \mathrm{~cm}$ o menos de largo y 1 a $2 \mathrm{~cm}$ de diámetro, sin ramificaciones laterales, con las paredes cementadas por micrita y el hueco central relleno de sedimento y arcilla, lo que permite clasificarlos como "root casts" según Klappa (1980). En esta capa no se encontraron fósiles. Dentro de las características micromorfológicas, los granos esqueletarios se distribuyen en el $30 \%$ del total de la muestra. Los minerales son de formas anhedrales, subangulosos y de baja esfericidad. Las especies minerales encontradas son: cuarzo monocristalino (17\%), feldespato potásico $(15 \%)$, plagioclasas $(21 \%)$, líticos volcánicos (19\%), vidrio volcánico (25\%), opacos y pesados (3\%). El plasma, formado totalmente por arcilla, ocupa el 55 \%. La matriz S es del tipo mosépica como en la capa anterior. Los huecos forman parte del $15 \%$ restante, con poros bifurcados y vesículas irregulares, sin relleno. Los rasgos pedológicos de esta capa son los siguientes: cutanes de grano y de poro, del tipo argillan, y escasos pedotúbulos aislados, de paredes arcillosas y centros rellenos por el material hospedante. Entre las pápulas se distinguen las 
formadas por restos de argillanes con contornos cerrados y las de óxidos de manganeso de contornos abiertos.

Capa superior: Limolita arenosa de $50 \mathrm{~cm}$ a $70 \mathrm{~cm}$ de espesor, del mismo color que las capas anteriores, maciza, con abundantes concreciones calcáreas dispersas, generalmente amorfas y de dimensiones variables. En esta capa no se encontraron fósiles. Las características micromorfológicas son las siguientes: los granos esqueletarios ocupan el $20 \%$ de la muestra, son anhedrales, subredondeados y de baja esfericidad. Las especies minerales determinadas son: cuarzo monocristalino (24\%), feldespato potásico (20\%), plagioclasas (27\%), líticos volcánicos $(11 \%)$, vidrio volcánico $(17 \%)$, opacos y pesados $(1 \%)$. El cemento carbonático ocupa el $80 \%$ restante y es de tipo micrítico. Los únicos rasgos pedológicos observados son fragmentos de argillanes redondeados.

Las limolitas areno-arcillosas de la Formación Cerro Azul aflorantes en Caleufú constituyen un depósito eólico sobre el que actuaron procesos pedológicos y diagenéticos. Tanto la estructura blocosa prismática (peds) como los rizolitos observados en la capa media son caracteres diagnósticos de la existencia de un paleosuelo (Retallack, 1988; 1990). Asimismo, las evidencias micromorfológicas de esta capa tales como la matriz $S$ del tipo mosépica, los poros bifurcados debidos a raíces y los argillanes y pedotúbulos contribuyen a identificar esta capa como un horizonte Bt. La capa inferior, en la que se encuentra la asociación faunística recuperada, presenta menos rasgos pedológicos que la anterior, ya que está más diagenizada, con concreciones calcáreas y cemento micrítico. En la capa superior hay abundantes concreciones calcáreas y está muy cementada. Los argillanes redondeados (interpretados como pedorelictos) junto al mayor redondeamiento de los granos esqueletales, son características que surgen como producto de la erosión, posteriores al desarrollo del paleosuelo, el que fue afectado por diagénesis. La precipitación de los carbonatos se efectuó durante las sucesivas variaciones verticales de la capa freática, característica de climas con alternancia entre períodos de mayor y menor humedad durante la formación del suelo. Los "peds" que se presentan en la capa media, de estructura prismática con caras superiores planas, son típicos de los 
suelos formados en un clima templado con variaciones estacionales de humedad y sequía (Birkeland, 1984). 
Análisis taxonómico

La colección de restos fósiles estudiada, depositada en la Colección de la Facultad de Ciencias Exactas y Naturales se halla compuesta por 2.257 especímenes, estando representadas 3 clases de vertebrados.

\author{
Clase REPTILIA Laurenti, 1768 \\ Orden SQUAMATA Oppel, 1811 \\ Suborden LACERTILIA Owen, 1842 \\ Infraorden SCINCOMORPHA Camp, 1923 \\ Familia TEIIDAE Gray, 1827 \\ Teiidae indet.
}

\begin{abstract}
Material: GHUNLPam 19608; 19609 dos restos de extremo posterior de dentario o maxilar?; 19610 fragmento anterior de dentario; 19612/4 un resto de vértebra incompleta; 19612/9 dos vértebras articuladas indeterminadas; 19854 dentario o maxilar?; 19855 dentario o maxilar? sin dientes; 19856 fragmento anterior de dentario; 19865/30 fragmento de vértebra; 19874/42 fragmentos de dos vértebras articuladas indeterminadas; 19914 fragmento posterior de dentario, sin dientes.
\end{abstract}

Descripción: Los especímenes asignados a la Familia Teiidae consisten, en su mayor parte, en fragmentos de dentarios y maxilares con dientes, caracterizados por la presencia de canal de Meckel ampliamente abierto, importante depósito de cemento en la base de los dientes, reemplazo dentario a partir de cavidades subcirculares basales, implantación dentaria subpleurodonte y heterodoncia.

Comentarios: Restos asignables a esta familia de reptiles fueron también hallados en las localidades de Telén, Laguna Chillhué, Quehué, Bajo Giuliani y Loventué (Albino y Montalvo, 2003).

Suborden SERPENTES Linnaeus, 1758 Superfamilia COLUBROIDEA Oppel, 1811 Colubroidea indet.

Material: GHUNLPam 19936; 19937; 19938 vértebras indeterminadas.

Descripción: Se trata de material vertebral incompletamente preservado, caracterizado por un centro vertebral alargado y angosto, superficies di- y 
parapofisarias distintivas, zigósfeno delgado y proceso prezigapofisario y parapofisario bien desarrollados.

Comentarios: Es la primera oportunidad en que se encuentra a representantes de esta superfamilia en niveles de la Formación Cerro Azul (Albino y Montalvo, 2003).

Clase AVES Linnaeus, 1758

Aves indet.

Material: GHUNLPam 19865/15; 19866/8; 19867/3; 19867/4;19875/40; 19875/55; $21157 / 6$; 21565/9; 21565/33; 21567/9; 22560/21; 22557/15 fragmentos de fémures; 19865/20; 19867/20; 19875/34 fragmentos de coracoides; 19867/16; 19875/41; 21565/18; $21565 / 21 ; 21565 / 32 ; 21942 / 10 ; 21972 / 1 ; 21972 / 2 ; 21972 / 3 ; 21973 / 1 ; 21973 / 2$ fragmentos de húmeros; 19865/34; 21559 fragmentos de zeugopodios; 19875/57 fragmento de costilla; $21157 / 1$ fragmento de carpo-metacarpo; $21566 / 22$ fragmento de tarso metatarso.

Comentarios: Los especímenes asignados a AVES indet. están representados por material postcraneano muy incompleto de individuos de talla pequeña, que no fueron determinados más que a ese nivel.

Clase MAMMALIA Linnaeus, 1758

Supercohorte MARSUPIALIA Illiger, 1811

Orden DIDELPHIMORPHIA Gill, 1872 [nom transl. Aplin y Archer, 1987]

Familia DIDELPHIDAE Gray, 1821

Subfamilia MARMOSINAE (Reig, 1981)

Marmosinae indet.

Material: GHUNLPam 19870 fragmento mandibular izquierdo con el canino y alvéolos de los p1-?2 (Abello et al., 2002).

\author{
Subfamilia DIDELPHINAE (Gray 1821) Simpson, 1927 \\ Hyperdidelphys Ameghino, 1904 \\ Hyperdidelphys sp.
}

Material: GHUNLPam 19614 fragmento mandibular izquierdo con los p2-3 y los m2-3 completos y el trigónido del m4 (Figura 2.2 y Abello et al., 2002) y 22559 fragmento mandibular derecho con porción de m3 emergente.

Comentarios: Es posible que los especímenes asignados a Hyperdidelphys sp. representen una nueva especie, ya que son más pequeños y menos robustos que 
los de $H$. pattersoni Reig, 1952, que es la especie más generalizada hasta ahora conocida para este género. Hyperdidelphys pattersoni procede de niveles huayquerienses del Noroeste argentino y de la provincia de La Pampa (Telén y EI Guanaco).

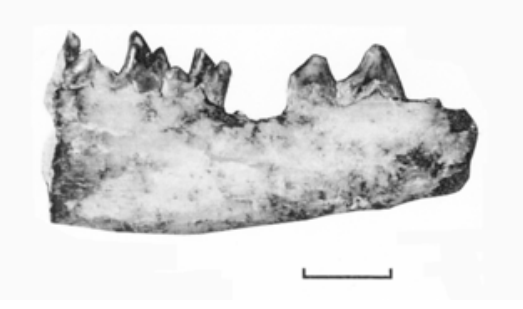

Figura 2.2. Hyperdidelphys sp. GHUNLPam 19614 mandíbula en vista lateral, escala 5 $\mathrm{mm}$

Didelphinae indet.

Material: GHUNLPam 19915 fragmento mandibular izquierdo con los alvéolos del m4 y parte de la fosa masetérica; 21229 fragmento mandibular izquierdo preservando tres alvéolos, los dos últimos pertenecientes probablemente al $\mathrm{m} 4 ; 21230$ fragmento mandibular izquierdo conservando los alvéolos del $\mathrm{m} 4$ y parte de la fosa masetérica; 21533 fragmento mandibular derecho con alvéolos y raíces de casi toda la serie molar; 21852 mitad anterior de un trigónido izquierdo (Abello et al., 2002) y GHUNLPam 21200; 21529; 21530 porciones de caninos y 21852 mitad anterior del trigónido de un molar izquierdo.

\section{Familia SPARASSOCYNIDAE (Reig, 1958) \\ Sparassocynus Mercerat, 1898 \\ Sparassocynus sp.}

Material: GHUNLPam 21228 fragmento mandibular izquierdo con el canino y p1-3, el último premolar en proceso de erupción (Figura 2.3 y Abello et al., 2002).

Comentarios: Sparasssocynus ha sido reconocido con seguridad para el Plioceno (S. bahiai Mercerat, 1898 para la Edad mamífero Montehermosense y S. derivatus Reig y Simpson, 1972 para la Edad mamífero Chapadmalalense). Recientemente, Goin et al. (2000) señalaron la presencia de "?Sparassocynidae" entre los materiales procedentes de Telén. Previamente había sido citado un nuevo esparasocínido en niveles huayquerienses del Noroeste argentino por Simpson (1974). Simpson señaló que esta forma ("Sparassocynus species 
innominata") presentaba rasgos primitivos con relación a las especies pliocenas del género, fundamentalmente por su menor tamaño y menor desarrollo de la cavidad epitimpánica (Abello et al., 2002).

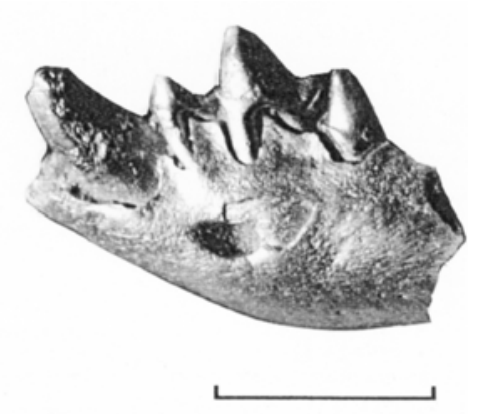

Figura 2.3. Sparassocynus sp. GHUNLPam 21228 mandíbula en vista lateral, escala 5 $\mathrm{mm}$

Orden Indet.

Familia ARGYROLAGIDAE Reig, 1981

Argyrolagus Ameghino, 1904

Argyrolagus sp.

Material: GHUNLPam 19616 mandíbula izquierda con los i1-2 y p3-m2; 21225 mandíbula derecha con los m1-2; 21226 mandíbula derecha con los m2-4 (Figura 2.4); 19615 mandíbula izquierda con los m1-2; 19617 fragmento de maxilar izquierdo con los P3-M3 completos (Figura 2.5); 21227 fragmento de premaxilar izquierdo con los 11-2 completos (Abello et al., 2002).

Comentarios: Los materiales asignados a Argyrolagus sp. manifiestan diferencias con los de las especies pliocenas de este género (A. palmeri Ameghino, 1904, A. parodii Rusconi, 1933 y A. scagliai Scaglia, 1970). Las especies Argyrolagus palmeri (Montehermosense) y A. parodii (Chapadmalalense) son sólo conocidas por sus materiales tipo; en el caso de A. parodii dicho ejemplar se ha perdido, por lo que su conocimiento se restringe a las descripciones dadas por Rusconi (1933) y Simpson (1970). En consecuencia, la determinación a nivel específico de este argirolágido dependerá de un mejor conocimiento de la sistemática del género, lo cual resulta muy difícil actualmente debido a la ausencia de nuevos materiales referibles a sus distintas especies (Abello et al., 2002). 


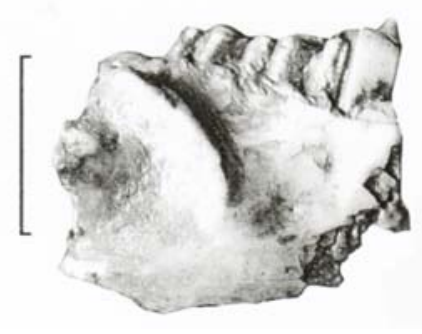

Figura 2.4. Argyrolagus sp. GHUNLPam 21226 mandíbula en vista lateral, escala $5 \mathrm{~mm}$

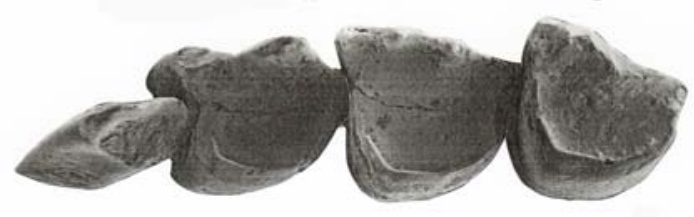

Figura 2.5. Argyrolagus sp. GHUNLPam 19617 P3-M3 en vista oclusal, escala 1 mm

Observaciones: Ninguno de los marsupiales es asignable a especies previamente reconocidas. En el caso del marmosino indeterminado, esto podría obedecer al carácter fragmentario de los restos disponibles. Sin embargo, este no es el caso de Sparassocynus sp., Hyperdidelphys sp. y Argyrolagus sp., ya que los especímenes de Caleufú se diferencian de las especies reconocidas para estos géneros (Abello et al., 2002).

Orden XENARTHRA COPE, 1883

Infraorden CINGULATA Illiger, 1811

Familia DASYPODIDAE Bonaparte, 1838

Subfamilia EUPHRACTINAE Pocock, 1924

Tribu EUPHRACTINI Pocock, 1924

Macroeuphractus Ameghino, 1887

Macroeuphractus sp.

Material: GHUNLPam 19596/2, /18 y /36; 21149 placas de la coraza aisladas (Esteban et al., 2003).

Macroeuphractus morenoi (Lydekker, 1894)

Proeuphractus scalabrinii Ameghino, 1920 (part.; nec Moreno y Mercerat, 1891) 
Material: GHUNLPam 19239/2, /3, /6, /7, /10, /12, /15, /17 (Figura 2.6 B), /22, /23, /24, / 25, /26, /27, /28, /29, /30/32/40, /46 /67/51, /53/54, /69, /82, /85, /86 y /91; 19596/1, /3, / 4, /8, /14, /15, /22, /25, /28 /32 y /34; 19816; 19941; 19943; 19944; 19945; 19947; 19951; 19953; 19955; 19958; $21561 / 30$ y /31/33 (Figura 2.6 A) y /34 placas de la coraza aisladas (Esteban et al., 2003).

\section{Proeuphractus Ameghino, 1886} Proeuphractus sp.

Material: GHUNLPam 19239/11 (Figura 2.6 C), /47, /60 y /62.

Comentarios: El material de Proeuphractus sp. se diferencia de $P$. limpidus Ameghino, 1886 (única especie del género) por su tamaño mayor y por la ornamentación superficial de las placas móviles. Si bien las diferencias en la ornamentación podrían deberse a variaciones intraespecíficas, el tamaño de las placas (más del doble en largo y ancho) es un carácter que permite convalidar lo sugerido por Esteban et al. (2001), en cuanto a la presencia de una especie nueva de Proeuphractus en niveles de la Formación Cerro Azul en la provincia de La Pampa (Esteban et al., 2003).

Chorobates villosissimus (Rovereto, 1914)

Proeuphractus minor Rovereto, 1914

Material: GHUNLPam 19239/1, /19; /35, /73, /97 y /100; 19596/19, /20, /23, /26 (Figura 2.6 D) y /52; 21561/1, /2, /3, /4, /5,/6, /7/8,/9 y /10;/11, /12 y /13 placas de la coraza aisladas (Esteban et al., 2003).

Tribu EUTATINI Bordas, 1933

Chasicotatus Scillato Yané, 1977

Chasicotatus sp.

Material: GHUNLPam 19968; 19972; 19973; 19977; 19978; 19979; 19980; 19981; 19986 placas de la coraza aisladas (Esteban et al., 2003).

Chasicotatus ameghinoi Scillato Yané, 1977 
Material: GHUNLPam 19239/8, /13 /93 y /101; 19596/5, /6, /21/31, /37, /41, /45 y /53; 19768; 21280; 21561/12, /14 (Figura 2.6 E), /16, /17, /18, /19, /20, /22, /23, /24 (Figura 2.6 F), /25, /26, /27, /28 y /29 placas de la coraza aisladas (Esteban et al., 2003).

Doellotatus Bordas, 1932

Doellotatus inornatus (Rovereto, 1914)

Eutatus inornatus Rovereto, 1914

Material: GHUNLPam 21588 placas de la coraza aisladas (Figura 2.6. G y Esteban et al., 2003).

Doellotatus chapadmalensis Bordas, 1933

Material: GHUNLPam 21087; 21561/15 (Figura 2.6. H) y /44 placas de la coraza aisladas (Esteban et al., 2003).

Ringueletia Reig, 1958

Ringueletia simpsoni (Bordas, 1933)

Doellotatus simpsoni Bordas, 1933

Material: GHUNLPam 19239/66; 19596/9, /16 y /17; 21561/38 (Figura 2.6 K), /39, /40, I 41, /42 y /43; 21562/1 (Figura 2.6. I); 22501 placas de la coraza aisladas.

Comentarios: Se trata del primer registro de esta especie en la Formación Cerro Azul, en consecuencia se amplió su distribución, ya que previamente había sido citada como exclusiva del Plioceno temprano (Edades mamífero Montehermosense y Chapadmalalense) de la costa atlántica en la provincia de Buenos Aires (Esteban et al., 2003). 


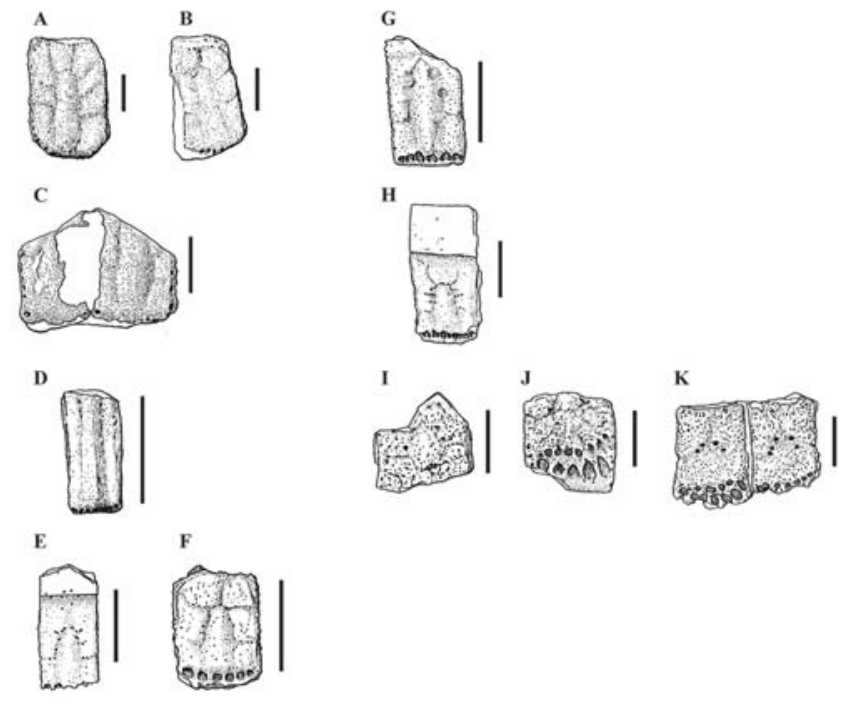

Figura 2.6. A-B. Macroeuphractus morenoi placas fijas, A. GHUNLPam 21561/33; B. GHUNLPam 19239/17; C. Proeuphractus GHUNLPam 19239/11, fragmento de placas móviles; D. Chorobates villosissimus GHUNLPam 19596/26, fragmento de placa móvil; E- F. Chasicotatus ameghinoi, E. GHUNLPam 21561/14, fragmento de placa móvil; F. GHUNLPam 21561/24, placa fija; G. Doellotatus inornatus GHUNLPam 21588, fragmento de placa móvil; H. Doellotatus chapadmalensis GHUNLPam 21561/15, placa móvil. I-K. Ringueletia simpsoni I. GHUNLPam 21562/1, fragmento de placa móvil; J. GHUNLPam 21561/38, fragmento de placa móvil; K. GHUNLPam 21561/41, placas fijas, escalas $1 \mathrm{~cm}$

Familia GLYPTODONTIDAE Burmeister, 1879 Glyptodontidae indet.

Material: GHUNLPam 19613 fragmento mandibular con 3 molariformes; 21129 fragmento de molariforme; 19871; 21725; 21905/1-3; 22507/2-11; 22538/3; 22545/1-5; 22558/1; 22562/1-7 placas de la coraza aisladas.

Comentarios: Los materiales son fragmentarios, están muy deteriorados y no permiten una asignación más precisa.

Infraorden PILOSA Flower, 1883

Familia MYLODONTIDAE Ameghino, 1889

Subfamilia SCELIDOTHERIINAE Ameghino, 1904

Scelidotheriinae indet.

Material: 21108 fragmento mandibular con 2 molariformes muy deteriorados; 21587 fragmentos de molariformes. 
Comentarios: Los materiales son muy fragmentarios. No es posible sobre esa base realizar una asignación más detallada.

Orden RODENTIA Bowdich, 1821

Suborden HYSTRICOGNATHI Tullberg, 1899

Infraorden CAVIOMORPHA Wood y Patterson (in Wood, 1955)

Familia ECHIMYIDAE Gray, 1825

Pampamys Verzi, Vucetich y Montalvo, 1995

Pampamys emmonsae Verzi, Vucetich y Montalvo, 1995

Material: GHUNLPam 19606 fragmento mandibular derecho con raíces de dp4 y m1 completo (Figura 2.7).

Comentarios: Si bien el único ejemplar recuperado es muy fragmentario y carece del dp4 (diente con características diagnósticas), la morfología y el tamaño de la porción preservada permiten asignarlo a Pampamys emmonsae (Tabla 2.1).

\begin{tabular}{|l|c|c|c|}
\hline Medidas dentarias & GHUNLPam 2214 Tipo & Media (paratipos) & GHUNLPam 19606 \\
\hline m1 DAP & 2,08 & 2,07 & 2,10 \\
\hline m1 DTA & 1,58 & 1,71 & 1,95 \\
\hline m1 DTP & 1,74 & 1,88 & 1,90 \\
\hline
\end{tabular}

Tabla 2.1. Medidas en mm de Pampamys emmonsae

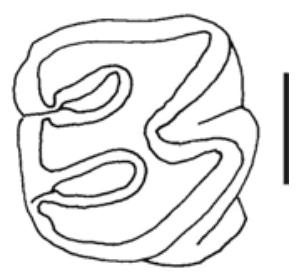

Figura 2.7. Pampamys emmonsae GHUNLPam 19606 m1, escala $1 \mathrm{~mm}$

Observaciones: La descripción original de esta especie (Verzi et al., 1995), se basó en materiales provenientes de niveles de la Formación Cerro Azul en Bajo Giuliani y Laguna Chillhué. Posteriormente, nuevos restos mandibulares y varios fragmentos craneanos fueron hallados en esas localidades y en Salinas Grandes de Hidalgo, Telén, Puesto Colorado y Loventué, lo que permitió vincular al género Pampamys con el viviente Thrichomys (Verzi et al., 1999 b). Los niveles de la 
Formación Cerro Azul en esas localidades fueron asignados a la Edad mamífero Huayqueriense (Mioceno tardío), edad que se consideró mínima para la diferenciación del linaje de Thrichomys (Verzi et al., 1999 b).

Los Eumysopinae "con molares simplificados" del Mioceno tardío experimentaron una importante radiación al sur de su distribución actual, seguramente relacionada con el desarrollo de ambientes abiertos en esta área (Verzi et al., 1994, 1995). Esta radiación tiene un notable registro en los afloramientos de la Formación Cerro Azul, donde además de Pampamys emmonsae, se encontraron Reigechimys plesiodon y R. octodontiformis (Verzi et al., 1994), Theridomysops parvulus, aff. Clyomys (Montalvo et al., 1998) у Eumysops sp. (Montalvo et al., 1995).

En este sentido, y como ejemplo, para Laguna Chillhué, sobre 223 especímenes asignados a roedores, 40 corresponden a Echimyidae y de estos el 67,5\% corresponde a Pampamys emmonsae. Esta diversidad y abundancia contrasta con la escasez de equímidos en el afloramiento de Caleufú, ya que un solo ejemplar de Pampamys emmonsae constituye el único registro de esta familia, representando el $0,11 \%$ sobre el total de especímenes de roedores. Puede sugerirse que la escasez de equímidos en la asociación de Caleufú sea consecuencia de la declinación que esta familia experimentó en el límite MioPlioceno en la región sur de su actual distribución (Verzi et al., 1994; Vucetich y Verzi, 1996).

Familia CHINCHILLIDAE Bennett, 1833 Lagostomus Brookes, 1828 Lagostomus (Lagostomopsis) Kraglievich, 1926 Lagostomus (Lagostomopsis) sp.

Material: GHUNLPam 19599/30 fragmento mandibular izquierdo con i1; 19600 fragmento mandibular izquierdo con p4-m3; 21223/1-3 molares inferiores aislados.

Comentarios: Los Chinchillidae están representados en esta localidad por un solo taxón, Lagostomus (Lagostomopsis) sp., por restos muy fragmentarios. La subfamilia Lagostominae se registra en la pampasia desde la Edad mamífero Chasiquense (Bondesio et al., 1980). Lagostomus (Lagostomopsis) sp. ya fue 
mencionada para otras asociaciones de la Formación Cerro Azul en las localidades de Salinas Grandes de Hidalgo (Zetti, 1972 a; Goin et al., 2000), Quehué (Montalvo et al., 1995) y Laguna Chillhué (Montalvo et al., 1996).

\section{Familia DINOMYIDAE Alston, 1876}

Tetrastylus Ameghino, 1886

Tetrastylus sp.

Material: GHUNLPam 19830 fragmento mandibular izquierdo con i1 roto y p4-m3, este último roto en su porción posterior (Figura 2.8); 21528 p4 izquierdo.

Comentarios: El espécimen más completo (GHUNLPam 19830) corresponde a un individuo juvenil: toda la superficie ósea presenta hueso poco conformado. La Tabla 2.2 muestra las medidas mandibulares y dentarias de ese resto. El i1 es un poco más ancho que los molariformes, pero no llega al ancho que presentan esos dientes en Telicomys. Cada molariforme está formado por cuatro prismas laminares, los dos últimos libres.

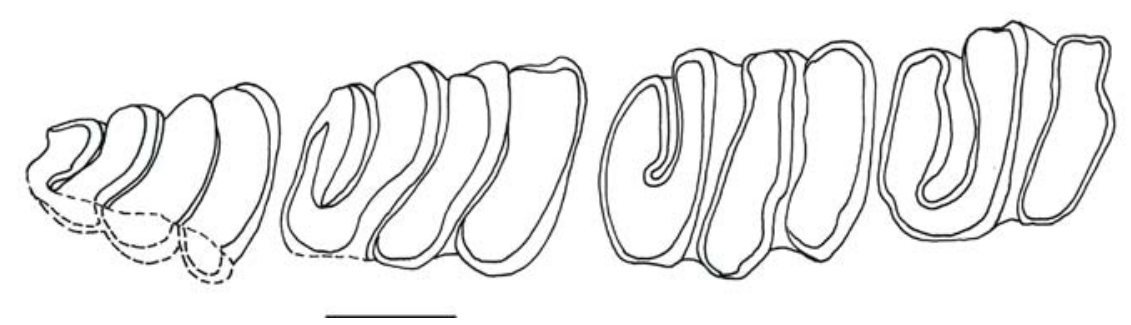

Figura 2.8. Tetrastylus sp. GHUNLPam 19830 mandíbula izquierda con i1 roto y p4-m3, escala $5 \mathrm{~mm}$

\begin{tabular}{|c|c|c|c|c|c|c|c|c|c|c|c|}
\hline $\mathrm{i} 1 \mathrm{AP}$ & $\mathrm{I} 1 \mathrm{~A}$ & $\mathrm{p} 4 \mathrm{~L}$ & $\mathrm{p} 4 \mathrm{~A}$ & $\mathrm{~m} 1 \mathrm{~L}$ & $\mathrm{~m} 1 \mathrm{~A}$ & $\mathrm{~m} 2 \mathrm{~L}$ & $\mathrm{~m} 2 \mathrm{~A}$ & $\mathrm{~m} 3 \mathrm{~L}$ & $\mathrm{~m} 3 \mathrm{~A}$ & diastema & a. mand \\
\hline 12,65 & 12,25 & 9,60 & 7,10 & 11,40 & 8,65 & 11,25 & 9,20 & 8,90 & 8,50 & 32,55 & 47,40 \\
\hline
\end{tabular}

Tabla 2.2. Medidas mandibulares y dentarias en $\mathrm{mm}$ de Tetrastylus sp. (GHUNLPam 19830)

Familia OCTODONTIDAE Waterhouse, 1839

Subfamilia CTENOMYINAE Tate, 1935 
Neophanomys Rovereto, 1914

Neophanomys sp.

Material: GHUNLPam 19602 mandíbula izquierda con i1 roto y m1-3; 19603 mandíbula derecha con i1 y dp4-m1; 19604 mandíbula derecha con i1 y dp4-m1; 19605 mandíbula izquierda con i1 roto y m1-2; 19847 mandíbula derecha con alvéolo de dp4 y m1; 19848 mandíbula izquierda con dp4-m1; 21886 mandíbula izquierda con dp4-m1 (Figura 2.9).

Comentarios: Los nuevos ejemplares tienen una morfología mandibular y del i1 similar a la de Neophanomys biplicatus Rovereto, 1914 y un tamaño algo mayor (Tabla 2.3).

La ontogenia de los molariformes difiere respecto de esta última en la secuencia de cierre de los fléxidos: el hipofléxido es más persistente y el metafléxido es marcadamente más efímero que el mesofléxido. El análisis radiográfico del material y la diferencia ontogenética señalada en la duración de los fléxidos sugiere claramente un grado de hipsodoncia más avanzado en los especímenes de Caleufú (Figura 2.10). Esto configura un patrón de cambio similar al hallado en el género Chasichimys (Verzi, 1999). De este modo, los nuevos especímenes asignados a Neophanomys son interpretados como un cronomorfo (sensu Martín, 1993), con caracteres derivados con respecto a los de Neophanomys biplicatus presentes en los afloramientos de la Formación Cerro Azul en las localidades de Bajo Giuliani, Quehué y Estancia Don Mariano (Montalvo y Verzi, 2002). 


\begin{tabular}{|c|c|c|c|c|c|c|c|c|c|c|c|}
\hline & 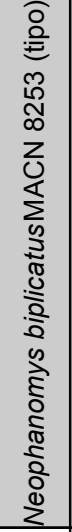 & 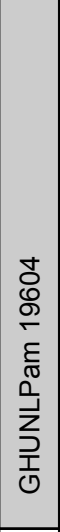 & 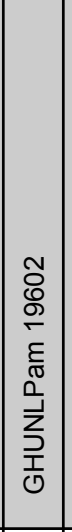 & 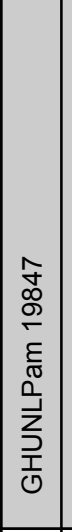 & 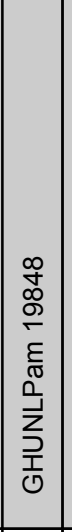 & 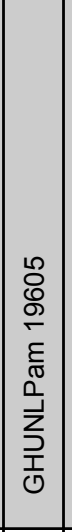 & 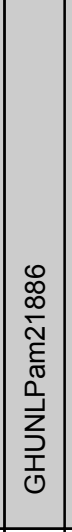 & 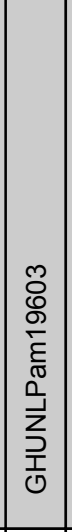 & $\times$ & $\subset$ & 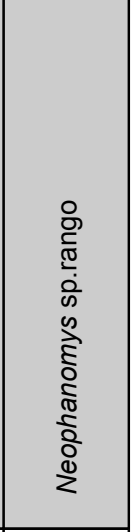 \\
\hline dp4-m1 L & 3,24 & 4,05 & & & 3,90 & 3,15 & 3,90 & 3,45 & 3,69 & 5 & $3,15-4,05$ \\
\hline $\mathrm{m} 1-3 \mathrm{~L}$ & & & 5,40 & & & & & & 5,40 & 1 & 5,40 \\
\hline $\mathrm{m} 1-2 \mathrm{~L}$ & & & 3,45 & & & & & & 3,45 & 1 & 3,45 \\
\hline $\mathrm{m} 2-3 \mathrm{~L}$ & & & 3,00 & & & & & & 3,00 & 1 & 3,00 \\
\hline dp4 AP & 1,63 & 1,95 & & & 1,95 & & 1,95 & 1,65 & 1,88 & 4 & $1,65-1,95$ \\
\hline dp4 TA & 1,06 & 1,20 & & & 1,35 & & 0,90 & 0,90 & 1,09 & 4 & $0,90-1,35$ \\
\hline dp4 TP & 1,18 & 1,35 & & & 1,50 & & 1,05 & 1,05 & 1,24 & 4 & $1,05-1,50$ \\
\hline m1 AP & 1,48 & 1,95 & 1,80 & 1,80 & 1,80 & 1,35 & 1,80 & 1,65 & 1,74 & 7 & $1,35-1,95$ \\
\hline m1 TA & 1,39 & 1,35 & 1,65 & 1,20 & 1,65 & 1,35 & 1,35 & & 1,43 & 6 & $1,20-1,65$ \\
\hline $\mathrm{m} 1 \mathrm{TP}$ & 1,36 & 1,35 & 1,50 & 1,20 & 1,65 & 1,20 & 1,20 & & 1,35 & 6 & $1,20-1,65$ \\
\hline $\mathrm{m} 2 \mathrm{AP}$ & 1,51 & & 1,65 & & & 1,65 & & & 1,65 & 2 & 1,65 \\
\hline $\mathrm{m} 2 \mathrm{TA}$ & 1,42 & & 1,50 & & & 1,65 & & & 1,58 & 2 & $1,50-1,65$ \\
\hline m2 TP & 1,21 & & 1,20 & & & 1,50 & & & 1,35 & 2 & $1,20-1,50$ \\
\hline m3 AP & & & 1,50 & & & & & & 1,50 & 1 & 1,50 \\
\hline m3 TA & & & 1,35 & & & & & & 1,35 & 1 & 1,35 \\
\hline m3 TP & & & 0,75 & & & & & & 0,75 & 1 & 0,75 \\
\hline i1 AP & 1,51 & & & & & 1,65 & & & 1,65 & 1 & 1,65 \\
\hline i1 T & 0,78 & & 0,75 & & & 0,60 & & 0,75 & 0,70 & 3 & $0,60-0,70$ \\
\hline
\end{tabular}

Tabla 2.3. Medidas dentarias en mm de Neophanomys sp. y del tipo de $N$. biplicatus

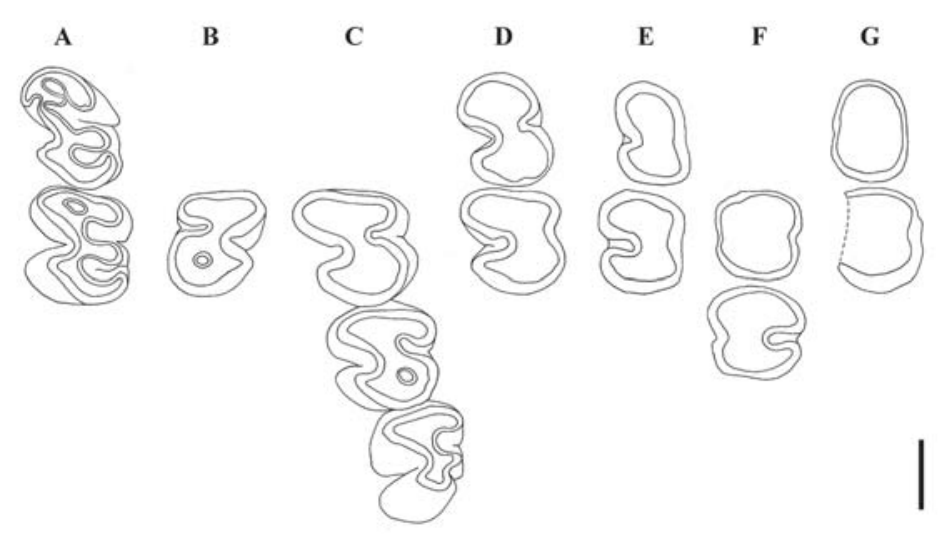


Figura 2.9. Neophanomys sp., vistas oclusales. A. GHUNLPam 19605 m1-2 izquierdos; B. GHUNLPam 19847 m1 derecho; C. GHUNLPam 19602 m1-3 izquierdos; D.

GHUNLPam 19848 dp4-m1 izquierdos; E. GHUNLPam 21886 dp4-m1 izquierdos; F. GHUNLPam 19604 dp4-m1 derechos; G. GHUNLPam 19603 dp4-m1 derechos, escala 1 $\mathrm{mm}$

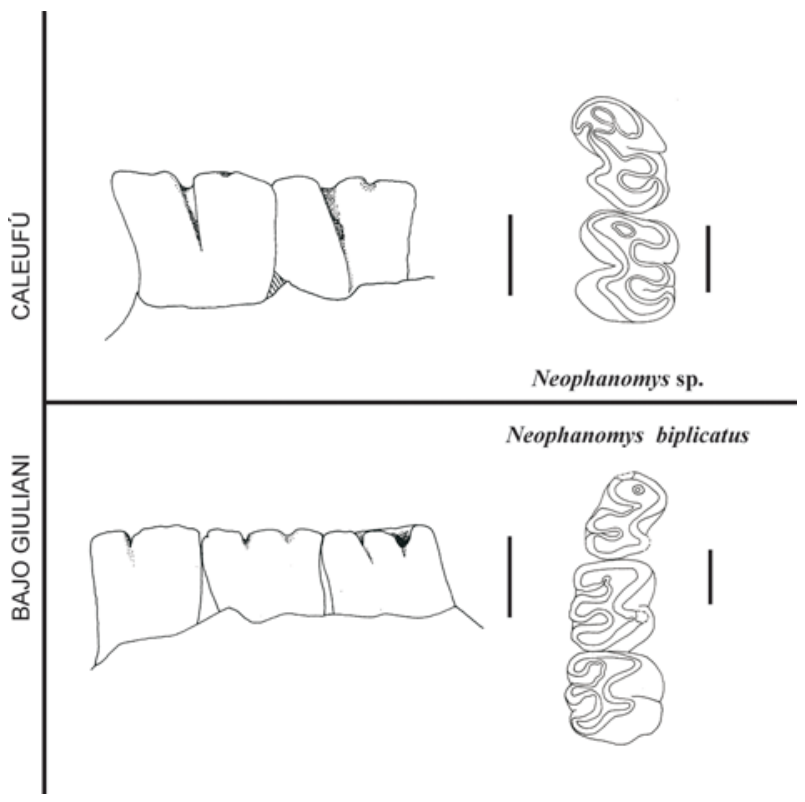

Figura 2.10. Neophanomys, vistas linguales y oclusales de las series dentarias de Neophanomys biplicatus GHUNLPam 5699 (procedente de Bajo Giuliani) y Neophanomys sp. GHUNLPam 19605, escalas $1 \mathrm{~mm}$

Xenodontomys Kraglievich, 1927 Xenodontomys elongatus Verzi, Montalvo y Tiranti, 2003

Material: GHUNLPam 19714 rostro con la porción intra-alveolar de los 11, DP4-M3 izquierdos y DP4-M2 derechos, holotipo (Figura 2.12) y 19721 paladar deteriorado con fragmento de mandíbula articulada; 19644, 19663 ambos DP4-M3; 19647 DP4-M3 derechos y M1-3 izquierdos; 19646 DP4-M3 izquierdos; 19723, 21240 DP4-M3 derechos; 19672 DP4-M3 izquierdos y DP4-M2 derechos; 21249 DP4-M3 derechos y DP4-M2 izquierdos; 19656, 21241 DP4-M2 izquierdos y derechos; 21252 DP4-M2 izquierdos y M1-2 derechos; 19648 ambos I1 y DP4-M1; 21253 M1-3 izquierdos y M2-3 derechos; 19661 ambos M1-3; 19736 ambos DP4; 19700 DP4-M1 derechos; 19717, 21262 DP4-M1 izquierdos; 21257 DP4-M2 izquierdos; 19728, 21251 M1-2 izquierdos; 19682, 19685, 19715 M1-3 izquierdos; 19722, 21268 M1-3 derechos; 19641, 19713, 21005, 21613 M2-3 izquierdos; 21263, 21271, 21276 M2-3 derechos; 19709, 19732, 19760, 21156, 21272/7 M3 derecho; 19740, 19746, 19747, 19750 M3 izquierdo; 19743, 19749, 19751, 19752, 19758, 21014, 21272/8, /10, /11 M1 ó M2 izquierdo; 19735, 19742, 19744, 19759, 19761, 21018 M1 ó M2 derecho; 19734 M1 derecho; 19679, 19708, 19730, 19731, 19762, 21022, 21266, 21272/6, /14, 21603 DP4 izquierdo; 19698, 19707, 21270, 21272/9 DP4 derecho; 19344, 21272/12 fragmento de molar superior; 21279 ambas hemimandíbulas con i1-m3; 19650, 19653, 19659, 19665, 19687, 19693, 19696, 21246, 21255, 21256 i1 roto y dp4-m3 derechos; 19645 (Figura 2.11), 19651, 19652, 19654, 19680, 19710, $19829,21235,21236,21237,21238,21242,21248,21254$ i1 roto y dp4-m3 izquierdos; 19633 i1 roto dp4 y m2-3 derechos; 19662 i1, dp4 y alvéolos de m1-3 derechos; 19849 i1 
y alvéolos de dp4-m3 derechos; 19850 i1 y alvéolos de dp4-m2 derechos; 19649, 19668 dp4-m3 derechos; 19658, 19660, 19666 i1, dp4 roto y m1-3 izquierdos; 19670, 19671, 21232 dp4-m3 izquierdos; 19684, 19694, 19726 i1 y m1-2 derechos; 19635, 19686, 19705, 19737, 21244, 21247, 21265, 21275 m1-2 derechos; 19695, 19701, 19724, 21261 m1-2 izquierdos; 21007 i1 y dp4-m1 derechos; 19677 i1 y dp4-m1 izquierdos; 21243 i1 y alvéolos de dp4-m1 izquierdos; 21245 dp4-m1 izquierdos; 19632, 19692, 19716; 21234 i1 y dp4-m2 derechos; 19634 i1 y dp4-m2 izquierdos; 19638, 19639, 19640, 19688, 19719, 21250 dp4-m2 izquierdos; 19642, 19664, 19676, 19718, 21231 i1 y dp4-m1 derechos; 19697 i1 y dp4-m1 izquierdos; 19712, 19720, 19733, 21267, 21269, 21584 dp4-m1 derechos; 19657, 19681, 21258 i1 y dp4-m2 izquierdos; 19669, 19673, 21233 i1 y dp4m2 derechos; 19667, 19683 dp4-m2 derechos; 21259 dp4-m2 izquierdos; 19675, 21093, 21239, 21264 m1-3 derechos; 21260 i1 y m1-3 izquierdos; 19631, 19636, 19678 m1-3 izquierdos; 19637 i1 y m2-3 derechos; 19643, 19699, 19703, 19706, 21008 m2-3 derechos; 19689, 21080, 21277 m2-3 izquierdos; 19674 i1 y dp4 izquierdos; 19598/2, 19702, 21273 i1 y dp4 derechos; 19704, 19727, 21272/4 m3 izquierdo; 19756, 21010, 21272/13 m3 derecho; 21274 m1 izquierdo; 19725 m2 derecho; 19748, 19753, 19754, 19757, 19763, 21085, 21601, 21272/5 m1 ó 2 izquierdo; 19739, 21272/3 m1 ó 2 derecho; 19755, 21012, 21013, 21015, 21016 dp4 derecho; 19745, 21019, 21077, 21272/1, 21272/2, 21612 dp4 izquierdo; 19467: i1 derecho; 21017, 21020, 21021, 21023, 21602 fragmentos de molares inferiores (ver Verzi et al., 2003) y GHUNLPam 21278; 21823/13; 21855 al 21868; 21869/1-10 y 21919 fragmentos mandibulares, porciones de paladares y dientes aislados.

Comentarios: Xenodontomys elongatus se distingue de las especies previamente descriptas (Xenodontomys simpsoni Kraglievich, 1961 y X. ellipticus Kraglievich, 1927) fundamentalmente por el mayor tamaño, la elongación de la figura oclusal de los molariformes (especialmente DP4-M3) y el mayor largo relativo de los DP4/4 (Verzi et al., 2003).

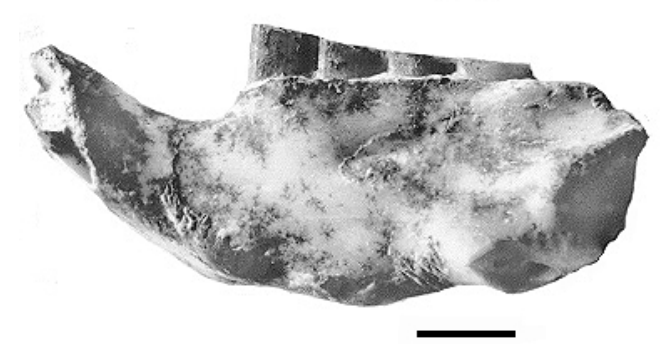

Figura 2.11. Xenodontomys elongatus vista externa de la hemimandíbula izquierda GHUNLPam 19645, escala $5 \mathrm{~mm}$ 


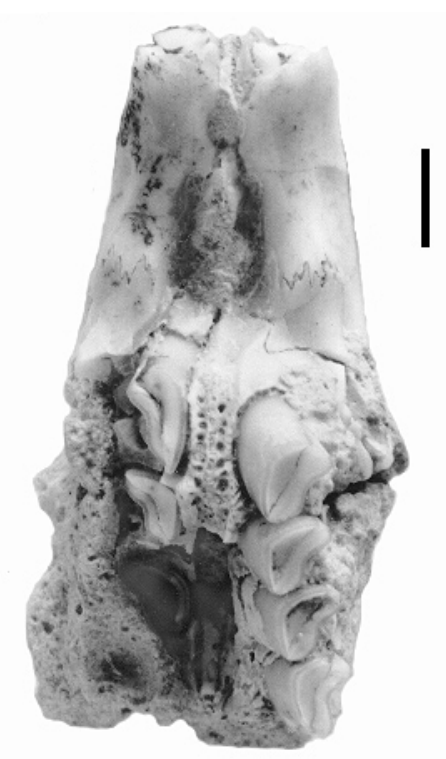

Figura 2.12. Xenodontomys elongatus vista ventral del rostro GHUNLPam 19714 (holotipo), escala $5 \mathrm{~mm}$

Observaciones: Esta especie ha permitido reforzar la hipótesis de que Xenodontomys representa una secuencia filética sin diversificación, con un patrón de cambio anagenético que incluye una tendencia al incremento de tamaño, el pasaje de una morfología oclusal subrómbica a otra subelíptica, el alargamiento de los molariformes (en especial los DP4/4) y el desarrollo de una capa de esmalte radial en el borde de ataque de cada diente (Verzi et al., 2003). En este contexto, las especies Xenodontomys simpsoni, $X$. ellipticus y $X$. elongatus son interpretadas como sucesivos cronomorfos (sensu Martin, 1993). Xenodontomys elongatus es interpretada como el cronomorfo más derivado de la secuencia filética (Verzi et al., 2003).

Verzi (2002) y Verzi et al. (2003) señalaron que el patrón evolutivo propuesto para Xenodontomys implica una hipótesis bioestratigráfica y biocronológica derivada. Los cambios dentarios (incluida la microestructura del esmalte) mostrados por la secuencia filética de Xenodontomys sugieren un orden decreciente de antigüedad para las localidades donde está presente: 1. Barrancas Coloradas, 2. El Guanaco, 3. Sección Seminario, 4. "Formación" Irene (estas dos últimas en la provincia de Buenos Aires) y 5 . Caleufú.

En Barrancas Coloradas y El Guanaco, el cronomorfo registrado es Xenodontomys simpsoni y la fauna de ambas localidades fue considerada más 
antigua con respecto a la de las localidades donde está presente Xenodontomys ellipticus (Sección Seminario y "Formación" Irene). Finalmente, el cronomorfo más derivado, Xenodontomys elongatus, se registra en Caleufú (Verzi et al., 2003).

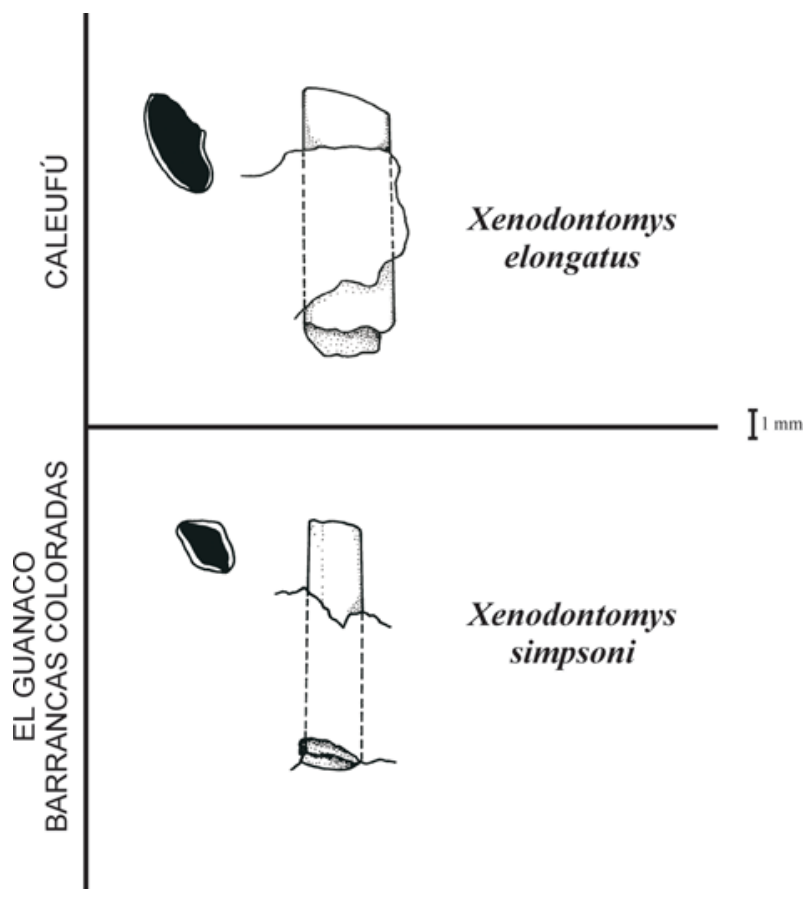

Figura 2.13. Xenodontomys, vistas oclusales y altura dentaria del $\mathrm{m} 1$ en $X$. simpsoni y $X$. elongatus, escala $1 \mathrm{~mm}$

Subfamilia OCTODONTINAE Waterhouse, 1839

Phtoramys Ameghino, 1889

Phtoramys aff. P. homogenidens

Material: GHUNLPam 19607 fragmento mandibular derecho con i1 roto y dp4-m2; 19833 fragmento mandibular izquierdo con i1 roto y m1-2; 19834 fragmento mandibular izquierdo con i1 roto y dp4-m2; 19845 porción de paladar con DP4 izquierdo; 19846 fragmento mandibular izquierdo con dp4-m1 y 21224 porción de paladar con M2-3 derechos.

Comentarios: Los incisivos son anchos (Tabla 2.4). Los molariformes son protohipsodontes. El dp4 es suboval y no presenta fosétidas en ninguno de los especímenes en los que se preserva. Los molares son también subovales, carácter que vincula a esta muestra con Phtoramys homogenidens Ameghino, 1887. Los fléxidos están enfrentados, siendo el mesofléxido más efímero que el hipofléxido. Ambos fléxidos quedan reducidos a fosétidas en los especímenes con 
más desgaste. Se recuperaron dos especímenes con molares superiores. Presentan un contorno oclusal más cuadrangular que los inferiores.

Se reconocen tres especies en el género Phtoramys, $P$. homogenidens, $P$. pulcher Rovereto, 1914 y P. hidalguense Pascual, Pisano y Ortega, 1965. Pascual et al. (1965) describieron esta última especie para niveles que posteriormente fueron asignados a la Formación Cerro Azul en Salinas Grandes de Hidalgo. Además, representantes de este género fueron hallados en Quehué, Laguna Chillhué, Bajo Giuliani y Barrancas Coloradas. Los materiales procedentes de Caleufú muestran caracteres que los vinculan más con la especie montehermosense Phtoramys homogenidens, pero la variabilidad que presentan los diferentes especímenes recuperados de esas localidades indica que el género Phtoramys requiere una exhaustiva revisión.

Este género fue considerado como ancestral a los Ctenomyinae (Pascual et al., 1965) pero Verzi (1994) lo incluyó dentro de la Subfamilia Octodontinae, considerándolo grupo hermano de los demás representantes de la misma.

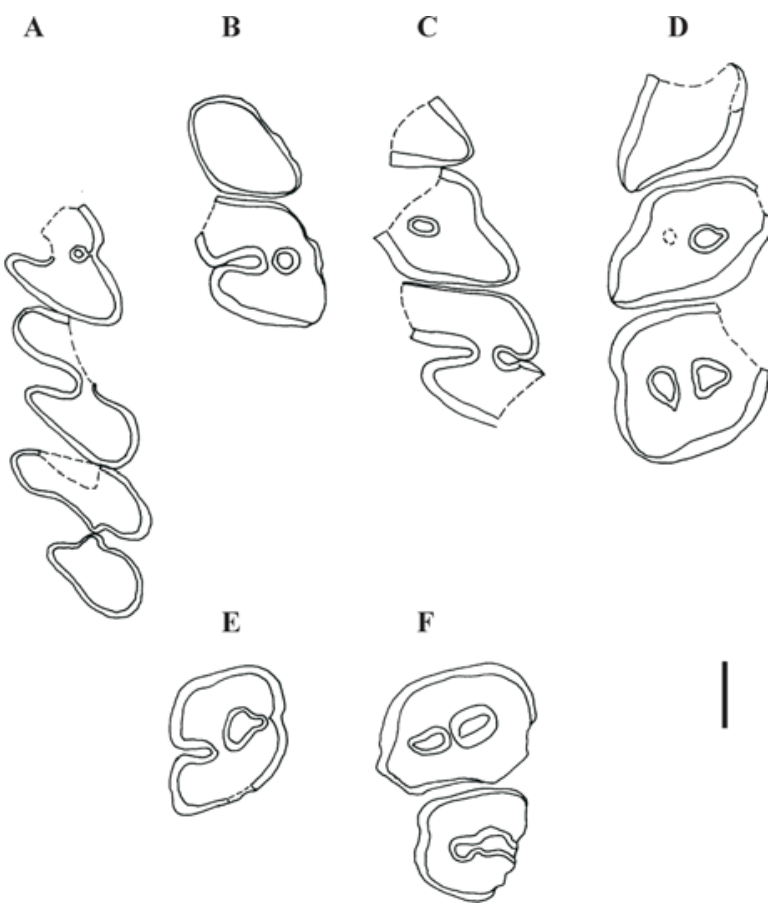

Figura 2.14. Phtoramys aff. P. homogenidens A. GHUNLPam 19833 m1-3 izquierdos; B. GHUNLPam 19846 dp4-m1 izquierdos; C. GHUNLPam 19834 dp4-m2 izquierdos; D. GHUNLPam 19607 dp4-m2 derechos; E. GHUNLPam 19845 DP4 izquierdo; F. GHUNLPam 21224 M2-3 derechos, escala 1mm 
Paleobiología de la asociación faunística de Caleufú (La Pampa, Formación Cerro Azul, Mioceno superior - Plioceno inferior), a través de análisis tafonómicos

\begin{tabular}{|l|l|l|l|l|l|l|l|l|l|l|l|}
\hline & i A & iT & dp4 AP & dp4 TA & dp4 TP & m1 AP & M1 TA & m1 TP & m2 AP & m2 TA & m2 TP \\
\hline GHUNLPam 19607 & 2,70 & & 1,80 & & 1,50 & 1,80 & 1,80 & 1,50 & 1,95 & & 1,65 \\
\hline GHUNLPam 19834 & 2,40 & 2,25 & & & & 1,80 & 1,45 & 1,65 & 1,95 & 2,25 & 1,80 \\
\hline GHUNLPam 19846 & & & 1,50 & 0,75 & 1,20 & 1,95 & 1,65 & 1,65 & & & \\
\hline GHUNLPam 19833 & 2,25 & 1,65 & & & 1,65 & 2,25 & 1,80 & 1,50 & 2,25 & 2,25 & 1,50 \\
\hline
\end{tabular}

\begin{tabular}{|l|c|c|c|c|c|c|c|c|c|}
\hline & DP4 AP & DP4 TA & DP4 TP & M2 AP & M2 TA & M2 TP & M3 AP & M3 TA & M3 TP \\
\hline GHUNLPam 21224 & & & & 1,50 & 1,80 & 1,80 & 1,50 & 1,20 & 0,75 \\
\hline GHUNLPam 19845 & 1,65 & 1,80 & 1,35 & & & & & & \\
\hline
\end{tabular}

Tabla 2.4. Medidas en $\mathrm{mm}$ de los dientes inferiores y superiores de Phtoramys aff. $P$. homogenidens

Octodontinae indet.

Material: GHUNLPam 19655 fragmento mandibular derecho con i1 roto y dp4-m3; 19765 fragmento mandibular izquierdo con i1, dp4-m1 y m2 emergiendo; 19766 fragmentos mandibulares izquierdo y derecho con i1 roto y m1-3, porción de rostro izquierdo con 11 y paladar con los DP4-M3 derechos y M1-2 izquierdos (Figura 2.15 B); 19780 fragmento mandibular derecho con i1 roto y dp4-m1; 19781 fragmento mandibular izquierdo con i1 roto y dp4-m1; 19782 fragmento mandibular izquierdo con i1 roto y dp4-m3; 19783 fragmento mandibular derecho con lóbulo posterior del m1 y m2-3; 19784 porción de paladar con M1-2 derechos; 19785 fragmento mandibular derecho con diastema, dp4-m1 y $\mathrm{m} 2$ seccionado; 19786 fragmento mandibular derecho con i1 roto, alvéolo del dp4 y m1; 19787 fragmento mandibular izquierdo con dp4 seccionado y m1-2; 19788 fragmento mandibular izquierdo con i1 roto y m1-2; 19789 fragmento mandibular izquierdo con diastema y dp4; 19790 fragmento mandibular derecho con i1 roto y dp4-m1; 19791 fragmento mandibular izquierdo con los dp4-m1 y parte del m2 seccionados; 19792 fragmento mandibular izquierdo con dp4 y lóbulo anterior del m1; 19793 fragmento mandibular derecho con i1 roto y dp4; 19794 fragmento mandibular izquierdo con $\mathrm{m} 1$; 19795 fragmento mandibular derecho con dp4-m1; 19812 fragmento mandibular izquierdo con dp4-m1; 19817 fragmento mandibular izquierdo con $\mathrm{m} 1-3 ; 19818$ fragmento mandibular derecho con m1-3; 19819 fragmento mandibular derecho con i1 roto y m1-3; 19820 fragmento mandibular derecho con i1 roto y dp4-m3; 19821 fragmento mandibular derecho con i1 roto y dp4-m2; 19822 fragmento mandibular izquierdo con i1 roto, dp4 seccionado y m1-2; 19823 fragmento mandibular izquierdo con alvéolo del i1 y dp4-m3; 19824 fragmento mandibular izquierdo con alvéolo del i1 y dp4-m2; 19825 porción de paladar con los M1-2 derechos; 19828 rostro y paladar con el I1 derecho roto y los DP4M2 izquierdos y derechos; 19872 rostro y paladar con los 11 rotos y los DP4-M1 izquierdos y derechos; 19877 fragmento mandibular izquierdo con dp4; 21006 fragmento mandibular izquierdo con $\mathrm{m} 1 ; 21208$ fragmento mandibular izquierdo con m1-2; 21209 fragmento mandibular derecho con i1 roto y dp4-m3; 21210 fragmento mandibular izquierdo con i1 roto y m1-3; 21211 fragmento mandibular izquierdo con i1 roto y $\mathrm{m} 3$; 21212 fragmento mandibular izquierdo con i1 roto y dp4-m2; 21213 fragmento mandibular derecho con i1 roto y dp4-m3; 21214 fragmento mandibular derecho con i1 roto y dp4-m2; 21215 fragmento mandibular derecho con i1 roto y dp4-m3 (Figura 2.15 A); 21216 fragmento mandibular derecho con dp4-m1; 21217 fragmento mandibular izquierdo con i1 roto y dp4; 21218 fragmento mandibular derecho con dp4; 21219 paladar con DP4 derecho y DP4-M1 izquierdos; 21220 fragmento mandibular izquierdo con dp4; 21824 fragmento mandibular derecho con i1 roto y dp4-m1; 21825 porción de paladar con 
los DP4 derecho e izquierdo; 21826 fragmento mandibular derecho con dp4-m1 y lóbulo anterior del m2; 21827 porción de paladar con DP4 derecho; 21829 fragmento mandibular izquierdo con $\mathrm{m} 2$ roto; 21870 fragmento mandibular derecho con dp4; 21075, 21127, 21128, 21221/1-5 molares inferiores aislados; 21126, 21222/1-2, 21830/1-2 molares superiores aislados.

Comentarios: Tamaño similar a Xenodontomys elongatus (Tabla 2.5). La figura oclusal de los molariformes tiene forma de ocho. En los molares inferiores y los molariformes superiores, los dos lóbulos que componen cada diente son comprimidos ántero posteriormente, mientras que los dp4 presentan el lóbulo anterior de forma triangular, prolongado hacia adelante. En los molariformes los hipo y mesoflexos/idos están enfrentados, pero en los superiores ambos flexos son más penetrantes, por lo tanto el istmo que relaciona los dos lóbulos es muy estrecho (Figura 2.15).

La asignación de estos especímenes sólo puede ser resuelta en el marco de una revisión exhaustiva de las especies conocidas de octodontinos con dientes euhipsodontes para el lapso Mioceno superior-Plioceno inferior.

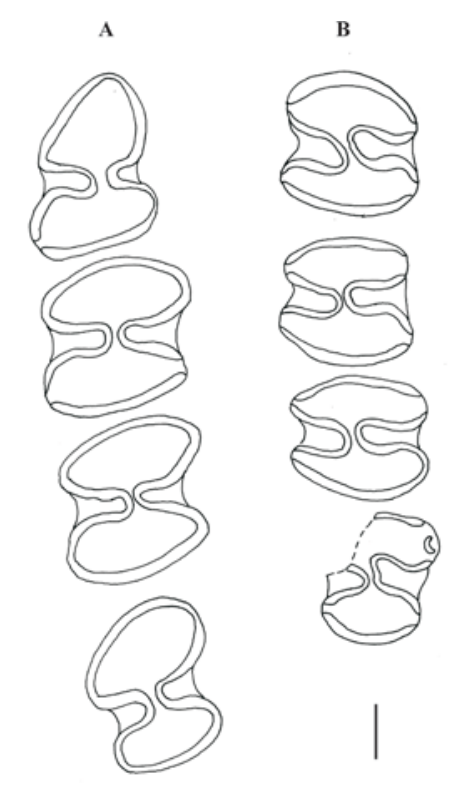

Figura 2.15. Octodontinae indet. A. GHUNLPam 21215 dp4-m3 derechos; B. GHUNLPam 19766 DP4-M3 derechos, escala $1 \mathrm{~mm}$

Se trata del primer hallazgo en niveles de la Formación Cerro Azul de representantes indudables de la Subfamilia Octodontinae con molariformes 
euhipsodontes. Zetti (1972 a) mencionó la presencia en Salinas Grandes de Hidalgo de Pseudoplataeomys Kraglievich, 1934, pero el material que sirvió de base para esa asignación fue posteriormente asignado al equímido Reigechimys octodontiformis (Verzi et al., 1994).

\begin{tabular}{|c|c|c|c|c|c|c|c|}
\hline 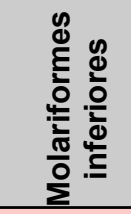 & $\begin{array}{l}\frac{\text { 응 }}{\Phi} \\
\stackrel{\Phi}{\varepsilon} \\
\text { 임 } \\
\end{array}$ & $\begin{array}{l}\stackrel{0}{E} \\
\stackrel{\underline{x}}{x} \\
\stackrel{\text {. }}{\Sigma} \\
\end{array}$ & 을 & 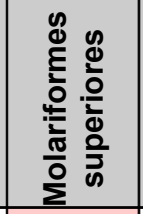 & 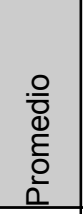 & $\begin{array}{l}\text { 으 } \\
\frac{E}{x} \\
\cdot \sqrt{\mathbb{E}} \\
\end{array}$ & 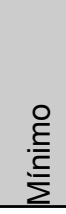 \\
\hline dp4-m3 L & 11,70 & 12,75 & 10,80 & & & & \\
\hline dp4-m2 L & 8,55 & 10,05 & 6,75 & & & & \\
\hline dp4-m1 L & 5,70 & 6,75 & 4,50 & DP4-M1 L & 5,03 & 5,10 & 4,95 \\
\hline $\mathrm{m} 1-2 \mathrm{~L}$ & 5,28 & 6,75 & 4,20 & M1-M2 L & 5,70 & 5,70 & 5,70 \\
\hline $\mathrm{m} 1-3 \mathrm{~L}$ & 8,08 & 9,60 & 7,20 & & & & \\
\hline $\mathrm{m} 2-3 \mathrm{~L}$ & 5,74 & 6,90 & 4,80 & & & & \\
\hline dp4 AP & 3,03 & 3,90 & 2,40 & DP4 AP & 2,55 & 3,30 & 2,10 \\
\hline dp4 TA & 1,75 & 2,55 & 1,20 & DP4 TA & 2,58 & 3,00 & 2,25 \\
\hline dp4 TP & 2,17 & 3,00 & 1,35 & DP4 TP & 2,64 & 3,15 & 2,40 \\
\hline $\mathrm{m} 1 \mathrm{AP}$ & 2,64 & 3,60 & 1,80 & M1 AP & 2,35 & 2,55 & 2,10 \\
\hline $\mathrm{m} 1 \mathrm{TA}$ & 2,55 & 3,30 & 1,35 & M1 TA & 2,60 & 2,85 & 2,40 \\
\hline $\mathrm{m} 1 \mathrm{TP}$ & 2,50 & 3,30 & 1,20 & M1 TP & 2,65 & 2,85 & 2,40 \\
\hline $\mathrm{m} 2 \mathrm{AP}$ & 2,73 & 3,75 & 2,10 & M2 AP & 2,70 & 2,70 & 2,70 \\
\hline $\mathrm{m} 2 \mathrm{TA}$ & 2,65 & 3,60 & 2,10 & M2 TA & 2,85 & 2,85 & 2,85 \\
\hline $\mathrm{m} 2 \mathrm{TP}$ & 2,44 & 2,85 & 1,95 & M2 TP & 2,70 & 2,70 & 2,70 \\
\hline m3 AP & 2,67 & 3,75 & 2,10 & & & & \\
\hline m3 TA & 2,36 & 2,85 & 1,95 & & & & \\
\hline m3 TP & 2,17 & 2,70 & 1,80 & & & & \\
\hline i1 AP & 2,91 & 4,20 & 1,65 & $11 \mathrm{AP}$ & 2,70 & 2,70 & 2,70 \\
\hline i1 T & 2,67 & 3,30 & 1,35 & $11 \mathrm{~T}$ & 3,00 & 3,00 & 3,00 \\
\hline a. mand. & 1,14 & 1,40 & 0,65 & & & & \\
\hline
\end{tabular}

Tabla 2.5. Promedio, valor máximo y valor mínimo de las medidas de los molariformes inferiores y superiores del Octodontinae indet. 


\title{
Familia CAVIIDAE Gray, 1821 \\ Neocavia Kraglievich, 1932 \\ Neocavia cf. N. lozanoi
}

\begin{abstract}
Material: GHUNLPam 19550 fragmento mandibular izquierdo con prisma posterior del $\mathrm{m} 1, \mathrm{~m} 2$ y prisma anterior del m3; 19559 fragmento mandibular izquierdo con p4-m3 (Figura 2.16); 19566 fragmento mandibular derecho con $\mathrm{m} 2-\mathrm{m} 3 ; 19568$ paladar con P4M2 izquierdos y P4-M1 y prisma anterior del M2 derechos; 19581 fragmento mandibular izquierdo con i1 roto y p4; 19582 fragmento mandibular izquierdo con p4-m2; 19588 fragmento mandibular derecho con m1-m2; 19589 fragmento mandibular izquierdo con m1-m2; 19622 fragmento mandibular izquierdo con i1 roto, base del p4 y m1; 21056 fragmento mandibular izquierdo con p4-m1; 21288 fragmento mandibular derecho con p4m3; 21332 fragmento mandibular derecho con i1 roto y $\mathrm{p} 4-\mathrm{m} 1 ; 21346$ paladar con P4M3 derechos muy deteriorados y P4-M3 izquierdos; 21351 paladar con P4-M3 izquierdos y P4-M1 derechos; 21353 paladar con P4-M1 izquierdos seccionados y P4-M2 derechos; 21355 paladar con M3 derecho; 21356 paladar con prisma posterior del M2 y M3 derechos; 21593 paladar con P4 izquierdo y derecho; 21854 porción de paladar con P4 seccionado y M1-M3 derechos y P4-M1 seccionados y M2-M3 izquierdos (ver Montalvo y Rocha, 2003) y GHUNLPam 19629; 19779; 21051; 21055; 21057; 21110; 21282; 21306; 21329 y 21330 porciones de paladar y hemimandíbulas.
\end{abstract}

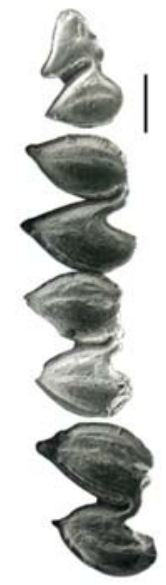

Figura 2.16. Neocavia cf. N. Iozanoi GHUNLPam 19559, vista oclusal; escala $1 \mathrm{~mm}$

Comentarios: Si bien los materiales asignados a este taxón son muy fragmentarios y no se han preservado especímenes que muestren ciertos caracteres diagnósticos descriptos para Neocavia (v.g. ampollas auditivas y frontales), lo que impidió profundizar el análisis de este taxón, comparten con el tipo de $N$. lozanoi Kraglievich, 1932, la morfología de las series oclusales de los molariformes y, en particular, el grado de desarrollo que adquieren los fléxidos internos. Se destacaron algunas diferencias como la presencia de una proyección aguda en el lóbulo anterior del prisma anterior del p4 que podría considerarse un 
carácter derivado, y la relación entre los flexos interno y externo en los molares superiores. Si bien, estas diferencias podrían haber sido consideradas dentro de rangos de variación intrapoblacional como se presentan en otros cávidos (Contreras, 1964; Quintana, 1996) se optó por mantener una nomenclatura abierta para la nominación de estos especímenes, si bien se señaló la presencia de un carácter derivado en los especímenes de Caleufú (Montalvo y Rocha, 2003).

Palaeocavia Ameghino, 1889

Palaeocavia sp.

Material: GHUNLPam 19531; 19534; 19536; 19541; 19543; 19545; 19547; 19551; 19553 al 19555; 19557; 19558; 19562 al 19565; 19570; 19571; 19575 al 19578; 19580; 19584 al $19587 ; 19592$ al $19595 ; 19618$ al $19620 ; 19623$ al $19627 ; 19630 ; 19767 ; 19772$ al 19774 ; 19776 al $19778 ; 19797 ; 19799$ al $19802 ; 19804 ; 19806 ; 19808 ; 19813 ; 19814 ; 19835$; 21009; 21024 al 21026; 21028; 21032; 21033; 21035 al 21037; 21040; 21041; 21043; 21045 al 21048; 21050; 21052 al 21060; 21073; 21078; 21081 al 21083; 21089; 21092; 21109; 21112 al 21119; 21196; 21197; 21287; 21307 al 21328; 21331; 21333 al 21345; 21348 al 21350; 21352; 21354; 21358; 21359; 21431/1-2; 21594; 21614/3; 21872; 21874 al 21884 y $21885 / 5-6$ porciones de paladares, fragmentos de hemimandíbulas y dientes aislados.

Comentarios: Los especímenes analizados presentan variación en el tamaño de los molariformes, tanto superiores como inferiores (Tabla 2.6). Se observaron algunas diferencias en la morfología dentaria que se describen a continuación.

P4-M2 semejantes entre sí con el flexo externo de desarrollo variable que puede o no superar el fondo del hipoflexo. Los prismas de los P4-M2 son desiguales, el pr. I es laminar, arqueado, con su cara anterior subplana, en tanto el pr. II tiende a ser globoso, más espeso en la cara labial, achicándose suavemente hacia la cara lingual. El hipoflexo en general mantiene un ancho uniforme en todo su desarrollo con su fondo de sección cuadrangular y dirigido hacia atrás. En esos molariformes, el pr. II está incidido externamente por una hendidura de desarrollo variable que en general es menos marcada en el P4. El cemento ocupa los $2 / 3$ del hipoflexo. El istmo que relaciona los pr. I y II es corto y de espesor variable, espesor que depende de la amplitud y profundidad de los flexos interno y externo. El pr. I del M3 tiende a ser cordiforme y se orienta levemente oblicuo hacia atrás. El pr. II es el de mayor diámetro ántero-posterior, 
presenta una prolongación adicional de ubicación labial, que puede ser redondeada y tener un desarrollo ántero-posterior variable. Los dos prismas se orientan paralelos entre sí y son transversos al eje del molar. La hendidura externa es amplia y muy poco profunda. La capa de esmalte en la zona del istmo se encuentra interrumpida en algunos especímenes.

Los p4-m3 son semejantes entre sí; el p4 es más pequeño que los m1-3. En ese diente, el pr. I es menor que el pr. II, con su cara externa dispuesta leve o fuertemente oblicua con respecto al eje del diente. Esta cara puede ser recta o levemente cóncava sin llegar a formar una hendidura adicional como en Microcavia (Quintana, 1996). El pr. I forma una columna interna continua, en algunos pocos especímenes puede estar interrumpida por una tenue concavidad en la zona media del prisma. El extremo labial de este prisma puede ser agudo o redondeado, pero siempre está orientado hacia la parte posterior del diente. EI istmo es alargado, de espesor uniforme, puede ser de paredes rectas, paralelo al eje del diente, oblicuo hacia adelante o curvo, dependiendo su configuración de la que adopten los fondos de los fléxidos. El hipofléxido se orienta hacia adelante, siendo en general su fondo cuadrangular aunque en algunos especímenes se extiende hacia adelante incidiendo más al pr. I. El pr. II es transverso, está incidido internamente en su porción anterior por un fléxido interno, que es tenue y poco profundo en los juveniles, en tanto que en los especímenes de mayor tamaño tiende a ser más marcado superando en general el fondo del hipofléxido. El esmalte se interrumpe en la cara lingual del istmo y en la cara interna del pr. II. El cemento interprismático recubre en general toda la cara posterior del pr. I. Los molares están formados por dos prismas de igual diámetro transverso 0 levemente desiguales. Ambos están orientados transversalmente. El hipofléxido es muy amplio y profundo, con el fondo orientado hacia adelante; de contorno rectangular o anguloso. La cara posterior del pr. I es de configuración variable, puede ser angulosa a levemente curva e incluso en algunos especímenes puede presentar una leve concavidad en su porción más labial. La cara interna del pr. I puede presentar una incipiente hendidura o formar una pared recta. El pr. I tiende a ser laminar, en tanto el pr. Il es más globoso. El istmo que une los prismas entre sí es delgado y puede ser curvo o recto, dependiendo de la configuración que 
adopten las hendiduras. La capa de esmalte de la zona del istmo se encuentra interrumpida internamente. La hendidura interna puede superar el fondo del hipofléxido y en general es amplia. En algunos especímenes el fondo de esta hendidura se achica suavemente adoptando un contorno redondeado.

\begin{tabular}{|c|c|c|c|c|c|}
\cline { 6 - 6 } & Promedio & Rango & & Promedio & Rango \\
\hline P4-M1 L & 6,33 & $4,20-7,10$ & p4-m1 L & 6,06 & $3,75-7,35$ \\
\hline P4-M2 L & 9,59 & $6,45-10,80$ & p4-m2 L & 8,82 & $4,80-11,25$ \\
\hline P4-M3 L & 12,75 & $9,75-15,75$ & p4-m3 L & 11,87 & $9,00-15,60$ \\
\hline M1-M2 L & 6,33 & $4,35-7,20$ & m1-m2 L & 6,49 & $4,35-7,80$ \\
\hline M2-M3 L & 6,79 & $5,25-7,80$ & m2-m3 L & 6,88 & $4,70-8,40$ \\
\hline M1-M3 L & 9,40 & $4,95-11,70$ & m1-m3 L & 9,59 & $7,50-12,30$ \\
\hline P4DAP & 3,14 & $1,95-3,65$ & p4DAP & 2,54 & $1,35-3,90$ \\
\hline pr. I & 2,83 & $2,55-3,15$ & pr. I & 1,51 & $0,90-2,85$ \\
\hline pr. II & 2,70 & $1,65-3,00$ & pr. II & 2,08 & $1,05-3,00$ \\
\hline M1 DAP & 2,92 & $1,95-3,45$ & m1 DAP & 3,28 & $1,95-4,05$ \\
\hline pr. I & 2,81 & $1,65-3,15$ & pr. I & 2,57 & $1,35-3,15$ \\
\hline pr. II & 2,62 & $1,65-3,15$ & pr. II & 2,68 & $1,65-3,30$ \\
\hline M2 DAP & 3,06 & $2,25-3,60$ & m2 DAP & 3,15 & $1,95-3,90$ \\
\hline pr. I & 2,83 & $1,60-3,45$ & pr. I & 2,53 & $1,80-3,15$ \\
\hline pr. II & 2,76 & $2,40-3,00$ & pr. II & 2,64 & $1,80-3,30$ \\
\hline M3 DAP & 3,79 & $2,85-4,60$ & m3 DAP & 3,55 & $2,40-4,65$ \\
\hline pr. I & 2,33 & $1,65-2,70$ & pr. I & 2,47 & $1,75-3,00$ \\
\hline pr. II & 2,16 & $1,40-2,70$ & pr. II & 2,59 & $1,75-3,45$ \\
\hline
\end{tabular}

Tabla 2.6. Promedio y rango de medidas de los molariformes superiores e inferiores de Palaeocavia sp. recuperados de la asociación de Caleufú

Figura 2.17. Palaeocavia sp. A. GHUNLPam 21073 p4-m3 derechos (individuo juvenil); B. GHUNLPam 21033 p4-m3 izquierdos; C. GHUNLPam 21036 P4-M3 izquierdos, escala 1 $\mathrm{mm}$ 
Observaciones: En la provincia de La Pampa el roedor cávido Palaeocavia fue citado para la Formación Cerro Azul en las localidades de Salinas Grandes de Hidalgo (Zetti, 1972 a; Goin et al., 2000), Valle de Quehué (Montalvo et al., 1995) y Laguna Chillhué (Montalvo et al., 1996), en asociaciones faunísticas asignadas a la Edad mamífero Huayqueriense (Mioceno tardío).

Palaeocavia cuenta actualmente con nueve especies (Mones, 1986) que no fueron revisadas con posterioridad a sus descripciones originales. Este género se cita desde el Huayqueriense y no tiene representantes actuales (Vucetich y Verzi, 1995). Las diferencias en el tamaño y en la morfología oclusal de las series molariformes y de cada diente en particular, observadas en la serie de Caleufú pueden ser consideradas en el marco de la variabilidad intrapoblacional. La caracterización de esta asociación como una unidad coetánea, avala la comparación de estas diferencias con aquellas que fueron descriptas para poblaciones de varias especies actuales de Galea y Microcavia (Contreras, 1964). Ya fue indicado que este rango de variación no constituye información diagnóstica a nivel de especie (Quintana, 1996), por lo que se considera que la asignación específica de estos especímenes sólo puede ser resuelta en el marco de una revisión exhaustiva de las especies del Mioceno superior-Plioceno inferior asignadas a Palaeocavia.

\section{Orthomyctera Ameghino, 1889}

\section{Orthomyctera sp.}

Material: GHUNLPam 19528 al 19530; 19533; 19535; 19537 al19540; 19542; 19544; 19546; 19548; 19549; 19556; 19561; 19567; 19569; 19572 al 19574; 19579; 19583; 19590; 19591; 19621; 19625; 19628; 19769 al 19771; 19775; 19796; 19798; 19803; $19805 ; 19807 ; 19809$ al $19811 ; 19815 ; 19836 ; 21029$ al $21031 ; 21034 ; 21038 ; 21039$; 21042 ; 21044; 21049; 21084; 21120; 21121; 21281; 21283; 21286; 21289 al 21305; $21873 ; 21885 / 1-3$ porciones de paladares, fragmentos de hemimandíbulas y dientes aislados.

Comentarios El género Orthomyctera fue sinonimizado con Dolichotis (Rovereto, 1914), pero luego Kraglievich $(1932,1934)$ mantuvo su identidad. Los especímenes asignados a Orthomyctera sp. recuperados de Caleufú, presentan variación en su tamaño y particularmente en el de los molariformes, tanto superiores como inferiores (Tablas 2.7 y 2.8). Sin embargo, la morfología dentaria 
es homogénea motivo por el que, tentativamente, esa variación es atribuida a diferencias ontogenéticas (Figura 2.19). Los molariformes superiores están compuestos por dos prismas cordiformes. Los fondos de los hipoflexos/idos son opuestos a los fondos de los flexos externos o internos en los dientes superiores e inferiores respectivamente. En el p4 el pr. I presenta un diámetro transverso menor al del pr. II. En los m1-2 los prismas son similares entre sí, en tanto en el m3 el prisma posterior es más espeso. Los molariformes superiores también están formados por dos prismas cordiformes y en el prisma posterior del M3 hay una proyección adicional.

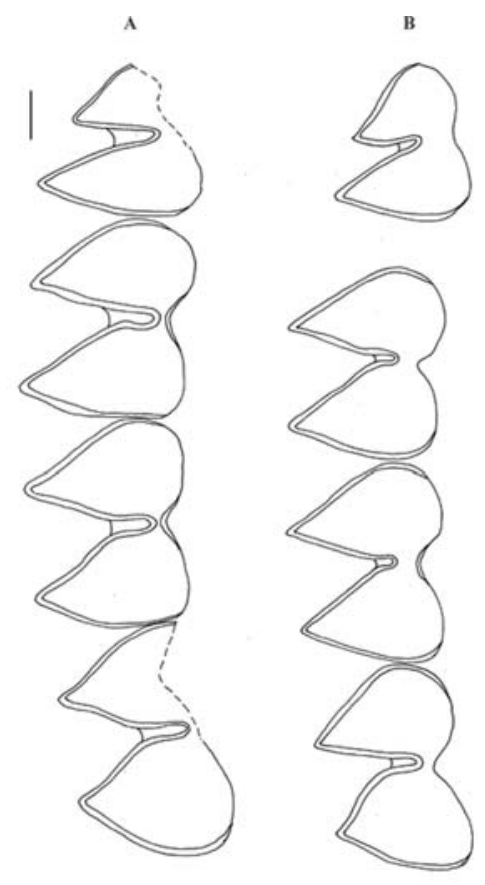

Figura 2.19 Orthomyctera sp. A. GHUNLPam 19546 p4-m3 izquierdos; B. GHUNLPam 21296 p4-m3 izquierdos, escala $1 \mathrm{~mm}$ 


\begin{tabular}{|c|c|c|c|c|c|c|}
\hline & \multicolumn{3}{|c|}{ Inferiores adultos } & \multicolumn{3}{|c|}{ Inferiores juveniles } \\
\hline & $\mathrm{N}$ & Promedio & Rango & $\mathrm{N}$ & Promedio & Rango \\
\hline p4-m1 L & 15 & \begin{tabular}{|l|}
7,92 \\
\end{tabular} & $7,10-8,45$ & 2 & 5,75 & $4,65-6,85$ \\
\hline p4-m2 L & 11 & 12,15 & $11,00-13,00$ & 1 & 7,00 & 7,00 \\
\hline p4-m3 L & 6 & 17,23 & $16,05-18,10$ & 1 & 9,70 & 9,70 \\
\hline $\mathrm{m} 1-\mathrm{m} 2 \mathrm{~L}$ & 10 & 8,69 & $7,65-9,40$ & 2 & 5,00 & 5,00 \\
\hline m2-m3 L & 5 & 9,49 & $9,05-9,80$ & 1 & 5,10 & 5,10 \\
\hline$m 1-m 3 L$ & 5 & 14,55 & $11,90-19,45$ & 1 & 7,50 & 7,50 \\
\hline p4 DAP & 16 & 3,48 & 3,00-4,05 & 3 & 2,75 & $1,80-3,30$ \\
\hline pr. I & 13 & 2,38 & $2,10-2,85$ & 3 & 1,75 & $0,90-2,40$ \\
\hline pr. II & 15 & 3,08 & $2,70-3,75$ & 3 & 2,10 & $1,05-2,70$ \\
\hline m1 DAP & 16 & 4,15 & $3,00-6,60$ & 3 & 2,70 & $2,25-3,45$ \\
\hline pr. I & 16 & 3,21 & $2,85-3,75$ & 3 & 1,70 & $1,05-2,70$ \\
\hline pr. II & 14 & 3,34 & $2,55-5,25$ & 3 & 1,70 & $1,05-2,85$ \\
\hline m2 DAP & 11 & 4,48 & $3,50-6,60$ & 2 & 2,25 & 2,25 \\
\hline $\mathrm{pr} I$ & 9 & 3,52 & $3,00-4,95$ & 3 & 1,75 & $1,20-2,85$ \\
\hline pr. II & 9 & 3,48 & $3,15-4,50$ & 2 & 0,90 & $0,75-1,05$ \\
\hline m3 DAP & 6 & 5,05 & $4,20-6,90$ & & & \\
\hline pr. I & 6 & 3,33 & $3,00-4,50$ & & & \\
\hline pr. II & 6 & 3,23 & $2,70-4,35$ & & & \\
\hline i transv & 2 & 2,03 & $1,8-2,25$ & & & \\
\hline $\mathrm{iA} / \mathrm{P}$ & 2 & 2,93 & $2,85-3,00$ & & & \\
\hline
\end{tabular}

Tabla 2.7. Promedio y rango de medidas de los molariformes superiores de Orthomyctera sp., discriminados en muy jóvenes y juveniles vs. adultos 


\begin{tabular}{|c|c|c|c|c|c|c|}
\hline & \multicolumn{3}{|c|}{ Superiores adultos } & \multicolumn{3}{c|}{ Superiores juveniles } \\
\hline & $\mathrm{N}$ & Promedio & Rango & $\mathrm{N}$ & Promedio & Rango \\
\hline P4-M1 L & 5 & 7,56 & $7,00-8,30$ & 2 & 3,75 & $3,30-4,20$ \\
\hline P4-M2 L & 5 & 11,30 & $10,50-11,85$ & 2 & 5,85 & $5,40-6,30$ \\
\hline P4-M3 L & 1 & 14,80 & 14,80 & 1 & 7,50 & 7,50 \\
\hline M1-M2 L & 6 & 7,08 & $6,20-7,80$ & 2 & 4,20 & 4,20 \\
\hline M2-M3 L & 2 & 7,58 & $7,35-7,80$ & 1 & 4,50 & 4,50 \\
\hline M1-M3 L & 2 & 10,95 & $10,60-11,30$ & 1 & 6,75 & 6,75 \\
\hline P4 DAP & 8 & 3,81 & $3,15-4,35$ & 3 & 1,55 & $1,05-1,80$ \\
\hline Pr. I & 7 & 3,24 & $3,00-3,45$ & 3 & 1,15 & $0,90-1,35$ \\
\hline Pr. II & 8 & 3,24 & $2,70-3,45$ & 3 & 1,25 & $1,05-1,35$ \\
\hline M1 DAP & 7 & 3,51 & $3,00-3,90$ & 2 & 2,03 & $1,95-2,10$ \\
\hline Pr. I & 7 & 3,11 & $2,85-3,30$ & 3 & 1,55 & $1,35-1,65$ \\
\hline Pr. II & 7 & 3,09 & $2,70-3,45$ & 2 & 1,50 & 1,50 \\
\hline M2 DAP & 5 & 3,48 & $3,00-3,90$ & 2 & 1,88 & $1,80-1,95$ \\
\hline Pr. I & 5 & 3,18 & $2,55-3,45$ & 2 & 1,50 & $1,35-1,65$ \\
\hline Pr. II & 6 & 3,18 & $2,55-3,45$ & 2 & 1,50 & $1,35-1,65$ \\
\hline M3 DAP & 3 & 4,65 & $4,50-4,80$ & 1 & 2,25 & 2,25 \\
\hline Pr. I & 4 & 2,93 & $2,55-3,30$ & 1 & 1,50 & 1,50 \\
\hline Pr. II & 3 & 2,50 & $2,40-2,55$ & 1 & 1,05 & 1,05 \\
\hline pr.accesorio & 3 & 1,35 & $1,05-1,50$ & 1 & 0,60 & 0,60 \\
\hline
\end{tabular}

Tabla 2.8. Promedio y rango de medidas de los molariformes superiores de Orthomyctera sp., discriminados en muy jóvenes y juveniles vs. adultos 
La mayoría de las especies integrantes de este género no han sido revisadas con posterioridad a las descripciones originales, muchas de las cuales fueron basadas en materiales fragmentarios, motivo por el que no puede ser resuelta la asignación específica de los materiales recuperados de Caleufú hasta tanto se realice una revisión exhaustiva de todo el género.

Suborden MYOMORPHA Brandt, 1877

Superfamilia MUROIDEA Miller y Gidley, 1918

Familia MURIDAE Illiger, 1811

Subfamilia SIGMODONTINAE Wagner, 1843

Gen. et sp. nov.

Material: GHUNLPam 19611 mandíbula izquierda con i1 roto y serie molar completa y 21853 mandíbula izquierda con porción posterior del $\mathrm{m} 1, \mathrm{~m} 2$ y raíces del m3 (Figura 2.19).

Descripción: Tamaño similar a Akodon iniscatus Thomas, 1919 y menor que Necromys bonapartei (Reig, 1978), Dankomys simpsoni Reig, 1978 y Auliscomys formosus Reig, 1978 (Tabla 2.9).

\begin{tabular}{|c|c|c|c|c|c|c|c|c|c|c|c|c|}
\hline & $\frac{\lrcorner}{\bar{\varepsilon}}$ & $\frac{\varangle}{\grave{\varepsilon}}$ & $\begin{array}{l}\overrightarrow{\tilde{E}} \\
\text { (2) }\end{array}$ & $\begin{array}{l}\text { ¿ } \\
\text { है }\end{array}$ & $\stackrel{\vec{m}}{\xi}$ & 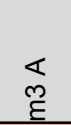 & $\bar{\alpha}$ & $\begin{array}{l}\vec{\jmath} \\
\stackrel{m}{\xi} \\
\stackrel{1}{\varepsilon}\end{array}$ & $\begin{array}{l}\frac{\dot{\lambda}}{\pi} \\
\stackrel{1}{\dot{1}} \\
\stackrel{1}{\varepsilon}\end{array}$ & $\frac{\vec{\sim}}{\frac{1}{\varepsilon}}$ & 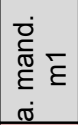 & $\begin{array}{l}\frac{\pi}{\frac{\pi}{2}} \\
\frac{0}{01} \\
\frac{\pi}{7} \\
\frac{\pi}{7}\end{array}$ \\
\hline GHUNLPam 19611 & 1,80 & 1,05 & 1,35 & 1,20 & 0,90 & 0,90 & & 3,90 & 4,22 & & & \\
\hline GHUNLPam 21853 & & & 1,35 & 1,20 & & & & & & & & \\
\hline A. cf. A. iniscatus MMP S 640 & 1,64 & 1,12 & 1,24 & 1,12 & 1,08 & & 1,02 & & 4,22 & 2,88 & 3,01 & 3,26 \\
\hline A. iniscatus BMNH 13-11-1-5 & 1,67 & 1,02 & 1,21 & 0,93 & 1,05 & 0,74 & 1,02 & 3,97 & 3,97 & 2,88 & 2,75 & 3,07 \\
\hline A. iniscatus BMNH 3-7-9-64 & 1,64 & 0,99 & 1,21 & 0,99 & 0,99 & 0,77 & 1,01 & 3,73 & 3,76 & 2,85 & 3,11 & \\
\hline Necromys bonapartei PVL 2396 & 1,83 & 1,24 & 1,46 & 1,27 & & & & & & & & \\
\hline Auliscomys formosus PVL 2397 & 2,48 & 1,61 & 1,95 & 1,64 & 1,70 & 1,43 & 1,46 & 6,21 & 6,32 & & & \\
\hline Dankomys simpsoni MMP M1153 & 2,20 & 1,46 & 1,55 & 1,55 & & & 1,61 & & & & 4,74 & \\
\hline
\end{tabular}

Tabla 2.9. Medidas dentarias y mandibulares de los sigmodontinos hallados en Caleufú y de los taxa nombrados en el texto

En GHUNLPam 19611, el espécimen más completo, no se han preservado los procesos condiloides, coronoides y angular, falta además, en la porción interna de la mandíbula, la pared alveolar ósea del incisivo. La diastema desciende en forma oblicua a partir de la cara anterior del m1. El foramen mentoniano es visible en norma labial, ubicado en la parte inferior de la diastema 
sobre su superficie látero-externa. La cresta masetérica superior nace en el borde anterior del $\mathrm{m} 1$ y se prolonga hacia atrás, dirigiéndose al proceso coronoides sin interrupción, como en Necromys bonapartei. La rama inferior es mucho más notoria, si bien está parcialmente rota en su porción anterior; nace en la mitad superior de la mandíbula, por arriba del agujero mentoniano y levemente por detrás del nacimiento del m1. La proyección capsular de la base del i1 no está completa, pero se observa un abultamiento en esa zona. En la cara interna de la mandíbula, a lo largo del sector correspondiente a la línea milohiodea, se observan varios forámenes.

El i1 es angosto y la cara esmaltada preservada en el ejemplar GHUNLPam 21853 es de color ámbar. La sección muestra que la cara de esmalte es levemente curva.

Los molares presentan desgaste de tipo "crestado" (Hershkovitz, 1990), siendo los cónidos más altos en la cara lingual. Las cúspides linguales son de ubicación anterior con respecto a las labiales (Figura 2.19).

El m1 es el diente de mayor tamaño anteroposterior (Tabla 2.9), presenta un fléxido anteromediano amplio y poco marcado, similar al de Auliscomys formosus, y si bien ese fléxido es de ubicación bien anterior, delimita al conúlido anterolingual que es más prolongado hacia adelante que en aquella especie. El fléxido formado por la unión de anterofléxido más metafléxido es angosto y poco profundo, perpendicular al eje anteroposterior del diente y en su fondo los bordes son paralelos entre sí y el procíngulo está limitado posteriormente por ese fléxido y el protofléxido. Este último es angosto en toda su extensión y se dirige fuertemente hacia adelante, carácter que comparte con Necromys bonapartei y Auliscomys formosus, ya que el protostílido se orienta fuertemente hacia atrás en la cara labial. El protolófido está limitado posteriormente por el hipofléxido que es ancho y profundo. El mesofléxido está delimitado por los bordes del metalófido y del entolófido casi paralelos entre sí, apenas orientados hacia adelante, de modo tal que su fondo es ancho, a diferencia de lo que ocurre en Akodon, Necromys y Auliscomys. La mesóstrida es la estría más profunda en vista lingual. Siempre en la cara lingual, el mesolófido está fusionado con el entolófido y no se observa remanente lingual del mesostílido como ocurre en Akodon; el lóbulo lingual 
formado es el de mayor dimensión anteroposterior y queda limitado por el mesofléxido y el posterofléxido. Este último fléxido es apenas menos profundo que el mesofléxido. A diferencia de lo que ocurre en Auliscomys formosus y Necromys bonapartei su fondo se orienta hacia adelante marcando una curva desde la cara lingual. El posterolófido es angosto en toda su extensión y se dirige hacia adelante en su extremo lingual. El múrido mediano es el más angosto del diente. A diferencia de lo observado en Akodon y en Necromys bonapartei, tanto el ectolófido como el ectostílido están ausentes. La cara posterolabial de este molar es casi plana y el distofléxido es apenas marcado.

El m2 es de morfología similar al de Auliscomys formosus. Su diámetro anteroposterior es intermedio entre $\mathrm{m} 1$ y $\mathrm{m} 3$. El metalófido es espeso, su cara anterior es recta. Está limitado posteriormente por el mesofléxido, cuyo fondo se orienta hacia adelante. Este fléxido es más ancho que el de Auliscomys formosus. El posterofléxido es menos ancho y profundo que el mesofléxido, pero no llega al grado de reducción que presenta ese fléxido en $A$. formosus ni en Necromys bonapartei. El posterofléxido se orienta en forma perpendicular al eje anteroposterior del molar. El distofléxido es apenas más marcado en este diente que en el m1. Labialmente, el conúlido anterolabial está muy reducido, más aún que en Auliscomys formosus, limitado labialmente por el protofléxido que es profundo, pero muy angosto. El hipofléxido es amplio, limitado por protolófido e hipolófido de desarrollo similar.

El m3 es el molar de menor tamaño. Lingualmente hay un solo fléxido, que correspondería al mesofléxido, cuyo fondo es redondeado. Este fléxido está prácticamente obliterado por el desgaste. El metalófido es espeso, su cara anterior es recta. El lófido posterior (entolófido más posterolófido) es espeso y su cara lingual es recta. A diferencia de lo que ocurre en el m3 de Auliscomys formosus, hay un vestigio de conúlido anterolabial, limitado posteriormente por un reducido protofléxido. El hipofléxido es amplio y profundo. No se observan fosétidas en este diente. 


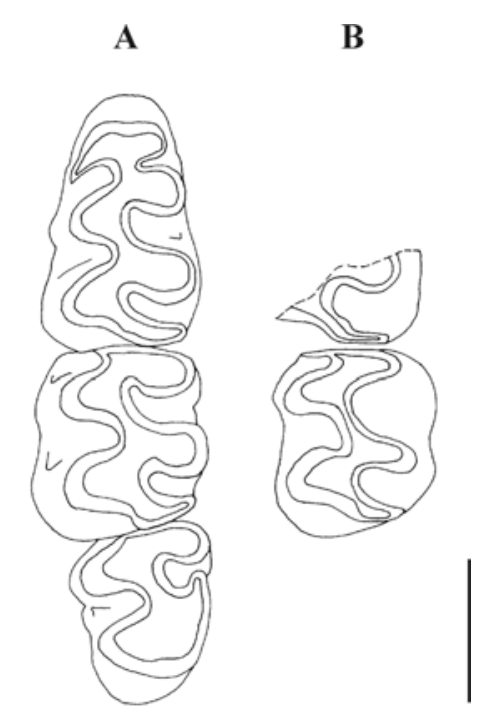

Figura 2.19. Sigmodontinae gen. et sp. nov. A. GHUNLPam 19611 serie molar izquierda completa y GHUNLPam 21853 m1-2 izquierdos, escala $1 \mathrm{~mm}$

Comentarios: La antigüedad del registro fósil de los roedores muroideos en América del Sur ha generado un considerable debate (ver Pardiñas et al., 2002 y bibliografía allí citada). En los últimos años se ha incrementado notablemente la información que permitirá mejorar el conocimiento acerca del origen de este grupo de roedores en América. Es el caso de las descripciones de paleoespecies con registro más antiguo como Auliscomys formosus, Necromys bonapartei, Dankomys simpsoni, Cholomys pearsoni Reig, 1980 y Panchomys steppani Pardiñas, 1997, entre otras.

En la secuencia temporal de este grupo, de acuerdo a Pardiñas y Tonni (2000) el registro más antiguo correspondía a la Edad mamífero Montehermosense (Plioceno temprano) con Auliscomys formosus, constatándose para la edad siguiente (Chapadmalalense inferior, Plioceno temprano) la aparición en el registro de neoespecies como Reithrodon auritus (Fischer, 1814) y paleoespecies como Necromys bonapartei.

En este contexto se analizaron los caracteres presentes en los especímenes recuperados de Caleufú, contrastándolos con los de las especies conocidas de mayor antigüedad en la región. Se diferencia de Necromys bonapartei en 1.- su menor tamaño; 2.- en el $\mathrm{m} 1$ : la presencia de fléxido anteromediano, la mayor complejidad del procíngulo, la ausencia de ectolófido y ectostílido (si bien este último está reducido en $N$. bonapartei), el mesofléxido de 
bordes más paralelos y con fondo espeso, no orientado hacia adelante, el posterofléxido orientado bien hacia adelante describiendo una curva suave que es acompañada por el posterolófido; 3.- en el m2: el posterofléxido más desarrollado con la cara posterior describiendo una curva suave y el distofléxido más marcado, el protofléxido menos profundo con el anteroconúlido muy reducido y el múrido mediano más ancho. Las diferencias descriptas son suficientes como para descartar la afinidad de este nuevo taxón con $N$. bonapartei.

Por otro lado, si bien se diferencia de Auliscomys formosus por 1.- su menor tamaño, 2.- la orientación de los fléxidos linguales en los m1 y m3.- en el m2 el menor contraste en la profundidad de los fléxidos linguales; comparte con esta especie más caracteres que con la anterior.

Lo expuesto permite desvincular al nuevo taxón de los akodontini más antiguos (Necromys bonapartei). Por otro lado, Pardiñas (1997: 552) manifiesta que "la revisión del holotipo de Auliscomys formosus indica que posiblemente esta especie sea referible a un nuevo género". El nuevo taxón comparte ciertos caracteres con Auliscomys formosus y ambos estarían desvinculados de los filotinos más antiguos.

La presencia de estos roedores sigmodontinos asociados a varios taxa típicos de la Edad mamífero Huayqueriense, indicaría que se trata del registro más antiguo de esta subfamilia en América del Sur. Por otro lado, este es uno de los registros que señala la mayor modernidad de esta asociación faunística con respecto a las registradas hasta el momento en la Formación Cerro Azul.

Orden NOTOUNGULATA Roth, 1903

Suborden TYPOTHERIA Zittel, 1892

Familia HEGETOTHERIIDAE Ameghino, 1894

Subfamilia PACHYRUKHINAE Kraglievich, 1934

Paedotherium Burmeister, 1888

Paedotherium minor Cabrera, 1937

Paedotherium minor Cabrera, 1937; Zetti, 1972; Cerdeño y Bond, 1998

Paedotherium affine Cabrera, 1937

Paedotherium borrelloi Zetti, 1972 
Material: GHUNLPam 19143 al 19527; 19601; 19690; 19711; 19729; 19738; 19741; 19831; 19832; 19837; 19838; 19844; 19853; 19897; 19898; 19903; 21070; 21072; 21088; 21094 al 21103; 21134; 21138; 21141 al 21143; 21198; 21201; 21204; $21206 ; 21360$ al 21474 ; 21475/1-32; 21476; 21519; 21520/1-5; 21534; 21540; 21560; 21575 al 21583; 21595 al $21598 ; 21600 ; 21605 / 1-2 ; 21608 ; 21609 ; 21721 ; 21723 ; 21780$ al 21822 ; $21823 / 1-12 ; 21861 ; 21890$ al 21894; 21895/1-4; 21896/1-7; 21908/1-4; 21915; 21967; 21969; 22508 al 22513; 22557/1-3; 22584/1-6: fragmentos de paladar, hemimandíbulas y dientes aislados.

Comentarios: La especie Paedotherium minor fue descripta originalmente por Cabrera (1937) para restos hallados en la Formación Arroyo Chasicó. En esa oportunidad también describió para los mismos niveles a Paedotherium affine, especie que fue considerada sinónimo de Paedotherium minor por Zetti (1972 b). En ese trabajo, Zetti (1972 b) describió una nueva especie, Paedotherium borrelloi de Edad mamífero Huayqueriense, basada en materiales provenientes de Salinas Grandes de Hidalgo. Cerdeño y Bond (1998), en una revisión de los Pachyrukhinae, consideraron que $P$. affine y $P$. borrelloi son sinónimos de $P$. minor.

De este modo Paedotherium minor estaría representada en niveles chasiquenses y huayquerienses de las Formaciones Arroyo Chasicó en la provincia de Buenos Aires y en todos los afloramientos fosilíferos de la Formación Cerro Azul.

Los especímenes asignados a Paedotherium minor de la serie analizada procedente de Caleufú corresponden exclusivamente a restos con dientes. Dado que no hay elementos postcraneanos asociados, la comparación con las otras especies de Paedotherium se basa en la morfología y medidas de los elementos preservados del cráneo y mandíbula, en particular de los dientes. La morfología de los molariformes es coincidente con la de Paedotherium minor. El promedio de tamaño de los molariformes de estos especímenes, tanto superiores como inferiores (Tablas 2.10 y 2.11), es un poco mayor que las medias brindadas por Cerdeño y Bond (1998) para Paedotherium minor, pero no llegan al tamaño de las de $P$. typicum (Ameghino, 1887) y $P$. bonaerense (Ameghino, 1887), especies de edades más modernas: Montehermosense, Chapadmalalense y Marplatense (Figuras 2.20 y 2.21). Cerdeño y Bond (1998) indicaron que el rango de medidas de Paedotherium minor se superpone al de las otras dos especies, pero su media 
es menor. Cabría esperar para la serie analizada procedente de Caleufú, una media menor, ya que esta muestra está sesgada por la presencia de especímenes juveniles. Puede ser que entre los especímenes medidos por Cerdeño y Bond (1998) se hubieran incluido juveniles, pero eso no está aclarado, de modo tal que se entiende que las medias corresponden a adultos o a especímenes sobre los que no se discriminó la edad.

\begin{tabular}{|c|c|c|c|c|c|c|c|}
\hline & 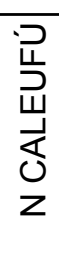 & 苞 & 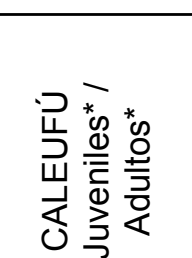 & 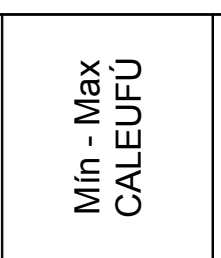 & 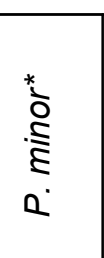 & 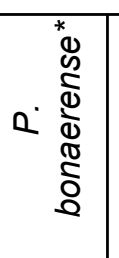 & 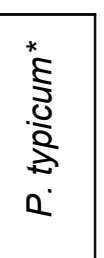 \\
\hline P2 L & 23 & 3,27 & $2,70 / 3,30$ & $2,35-4,65$ & 3,16 & 3,38 & 3,26 \\
\hline $\mathrm{P} 2 \mathrm{~A}$ & 23 & 2,19 & $1,75 / 2,21$ & $1,50-3,00$ & 2,08 & 2,36 & 2,16 \\
\hline$\overline{P 3} \mathrm{~L}$ & 28 & 3,86 & $3,08 / 3,95$ & $3,00-5,25$ & 3,76 & 4,62 & 3,89 \\
\hline P3 A & 28 & 2,48 & $2,03 / 2,53$ & $2,00-3,15$ & 2,38 & 2,89 & 2,47 \\
\hline P4 L & 35 & 4,21 & $3,39 / 4,35$ & $2,75-5,65$ & 4,26 & 4,76 & 4,32 \\
\hline $\mathrm{P} 4 \mathrm{~A}$ & 35 & 2,61 & $2,20 / 2,68$ & $2,00-3,30$ & 2,62 & 3,08 & 2,70 \\
\hline M1 L & 45 & 4,76 & $4,25 / 4,83$ & $3,45-5,75$ & 4,46 & 4,65 & 4,81 \\
\hline M1 A & 45 & 2,97 & $2,48 / 3,04$ & $2,00-3,55$ & 2,79 & 3,15 & 3,03 \\
\hline M2 L & 49 & 4,47 & $4,03 / 4,53$ & $3,40-5,50$ & 4,19 & 4,42 & 4,67 \\
\hline M2 A & 49 & 2,96 & $2,63 / 3,00$ & $2,10-3,55$ & 2,70 & 3,06 & 3,02 \\
\hline M3 L & 37 & 4,54 & $3,58 / 4,68$ & $3,00-6,40$ & 4,42 & 4,86 & 5,06 \\
\hline M3 A & 37 & 2,63 & $2,14 / 2,69$ & $2,00-3,60$ & 2,44 & 2,77 & 2,82 \\
\hline P2-M3 L & 6 & 22,32 & 22,32 & $17,70-24,75$ & 22,00 & 24,20 & 23,20 \\
\hline M1-3 L & 27 & 12,95 & $11,84 / 13,27$ & $10,60-15,15$ & 12,20 & 13,20 & 13,70 \\
\hline
\end{tabular}

Tabla 2.10. Promedio $\left({ }^{*}\right)$ de las medidas de los molariformes superiores ( $L$ largo, $A$ ancho) de Paedotherium minor de Caleufú (se indica la media para los especímenes juveniles y adultos) y de $P$. minor, $P$. bonaerense y $P$. typicum tomadas de Cerdeño y 
Paleobiología de la asociación faunística de Caleufú (La Pampa, Formación Cerro Azul, Mioceno superior - Plioceno inferior), a través de análisis tafonómicos

Bond (1998)
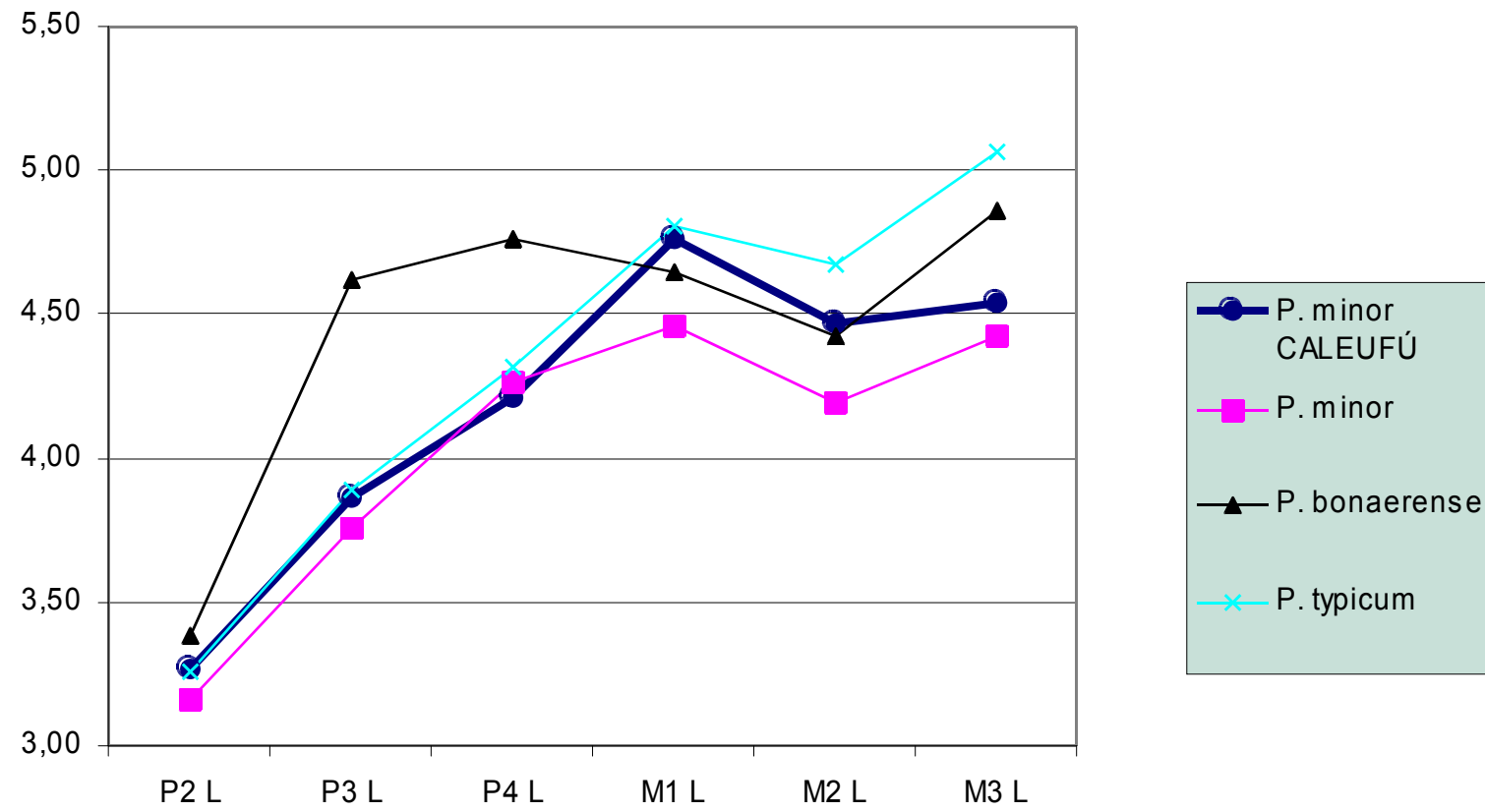

Figura 2.20. Gráfico comparativo del promedio del largo de los molariformes superiores de Paedotherium minor recuperados de Caleufú y de $P$. minor, $P$. bonaerense y $P$. typicum (tomadas de Cerdeño y Bond, 1998)

\begin{tabular}{|c|c|c|c|c|c|c|c|}
\hline & 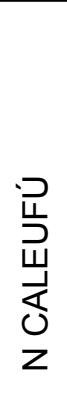 & 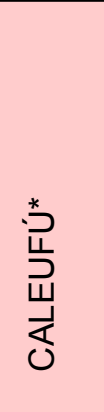 & 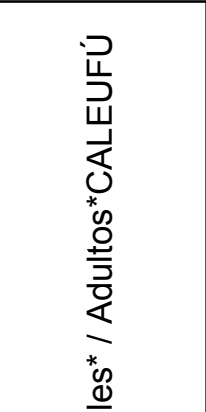 & 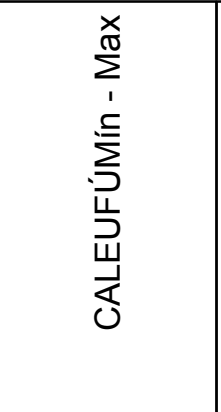 & 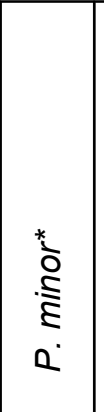 & 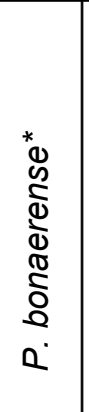 & 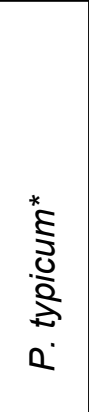 \\
\hline $\mathrm{p} 2 \mathrm{~L}$ & 23 & 2,41 & $2,00 \leftrightarrows 2,47$ & $2,00-2,85$ & 2,36 & 2,59 & 2,55 \\
\hline p2 A & 23 & 1,52 & $1,37 \$ 1,55$ & $1,20-2,00$ & 1,44 & 1,53 & 1,49 \\
\hline p3 L & 52 & 3,31 & $2,97 / 3,39$ & $2,00-4,20$ & 3,25 & 4,14 & 3,37 \\
\hline p3 A & 52 & 2,11 & $1,75 / 2,18$ & $1,15-2,90$ & 2,04 & 2,48 & 2,18 \\
\hline p4 L & 55 & 3,77 & $3,35 / 3,95$ & $2,20-5,10$ & 3,76 & 4,38 & 3,80 \\
\hline p4 A & 55 & 2,27 & $1,93 / 2,40$ & $1,45-3,00$ & 2,23 & 2,57 & 2,34 \\
\hline $\mathrm{m} 1 \mathrm{~L}$ & 60 & 4,16 & $3,65 / 4,31$ & $3,00-5,55$ & 4,11 & 4,52 & 4,26 \\
\hline $\mathrm{m} 1 \mathrm{~A}$ & 60 & 2,44 & $1,99 / 2,58$ & $1,20-3,00$ & 2,32 & 2,65 & 2,45 \\
\hline $\mathrm{m} 2 \mathrm{~L}$ & 60 & 4,29 & $3,77 / 4,42$ & $3,10-5,20$ & 4,13 & 4,53 & 4,37 \\
\hline $\mathrm{m} 2 \mathrm{~A}$ & 60 & 2,50 & $2,01 / 2,63$ & $1,70-3,00$ & 2,30 & 2,59 & 2,48 \\
\hline $\mathrm{m} 3 \mathrm{~L}$ & 50 & 5,90 & $5,17 / 6,03$ & $3,19-7,70$ & 5,66 & 6,05 & 6,00 \\
\hline $\mathrm{m} 3 \mathrm{~A}$ & 50 & 2,41 & $2,03 / 2,48$ & $1,45-3,55$ & 2,19 & 2,36 & 2,32 \\
\hline $\mathrm{p} 2-\mathrm{m} 3 \mathrm{~L}$ & 1 & 22,05 & 22,05 & $20,50-23,60$ & 22,50 & 24,70 & 23,20 \\
\hline $\mathrm{m} 1-3 \mathrm{~L}$ & 15 & 14,37 & $11,42 / 15,10$ & $10,75-16,85$ & 13,30 & 14,30 & 14,20 \\
\hline
\end{tabular}


Tabla 2.11. Promedio $\left({ }^{*}\right)$ de las medidas de los molariformes inferiores ( $L$ largo, $A$ ancho) de Paedotherium minor de Caleufú (se indica la media para los especímenes juveniles y adultos) y de $P$. minor, $P$. bonaerense y $P$. typicum tomadas de Cerdeño y Bond (1998)

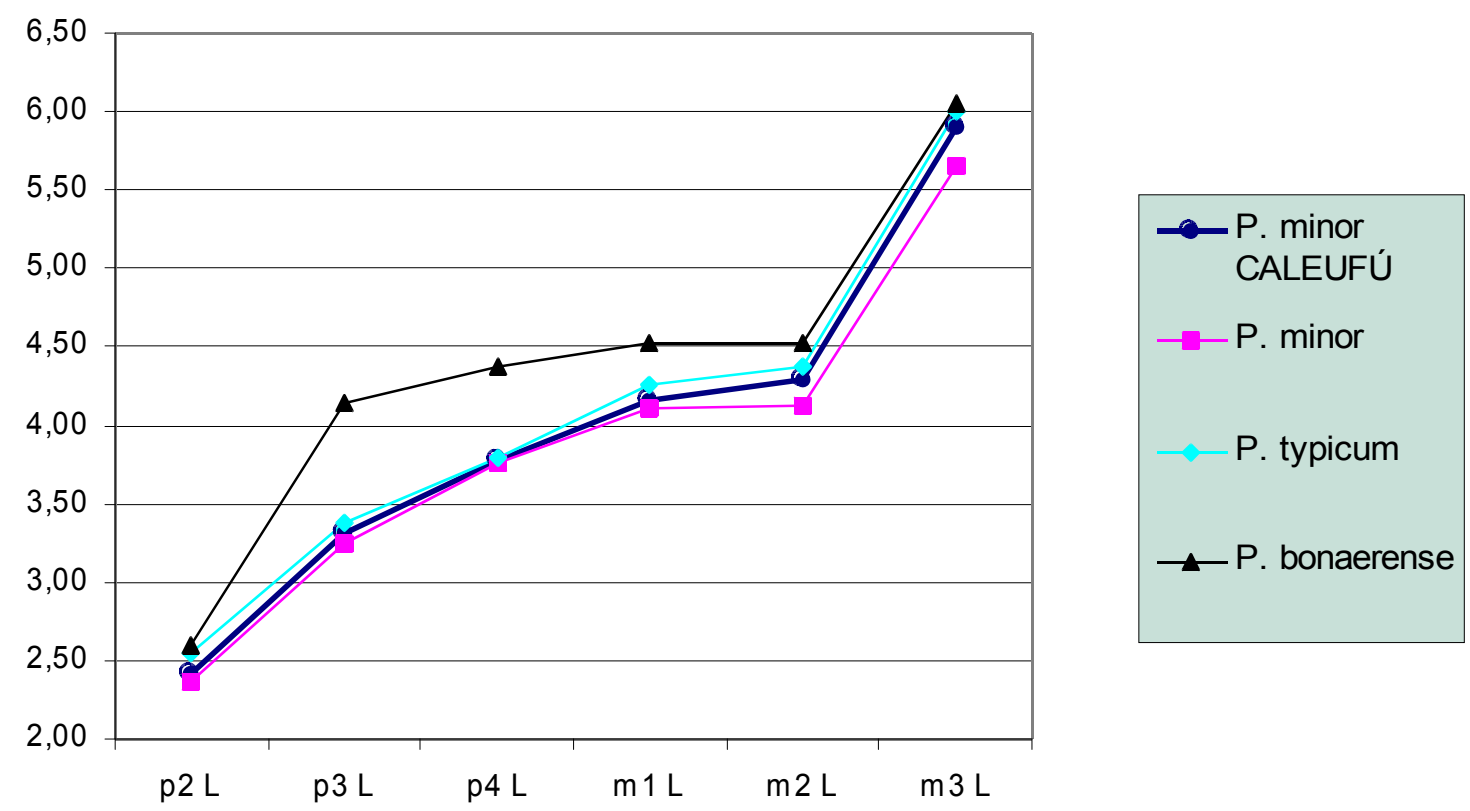

Figura 2.21. Gráfico comparativo del promedio del largo de los molariformes inferiores de Paedotherium minor recuperados de Caleufú y de $P$. minor, $P$. bonaerense y $P$. typicum (tomadas de Cerdeño y Bond, 1998)

Paedotherium minor es el taxón más frecuente en esta asociación. Entre estos, se destaca que el $5,16 \%$ de los especímenes asignados a este taxón corresponden a individuos muy jóvenes, con dentición de leche.

Familia MESOTHERIIDAE Alston, 1876

Subfamilia MESOTHERIINAE Simpson, 1945

Pseudotypotherium Ameghino, 1904

Pseudotypotherium subinsigne (Rovereto, 1914)

Pseudotypotherium subinsigne Rovereto, 1914; Cerdeño y Montalvo, 2001

Typotheriodon grandis Cabrera, 1939

Typotheriopsis minimus Cabrera, 1939

Pseudotypotherium carhuense Cabrera, 1939; Francis, 1965

Material: GHUNLPam 21137 porción de paladar izquierdo con P3-M2 (Figura 2.22 A). 
Comentarios: Los mesoterinos recuperados de otros afloramientos de la Formación Cerro Azul fueron revisados por Cerdeño y Montalvo (2001) y se identificó en los mismos a Pseudotypotherium subinsigne y a Typotheriopsis silveyrai Cabrera, 1937. En esa oportunidad se destacó que el carácter principal que permite la diferenciación de estas dos especies es la ausencia o presencia de surco lingual en el P4. En la asociación de Caleufú, 10 restos son asignables a Mesotheriinae, pero el material es en general muy fragmentario, solo el ejemplar GHUNLPam 21137 ha preservado su P4. Este presenta un surco lingual, siendo bilobulado, carácter que permite su asignación a Pseudotypotherium subinsigne.

\section{Pseudotypotherium? o Typotheriopsis?}

Material: GHUNLPam 19840 M3 izquierdo; 19841 fragmento de molar indet.; 19842 fragmento de incisivo; 19868 fragmento mandibular con los i1 izquierdo y derecho, i2 seccionados, m1-3 derechos y p4-m3 izquierdos; 19873 paladar con parte de M3 derecho; 19876 fragmento mandibular derecho con lóbulo posterior del m2 y m3 y porción de paladar con parte de un molar; 21106 fragmento de incisivo inferior; 21107 paladar un fragmento de molar izquierdo; 21148 fragmento mandibular derecho con m2-3 (Figura $2.22 \mathrm{~B})$.

Comentarios: Como ya se indicó, los restos asignados a esta subfamilia son fragmentarios o carecen de rasgos diagnósticos que permitan precisar más su asignación. Se destaca en esta muestra el ejemplar GHUNLPam 21148 (Figura 2.23 B) que corresponde a un individuo juvenil. La porción de hueso mandibular que se ha preservado presenta evidencias de escasa osificación, manifestada por un bandeado paralelo. Los dos dientes preservados son cónicos y corresponden a la dentición definitiva. El diámetro AP del $\mathrm{m} 3$ en la base es de $1,96 \mathrm{~cm}$, mientras que en la superficie oclusal es de $1,30 \mathrm{~cm}$, en tanto el $\mathrm{m} 2$ en la base mide 1,58 cm y su superficie oclusal mide $1,39 \mathrm{~cm}$. El m2 presenta la típica morfología de estos dientes en los adultos, pero en el $\mathrm{m} 3$ el surco lingual es muy profundo y presenta en su fondo una ensanchamiento orientado hacia el lóbulo posterior del molar. Los caracteres preservados en este espécimen son insuficientes como para poder asignarlo a Pseudotypotherium o a Typotheriopsis. 
A

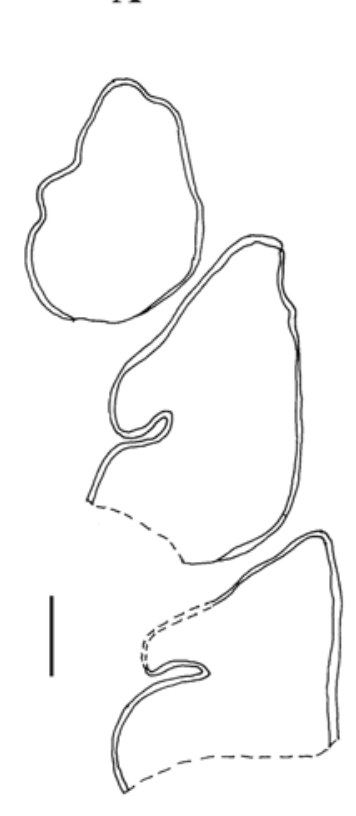

B

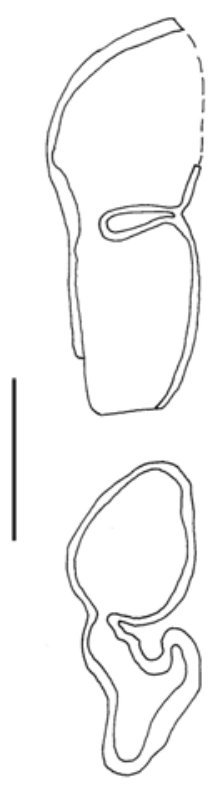

Figura 2.22 A. Pseudotypotherium subinsigne GHUNLPam 21137 P3-M1; B. Mesotheriinae indet. GHUNLPam $21148 \mathrm{~m} 2-3$, escalas $5 \mathrm{~mm}$

Familia TOXODONTIDAE Owen, 1845

Toxodontidae indet.

Material: GHUNLPam 21145; 21913/1 fragmentos de dientes.

Comentarios: El alto grado de fragmentación de los únicos especímenes conservados no permite más que la asignación a nivel de familia.

Orden LITOPTERNA Ameghino, 1889 Familia PROTEROTHERIIDAE Ameghino, 1887 Proterotheriidae indet.

Material: GHUNLPam 19826 fragmento mandibular derecho con m2-3 (Figura $2.23 \mathrm{~A}$ ); 19843 y 19869 molares inferiores; 21240/1; /2; 21536; 21537; 21538 y 21920 fragmentos de molares; 21589 fragmento mandibular izquierdo con $\mathrm{m} 2$ y parte del m3 (Figura 2.23 B).

Comentarios: Excepto los especímenes GHUNLPam 19826 y 21589, el resto de los materiales son fragmentos de dientes muy deteriorados. Los dos ejemplares nombrados corresponden a individuos adultos, con un muy alto grado de 
desgaste de sus molares, motivo que también dificulta su asignación taxonómica. Las medidas de estos materiales se muestran en la Tabla 2.12, donde se comparan con las disponibles de otras especies huayquerienses, tomadas de Soria (2001). Para niveles de la Formación Cerro Azul (= Formación Epecuén) en Salinas Grandes de Hidalgo fue descripto Diplasotherium pampa Soria, 2001.

\begin{tabular}{|l|c|c|c|c|}
\hline & m2 AP & m2 transv. & M3 AP & m3 transv. \\
\hline GHUNLPam 19826 & 14,50 & 12,20 & 21,60 & 11,80 \\
\hline GHUNLPam 21589 & 14,50 & 12,80 & & \\
\hline Diplasotherium pampa & 16,60 & 11,90 & & \\
\hline Neobrachytherium ameghinoi & 14,20 & 11,40 & 15,90 & 10,00 \\
\hline N. intermedium & 14,70 & 11,00 & 16,00 & \\
\hline Lophogonodon gradatum & 15,00 & 12,30 & 16,00 & 12,80 \\
\hline L. paranensis (promedios) & 15,70 & 12,60 & 17,50 & 11,20 \\
\hline
\end{tabular}

Tabla 2.12. Medidas de los Proterotheriidae de Caleufú y de especies asignadas a niveles huayquerienses de Argentina

A

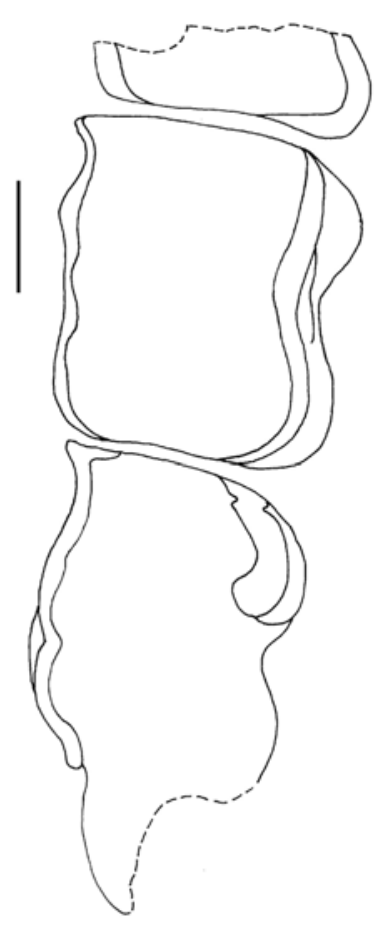

B

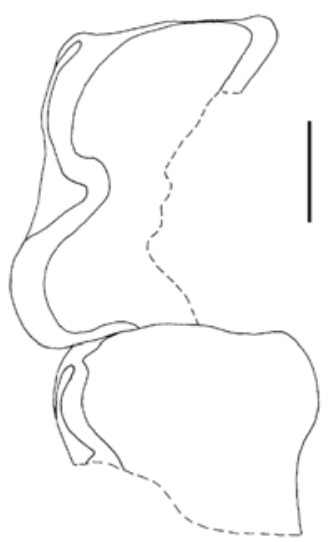

Figura 2.23. Litopterna indet. A. GHUNLPam 19826 porción de $\mathrm{m} 1$ y m2-3 derechos y $\mathrm{B}$. GHUNLPam 21589, porción de m2 y m3 izquierdos, escalas $5 \mathrm{~mm}$ 
Orden CARNIVORA Bowdich, 1821

Carnivora indet.

Material: GHUNLPam 21139 porción anterior de maxilar con raíz de canino?; 21722 fragmento mandibular derecho con alvéolos de incisivos, raíz de canino? y alvéolos de premolar?

Comentarios: Los especímenes que se atribuyen al Orden Carnivora son muy incompletos como para realizar mayores ajustes sistemáticos. Por el tamaño y las características que presentan, ambos podrían corresponder al mismo taxón. En niveles de la Formación Cerro Azul asignados a la Edad mamífero Huayqueriense (Mioceno tardío) los únicos representantes de este orden hallados hasta el momento corresponden a la Familia Procyonidae (Zetti, 1972 a). Los caracteres que presentan los dos nuevos especímenes de Caleufú no coinciden con los esperables en un representante de esa familia, pero el material es muy incompleto como para asignarlo con mayor precisión.

Comparación de la asociación faunística de Caleufú con otras de la Formación Cerro Azul

En la Tabla 2.13 se indican los taxa registrados en todas las localidades de la Formación Cerro Azul. La asociación faunística de Caleufú está constituida por 36 taxa de vertebrados. El valor indica una gran diversidad, sólo superada por las asociaciones de Telén, Laguna Chillhué y Salinas Grandes de Hidalgo. Los reptiles están representados por la Familia Teiidae, también presente en Telén, Laguna Chillhué, Quehué y Bajo Giuliani y la Superfamilia Colubroidea registrada sólo en esta localidad. Los especímenes asignados a Aves no han sido identificados más que a ese nivel.

Entre los mamíferos se contabilizaron 33 taxa que incluyen a 7 órdenes y 16 familias. 


\begin{tabular}{|c|c|c|c|c|c|c|c|c|c|c|c|c|c|c|c|c|c|c|c|c|c|c|c|}
\hline & 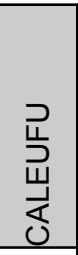 & 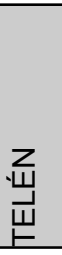 & 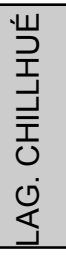 & 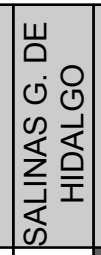 & 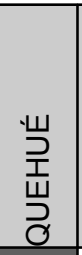 & 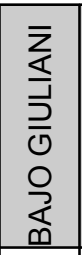 & 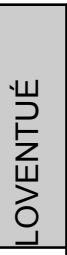 & 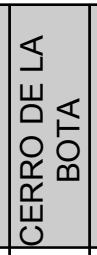 & 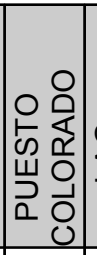 & 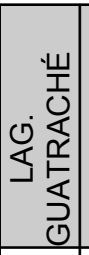 & 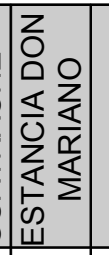 & 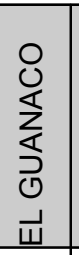 & 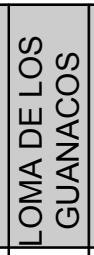 & 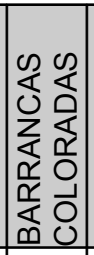 & 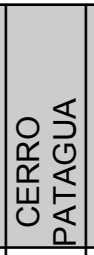 & 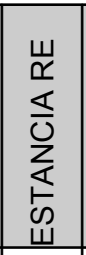 & $\frac{O}{U}$ & $\begin{array}{l}\mathbb{r} \\
\mathbb{1} \\
0 \\
\\
\dot{\mathbb{d}} \\
\mathbb{d} \\
0\end{array}$ & 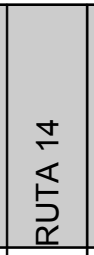 & 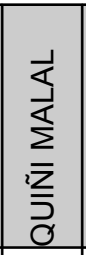 & 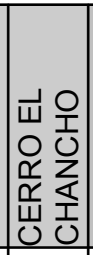 & 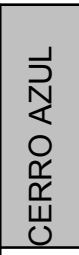 & 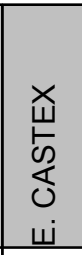 \\
\hline Ceratophryinae indet. & & & & & $\bullet$ & & & & & & & & & & & & & & & & & & \\
\hline Chelonia indet. & & & & & & $\bullet$ & & & & & & & & & & & & & & & & & \\
\hline Teiidae indet. & $\bullet$ & $\bullet$ & $\bullet$ & & $\bullet$ & $\bullet$ & $\bullet$ & & & & & & & & & & & & & & & & \\
\hline Argentavis magnificens & & & & $\bullet$ & & & & & & & & & & & & & & & & & & & \\
\hline Aves indet. & $\bullet$ & & & & & & & & & & & & & & & & & & & & & & \\
\hline Thylamys pinei & & & $\bullet$ & & & $\bullet$ & & & & & & & & & & & & & & & & & \\
\hline Zygolestes tatei & & & & & & $\bullet$ & & & & & & & & & & & & & & & & & \\
\hline Marmosinae indet. & $\bullet$ & & & & & & & & & & & & & & & & & & & & & & \\
\hline Hyperdidelphys sp. & $\bullet$ & & & & & & & & & & & & & & & & & & & & & & \\
\hline Lutreolina sp. & & & & - & & & & & & & & & & & & & & & & & & & \\
\hline Didelphinae indet. & $\bullet$ & $\bullet$ & & & $\bullet$ & & & & & & & & & & & & & & & & & & \\
\hline Sparassocinidae indet. & & $\bullet$ & & & & & & & & & & & & & & & & & & & & & \\
\hline Sparassocynus sp. & $\bullet$ & & & & & & & & & & & & & & & & & & & & & & \\
\hline Borhyaenidium musteloides & & & & $\bullet$ & & & & & & & & & & & & & & & & & & & \\
\hline Borhyaenidae indet. & & - & & - & & & & & & & & & & & & & & & & & & & \\
\hline
\end{tabular}

Tabla 10. Vertebrados presentes en las localidades fosilíferas de la Formación Cerro Azul 


\begin{tabular}{|c|c|c|c|c|c|c|c|c|c|c|c|c|c|c|c|c|c|c|c|c|c|c|c|}
\hline & 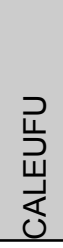 & $\begin{array}{l}\text { uㅡ } \\
\vec{w} \\
\end{array}$ & 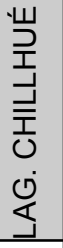 & 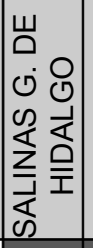 & 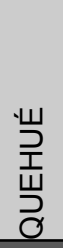 & 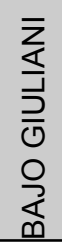 & 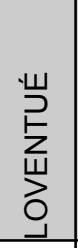 & 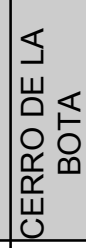 & 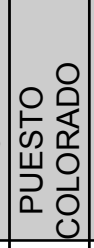 & 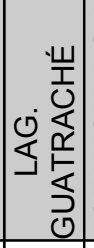 & 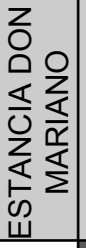 & 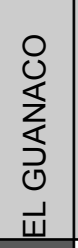 & 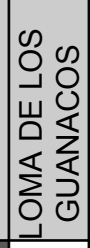 & 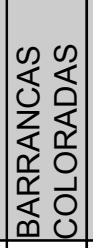 & 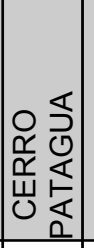 & 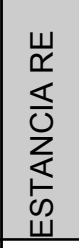 & $\frac{0}{\frac{0}{L}}$ & 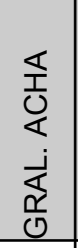 & 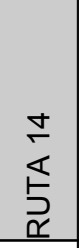 & 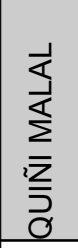 & 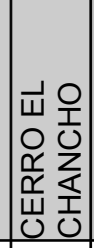 & 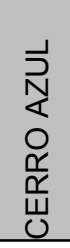 & 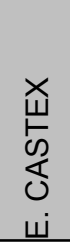 \\
\hline Achlysictis of $A$. lelongi & & & & $\bullet$ & $\bullet$ & & & & & & & $\bullet$ & & & & & & & & & & & \\
\hline Pliolestes venetus & & & $\bullet$ & & & $\bullet$ & & & & & & 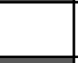 & & & & & & & & & & & \\
\hline Microtragulus rusconii & & $\bullet$ & & & & $\bullet$ & & & & & & $\bullet$ & & & & & & & & & & & \\
\hline Argyrolagus sp. & $\bullet$ & & - & & & 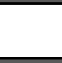 & & & & & & 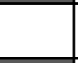 & & & & & & & & & & & \\
\hline Palaeocavia sp. & $\bullet$ & $\bullet$ & $\bullet$ & $\bullet$ & $\bullet$ & $\bullet$ & $\bullet$ & & $\bullet$ & & $\bullet$ & $\bullet$ & & $\bullet$ & & $\bullet$ & & & $\bullet$ & & & & \\
\hline Orthomyctera sp. & $\bullet$ & $\bullet$ & 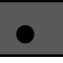 & $\bullet$ & $\bullet$ & $\bullet$ & $\bullet$ & & $\circ$ & & & & $\bullet$ & $\bullet$ & $\bullet$ & $\bullet$ & & & & & & $\bullet$ & \\
\hline Neocavia cf. N. Iozanoi & $\bullet$ & & & & & & & & & & & & & & & & & & & & & & \\
\hline Dolicavia? & & $\bullet$ & & & $\bullet$ & $\bullet$ & & & & & & $\bullet$ & & & & & & & & & & & \\
\hline Cardiomys sp. & & $\bullet$ & $\bullet$ & $\bullet$ & $\bullet$ & 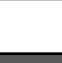 & $\bullet$ & & $\bullet$ & $\bullet$ & & 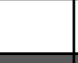 & & & $\bullet$ & & & & & & & & \\
\hline Lagostomus (Lagostomopsis) sp. & $\bullet$ & $\bullet$ & $\bullet$ & - & $\bullet$ & $\bullet$ & $\bullet$ & $\bullet$ & $\bullet$ & $\bullet$ & $\bullet$ & $\bullet$ & $\bullet$ & $\bullet$ & $\bullet$ & $\bullet$ & & & & & & & \\
\hline Tetrastylus sp. & $\bullet$ & & $\bullet$ & & & - & & & & & & & & & & & & & & & & & \\
\hline Tetrastylus araucanus & & & & $\bullet$ & & & & & & & & & & & & & & & & & & & \\
\hline Dinomyidae indet. & & $\bullet$ & $\bullet$ & & & & & $\bullet$ & & & & & $\bullet$ & & & & & & & & & & \\
\hline Octodontoidea indet. sp. A & & $\bullet$ & $\bullet$ & & & $\bullet$ & & & & & $\bullet$ & & & & & & & & & & & & \\
\hline Octodontoidea indet. sp. B & & & & & & & $\bullet$ & & & & & & & & & & & & & & & & \\
\hline Pampamys emmonsae & $\bullet$ & $\bullet$ & $\bullet$ & $\bullet$ & & $\bullet$ & $\bullet$ & & $\bullet$ & & & & & & & & & & & & & & \\
\hline Theridomysops parvulus & & 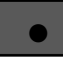 & & & & & & & & & & & & & & & & & & & & & \\
\hline cf. Clyomys & & & & & & & & & & & & & & $\bullet$ & & & & & & & & & \\
\hline Reigechimys plesiodon & & & $\bullet$ & & $\bullet$ & & & & & & & & & & & & & & & & & & \\
\hline Reigechimys octodontiformis & & & & $\bullet$ & & & & & & & $\bullet$ & & & & & & & & & & & & \\
\hline Reigechimys sp. & & $\bullet$ & & & & $\bullet$ & $\bullet$ & & $\bullet$ & & & & & & & $\bullet$ & & & & & & & \\
\hline
\end{tabular}

Tabla 10. continuación 


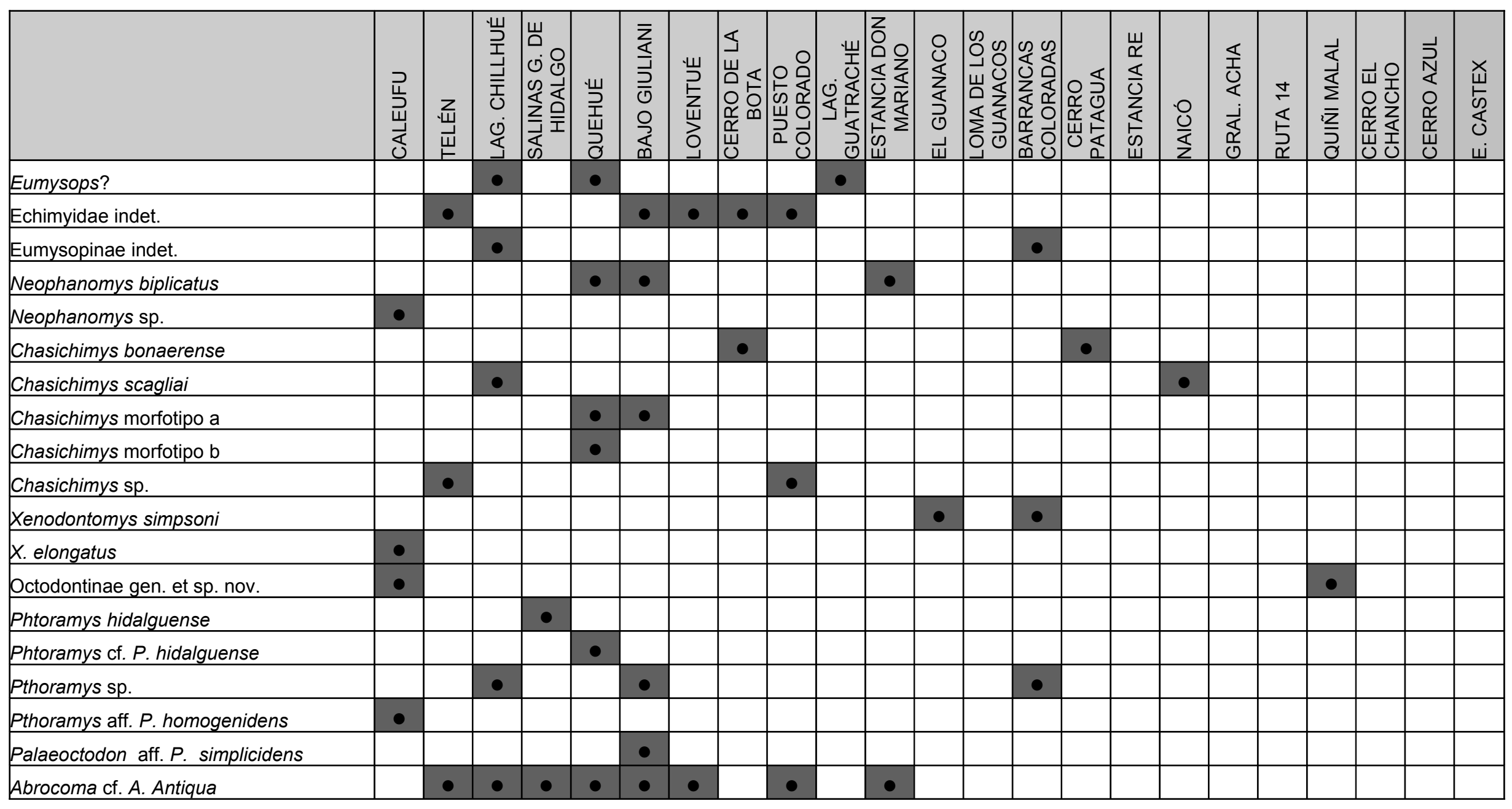

Tabla 10. continuación 


\begin{tabular}{|c|c|c|c|c|c|c|c|c|c|c|c|c|c|c|c|c|c|c|c|c|c|c|c|}
\hline & 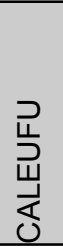 & 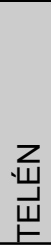 & 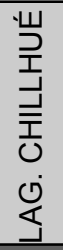 & 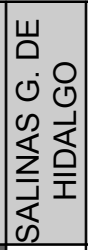 & $\begin{array}{l}\stackrel{\uplus}{\supset} \\
\stackrel{T}{\Psi} \\
\stackrel{0}{0}\end{array}$ & $\begin{array}{l}\bar{z} \\
\vdots \\
\\
0 \\
0 \\
0 \\
\frac{1}{0}\end{array}$ & 㞾 & 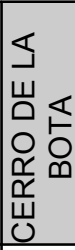 & 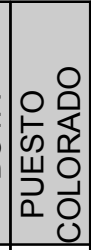 & 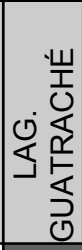 & 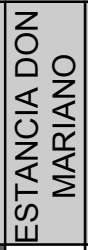 & 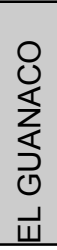 & 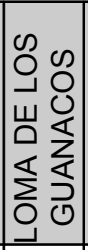 & 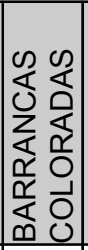 & 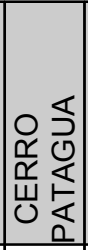 & 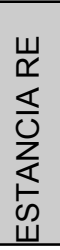 & $\frac{0}{\frac{0}{\pi}}$ & $\begin{array}{l}\frac{1}{1} \\
0 \\
0 \\
\dot{1} \\
\mathbb{1} \\
0 \\
0\end{array}$ & 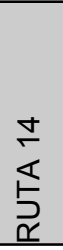 & $\begin{array}{l}\frac{1}{3} \\
\frac{1}{2} \\
\frac{2}{3} \\
0 \\
0\end{array}$ & 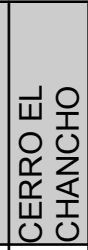 & \begin{tabular}{l}
1 \\
\multicolumn{1}{c}{} \\
$\frac{1}{0}$ \\
0 \\
$\frac{1}{\alpha}$ \\
$\frac{\pi}{山}$ \\
0
\end{tabular} & 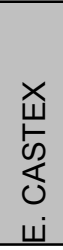 \\
\hline Kiyutherium orientalis & & & $\bullet$ & & & & & & & - & & & & & & & & & & & & & \\
\hline Cricetidae gen. et sp. nov. & $\bullet$ & & & & & & & & & & & & & & & & & & & & & & \\
\hline Paedotherium minor & - & - & - & - & - & - & - & - & - & - & - & - & - & $\bullet$ & - & $\bullet$ & & $\bullet$ & $\bullet$ & & & & \\
\hline Hemihegetotherium achataleptum & & & - & - & & $\bullet$ & - & $\bullet$ & $\bullet$ & & & & $\bullet$ & & $\bullet$ & & & & & & & & $\bullet$ \\
\hline Typotheriopsis silveyrai & & - & 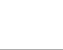 & 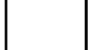 & - & - & - & - & - & • & - & & $\bullet$ & & - & & - & $\bullet$ & & & - & & \\
\hline Pseudotypotherium subinsigne & $\bullet$ & $\bullet$ & $\bullet$ & - & $\bullet$ & $\bullet$ & - & $\bullet$ & $\bullet$ & $\bullet$ & $\bullet$ & & - & & $\bullet$ & $\bullet$ & $\bullet$ & $\bullet$ & & & $\bullet$ & & \\
\hline Mesotheriidae indet.. & $\bullet$ & & & & & & & & & & & & & & & & & & & & & & \\
\hline Palaeotoxodon sp. & & & & & - & & & & & & & & & & & & & & & & & & \\
\hline Pisanodon nazari & & & & - & & & & & & & & & & & & & & & & & & & \\
\hline Toxodontidae indet.. & $\bullet$ & & & & & & & - & & & & & & & & $\bullet$ & & & & & & & \\
\hline Proterotheriinae indet. & $\bullet$ & - & $\bullet$ & & & - & & & & & & & & & & & & & & $\bullet$ & & & \\
\hline Eoauchenia cingulata & & & & $\bullet$ & & & & & & & & & & & & & & & & & & & \\
\hline Diplasotherium pampa & & & & $\bullet$ & & & & & & & & & & & & & & & & & & & \\
\hline Macraucheniinae indet. & & - & - & & & & - & $\bullet$ & $\bullet$ & & & - & & & & & & & & & & & \\
\hline Promacrauchenia sp. & & & & - & & & & & & & & & & & & & & & & & & & \\
\hline Macrauchenia latidens & & & & $\bullet$ & & & & & & & & & & & & & & & & & & & \\
\hline Vetelia perforata & & & & & & & & & & & & & $\bullet$ & & & & & & & & & & \\
\hline Macroeuphractus morenoi & $\bullet$ & - & $\bullet$ & - & $\bullet$ & & 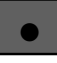 & & & - & & & & & & & & & & & & & \\
\hline Macroeuphractus sp. & $\bullet$ & & & & & & & & & & & & & & & & & & & & & & \\
\hline Macrochorobates scalabrinii & & $\bullet$ & $\bullet$ & $\bullet$ & $\bullet$ & & - & & & & & & & & & & & & & & & & \\
\hline Proeuphractus sp. & $\bullet$ & - & $\bullet$ & & - & & & & & - & & & & & & & & & & & & & \\
\hline
\end{tabular}

Tabla 10. continuación 


\begin{tabular}{|c|c|c|c|c|c|c|c|c|c|c|c|c|c|c|c|c|c|c|c|c|c|c|c|}
\hline & 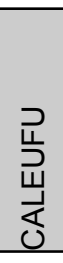 & $\begin{array}{l}\text { 㞾 } \\
\underset{w}{W}\end{array}$ & 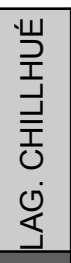 & 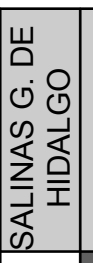 & 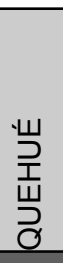 & 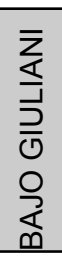 & 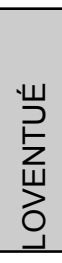 & 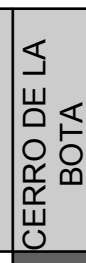 & 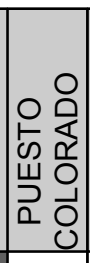 & 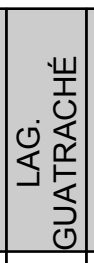 & 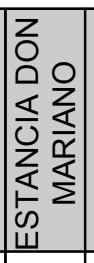 & 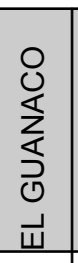 & 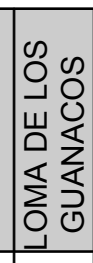 & 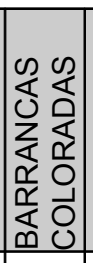 & 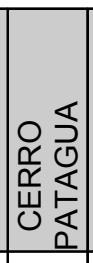 & 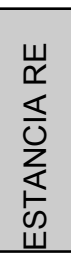 & $\begin{array}{l}0 \\
\frac{U}{\Sigma} \\
Z\end{array}$ & 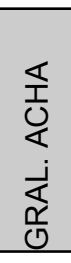 & 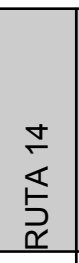 & 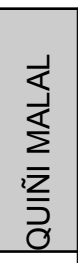 & 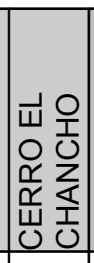 & 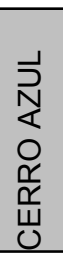 & 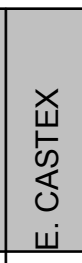 \\
\hline Zaedyus pichiy & & $\bullet$ & $\bullet$ & & $\bullet$ & & & $\bullet$ & & & & & & & & & & & & & & & \\
\hline Gen. nov. A & & & $\bullet$ & $\bullet$ & . & & & 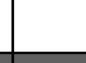 & & & & & & & & & & & & & & & \\
\hline Chorobates villosissimus & $\bullet$ & $\bullet$ & $\bullet$ & $\bullet$ & $\bullet$ & & $\bullet$ & $\bullet$ & & & & & & & & & & & & & & & \\
\hline Chasicotatus ameghinoi & $\bullet$ & $\bullet$ & $\bullet$ & $\bullet$ & $\bullet$ & $\bullet$ & $\bullet$ & & & & & & $\bullet$ & & & & $\bullet$ & & & & & & \\
\hline Chasicotatus sp. & $\bullet$ & & & & & & & & & & & & & & & & & & & & & & \\
\hline Doellotatus inornatus & $\bullet$ & $\bullet$ & $\bullet$ & & $\bullet$ & & $\bullet$ & $\bullet$ & & & & & & & & & & & & & & & \\
\hline D. chapadmalensis & $\bullet$ & & & $\bullet$ & & & & & & & & & & & & & & & & & & & \\
\hline Ringueletia simpsoni & $\bullet$ & & & & & & & & & & & & & & & & & & & & & & \\
\hline Dasypodidae indet. & & & . & & & & $\bullet$ & $\bullet$ & $\bullet$ & & $\bullet$ & $\bullet$ & $\bullet$ & $\bullet$ & & $\bullet$ & & & $\bullet$ & & & & \\
\hline Hoplophractus sp. & & $\bullet$ & $\bullet$ & $\bullet$ & $\bullet$ & & & & & $\bullet$ & $\bullet$ & & & & & & & & & & & & \\
\hline Hoplophorus sp. & & $\bullet$ & $\bullet$ & $\bullet$ & $\bullet$ & & & & & $\bullet$ & & & & & & & & & & & & & \\
\hline Aspidocalyptus sp. & & $\bullet$ & $\bullet$ & $\bullet$ & $\bullet$ & & & & & $\bullet$ & & & & & & & & & & & & & \\
\hline Coscinocercus sp. & & $\bullet$ & - & $\bullet$ & $\bullet$ & & & & & $\bullet$ & & & & & & & & & & & & & \\
\hline Glyptodontidae indet. & $\bullet$ & & & & & $\bullet$ & $\bullet$ & $\bullet$ & & & & $\bullet$ & $\bullet$ & $\bullet$ & $\bullet$ & $\bullet$ & & $\bullet$ & $\bullet$ & $\bullet$ & & & \\
\hline Plesiomegatherium sp. & & & & $\bullet$ & & & & & & & & & & & & & & & & & & & \\
\hline Elassotherium altirostre & & $\bullet$ & & $\bullet$ & & & & & & & & & & & & & & & & & & & \\
\hline Elassotherium $\mathrm{sp}$. & & & & & & 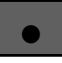 & & & & & & & & & & & & & & & & & \\
\hline Scelidotheriinae indet. & $\bullet$ & & & & & & & & & & $\bullet$ & & & & & & & & & & & & \\
\hline
\end{tabular}

Tabla 10. continuación 


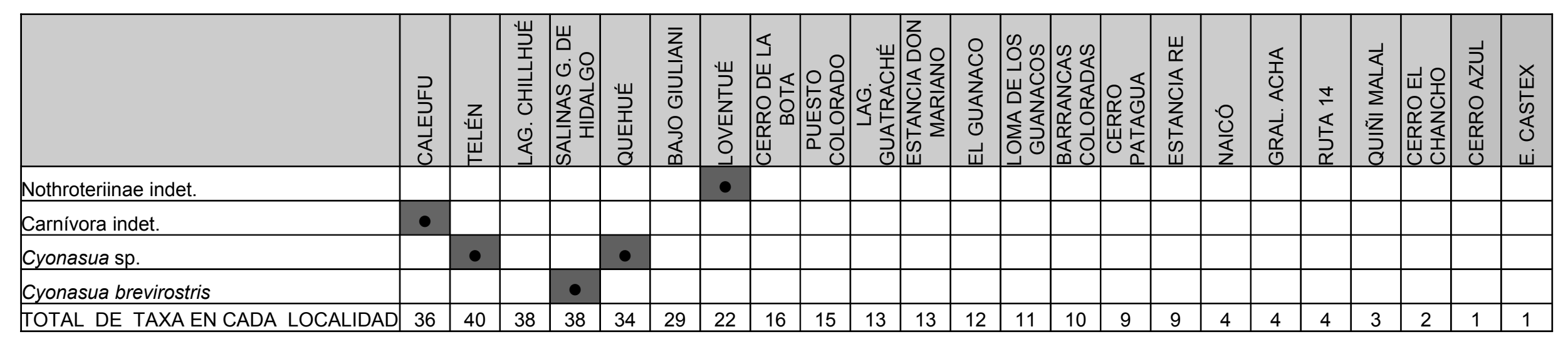

Tabla 10. continuación 
En la Tabla 2.14 se muestra la cantidad de especies, géneros y familias que la asociación de Caleufú comparte con otras localidades de la Formación Cerro Azul cuya diversidad taxonómica es alta.

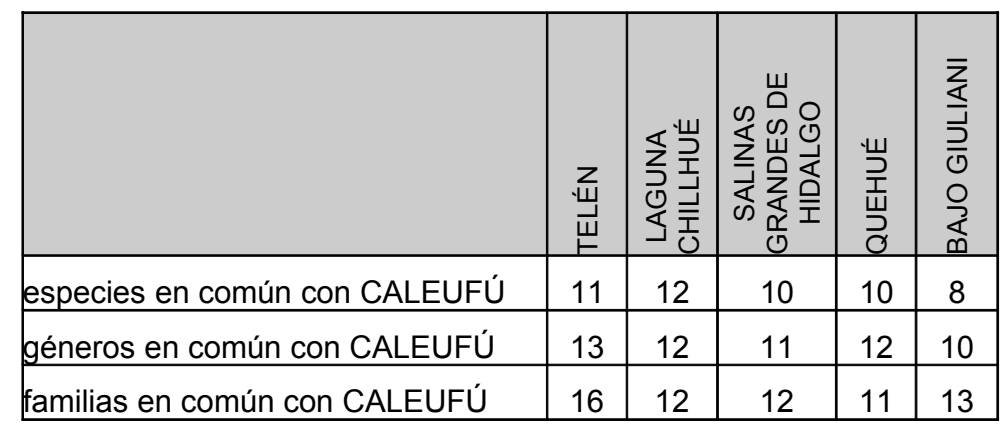

Tabla 2.14. Número de especies, géneros y familias compartidas entre Caleufú y algunas localidades de la Formación Cerro Azul con diversidad taxonómica alta

Con la asociación recuperada en Telén, la de Caleufú comparte 16 familias (Tabla 2.14). En Telén se han hallado especímenes asignados a la Familia Procyonidae (Orden Carnívora) mientras que en Caleufú hay representantes de ese orden pero los especímenes no permiten mayor precisión en su asignación. Por otro lado, entre los roedores, en Caleufú se registran representantes de la Familia Muridae, que hasta el momento, no fue hallada en ninguno de los otros afloramientos de la Formación Cerro Azul.

La mayoría de las asociaciones faunísticas recuperadas de la Formación Cerro Azul fueron asignadas al Mioceno tardío, Edad mamífero Huayqueriense (Pascual, 1961; Pascual y Bocchino, 1963; Pascual et al., 1965; Ortega Hinojosa, 1967; Zetti, 1972 a y b; Campbell y Tonni, 1980, 1981; Tambussi, 1987; Montalvo y Casadío, 1988; Goin y Montalvo, 1988; Vizcaíno y Fariña, 1999; Verzi, 1999; Verzi et al., 1990, 1991, 1993, 1994, 1995, 1996, 1999 a y b, 2003; Montalvo y Rocha, 2001, 2003; Montalvo y Cerdeño, 2002; Montalvo et al., 1995, 1996, 1998, 1999, 2000 a y b; Rocha y Montalvo, 1999; Goin et al., 1997, 2000; Esteban et al., 1996, 2001, 2003; Cerdeño y Montalvo, 2001, 2002) y solo las de Cerro Patagua y Cerro de la Bota a la Edad mamífero Chasiquense (Verzi, 1999). 
La asociación de Caleufú comparte con otras asociaciones de mayor o similar diversidad taxonómica varios taxa propios de la Edad mamífero Huayqueriense, como Palaeocavia sp., Orthomyctera sp., Lagostomus (Lagostomopsis) sp., Pampamys emmonsae, Paedotherium minor, Pseudotypotherium subinsigne, Macroeuphractus morenoi, Proeuphractus sp., Chorobates villosissimus, Chasicotatus ameghinoi y Doellotatus inornatus. Es notorio que el único roedor Echimyidae registrado es un espécimen de Pampamys emmonsae. Los equímidos son diversos y abundantes en varias asociaciones huayquerienses de la Formación Cerro Azul, pero experimentaron una importante declinación en el límite Mio-Plioceno al sur de su actual distribución.

En la asociación de Caleufú se han recuperado, además, otros taxa indicadores de mayor modernidad. Entre los dasipódidos, Ringueletia simpsoni especie que hasta el momento se registraba en niveles asignados al Montehermosense - Marplatense temprano de la costa atlántica en la provincia de Buenos Aires (Scillato Yané, 1982).

Los roedores muestran mayor diversidad de taxa más modernos. Los nuevos especímenes de Neophanomys sp. son interpretados como un cronomorfo, que presenta caracteres derivados con respecto a los de los especímenes de $N$. biplicatus presentes en otros afloramientos de la Formación Cerro Azul (Bajo Giuliani, Quehué y Estancia Don Mariano). Xenodontomys elongatus fue considerado el cronomorfo más derivado de Xenodontomys y la fauna de Caleufú más moderna con respecto a las de Barrancas Coloradas y El Guanaco que contienen a X. simpsoni (Verzi et al., 2003). Neocavia cf. N. Iozanoi presenta algunas diferencias con respecto a la especie tipo, registrada en niveles huayquerienses de Catamarca, como la presencia de una proyección aguda en el lóbulo anterior del prisma anterior del p4 que podría considerarse un carácter derivado (Montalvo y Rocha, 2003). El Octodontinae indet. constituye un taxón con caracteres muy derivados con respecto a cualquier otro representante de esa subfamilia hallado en otros niveles de la Formación Cerro Azul. Phtoramys muestra caracteres que lo vinculan con $P$. homogenidens, especie típica de la Edad mamífero Montehermosense. Se registran representantes de la Familia 
Muridae, familia cuyo registro más antiguo correspondía al Montehermosense (Pardiñas y Tonni, 1998; Pardiñas, 2000; ver Pardiñas et al., 2002).

Considerando que se postuló una gradación entre las especies de Paedotherium desde el Chasiquense al Montehermosense (Zetti, 1972 b), el mayor tamaño de los especímenes de Paedotherium minor procedentes de la asociación de Caleufú, podría ser otro indicio de mayor modernidad para esta fauna.

De lo expuesto surge que la asociación faunística de Caleufú presenta 11 taxa atribuibles a la Edad mamífero Huayqueriense y 6 taxa indicadores de mayor modernidad, si bien ninguno de ellos puede ser asignado a taxa montehermosenses, por lo que puede ser ubicada en el Mioceno tardío - Plioceno temprano. Estos registros avalan la propuesta de Verzi et al. (2003) de que esta asociación podría corresponder a la parte final del Mioceno tardío, cercana, pero algo más antigua que la Edad mamífero Montehermosense. 


\section{Capítulo 3 \\ REPRESENTACIÓN TAXONÓMICA Y ANATÓMICA DE LOS RESTOS RECUPERADOS}




\section{Cálculo del número de restos (NR)}

La asociación faunística que se describe, como se mencionó antes, fue hallada en una superficie pequeña (alrededor de $1.590 \mathrm{~m}^{2}$ ) donde se recuperaron 6.516 restos (NR) en cinco campañas de recolección. El 49,88 \% del total de los restos eran fragmentos óseos indeterminables anatómicamente (Figura 3.1). Entre los restos identificables se recuperaron 66 que corresponden a coprolitos.

66 coprolitos

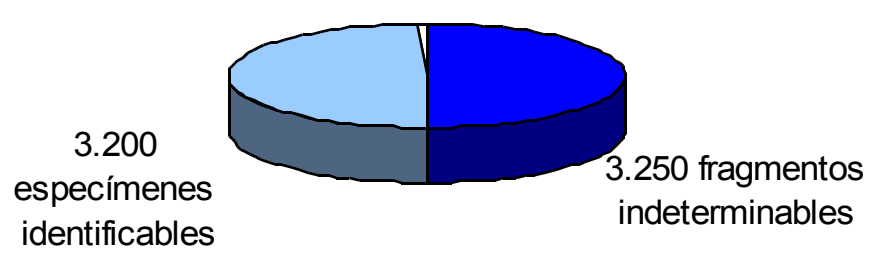

Figura 3.1. Total de restos de la asociación

Se calculó la proporción de restos no identificables ni taxonómica ni anatómicamente con respecto al total de restos recuperados. Para esto se utilizó el índice propuesto por Morales (1987) que surge de dividir el número de restos sin identificar por el de identificados y multiplicar el resultado por 100. Para esta asociación \{(3250/3266)X100\} el valor obtenido es de 99,51 que supera ampliamente el valor considerado óptimo, que oscila alrededor de 10. Por lo tanto aquel valor indica que, en esta asociación la posibilidad de resolución en la identificación es baja, en concordancia con la preservación de los restos recuperados. No es posible comparar el valor obtenido en la asociación de Caleufú con otras procedentes de la Formación Cerro Azul, ya que en esos casos y sin criterio de prospección tafonómica, los fragmentos indeterminables fueron descartados en el campo directamente o en las primeras etapas de las tareas de laboratorio. 
El análisis de la representación taxonómica y parataxonómica de esta asociación se realizó sobre la base de 3.200 especímenes identificados taxonómicamente y los 66 especímenes correspondientes a coprolitos.

Los restos presentaban un muy bajo grado de asociación o articulación entre elementos anatómicos, por ese motivo 943 especímenes $(29,47 \%)$ que corresponden a elementos postcraneanos, sólo fueron determinados anatómicamente y se asignaron a mamíferos indeterminables (Figura 3.2).
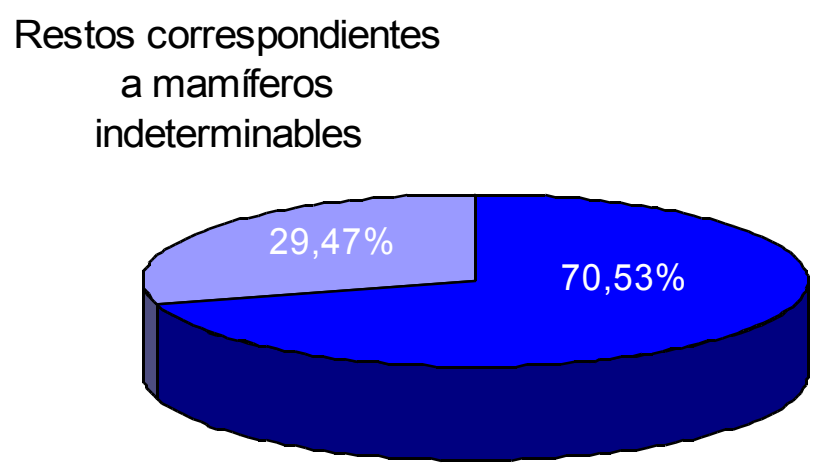

Elementos esqueléticos determinados taxonómicamente

Figura 3.2. Porcentaje de elementos esqueléticos determinados sólo anatómicamente y elementos identificados anatómica y taxonómicamente $(N R=3.200)$

\section{Cálculo del número de especímenes identificados por taxón (NEIT)}

El listado faunístico fue realizado sobre la base de un NEIT de 2.257 especímenes, que corresponden fundamentalmente a elementos craneanos (mandíbulas y maxilares) para la mayoría de los mamíferos y reptiles, placas de la coraza para los Xenarthra, y vértebras y otros elementos esqueléticos en los casos de reptiles y aves. Estas dos últimas clases nombradas están representadas por 59 especímenes (Tabla 3.1). En esa tabla se indican como mamíferos indeterminables los elementos postcraneanos que solo se pudieron identificar hasta el nivel de Clase y, como mamíferos, a todos los especímenes (correspondientes a elementos craneanos) que fueron identificados a nivel de 
Orden o por debajo de este. Se incluye en esa categoría a 6 restos craneanos clasificados como mamíferos indeterminables.

\begin{tabular}{|l|r|}
\hline Clase & NEIT \\
\hline Reptiles & 28 \\
\hline Aves & 31 \\
\hline Mamíferos & 2.198 \\
\hline Subtotal & 2.257 \\
\hline Mamíferos indet. & 943 \\
\hline TOTAL & 3.200 \\
\hline
\end{tabular}

Tabla 3.1. Número de restos identificados en cada categoría taxonómica

En la Tabla 3.2 se compara el porcentaje de elementos esqueléticos asignados a reptiles, con los hallazgos realizados en otros afloramientos fosilíferos de la Formación Cerro Azul. En el caso de Caleufú, el NEIT es alto ya que se incluyen allí restos que corresponden al cráneo (8 especímenes) y al postcráneo (20 especímenes). Sin embargo, ya que en las otras localidades de esta formación el material postcraneano hallado aislado no ha sido determinado, los datos que figuran en la tabla corresponden sólo a restos craneanos identificados.

\begin{tabular}{|l|r|c|c|}
\hline Localidad & \multicolumn{1}{|c|}{ NEIT } & Reptiles & $\%$ \\
\hline TELÉN & 4.730 & 1 & 0,02 \\
\hline LAGUNA CHILLHUÉ & 1.962 & 2 & 0,10 \\
\hline QUEHUÉ & 2.114 & 3 & 0,14 \\
\hline LOVENTUE & 647 & 2 & 0,31 \\
\hline BAJO GIULIANI & 1.644 & 9 & 0,55 \\
\hline CALEUFÚ & 3.200 & 28 & 0,88 \\
\hline
\end{tabular}

Tabla 3.2. NEIT total y de reptiles hallados en diferentes localidades fosilíferas de la Formación Cerro Azul

Con respecto a las aves, en una revisión del material de vertebrados de la colección paleontológica de la UNLPam (Montalvo y Szelagowski, 1999), se indicó que la falta de restos de aves seguramente no obedecía a una ausencia en el registro, sino a un defecto en la determinación de los materiales. La revisión exhaustiva del material correspondiente a elementos postcraneanos de la asociación de Caleufú confirma esto, ya que el NEIT de aves es de 31. De todos 
modos, hay que destacar que estos restos fueron producidos por aves de tamaño muy pequeño.

Ya se indicó para elementos craneanos de mamíferos un NEIT total de 2.198 (Tabla 3.1). Estos especímenes fueron determinados taxonómicamente hasta el nivel posible. En la Tabla 3.3 se muestra el NEIT de cada grupo de mamíferos.

\begin{tabular}{|l|c|r|}
\hline & NEIT & \multicolumn{1}{c|}{$\%$} \\
\hline MARSUPIALIA & 19 & 0,86 \\
\hline XENARTHRA & 490 & 22,29 \\
\hline RODENTIA & 901 & 40,99 \\
\hline NOTOUNGULATA & 770 & 35,03 \\
\hline LITOPTERNA & 10 & 0,45 \\
\hline CARNÍVORA & 2 & 0,09 \\
\hline Mamíferos indet. & 6 & 0,27 \\
\hline Total & 2.198 & 100,00 \\
\hline
\end{tabular}

Tabla 3.3. NEIT para los grupos de mamíferos presentes en Caleufú

Los datos obtenidos a partir de la cuantificación del NEIT a nivel de Orden, con respecto al NEIT total, para la asociación de Caleufú fueron comparados con los mismos datos de otras asociaciones de la Formación Cerro Azul (Tabla 3.4).

\begin{tabular}{|l|c|c|c|c|c|c|c|}
\hline & $\begin{array}{c}\% \\
\text { Marsupialia }\end{array}$ & $\begin{array}{c}\% \\
\text { Xenarthra }\end{array}$ & $\begin{array}{c}\% \\
\text { Notoungulata }\end{array}$ & $\begin{array}{c}\% \\
\text { Litopterna }\end{array}$ & $\begin{array}{c}\% \\
\text { Rodentia }\end{array}$ & $\begin{array}{c}\% \\
\text { Carnivora }\end{array}$ & NEIT \\
\hline SALINAS G. DE HIDALGO & 0,54 & 69,40 & 18,99 & 0,54 & 5,67 & 0,18 & 1111 \\
\hline BAJO GIULIANI & 1,16 & 37,77 & 23,97 & 0,24 & 16,61 & & 1644 \\
\hline LAGUNA CHILLHUÉ & 0,31 & 55,45 & 19,06 & 0,36 & 12,69 & & 1962 \\
\hline QUEHUÉ & 0,57 & 38,60 & 21,38 & & 7,76 & 0,05 & 2114 \\
\hline CALEUFÚ & 0,59 & 15,31 & 24,06 & 0,31 & 28,16 & 0,06 & 3200 \\
\hline TELEN & 0,34 & 49,83 & 11,69 & 0,23 & 11,46 & 0,11 & 4730 \\
\hline ESTANCIA DON MARIANO & & 39,51 & 18,52 & & 18,52 & & 81 \\
\hline CERRO EL CHANCHO & & 45,00 & 9,73 & & 10,00 & & 40 \\
\hline LAGUNA GUATRACHÉ & 1,16 & 68,60 & 5,81 & 1,16 & 11,63 & & 86 \\
\hline CERRO DE LOS GUANACOS & & 31,75 & 53,97 & & 14,29 & & 126 \\
\hline BARRANCAS COLORADAS & & 27,34 & 19,14 & & 28,52 & & 256 \\
\hline EL GUANACO & 1,33 & 12,33 & 25,33 & 0,33 & 25,67 & & 300 \\
\hline CERRO DE LA BOTA & & 44,59 & 9,73 & & 0,71 & & 370 \\
\hline PUESTO COLORADO & 0,20 & 68,10 & 8,38 & 0,20 & 12,68 & & 489 \\
\hline LOVENTUÉ & 0,31 & 65,07 & 16,69 & 0,16 & 9,58 & & 647 \\
\hline
\end{tabular}

Tabla 3.4. Frecuencia de hallazgos de los diferentes órdenes de mamíferos en afloramientos de la Formación Cerro Azul 
Las asociaciones faunísticas se agruparon de acuerdo con su NEIT total (Tabla 3.4). La de Caleufú se comparó con las que también tienen un alto NEIT total (más de 1.000 especímenes): Bajo Giuliani, Telén, Laguna Chillhué, Salinas Grandes de Hidalgo y Quehué. Se pone en evidencia que en la asociación de Caleufú, a diferencia de lo que ocurre en las otras localidades, es baja la proporción de especímenes asignados a xenartros. En cambio, es alta la de notoungulados y muy alta la de roedores. Con respecto a las proporciones obtenidas para especímenes asignados a litopternos, marsupiales y carnívoros las proporciones son bajas (como ocurre en todas las asociaciones registradas hasta el momento). Por otro lado, la comparación de las proporciones de cada orden de la asociación de Caleufú con las de bajo NEIT total, evidencia similitud en las proporciones con las de la asociación de El Guanaco.

Como ya se indicó, la proporción de especímenes asignados a marsupiales en el contexto del NEIT total de cada asociación es bajo. En la Tabla 3.5 se detalla el NEIT de los taxa presentes en Caleufú.

\begin{tabular}{|l|c|}
\hline & NEIT \\
\hline Marmosinae indet. & 1 \\
\hline Didelphinae indet. & 8 \\
\hline Hyperdidelphys sp. & 2 \\
\hline Sparassocynus sp. & 2 \\
\hline Argyrolagus sp. & 6 \\
\hline TOTAL & 19 \\
\hline
\end{tabular}

Tabla 3.5. NEIT de los taxa de marsupiales de Caleufú

En general, los especímenes asignados al Orden Xenarthra son muy frecuentes y diversos en los afloramientos de la Formación Cerro Azul (ver Tabla 3.4).

La abundancia de xenartros registrada en esos afloramientos surge por el alto grado de desarticulación que presentan los elementos constituyentes de las corazas de cada individuo. Normalmente en estas asociaciones, las placas óseas se encuentran aisladas, de modo tal que se obtiene siempre un NEIT alto para este orden, que supera al NEIT total para los otros grupos de vertebrados presentes. En la Tabla 3.6 se indican las localidades de la Formación Cerro Azul 
donde también fueron citados los taxa de Dasypodidae que se encontraron en Caleufú.

\begin{tabular}{|c|c|c|c|c|c|c|c|c|c|c|}
\hline & 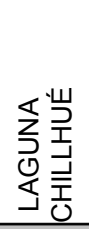 & $\begin{array}{c}\text { zu } \\
\text { 岸 } \\
\end{array}$ & 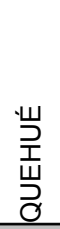 & 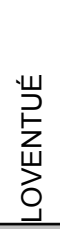 & 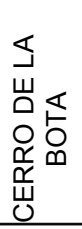 & 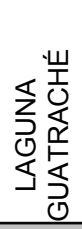 & 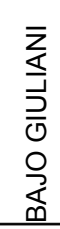 & 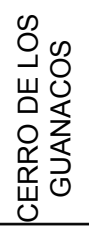 & 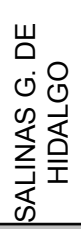 & 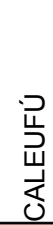 \\
\hline \multicolumn{11}{|c|}{ Macroeuphractus morenoi } \\
\hline \multicolumn{11}{|c|}{ Proeuphractus sp. } \\
\hline \multicolumn{11}{|c|}{ Chorobates villosissimus } \\
\hline \multicolumn{11}{|c|}{ Chasicotatus ameghinoi } \\
\hline \multicolumn{11}{|c|}{ Doellotatus inornatus } \\
\hline \multicolumn{11}{|l|}{\begin{tabular}{|l|} 
Doellotatus \\
chapadmalensis \\
\end{tabular}} \\
\hline Ringueletia simpsoni & & & & & & & & & & \\
\hline
\end{tabular}

Tabla 3.6. Distribución de los taxa de dasipódidos en algunas localidades de la Formación Cerro Azul

Esta distribución muestra una gran diversidad taxonómica de la asociación de Caleufú, con el registro de una especie citada por primera vez para la Formación Cerro Azul.

En esta asociación se recuperaron 490 restos $(15,31 \%$ sobre el total de especímenes identificados) correspondientes al Orden Xenarthra. Sólo $2(0,41 \%)$ fueron asignados a la Subfamilia Scelidotheriinae (Mylodontidae), el 6,33\% corresponde a representantes de la Familia Glyptodontidae, mientras que 457 restos $(93,27 \%)$ a Dasypodidae. De estos últimos, 139 placas aisladas o conjuntos de 2 ó 3 placas asociadas pudieron ser utilizadas en la elaboración del listado faunístico, y sólo 10 especímenes corresponden a dientes o fragmentos mandibulares con dientes (Tabla 3.7).

Los valores del NEIT para cada taxón mostrados en la Tabla 3.7 evidencian un muy bajo grado de preservación, aún más si se considera que la coraza de un dasipódido actual puede estar constituida por más de 800 placas. 


\begin{tabular}{|l|c|}
\hline Macroeuphractus sp. & 4 \\
\hline Macroeuphractus morenoi & 54 \\
\hline Proeuphractus sp. & 4 \\
\hline Chorobates villosissimus & 23 \\
\hline Chasicotatus sp. & 9 \\
\hline Chasicotatus ameghinoi & 29 \\
\hline Doellotatus inornatus & 1 \\
\hline Doellotatus chapadmalensis & 3 \\
\hline Ringueletia simpsoni & 12 \\
\hline Dasypodidae indet. & 318 \\
\hline Glyptodontidae indet. & 31 \\
\hline Scelidotheriinae indet. & 2 \\
\hline TOTAL & 490 \\
\hline
\end{tabular}

Tabla 3.7. NEIT para representantes del Orden Xenarthra presentes en la asociación faunística de Caleufú

Entre los roedores caviomorfos están representadas las Familias Caviidae, Dinomyidae, Chinchillidae, Echimyidae y Octodontidae. Como novedad en el registro para la Formación Cerro Azul se hallaron 2 hemimandíbulas asignadas a roedores Muridae Sigmodontinae (Tabla 3.8).

Los fragmentos de incisivos y las porciones de mandíbulas y paladares sin dientes, contabilizaron 246 especímenes, que sólo pueden ser determinados hasta el nivel de Rodentia indet.

\begin{tabular}{|l|c|}
\hline & NEIT \\
\hline Neocavia cf. N. Iozanoi & 29 \\
\hline Orthomyctera sp. & 79 \\
\hline Palaeocavia sp. & 164 \\
\hline Caviidae indet. & 50 \\
\hline Tetrastylus sp. & 2 \\
\hline Lagostomus (Lagostomopsis) sp. & 5 \\
\hline Pampamys emmonsae & 1 \\
\hline Phtoramys aff. P. homogenidens & 6 \\
\hline Neophanomys sp. & 7 \\
\hline Xenodontomys elongatus & 244 \\
\hline Octodontinae indet. & 66 \\
\hline Sigmodontinae gen. y sp. nov. & 2 \\
\hline Rodentia indet. & 246 \\
\hline TOTAL & 901 \\
\hline
\end{tabular}

Tabla 3.8. NEIT de roedores presentes en la asociación faunística de Caleufú 
A la Familia Caviidae se asignaron 322 especímenes. Esta representación es alta comparada con la de otras asociaciones de la Formación Cerro Azul (Tabla 3.9).

\begin{tabular}{|l|r|c|r|}
\hline & NEIT & Caviidae & \multicolumn{1}{c|}{$\%$} \\
\hline LAGUNA CHILLHUÉ & 1.962 & 51 & 2,60 \\
\hline PUESTO COLORADO & 489 & 17 & 3,48 \\
\hline EL GUANACO & 300 & 13 & 4,33 \\
\hline TELÉN & 4.730 & 232 & 4,90 \\
\hline BAJO GIULIANI & 1.644 & 112 & 6,81 \\
\hline CALEUFÚ & 3.200 & 322 & 10,06 \\
\hline BARRANCAS COLORADAS & 256 & 41 & 16,02 \\
\hline
\end{tabular}

Tabla 3.9. Frecuencia de hallazgos de especímenes asignados a la Familia Caviidae en algunas asociaciones faunísticas de la Formación Cerro Azul

Palaeocavia sp. es el cávido más frecuente, seguido por Orthomyctera sp., en tanto Neocavia cf. $N$. lozanoi es el cávido más pequeño en esta asociación, con el más bajo NEIT (ver Tabla 3.8). Los especímenes que figuran en la Tabla 3.8 como cávidos indeterminados corresponden a fragmentos de dientes o porciones mandibulares o de paladar.

Entre los materiales asignados a la Familia Dinomyidae, se cuentan 2 especímenes de Tetrastylus sp., que constituyen los roedores de mayor masa corporal en esta asociación, ya que superaban los $5 \mathrm{~kg}$. Representantes de esta familia fueron hallados también en otros afloramientos de la Formación Cerro Azul (Tabla 3.10), pero el número de especímenes es siempre bajo y generalmente son muy fragmentarios. En la asociación de Caleufú, su frecuencia es muy baja.

\begin{tabular}{|l|c|c|c|}
\hline Localidad & NEIT & Dinomyidae & $\%$ \\
\hline TELÉN & 4.730 & 1 & 0,02 \\
\hline CALEUFÚ & 3.200 & 2 & 0,06 \\
\hline LAGUNA CHILLUÉ & 1.962 & 2 & 0,10 \\
\hline BAJO GIULIANI & 1.644 & 2 & 0,12 \\
\hline SALINAS G. DE HIDALGO & 1.111 & 3 & 0,27 \\
\hline CERRO DE LA BOTA & 370 & 5 & 1,35 \\
\hline LAGUNA GUATRACHÉ & 86 & 1 & 1,16 \\
\hline LOMA DE LOS GUANACOS & 126 & 2 & 1,59 \\
\hline CERRO EL CHANCHO & 40 & 1 & 2,50 \\
\hline
\end{tabular}

Tabla 3.10. Asociaciones faunísticas de la Formación Cerro Azul donde se han registrado especímenes asignados a la Familia Dinomyidae 
Los Chinchillidae están representados por 5 especímenes asignados a Lagostomus (Lagostomopsis) sp. El NEIT de este taxón es muy bajo en la asociación analizada. En la Tabla 3.11 se compara el porcentaje de especímenes asignados a Lagostomus (Lagostomopsis) sp. sobre el total de roedores, para algunas asociaciones.

\begin{tabular}{|l|c|c|c|}
\hline \multicolumn{1}{|c|}{ Localidad } & NEIT & $\begin{array}{c}\text { Lagostomus } \\
\text { (Lagostomopsis }\end{array}$ & \\
\hline CALEUFÚ & 3.200 & 5 & 0,16 \\
\hline PUESTO COLORADO & 489 & 7 & 1,43 \\
\hline TELÉN & 4.730 & 76 & 1,61 \\
\hline LAGUNA CHILLHUÉ & 1.962 & 68 & 3,47 \\
\hline BAJO GIULIANI & 1.644 & 59 & 3,59 \\
\hline BARRANCAS COLORADAS & 256 & 15 & 5,86 \\
\hline EL GUANACO & 300 & 44 & 14,67 \\
\hline
\end{tabular}

Tabla 3.11. Algunas de las asociaciones faunísticas de la Formación Cerro Azul donde se ha registrado Lagostomus (Lagostomopsis) sp.

La Familia Echimyidae está representada por un espécimen asignado a Pampamys emmonsae. La mayor frecuencia para esta especie se registra en la asociación de Laguna Chillhué (Tabla 3.12). En el resto de las asociaciones en las que está presente, su frecuencia es más baja, pero sólo en Caleufú es la única especie representante de esa familia.

\begin{tabular}{|l|c|c|c|}
\hline \multicolumn{1}{|c|}{ Localidad } & & $\begin{array}{c}\text { Pampamy } \\
\text { s } \\
\text { emmonsa } \\
e\end{array}$ & \\
\hline CALEUFÚ & 3.200 & 1 & 0,03 \\
\hline TELÉN & 4.730 & 4 & 0,08 \\
\hline SALINAS G. DE HIDALGO & 1.111 & 1 & 0,09 \\
\hline LOVENTUÉ & 647 & 2 & 0,31 \\
\hline BAJO GIULIANI & 1.644 & 6 & 0,36 \\
\hline PUESTO COLORADO & 489 & 2 & 0,41 \\
\hline LAGUNA CHILLHUÉ & 1.962 & 27 & 1,38 \\
\hline
\end{tabular}

Tabla 3.12. Asociaciones faunísticas de la Formación Cerro Azul donde se ha registrado Pampamys emmonsae 
EI NEIT de la Familia Octodontidae es de 323 especímenes. Cada una de las dos subfamilias, Ctenomyinae y Octodontinae, incluye en esta asociación a dos especies, y en cada una hay una especie frecuente. Entre los Ctenomyinae, Xenodontomys elongatus es la de mayor NEIT (ver Tabla 3.8), además de ser la más frecuente entre los roedores. El género Xenodontomys está presente en los afloramientos de la Formación Cerro Azul de El Guanaco y Barrancas Coloradas, con la especie $X$. simpsoni. En ambos afloramientos, el porcentaje de restos asignados a esa especie es bajo en el contexto del NEIT de cada asociación (Tabla 3.13) y, además, en la asociación de El Guanaco X. simpsoni es el único octodóntido presente.

\begin{tabular}{|l|c|c|c|}
\hline Localidad & NEIT & Xenodontomys & $\%$ \\
\hline BARRANCAS COLORADAS & 256 & 9 & 3,51 \\
\hline EL GUANACO & 300 & 13 & 4,33 \\
\hline CALEUFÚ & 3.200 & 244 & 7,62 \\
\hline
\end{tabular}

Tabla 3.13. Asociaciones faunísticas de la Formación Cerro Azul donde se ha registrado Xenodontomys

Neophanomys sp. es el otro Ctenomyinae presente en esta asociación. Los nuevos especímenes tienen caracteres derivados con respecto a Neophanomys biplicatus, especie hallada en las asociaciones de Bajo Giuliani, Quehué y Estancia Don Mariano. Considerada a nivel genérico, su representatividad es baja para todas las asociaciones faunísticas (Tabla 3.14).

\begin{tabular}{|l|c|c|c|}
\hline Localidad & NEIT & Neophanomys & $\%$ \\
\hline QUEHUÉ & 2.114 & 1 & 0,05 \\
\hline BAJO GIULIANI & 1.644 & 3 & 0,18 \\
\hline CALEUFÚ & 3.200 & 7 & 0,22 \\
\hline ESTANCIA DON MARIANO & 81 & 1 & 1,23 \\
\hline
\end{tabular}

Tabla 3.14. Asociaciones faunísticas de la Formación Cerro Azul donde se ha registrado Neophanomys 
El otro roedor octodóntido frecuente es un representante de la Subfamilia Octodontinae (ver Tabla 3.8) con molariformes euhipsodontes.

Al octodontino Phtoramys aff. $P$. homogenidens se asignaron 6 especímenes. Representantes del género Phtoramys fueron hallados en Salinas Grandes de Hidalgo, Quehué, Laguna Chillhué, Bajo Giuliani y Barrancas Coloradas. En la primera localidad se registró Phtoramys hidalguense.

Como ya se indicó en la Tabla 3.4 al Orden Notoungulata se asignaron 770 especímenes que constituyen el $24,06 \%$ del NEIT total en la asociación. En la Tabla 3.15 se indica el NEIT de los diferentes taxa asignados en este orden.

\begin{tabular}{|l|r|}
\hline & NEIT \\
\hline Paedotherium minor & 737 \\
\hline Pseudotypotherium subinsigne & 1 \\
\hline Mesotheriinae indet. & 9 \\
\hline Toxodontidae indet. & 2 \\
\hline Notoungulata indet. & 23 \\
\hline TOTAL & 770 \\
\hline
\end{tabular}

Tabla 3.15. NEIT de notoungulados presentes en la asociación faunística de Caleufú

En las asociaciones faunísticas de la Formación Cerro Azul, los representantes de la Familia Hegetotheriidae (Hegetotheriinae y Packyrukhinae) son siempre abundantes; pero su abundancia está dada por los representantes de la Subfamilia Packyrukhinae (Tabla 3.16). La Subfamilia Hegetotheriinae está representada por Hemihegetotherium achataleptum, registrada, hasta el momento, en 10 afloramientos de esta formación con 31 especímenes, lo que indica una frecuencia muy baja (Cerdeño y Montalvo, 2002). Esta especie no se ha registrado en la asociación de Caleufú. Los Packyrukhinae están representados fundamentalmente por Paedotherium minor. Este taxón es el más frecuente en la asociación de Caleufú (NEIT=737). Ya fue indicado que es uno de los mamíferos de hallazgo más frecuente en el Neógeno de la región pampeana (Bond et al., 1995). 


\begin{tabular}{|l|r|c|c|}
\hline & NEIT & Hegetotheriidae & $\%$ \\
\hline PUESTO COLORADO & 489 & 40 & 8,18 \\
\hline TELÉN & 4.730 & 532 & 11,25 \\
\hline LAGUNA CHILLHUÉ & 1.962 & 267 & 13,61 \\
\hline ESTANCIA DON MARIANO & 81 & 14 & 17,28 \\
\hline BARRANCAS COLORADAS & 256 & 49 & 19,14 \\
\hline CALEUFÚ & 3.200 & 737 & 23,03 \\
\hline EL GUANACO & 300 & 79 & 26,33 \\
\hline
\end{tabular}

Tabla 3.16. Algunas de las asociaciones faunísticas de la Formación Cerro Azul donde se han registrado representantes de la Familia Hegetotheriidae

EI NEIT para la Familia Mesotheriidae es de 10 especímenes en Caleufú. Representantes de esta familia se han registrado en 16 localidades donde aflora la Formación Cerro Azul (Tabla 3.17).

\begin{tabular}{|l|r|c|r|}
\hline & NEIT & Mesotheriidae & $\%$ \\
\hline PUESTO COLORADO & 489 & 1 & 0,20 \\
\hline QUEHUÉ & 2.114 & 6 & 0,28 \\
\hline CALEUFÚ & 3.200 & 10 & 0,31 \\
\hline BAJO GIULIANI & 1.644 & 6 & 0,36 \\
\hline TELÉN & 4.730 & 26 & 0,55 \\
\hline SALINAS G. DE HIDALGO & 1.111 & 13 & 1,17 \\
\hline LAGUNA CHILLHUÉ & 1.962 & 41 & 2,09 \\
\hline CERRO DE LA BOTA & 370 & 8 & 2,16 \\
\hline LOVENTUÉ & 647 & 15 & 2,32 \\
\hline LOMA DE LOS GUANACOS & 126 & 51 & 40,48 \\
\hline
\end{tabular}

Tabla 3.17. Algunas de las asociaciones faunísticas de la Formación Cerro Azul donde se han registrado representantes de la Familia Mesotheriidae

La frecuencia de hallazgos de mesotéridos es muy alta sólo en Loma de los Guanacos; sin embargo, en esta localidad el porcentaje está, seguramente, sobredimensionado debido al bajo NEIT total en esa asociación (126 restos).

A la Familia Toxodontidae se asignaron 2 fragmentos de dientes, que debido a su mala preservación no permiten una asignación sistemática más precisa. Este problema afecta a los restos asignados a esta familia en todos los 
afloramientos de la Formación Cerro Azul y su frecuencia de hallazgo es siempre muy baja.

Finalmente, al Orden Notoungulata se asignaron 23 fragmentos de dientes que, por su grado de fragmentación, no pueden ser asignados taxonómicamente más que hasta ese nivel.

El Orden Litopterna está representado por 10 especímenes, que corresponden a la Familia Proterotheriidae. La representatividad de este orden es muy baja en los afloramientos de la Formación Cerro Azul (Tabla 3.18).

\begin{tabular}{|l|r|c|c|}
\hline & NEIT & Litopterna & $\%$ \\
\hline PUESTO COLORADO & 489 & 1 & 0,20 \\
\hline TELÉN & 4.730 & 11 & 0,23 \\
\hline BAJO GIULIANI & 1.644 & 4 & 0,24 \\
\hline CALEUFÚ & 3.200 & 10 & 0,31 \\
\hline EL GUANACO & 300 & 1 & 0,33 \\
\hline LAGUNA CHILLHUÉ & 1.962 & 9 & 0,46 \\
\hline
\end{tabular}

Tabla 3.18. Algunas de las asociaciones faunísticas de la Formación Cerro Azul donde se han registrado representantes del Orden Litopterna

El Orden Carnivora está representado en Caleufú por dos especímenes. Hasta el momento en la Formación Cerro Azul se había registrado la Familia Procyonidae, en afloramientos de Salinas Grandes de Hidalgo, Quehué y Telén. Los materiales de Caleufú presentan muy pocos caracteres diagnósticos, pero suficientes como para sugerir que no corresponderían a representantes de la Familia Procyonidae, la única presente hasta el momento en niveles de la Formación Cerro Azul.

Cálculo del número mínimo de elementos esqueléticos (NME) y número mínimo de individuos (NMI)

A efectos de realizar el análisis de la asociación de Caleufú, se calcularon los índices NME y NMI.

Los representantes acorazados del Orden Xenarthra fueron identificados taxonómicamente sobre la base de las placas de la coraza, elementos que se 
encuentran en general aislados y con un alto grado de meteorización, de modo tal que se han borrado caracteres diagnósticos. El número total de placas recuperadas y, en particular, el de identificadas fue bajo. Para la obtención de los NME y NMI se utilizó el criterio de presencia de taxa, dando a cada taxón el valor arbitrario de 1 para ambos índices, de modo tal que las pocas placas identificadas para cada taxón fueron consideradas como integrantes de la coraza de un sólo individuo. En el caso de los Dasypodidae fueron identificados representantes de 9 taxa (a nivel genérico o específico), por lo que se le adjudicó un NME y un NMI de 9. El mismo camino se utilizó para obtener el NME y NMI de los Glyptodontidae indeterminados. Para calcular estos índices en los xenartros Mylodontidae se utilizaron los molariformes.

El NME total para el resto de los taxa (incluyendo los pequeños reptiles) comprende el total de hemimandíbulas, maxilares y dientes aislados, excepto para las aves que se basó en elementos postcraneanos.

Para los roedores indeterminables, el NME fue evaluado como en los otros taxa (basado en las porciones de hemimandíbulas, maxilares y dientes, en este caso incisivos aislados). Ya que los elementos esqueléticos mencionados son muy fragmentarios se consideró que pueden haber formado parte de piezas registradas entre los grupos de roedores con mayor ajuste sistemático y se optó por no contabilizar el NMI para los roedores indeterminables.

En el caso de los dientes aislados, el NME incluye el total de dientes encontrados aislados, excluyendo los incisivos de roedores que se contabilizan aparte. Estos corresponden a todas las piezas de Paedotherium minor (144 dientes) y los molariformes de los roedores caviomorfos Xenodontomys elongatus, Octodontinae indet. y Caviidae indet. (134 dientes). Además, se incluyó a los dientes aislados que fueron utilizados como elementos diagnósticos para otros taxa.

Bajo el ítem elementos del cráneo se incluyen las porciones de zonas occipitales, bulas timpánicas y fragmentos de la bóveda craneana recuperados aislados. 
El NME para toda la asociación es de 1.733 especímenes. En la Tabla 3.19 se compara el total de restos (NR) recuperados por cada categoría esquelética y el NME asignado a esa categoría.

\begin{tabular}{|l|c|c|}
\hline ELEMENTO & NR & NME \\
\hline Elementos del cráneo & 55 & 34 \\
\hline Maxilares & 436 & 261 \\
\hline Hemimandíbulas & 893 & 439 \\
\hline Dientes aislados & 324 & 286 \\
\hline Incisivos & 78 & 78 \\
\hline Vértebras & 128 & 128 \\
\hline Costillas & 23 & 9 \\
\hline Escápulas & 26 & 12 \\
\hline Húmeros & 51 & 23 \\
\hline Ulnas & 63 & 32 \\
\hline Radios & 22 & 14 \\
\hline Innominados & 45 & 23 \\
\hline Fémures & 149 & 70 \\
\hline Tibias & 67 & 49 \\
\hline Calcáneos & 69 & 69 \\
\hline Astrágalos & 25 & 25 \\
\hline Metápodos & 212 & 112 \\
\hline Basipodios & 43 & 43 \\
\hline Falanges & 16 & 16 \\
\hline Placas & 475 & \\
\hline Corazas & & 10 \\
\hline TOTAL & 3.200 & 1.733 \\
\hline
\end{tabular}

Tabla 3.19. NR y NME de la asociación de Caleufú

El NME total de especímenes craneanos es de 1.098, con mayor proporción de hemimandíbulas, maxilares y dientes aislados (Figura 3.3), en tanto para los elementos postcraneanos el NME es 635, incluyendo los restos asignados a aves y reptiles (Figura 3.4). 


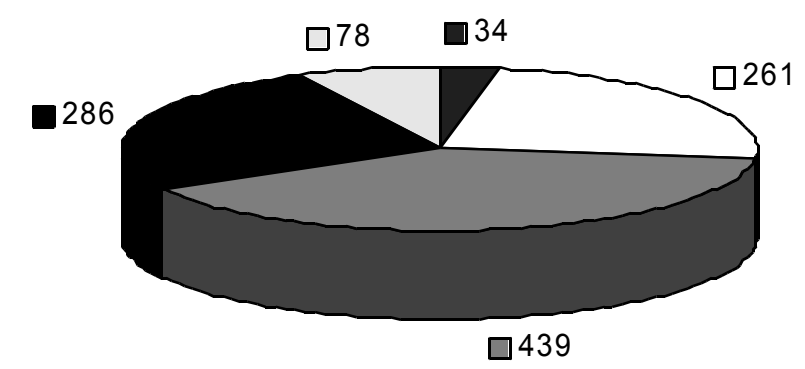

\begin{tabular}{|ll|}
\hline$\square$ elementos del cráneo & $\square$ paladares \\
$\square$ mandíbulas & $\square$ dientes aislados \\
$\square$ incisivos & \\
\hline
\end{tabular}

Figura 3.3. NME craneanos, mandibulares y dentarios

Esta distribución del NME, indica una escasez de elementos postcraneanos en la asociación, con valores relativamente altos para vértebras y metápodos.

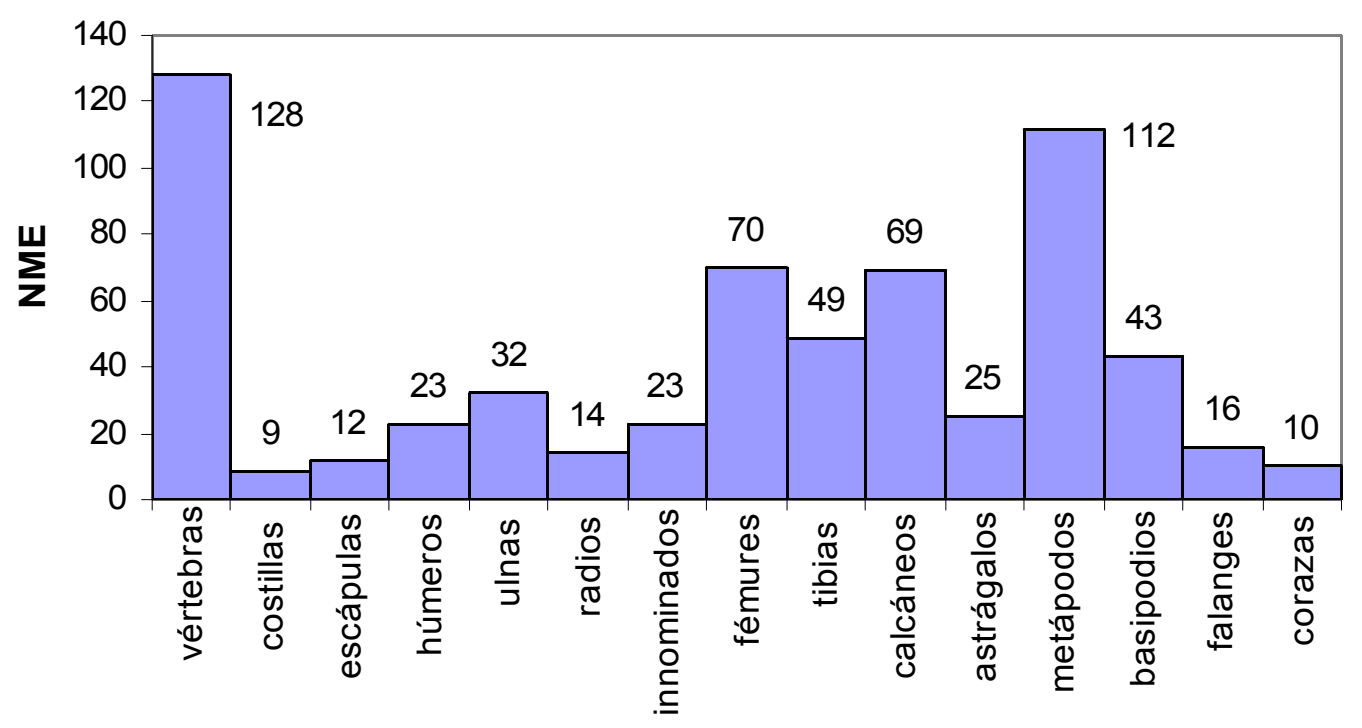

Figura 3.4. Distribución del NME postcraneanos

En la Figura 3.5 se comparan el NEIT y el NME para cada grupo de vertebrados presente. Los valores que muestran un rango mayor corresponden a Xenarthra, pero en ese caso debe recordarse que para obtener el NEIT se contabilizaron placas de la coraza, mientras que el NME es un valor estimado de 
corazas. En los casos de los órdenes Rodentia y Notoungulata y del material postcraneano asignado a Mammalia indet., la diferencia en ambos valores puede deberse al grado de fragmentación que han sufrido los elementos esqueléticos de estos grupos.

El valor obtenido en la Figura 3.5 para el NME de Mammalia indet. (644) surge de sumar los elementos postcraneanos de mamíferos (620 especímenes), del que se excluyeron los 10 elementos asignados a Xenarthra, más los elementos del cráneo indeterminados $(\mathrm{NME}=34)$.

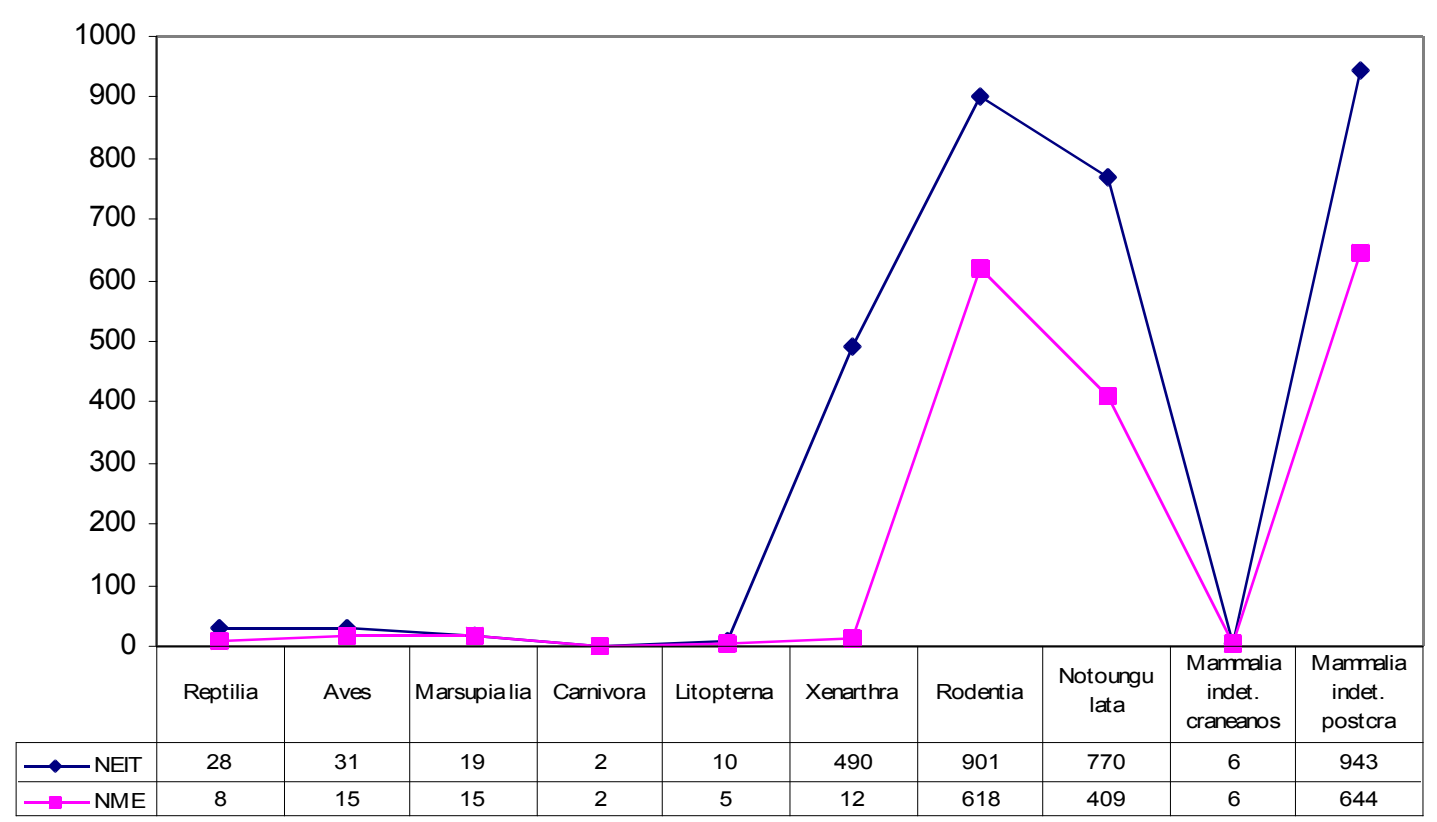

Figura 3.5. Comparación de los valores de NEIT y NME para los diferentes grupos de vertebrados presentes en la asociación de Caleufú

Excluyendo los elementos postcraneanos asignados a Mammalia indet., el NME calculado para los taxa presentes en la asociación asciende a 1.089 especímenes (Tabla 3.20). En esa tabla se indica también el valor del NMI para cada taxón. Para el caso de las aves el elemento esquelético utilizado para estimar el NMI fue el fémur, en tanto para los reptiles se utilizaron los maxilares. Ya se mencionó que para los Xenarthra acorazados se optó por asignar el valor de 1 para cada taxón presente. Los dientes fueron utilizados para el cálculo del 


\begin{tabular}{|l|c|c|}
\hline & NME & NMI \\
\hline Teiidae & 7 & 4 \\
\hline Colubridae & 1 & 1 \\
\hline Aves & 15 & 4 \\
\hline Marmosinae indet. & 1 & 1 \\
\hline Didelphinae indet. & 5 & 3 \\
\hline Hyperdidelphys sp. & 2 & 2 \\
\hline Sparassocynus sp. & 2 & 2 \\
\hline Argyrolagus sp. & 5 & 2 \\
\hline Macroeuphractus sp. & 1 & 1 \\
\hline Macroeuphractus morenoi & 1 & 1 \\
\hline Proeuphractus sp. & 1 & 1 \\
\hline Chorobates villosissimus & 1 & 1 \\
\hline Chasicotatus sp. & 1 & 1 \\
\hline Chasicotatus ameghinoi & 1 & 1 \\
\hline Doellotatus inornatus & 1 & 1 \\
\hline Doellotatus chapadmalensis & 1 & 1 \\
\hline Ringueletia simpsoni & 1 & 1 \\
\hline Glyptodontidae indet. & 1 & 1 \\
\hline Mylodontidae indet. & 1 & 1 \\
\hline Neocavia cf. N. lozanoi & 21 & 10 \\
\hline Orthomyctera sp. & 47 & 24 \\
\hline Palaeocavia sp. & 102 & 45 \\
\hline Caviidae indet. & 63 & 0 \\
\hline Tetrastylus sp. & 2 & 2 \\
\hline Lagostomus (Lagostomopsis) sp. & 2 & 2 \\
\hline Sigmodontinae gen. et sp. nov. & 2 & 2 \\
\hline Phtoramys aff. P. homogenidens & 6 & 4 \\
\hline Pampamys emmonsae & 1 & 1 \\
\hline Octodontinae indet. & 44 & 20 \\
\hline Neophanomys sp. & 7 & 7 \\
\hline Xenodontomys elongatus & 202 & 54 \\
\hline Rodentia indet. & 119 & 0 \\
\hline Paedotherium minor & 393 & 96 \\
\hline Pseudotypotherium subinsigne & 1 & 1 \\
\hline Mesotheriinae indet. & 6 & 2 \\
\hline Toxodontidae indet. & 2 & 1 \\
\hline Notoungulata indet. & 7 & 4 \\
\hline Proterotheriidae indet. & 5 & 3 \\
\hline Carnivora indet. & 2 & 1 \\
\hline Mammalia indet. & 6 & 6 \\
\hline TOTAL & & 315 \\
\hline
\end{tabular}

Tabla 3.20. NME y NMI de los taxa presentes en la asociación faunística de Caleufú. No se contabilizó el NMI para Rodentia indet. y Caviidae indet. ya que se consideró que pueden haber sido contados con alguno de los taxa determinados

NMI en el resto de los taxa, y dado que las hemimandíbulas son los elementos esqueléticos más comunes, en la mayoría de los taxa de mamíferos se utilizó el 
m1 (eligiendo izquierdo o derecho según el caso). Se tuvo particularmente en cuenta, por otro lado, la edad del individuo productor del resto, es decir si el elemento conservado provenía de un individuo muy joven, joven o adulto (ver Materiales y métodos). Se observa en la Tabla 3.20 que la asociación faunística de Caleufú está compuesta, al menos, por 36 taxa y 315 individuos, con una marcada preponderancia de tres especies: Paedotherium minor, Xenodontomys elongatus y Palaeocavia sp., que son las que tienen NMI más alto.

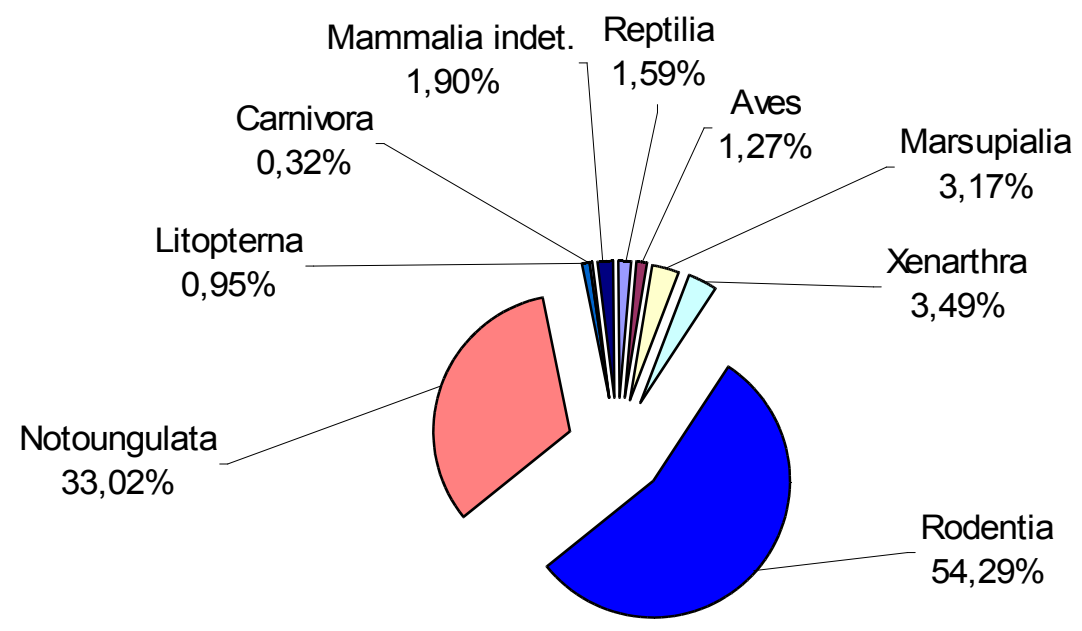

Figura 3.6. Porcentaje de grupos de vertebrados presentes en Caleufú calculado sobre la base del NMI

La representatividad de cada grupo de vertebrados presente en esta asociación se muestra en la Figura 3.6. En esta figura se puede observar que el mayor porcentaje de individuos corresponde al Orden Rodentia, con un NMI=171. Éste es también el orden que muestra mayor diversidad taxonómica, ya que hay al menos 11 taxa. Las especies más abundantes de este orden son Xenodontomys elongatus (NMl=54), Palaeocavia sp. (NMl=45), Orthomyctera sp. $(\mathrm{NMI}=24)$, Octodontinae indet. $(\mathrm{NMI}=20)$ y Neocavia cf. $\mathrm{N}$. Iozanoi $(\mathrm{NMI}=10)$.

En el Orden Notoungulata el número de individuos es menor $(\mathrm{NMI}=104)$ y su diversidad taxonómica también, ya que está representado por al menos tres taxa, pero en este orden se encuentra la especie más abundante en esta asociación, Paedotherium minor (NMI=96).

De lo expuesto surge que, para los órdenes de mamíferos, el NMI mantiene proporciones similares a las obtenidas calculando el NEIT (ver Tabla 3.3). 
NMI y masa corporal estimada

Para interpretar cómo fue formada la concentración de elementos en esta asociación, y considerando que los restos correspondientes a microvertebrados pueden haber sido aportados por la actividad de depredadores, los especímenes fueron agrupados en dos categorías de acuerdo a su masa corporal estimada y al contexto general de preservación de cada tipo de elemento conservado.

Con el objeto de obtener la masa corporal estimada, el listado faunístico de la asociación de Caleufú fue confrontado con el de la asociación de Salinas Grandes de Hidalgo cuya fauna, de Edad mamífero Huayqueriense es similar a la analizada. A los integrantes de ese listado se les asignaron estimaciones de masa corporal, utilizando para ello el criterio de comparación aproximada con formas actuales de tamaño semejante (Vizcaíno y Fariña, 1999). En aquel trabajo se asignaron 4 categorías: (1) menos de 1 kg; (2) entre 1 y 10 kg; (3) entre 10 y 100 $\mathrm{kg}$ y (4) más de $100 \mathrm{~kg}$.

En este caso, y dadas las características de la asociación de Caleufú, se organizó el listado utilizando solamente dos categorías. La categoría I incluye los restos de individuos asignados a Reptilia, Aves, Mammalia indet., Marsupialia, Rodentia (excepto Dinomyidae), Hegetotheriidae y Carnivora indet. cuya masa corporal estimada es menor a $5 \mathrm{~kg}$. La categoría II agrupa los restos de individuos de más de $5 \mathrm{~kg}$ de masa corporal estimada, incluyendo a todos los especímenes de Xenarthra, Rodentia de la Familia Dinomyidae, Notoungulata (excepto Paedotherium minor), Litopterna y Mammalia indet.

Se revisó el caso de Paedotherium minor, que fue ubicado por Vizcaíno y Fariña (1999) en la categoría 2 (entre 1 y $10 \mathrm{~kg}$ ). Una reciente estimación de las masas corporales de varios Pachyrukhinae indica que, para los taxa presentes al final del biocrón de este grupo, las masas estimadas no superaron $1 \mathrm{~kg}$ (Giallombardo et al., 2002). Se discutirá más adelante, además, que en la asociación de Caleufú este taxón está representado por un porcentaje elevado de individuos juveniles. Esto implica que un gran número de elementos conservados 
han sido producidos por individuos de masa corporal menor. De acuerdo a esto, fue incluido en la categoría I.

Con respecto a los restos craneanos asignados a Mammalia indet. ( $\mathrm{NME}=6$; $\mathrm{NMI}=6)$, para su ubicación en alguna de las dos categorías se utilizó directamente el criterio de "tamaño" del resto preservado, por comparación con mamíferos actuales.

Además de maxilares, hemimandíbulas y dientes aislados, en las dos categorías (I y II) se incluyeron los elementos esqueléticos postcraneanos que interesan a fin de realizar comparaciones de esta asociación con datos bibliográficos: escápulas, húmeros, radios, ulnas, innominados, fémures, tibias, vértebras, metapodos y falanges (Tablas 3.21 y 3.22). Los elementos esqueléticos que no fueron incluidos en esas tablas: elementos indeterminables del cráneo, costillas, calcáneos, astrágalos y basipodios, se muestran en la Tabla 3.23 y también fueron separados de acuerdo a las dos categorías.

La mayor proporción en los elementos conservados pertenecientes a la categoría I (grupo de los microvertebrados) corresponde a restos producidos por individuos que se encuentran muy por debajo de los $5 \mathrm{~kg}$ de masa corporal estimada, incluso por debajo de $1 \mathrm{~kg}$ de masa corporal estimada. Las tres especies abundantes, Paedotherium minor, Xenodontomys elongatus y Palaeocavia sp. no superan el kg.

Los valores correspondientes al NMI y NME fueron agrupados de acuerdo a esas 2 categorías (Tablas 3.21 y 3.22 ). 


\begin{tabular}{|c|c|c|c|c|}
\hline & 芯 - & $\dot{\vec{ர}}$ & & \\
\hline Reptilia & 5 & 8 & & \\
\hline Aves & 4 & 15 & & \\
\hline Mammalia indet. & 4 & 4 & & \\
\hline Marmosinae indet. & 1 & 1 & & \\
\hline Didelphinae indet. & 3 & 5 & & \\
\hline Hyperdidelphys sp. & 2 & 2 & & \\
\hline Sparassocynus sp. & 2 & 2 & & \\
\hline Argyrolagus sp. & 2 & 5 & & \\
\hline Neocavia cf. N. Iozanoi & 10 & 21 & & \\
\hline Orthomyctera sp. & 24 & 47 & \multirow{3}{*}{\multicolumn{2}{|c|}{ NME Cat. I }} \\
\hline Palaeocavia sp. & 45 & 102 & & \\
\hline Caviidae indet. & 0 & 63 & & \\
\hline Lagostomus (Lagostomopsis) sp. & 2 & 2 & escápulas & 11 \\
\hline Sigmodontinae gen. et sp. nov. & 2 & 2 & húmeros & 22 \\
\hline Phtoramys aff. P. homogenidens & 4 & 6 & radios & 12 \\
\hline Pampamys emmonsae & 1 & 1 & \begin{tabular}{|l|} 
ulnas \\
\end{tabular} & 31 \\
\hline Octodontinae indet. & 20 & 44 & innominados & 21 \\
\hline Neophanomys sp. & 7 & 7 & fémures & 63 \\
\hline Xenodontomys elongatus & 54 & 202 & tibias & 44 \\
\hline Rodentia indet. & 0 & 119 & vértebras & 114 \\
\hline Paedotherium minor & 96 & 393 & metápodos & 92 \\
\hline Carnivora indet. & 1 & 2 & falanges & 13 \\
\hline TOTAL & 289 & 1.053 & TOTAL & 423 \\
\hline
\end{tabular}

Tabla 3.21. NME total para microvertebrados

\begin{tabular}{|c|c|c|c|c|}
\hline & $\sum_{\Sigma}=$ & $\sum_{=}^{W}$ & & \\
\hline Macroeuphractus sp. & 1 & 1 & & \\
\hline Macroeuphractus morenoi & 1 & 1 & & \\
\hline Proeuphractus sp. & 1 & 1 & & \\
\hline Chorobates villosissimus & 1 & 1 & & \\
\hline Chasicotatus sp. & 1 & 1 & & \\
\hline Chasicotatus ameghinoi & 1 & 1 & & \\
\hline Doellotatus inornatus & 1 & 1 & & \\
\hline Doellotatus chapadmalensis & 1 & 1 & \multicolumn{2}{|c|}{ NME Cat. II } \\
\hline Ringueletia simpsoni & 1 & 1 & escápulas & 1 \\
\hline Glyptodontidae indet. & 1 & 1 & húmeros & 1 \\
\hline Mylodontidae indet. & 1 & 1 & radios & 2 \\
\hline Tetrastylus sp. & 2 & 2 & ulnas & 1 \\
\hline Pseudotypotherium subinsigne & 1 & 1 & innominados & 1 \\
\hline Mesotheriinae indet. & 2 & 6 & fémures & 7 \\
\hline Toxodontidae indet. & 1 & 2 & tibias & 5 \\
\hline Notoungulata indet. & 4 & 7 & vértebras & 12 \\
\hline Proterotheriidae indet.. & 3 & 5 & metápodos & 8 \\
\hline Mammalia indet. & 2 & 2 & falanges & 3 \\
\hline \begin{tabular}{|r|} 
TOTAL \\
\end{tabular} & 26 & 36 & TOTAL & 41 \\
\hline
\end{tabular}

Tabla 3.22. NME total para mamíferos de masa corporal estimada mayor a $5 \mathrm{~kg}$ 


\begin{tabular}{|c|c|c|c|}
\hline & $\sum_{\sum}^{\omega} \frac{5}{\tilde{\pi}}$ & $\sum_{\sum} \underset{N}{\mathbb{N}}$ & $\sum_{z}$ \\
\hline Elementos del cráneo & 34 & & 34 \\
\hline Costillas & 6 & 3 & 9 \\
\hline Calcáneos & 69 & & 69 \\
\hline Astrágalos & 25 & & 25 \\
\hline Basipodios & 37 & 6 & 43 \\
\hline Total & 171 & 9 & 180 \\
\hline
\end{tabular}

Tabla 3.23. NME de otros elementos esqueléticos

El NMI en la categoría I (microvertebrados) es de 289 individuos y 26 para mamíferos de la categoría II. EI NME total de la categoría I es 1.647 especímenes y de 86 especímenes para los representantes de la categoría II.

Diversidad y abundancia relativa de los componentes anatómicos representados en la asociación y en cada taxón

En la Figura 3.7 se indica la distribución de los elementos esqueléticos (hemimandíbulas, maxilares, dientes aislados y elementos del postcráneo) de acuerdo al NME de cada tipo de elementos en la asociación (NME total=1.733).

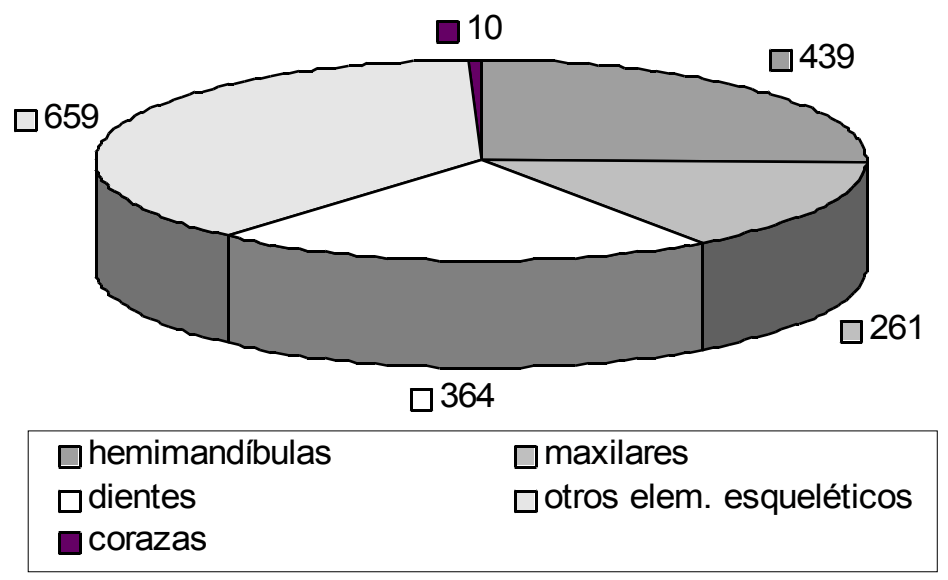

Figura 3.7. Distribución de los elementos esqueléticos (NME) 
Como se indicó más arriba, los diferentes taxa de mamíferos identificados en la asociación fueron reconocidos fundamentalmente a través de los dientes, excepto en el caso de los xenartros acorazados.

Los elementos postcraneanos sólo se identificaron hasta el nivel de clase. Las proporciones de elementos craneanos recuperados se indican en la Figura 3.8.

Se observa en esa figura que para la mayoría de los taxa, los elementos esqueléticos representados con un alto porcentaje son las hemimandíbulas, y hay 10 taxa representados exclusivamente por ellas. Sólo un taxón está representado por un maxilar.

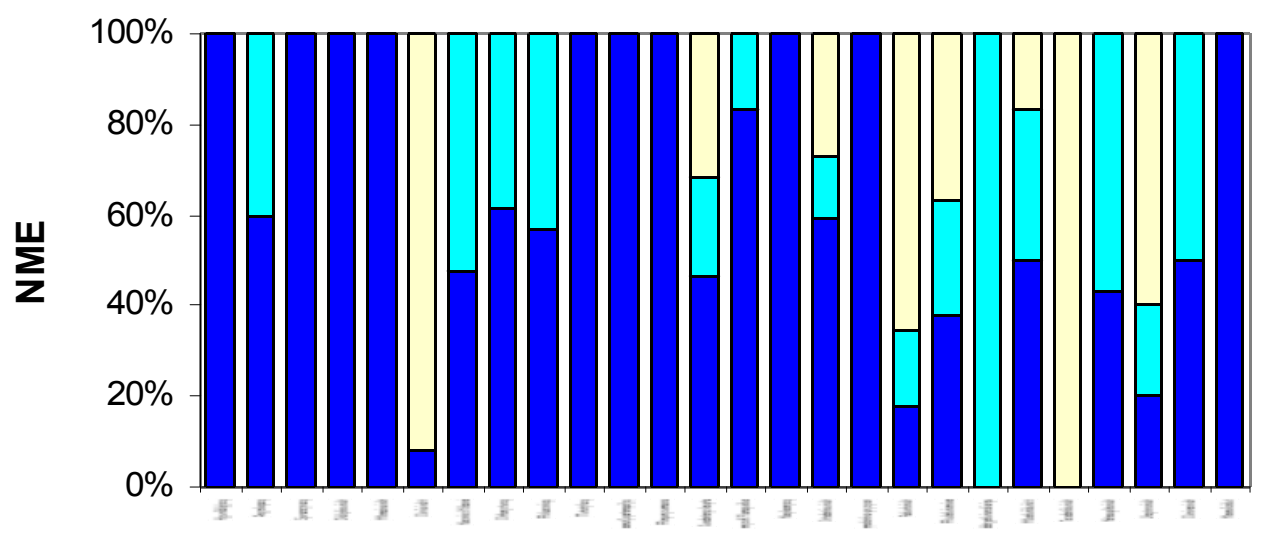

\section{$\square$ hemimandíbulas $\square$ maxilares $\square$ dientes}

Figura 3.8. Proporciones de los elementos esqueléticos craneanos, mandibulares y dentarios recuperados

Una vez obtenido el NME de la asociación (1.733 especímenes), se calculó la abundancia relativa de cada elemento esquelético por taxón sobre la base del NME calculado para cada uno.

Los cálculos fueron realizados exclusivamente para mamíferos (NME= 1.056); no se consideraron los especímenes asignados sólo hasta el nivel de Clase: elementos postcraneanos asignados a Mammalia indet. (NME=644), 
reptiles y aves $(\mathrm{NME}=23)$. Tampoco se consideró el valor asignado a las corazas de Xenarthra (NME=10).

En primer lugar, se evaluó qué representatividad tiene cada elemento esquelético conservado en el marco del número mínimo de individuos de ese grupo

NMEi / (EixNMI) x100

donde NMEi es el número mínimo de elementos esqueléticos particulares y Ei es el número esperado de ese elemento esquelético en un individuo.

Para los marsupiales $(\mathrm{NMI}=10)$ la abundancia relativa de cada elemento esquelético se muestra en la Tabla 3.24. EI NME total para este grupo es de 15 especímenes.

\begin{tabular}{|l|c|c|c|c|}
\hline & & & & \\
& $\sum$ & $\sum$ & $\bar{\Sigma}$ & ๙ \\
\hline Hyperdidelphys sp. Hemimandíbulas & 2 & 2 & 2 & 50,00 \\
\hline Argyrolagus sp. Hemimandíbulas & 3 & 2 & 2 & 75,00 \\
\hline Argyrolagus sp. Maxilares & 2 & & 2 & 50,00 \\
\hline Sparassocynus sp. Hemimandíbulas & 2 & 2 & 2 & 50,00 \\
\hline Didelphinae indet. Hemimandíbulas & 5 & 3 & 2 & 83,33 \\
\hline Marmosinae indet. Hemimandíbulas & 1 & 1 & 2 & 50,00 \\
\hline
\end{tabular}

Tabla 3.24. Abundancia relativa de los elementos esqueléticos en Marsupiales

Para los Xenarthra, la abundancia relativa fue calculada sólo para los elementos asignados a Mylodontidae (Tabla 3.25), cuyo NME es de 1 espécimen (dientes).

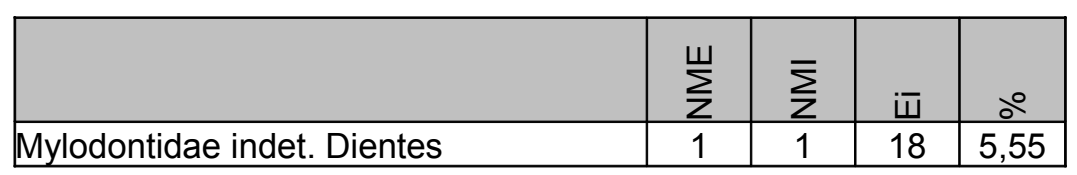

Tabla 3.25. Abundancia relativa de los elementos esqueléticos en Mylodontidae 
El Orden Notoungulata tiene un NMI asignado de 104 individuos y un NME total de 409 especímenes. La abundancia relativa de cada elemento esquelético considerado se muestra en la Tabla 3.26 .

\begin{tabular}{|c|c|c|c|c|}
\hline & $\sum_{\Sigma}^{W}$ & $\sum_{\Sigma}$ & iَ & $0^{\circ}$ \\
\hline Paedotherium minor Hemimandíbulas & 148 & \multirow{3}{*}{96} & 2 & 77,08 \\
\hline Paedotherium minor Maxilares & 101 & & 2 & 52,60 \\
\hline Paedotherium minor Dientes & 144 & & 30 & 5,00 \\
\hline Pseudotypotherium subinsigne Maxilar & 1 & 1 & 2 & 50,00 \\
\hline Mesotheriidae indet. Hemimandíbulas & 3 & \multirow{3}{*}{2} & 2 & 75,00 \\
\hline Mesotheriidae indet. Maxilares & 2 & & 2 & 50,00 \\
\hline Mesotheriidae indet. Dientes & 1 & & 24 & 2,08 \\
\hline Toxodontidae indet. Dientes & 2 & 1 & 30 & 6,67 \\
\hline Notoungulata indet. Hemimandíbulas & 3 & \multirow{2}{*}{4} & 2 & 37,50 \\
\hline Notoungulata indet. Maxilares & 4 & & 2 & 50,00 \\
\hline
\end{tabular}

Tabla 3.26. Abundancia relativa de los elementos esqueléticos en notoungulados

En el Orden Rodentia se contabilizó un NME total de 618 especímenes. La frecuencia relativa de cada elemento asignado a este orden cuyo NMI es de 171 individuos, se muestra en la Tabla 3.27.

En el caso de Caviidae indet., el NMI que se consideró es el total para los taxa identificados de esta familia ( $\mathrm{NMI}=79$ ); para los especímenes asignados a Rodentia indet., el NMI considerado es el total del orden (NMI=171). 
Paleobiología de la asociación faunística de Caleufú (La Pampa, Formación Cerro Azul, Mioceno superior - Plioceno inferior), a través de análisis tafonómicos

\begin{tabular}{|l|l|l|l} 
¿ & $\sum$ & ¿ & ஃீ \\
\hline
\end{tabular}




\begin{tabular}{|c|c|c|c|c|}
\hline Caviidae indet. Hemimandíbulas & 5 & \multirow{2}{*}{79} & 2 & 3,16 \\
\hline Caviidae indet. Dientes & 58 & & 16 & 4,59 \\
\hline Neocavia cf. N. lozanoi Hemimandíbulas & 10 & \multirow[t]{2}{*}{10} & 2 & 50,00 \\
\hline Neocavia cf. N. Iozanoi Maxilares & 11 & & 2 & 45,45 \\
\hline Orthomyctera sp. Hemimandíbulas & 29 & \multirow[t]{2}{*}{24} & 2 & 60,42 \\
\hline Orthomyctera sp. Maxilares & 18 & & 2 & 37,50 \\
\hline Palaeocavia sp. Hemimandíbulas & 58 & \multirow[t]{2}{*}{45} & 2 & 64,44 \\
\hline Palaeocavia sp. Maxilares & 44 & & 2 & 48,89 \\
\hline Tetrastylus sp. Hemimandíbulas & 2 & 2 & 2 & 50,00 \\
\hline Lagostomus (Lagostomopsis) sp. Hemimandíbulas & 2 & 2 & 2 & 50,00 \\
\hline Pampamys emmonsae Hemimandíbula & 1 & 1 & 2 & 50,00 \\
\hline Xenodontomys elongatus Hemimandíbulas & 94 & \multirow{3}{*}{54} & 2 & 87,04 \\
\hline Xenodontomys elongatus Maxilares & 44 & & 2 & 40,74 \\
\hline Xenodontomys elongatus Dientes & 64 & & 16 & 7,41 \\
\hline Phtoramys aff. P. homogenidens Hemimandíbulas & 5 & \multirow[t]{2}{*}{4} & 2 & 62,50 \\
\hline Phtoramys aff. P. homogenidens Maxilares & 1 & & 2 & 12,50 \\
\hline Neophanomys sp. Hemimandíbulas & 7 & 7 & 2 & 50,00 \\
\hline Octodontinae indet. Hemimandíbulas & 26 & \multirow{3}{*}{20} & 2 & 65,00 \\
\hline Octodontinae indet. Maxilares & 6 & & 2 & 15,00 \\
\hline Octodontinae indet. Dientes & 12 & & 16 & 3,75 \\
\hline Sigmodontinae gen. et sp. nov. Hemimandíbulas & 2 & 2 & 2 & 50,00 \\
\hline Rodentia indet. Hemimandíbulas & 21 & \multirow{3}{*}{171} & 2 & 6,14 \\
\hline Rodentia indet. Maxilares & 20 & & 2 & 5,85 \\
\hline Rodentia indet. Incisivos & 78 & & 4 & 11,40 \\
\hline
\end{tabular}

Tabla 3.27. Abundancia relativa de los elementos esqueléticos en roedores

Los especímenes asignados al Orden Litopterna (Familia Proterotheriidae) ascienden a 5 y el NMI de este orden es de 3 individuos. En la Tabla 3.28 se muestra la abundancia relativa de cada elemento esquelético.

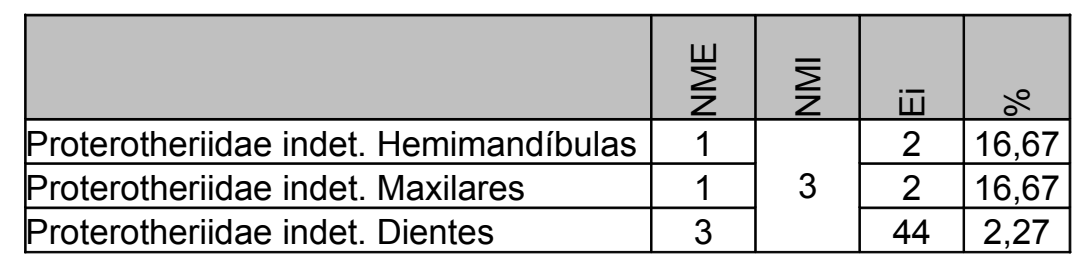

Tabla 3.28. Abundancia relativa de los elementos esqueléticos en litopternos

En cuanto a los representantes del Orden Carnivora, la abundancia relativa de sus elementos esqueléticos se muestra en la Tabla 3.29. 


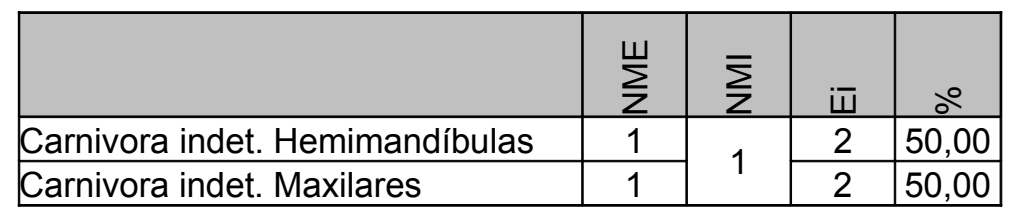

Tabla 3.29. Abundancia relativa de los elementos esqueléticos de Carnívora indet.

Finalmente se incluyen los especímenes que pudieron ser asignados sólo a nivel de clase. Se trata de 6 especímenes sobre los que se obtuvo un NMI de 6 individuos. Su abundancia relativa se indica en la Tabla 3.30.

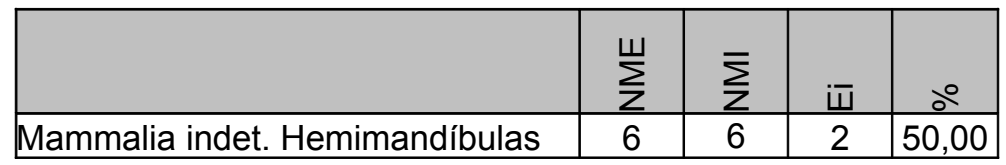

Tabla 3.30. Abundancia relativa de los elementos esqueléticos en Mammalia indet.

Los promedios de abundancia relativa de los elementos esqueléticos (basados en elementos craneanos) asignados a cada orden, se muestran en la Figura 3.9.

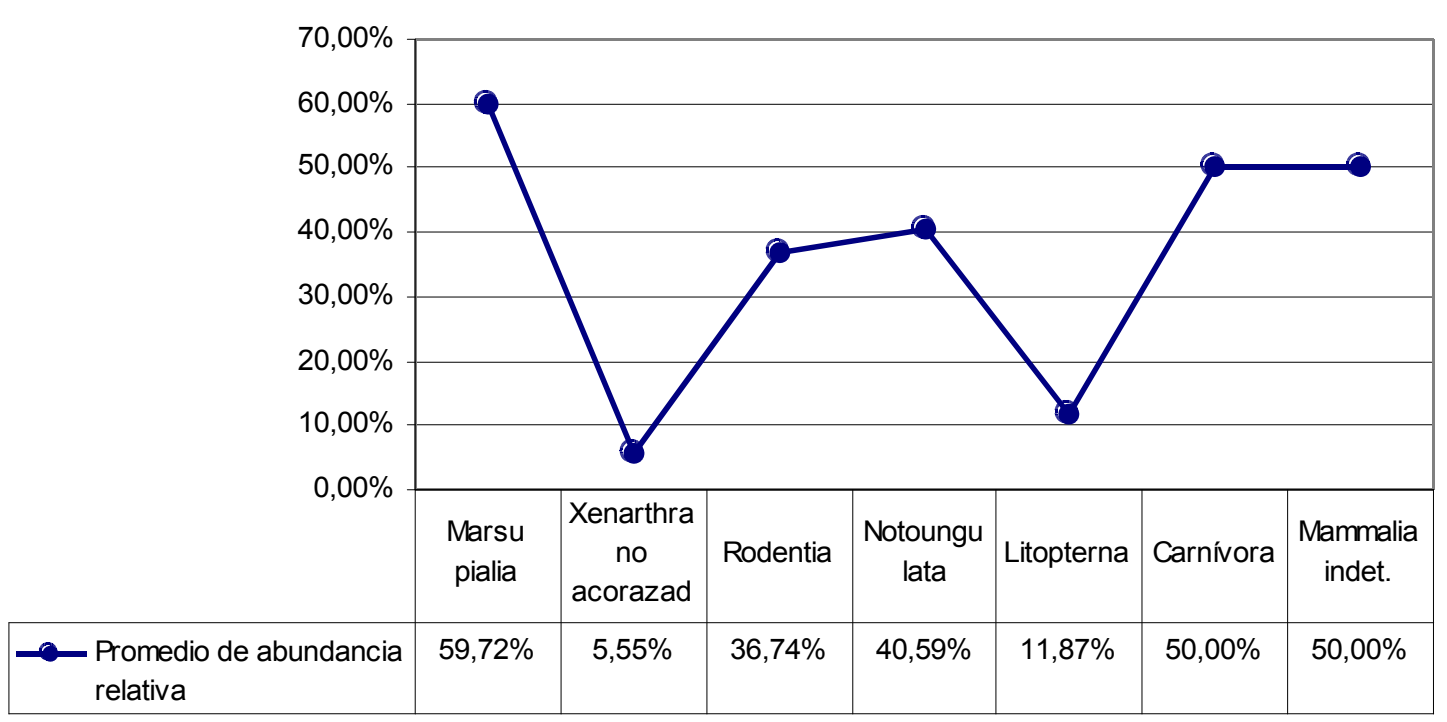

Figura 3.9. Promedio de abundancia relativa de los elementos esqueléticos recuperados de cada orden de mamíferos

En esa figura se observa que son los marsupiales los que presentan el promedio más alto de abundancia relativa de sus elementos esqueléticos. 
El promedio de abundancia relativa de los elementos esqueléticos de todos los taxa de mamíferos es de $36,35 \%$, valor que indica la escasa representatividad de elementos del esqueleto para cada uno de los taxa presentes.

\section{Análisis de la representación anatómica y taxonómica de los microvertebrados}

Se planteó que la acumulación de microvertebrados pudo haber sido producida por depredadores. A fin de evaluar esa hipótesis se tuvo en cuenta la posible selección de las presas realizada por el depredador, y para ello se analizó la información aportada por la representación taxonómica, la masa corporal estimada de los taxa representados, el espectro de edad de las presas y sus hábitos de vida. De acuerdo a lo propuesto por Andrews (1990) y Fernández Jalvo y Andrews (1992), se contrastó aquella hipótesis con los datos obtenidos de la abundancia relativa de elementos craneales y postcraneales.

- Representación taxonómica

Como se indicó antes, la asociación de microvertebrados de Caleufú está compuesta al menos por 20 taxa (ver Tabla 3.21), de los cuales sólo 6 están representados por 10 ó más individuos. En la Figura 3.10 se observa que Paedotherium minor es la especie más abundante, seguida por los roedores Xenodontomys elongatus y Palaeocavia sp.

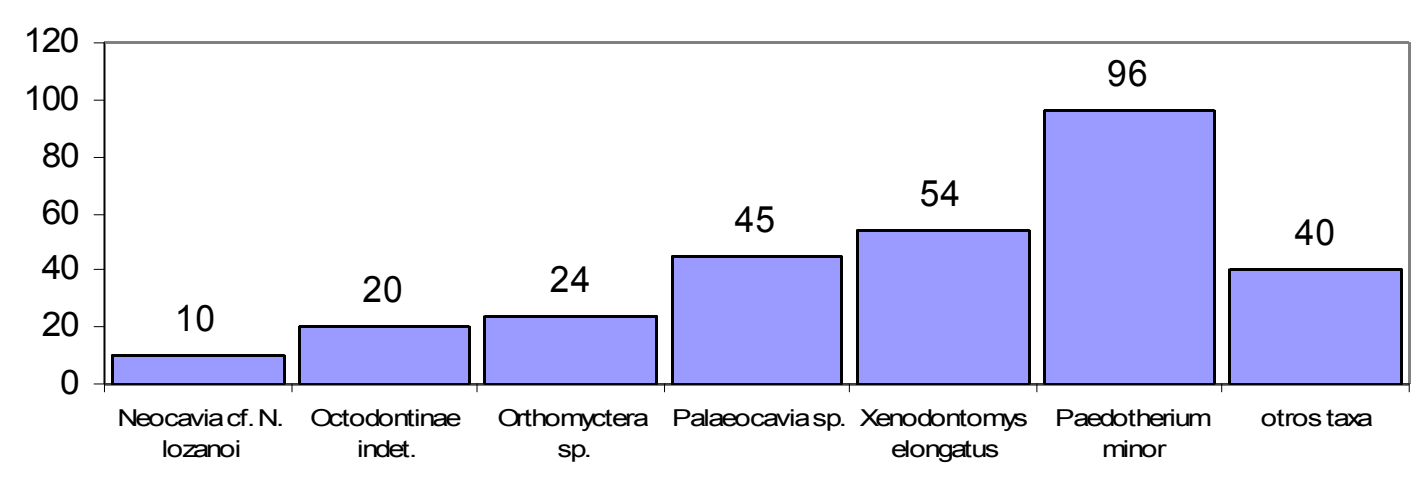

Figura 3.10. NMI de los taxa más frecuentes en la asociación de microvertebrados

- Espectro de edad 
Los especímenes de la asociación de micromamíferos fueron agrupados de acuerdo a la edad estimada del organismo productor. Las clases de edad establecidas son muy jóvenes, juveniles y adultos. El grupo de los muy jóvenes incluye solamente a especímenes que presentan dientes de leche o dientes emergentes. Este grupo y el de los juveniles fueron identificados por el grado de osificación de cada elemento esquelético, ya que ambos se caracterizan por presentar áreas donde aún son evidentes las trabéculas óseas (Montalvo, 2002). En los dos casos la observación del espécimen a simple vista o bajo lupa binocular muestra la superficie ósea con zonas formadas principalmente por un reticulado esponjoso que corresponde a las trabéculas óseas que se entrecruzan en diferentes direcciones. En los especímenes correspondientes a individuos muy jóvenes, grandes áreas de la superficie ósea presentan esta característica (Figuras 3.11 y 3.12). En los especímenes asignados a juveniles, el desarrollo gradual del tejido compacto limita aquellas áreas a espacios más reducidos (Lámina 3.1). La misma característica ósea se utilizó para los elementos del postcráneo, a lo que se agregó, en los casos posibles, la separación de epífisis y diáfisis.

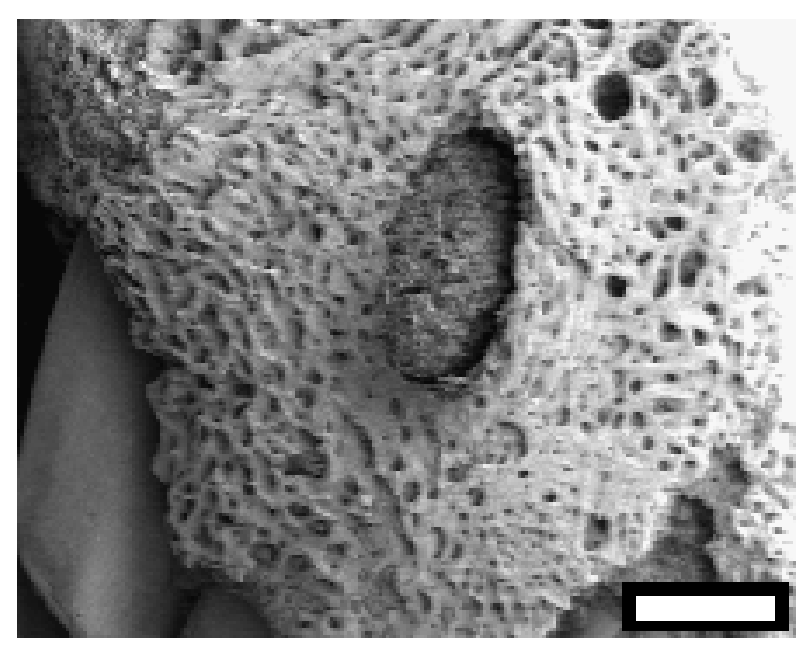

Figura 3.11. Porción de paladar de un individuo juvenil de Paedotherium minor (GHUNLPam 19711), escala $1000 \mu$ 


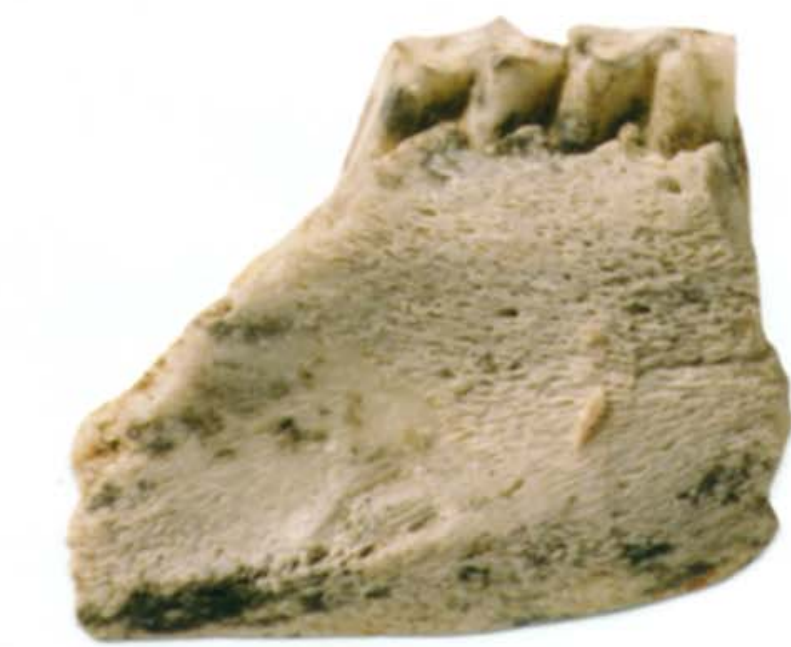

A

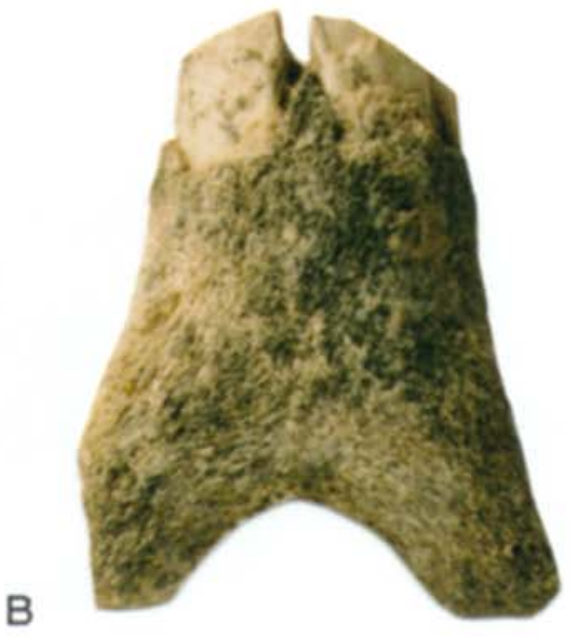

Lámina 3.1. Aspecto de la superficie ósea en especimenes asignados a juveniles. A. hemimandibula derecha de Paedotherium minor (GHUNLPam 19153); B. sinfisis mandibular de Paedotherium minor (GHUNLPam 21435), escalas 5 mm. 
Lámina 3.1. Aspecto de la superficie ósea en especímenes asignados a juveniles. A. hemimandíbula derecha de Paedotherium minor (GHUNLPam 19153); B. sínfisis mandibular de Paedotherium minor (GHUNLPam 21435), escalas $5 \mathrm{~mm}$. 


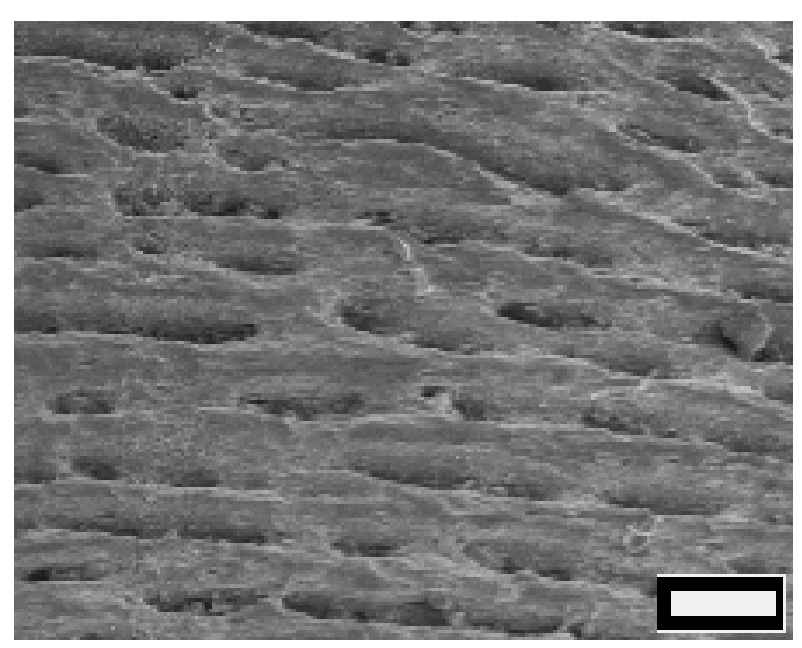

Figura 3.12. Área trabecular en la superficie de una hemimandíbula de un individuo juvenil de Xenodontomys elongatus (GHUNLPam 19710), escala $100 \mu$

En algunos roedores y en Paedotherium minor, que tienen molariformes euhipsodontes, se utilizó además para la evaluación de la edad el aumento o no del tamaño hacia la base de cada diente (Verzi et al., 2003).

Sobre la base de los taxa asignados a la categoría I (menos de $5 \mathrm{~kg}$ de masa corporal estimada), se evaluó para esa asociación el porcentaje de individuos asignados a alguna de las tres clases de edad establecidas (Tabla 3.31): individuos muy jóvenes, juveniles y adultos.

En la asociación de microvertebrados, cuyo NMI es de 289 individuos, el $11,07 \%$ corresponde a individuos muy jóvenes, el 17,99 \% a jóvenes y el 70,93 \% a adultos. 
Paleobiología de la asociación faunística de Caleufú (La Pampa, Formación Cerro Azul, Mioceno superior - Plioceno inferior), a través de análisis tafonómicos

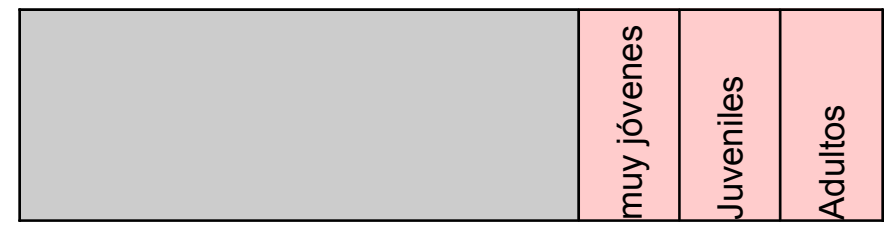




\begin{tabular}{|l|c|c|c|}
\hline Reptilia & & & 5 \\
\hline Aves & & & 4 \\
\hline Mammalia indet. & & 1 & 3 \\
\hline Marmosinae indet. & & & 1 \\
\hline Didelphinae indet. & & & 3 \\
\hline Hyperdidelphys sp. & 1 & & 1 \\
\hline Sparassocynus sp. & 1 & & 1 \\
\hline Argyrolagus sp. & & & 2 \\
\hline Neocavia cf. N. lozanoi & 1 & 1 & 8 \\
\hline Orthomyctera sp. & 4 & 2 & 18 \\
\hline Palaeocavia sp. & 2 & 5 & 38 \\
\hline Lagostomus (Lagostomopsis) sp. & & 1 & 1 \\
\hline Sigmodontinae gen. Et sp. nov. & & & 2 \\
\hline Phtoramys aff. P. homogenidens & & 1 & 3 \\
\hline Pampamys emmonsae & & & 1 \\
\hline Octodontinae indet. & 1 & 4 & 15 \\
\hline Neophanomys sp. & & 2 & 5 \\
\hline Xenodontomys elongatus & 1 & 15 & 38 \\
\hline Paedotherium minor & 21 & 20 & 55 \\
\hline Carnivora indet. & & & 1 \\
\hline TOTAL & 32 & 52 & 205 \\
\hline
\end{tabular}

Tabla 3.31. Número de individuos asignados a cada taxón y a la asociación de micromamíferos

Considerando sólo los mamíferos ( $\mathrm{NMI}=280$ ), el $\mathrm{NMI}$ de las categorías muy joven y juvenil es de 84 individuos, que constituye el $30 \%$ del total. Si se tienen en cuenta solo los seis taxa más abundantes de esa asociación (NMl=249), se contabilizaron 77 individuos muy jóvenes y jóvenes. En otros términos, en la asociación de micromamíferos el $91,77 \%$ de los individuos muy jóvenes y juveniles corresponden a los 6 taxa más frecuentes. La proporción de cada clase de edad entre esos taxa se muestra en la Figura 3.31. Si bien es alto el porcentaje de individuos adultos en cada taxón, en la mayoría de ellos hay representantes muy jóvenes y jóvenes. En Paedotherium minor, en particular, el porcentaje de adultos es más bajo, ya que hay $21,88 \%$ de muy jóvenes y $20,83 \%$ de juveniles. 


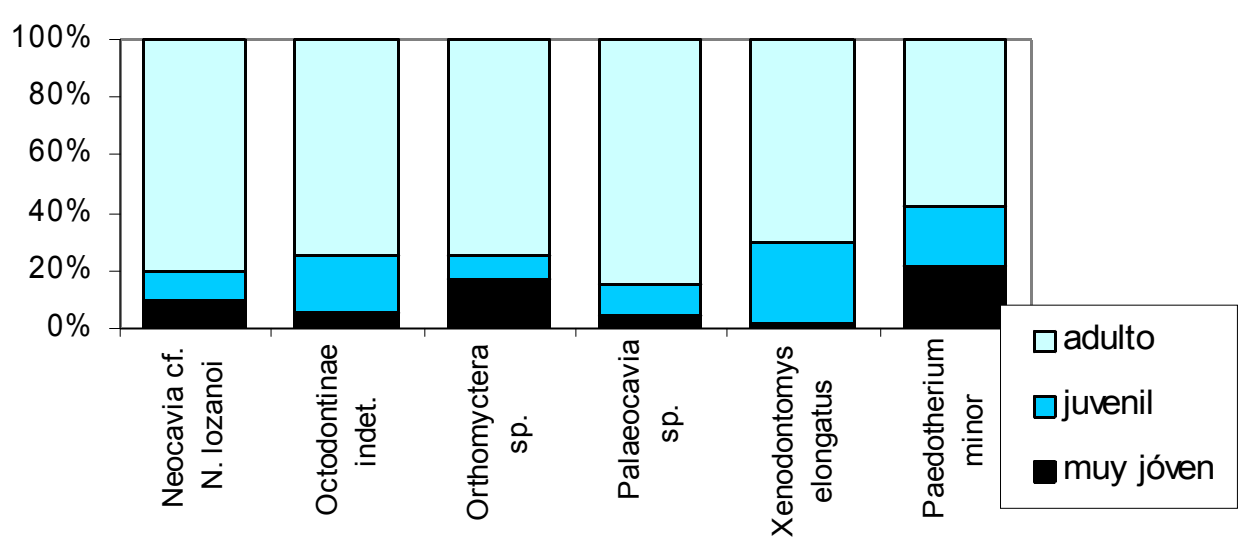

Figura 3.13. Proporción de las clases de edad en los taxa más abundantes

- Masa corporal y hábitos de vida

Ya se indicó que la categoría I (asociación de microvertebrados) incluye a todos los taxa de menos de $5 \mathrm{~kg}$ de masa corporal estimada. En particular los 6 taxa más frecuentes en esa asociación corresponden a individuos cuya masa corporal estimada, sobre la base de su comparación con especies actuales de tamaño similar, se encuentra en el rango de $300 \mathrm{~g}$ a $1 \mathrm{~kg}$. Pero debe advertirse que los especímenes correspondientes a individuos de Paedotherium minor que llegarían a ese valor máximo de talla corporal son muy escasos, ya que además de prevalecer los asignados a muy jóvenes y juveniles, son abundantes los ejemplares de adultos de tamaño pequeño. El total de juveniles sesga por lo tanto las consideraciones acerca de la masa corporal estimada de los individuos presa.

El tamaño de las presas constituye un importante sesgo a tener en cuenta al momento de evaluar las asociaciones formadas por depredadores ya que permite predecir el tamaño del depredador. Este debe matar a su presa rápidamente y por ese motivo prefiere presas más pequeñas que él. Los depredadores más eficientes pueden buscar presas de su mismo tamaño o incluso mayores, pero ese comportamiento se da cuando varios individuos actúan juntos en la caza; por ejemplo esta modalidad es común entre algunos mamíferos carnívoros. Las aves nocturnas generalmente toman presas menores a sí mismas y lo mismo ocurre en general con las diurnas, sin embargo estas últimas pueden tomar presas de mayor tamaño (Andrews, 1990). 
Con respecto a los hábitos de vida, entre los Caviidae actuales, Microcavia solo usualmente construye cuevas, pero puede usar las realizadas por armadillos y vizcachas, mientras que los representantes actuales de la Familia Octodontidae son fosoriales o semifosoriales. Para niveles del Plioceno superior de los acantilados entre Mar del Plata y Miramar (provincia de Buenos Aires) fueron descriptas cuevas con Actenomys (Genise, 1989), taxón relacionado con Xenodontomys elongatus (Verzi et al., 2003); algunas de esas cuevas contenían representantes de Paedotherium.

Las especies actuales de la Familia Caviidae son fundamentalmente diurnas, mientras que entre los Octodontidae actuales, los Octodontinae incluyen taxa de hábitos diurnos y otros de hábitos nocturnos y los Ctenomyinae del género Ctenomys tienen su máxima actividad por la mañana muy temprano y por la tarde. Con respecto a Paedotherium, se sugirió la posibilidad de que tuviera hábitos nocturnos (Straccia, 2000). Con estos datos es difícil evaluar en qué momento del día podrían haber sido hechas las capturas de las presas.

\section{- Abundancia relativa}

La abundancia relativa de cada elemento esquelético fue evaluada solo para la asociación de micromamíferos.

Para el cálculo del Ei del material postcraneano se optó por tomar el número de elementos del esqueleto de un roedor. Esto implica errores de cálculo ya que considerando los taxa de micromamíferos, los más abundantes en esta asociación son el notoungulado Paedotherium minor y varios roedores, con diferencias en su constitución esquelética. Considerando que estas variaciones afectan al número total de vértebras, metápodos y falanges, que son los elementos esqueléticos que se encuentran en número mayor a 2 en un esqueleto, y que, en particular el NME de estos elementos es bajo en la asociación, los errores introducidos en el cálculo son mínimos.

Sí se tuvieron en cuenta los taxa representados al momento de evaluar la abundancia relativa de los molariformes ya que los roedores caviomorfos tienen la siguiente fórmula dentaria $1 / 1,0 / 0,1 / 1,3 / 3$, con 16 molariformes mientras que la de Paedotherium minor es $1 / 2$ 0/0 3/3, 3/3. A fin de homogeneizar esos datos, 
para su evaluación se consideraron exclusivamente el último premolar y los molares (16 molariformes). De este modo, para obtener el valor de la abundancia relativa de los molariformes se tuvieron en cuenta los molariformes aislados mencionados correspondientes a Paedotherium minor (NME=123) y el total de molariformes aislados de los roedores caviomorfos, en particular de Caviidae indet., del Octodontinae indet. y de Xenodontomys elongatus (NME=134), que son los roedores que han aportado especímenes aislados.

EI NMI total de la asociación de micromamíferos es de 280 individuos, valor que se tomó como referencia para los cálculos. Los valores obtenidos de abundancia relativa de cada elemento esquelético se muestran en la Tabla 3.32.

\begin{tabular}{|l|c|c|c|c|}
\cline { 2 - 5 } \multicolumn{1}{c|}{} & NME & NMI & Ei & $\%$ \\
\hline Hemimandíbulas & 425 & 280 & 2 & 75,89 \\
\hline Maxilares & 248 & 280 & 2 & 44,29 \\
\hline Molariformes & 257 & 280 & 16 & 5,74 \\
\hline Incisivos & 78 & 280 & 4 & 6,96 \\
\hline Escápulas & 11 & 280 & 2 & 1,96 \\
\hline Húmeros & 22 & 280 & 2 & 3,93 \\
\hline Radios & 12 & 280 & 2 & 2,14 \\
\hline Ulnas & 31 & 280 & 2 & 5,54 \\
\hline Innominados & 21 & 280 & 2 & 3,75 \\
\hline Fémures & 63 & 280 & 2 & 11,25 \\
\hline Tibias & 44 & 280 & 2 & 7,86 \\
\hline Vértebras & 114 & 280 & 36 & 1,13 \\
\hline Metápodos & 92 & 280 & 20 & 1,64 \\
\hline Falanges & 13 & 280 & 56 & 0,08 \\
\hline
\end{tabular}

Tabla 3.32. Representación de cada elemento anatómico en la asociación de micromamíferos

En la Tabla 3.32 y en la Figura 3.14 se observa que en la asociación sólo es relativamente alta la representatividad de las mandíbulas y en menor proporción los maxilares. Los demás elementos esqueléticos tienen una representatividad muy baja, de modo tal que el promedio de la abundancia relativa de $12,30 \%$, siendo de $33,22 \%$ para los elementos del cráneo y de 3,92 \% para los del postcráneo. 


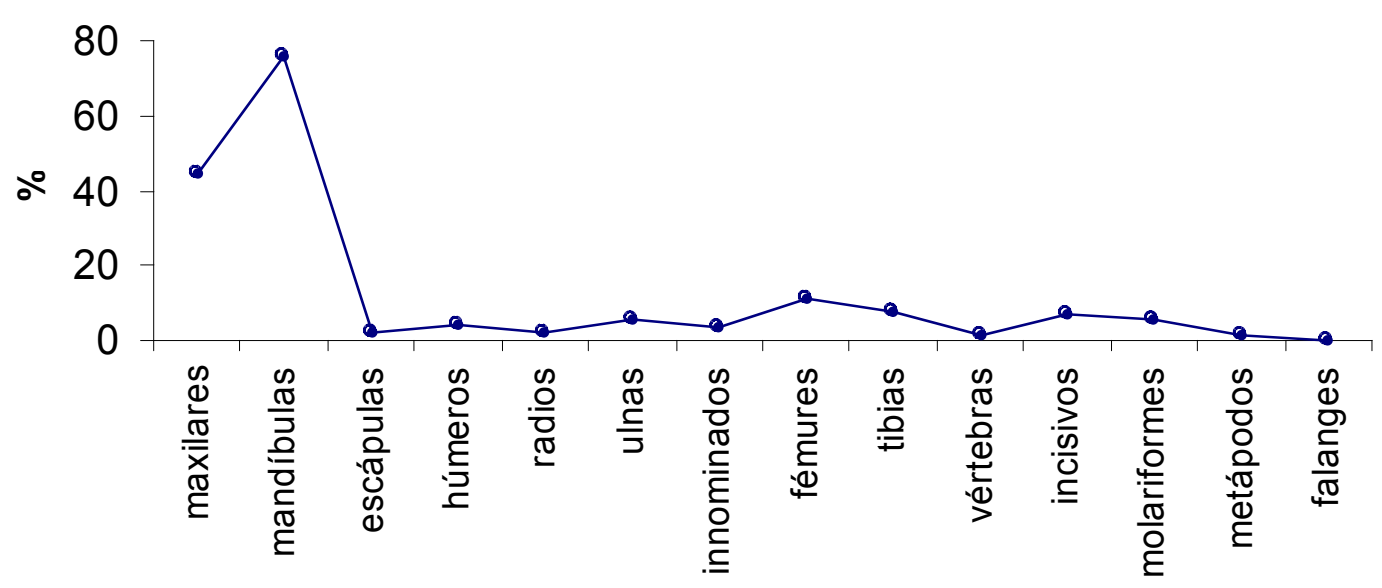

Figura 3.14. Representación de la abundancia relativa de los elementos esqueléticos en la asociación de micromamíferos

- Índices

Para analizar las variaciones en la representación entre los elementos craneales y los postcraneales se utilizaron los índices propuestos por Andrews (1990).

El primero compara directamente las frecuencias de 2 grupos de elementos, los postcraneales y los craneales

$\{$ (fémures + tibias + húmeros + radios + ulnas) $\times 20 /$ (mandíbulas + maxilares + molares) $\times 10\} \times 100$

Andrews (1990) propuso multiplicar el primer término de esta fórmula por 16 y el segundo por 10, para corregir las diferencias en el número de elementos esqueléticos de acuerdo a los casos que él analizó.

Como se comentó antes, en la asociación de Caleufú, los dientes fueron aportados por roedores caviomorfos (con 16 molariformes) y por Paedotherium minor (contabilizando en este caso 16 molariformes), por lo que, para igualar ambos términos, se multiplicó el primero de la fórmula por 20 .

De este modo, el índice elementos postcraneales / elementos craneales (pc/c) es de 36,17 \% para esta asociación. 
El segundo índice relaciona los elementos apendiculares proximales con los craneales

(fémures + húmeros / mandíbulas + maxilares) x 100

Para la asociación de micromamíferos este índice es de 12,63\%.

Para analizar la pérdida preferencial de las partes distales de los esqueletos apendiculares se aplicó el índice

(tibias + radios / fémures + húmeros) x 100

Para la asociación de micromamíferos de Caleufú este índice es de 65,88 \%.

Finalmente hay dos índices que permiten evaluar el grado de pérdida de dientes. Es el porcentaje de dientes aislados y el porcentaje de incisivos aislados. Estos índices no se tomaron en esta asociación, debido a que si bien hay dientes aislados (molariformes e incisivos), hay muy pocas hemimandíbulas y maxilares a las que les falten dientes. Los dientes aislados corresponderían a dientes que se han separado en el momento en que el espécimen se rompió y no a dientes perdidos por la acción de jugos digestivos.

La Tabla 3.34 resume valores surgidos de los índices utilizados.

\begin{tabular}{|l|c|}
\hline ÍNDICE & $\%$ \\
\hline $\mathrm{pc} / \mathrm{c}$ & 36,17 \\
\hline $\mathrm{f}+\mathrm{h} / \mathrm{md}+\mathrm{mx}$ & 12,63 \\
\hline $\mathrm{t}+\mathrm{r} / \mathrm{f}+\mathrm{h}$ & 65,88 \\
\hline
\end{tabular}

Tabla 3.34. Resultados de los índices utilizados en la asociación de micromamíferos

Los valores muy por debajo de 100 de los índices pc/c y f+h/md+mx indican la abundancia del material craneal con respecto al postcraneal. El índice $t+r / f+h$ menor a 100 marca una mayor pérdida de elementos distales de los miembros con respecto a los proximales. 
Consideraciones acerca de la asociación de microvertebrados

Los datos expuestos sugieren que los restos de microvertebrados, en el contexto de la asociación faunística de Caleufú, pueden haber sido acumulados por la actividad de un depredador. La abundancia de tres taxa dominantes, cuyas masas corporales no superan $1 \mathrm{~kg}$ y con un alto porcentaje de individuos muy jóvenes y juveniles, indica una selección de las presas. Lyman et al. (2003) señalaron que para asociaciones producidas por aves actuales el NMI está influenciado por el tamaño de las presas y también por la edad en el momento de su muerte, ya que encontraron que hay una tendencia al incremento del NMI en los casos de egagrópilas con presas juveniles, de modo tal que esta característica corresponde a un atributo originado en la etapa bioestratinómica de la historia tafonómica. Los individuos muy jóvenes y juveniles constituyen un grupo abundante en la asociación; este sesgo se puede interpretar como una selección de los depredadores hacia individuos de ese grupo y por lo tanto de pequeño tamaño. Debe mencionarse aquí que ciertos atributos tafonómicos originados posteriormente, tales como el encostramiento e inclusión en concreciones calcáreas, favorecieron la preservación de los especímenes correspondientes a estos individuos, caracterizados por tener hueso muy poroso y ser de tamaño muy pequeño.

El análisis de la abundancia relativa de las porciones de cada elemento esquelético mostró una representatividad alta de mandíbulas y maxilares sobre cualquier otro elemento del postcráneo. Estos datos permiten plantear dos hipótesis alternativas. La primera postula que la abundancia relativa de todos los elementos esqueléticos, los índices que relacionan elementos del cráneo y del postcráneo y la abundancia relativa de cada parte de los elementos del postcráneo estén sesgados por procesos ocurridos después del enterramiento. En contra de este planteo se puede mencionar que esos procesos deberían haber afectado del mismo modo a elementos del postcráneo y del cráneo, por lo que es difícil explicar la desproporción existente en esta asociación entre ambos tipos de elementos. En segundo lugar se puede plantear que, realmente, la escasez de elementos del postcráneo responda a un comportamiento particular del 
depredador que implique la selección de algunas partes del cuerpo de la presa para su ingestión. Esta última hipótesis se discute más adelante. 


\section{Capítulo 4}

\section{OTROS ATRIBUTOS TAFONÓMICOS}




\section{GRADO DE BIODEGRADACIÓN}

Los mecanismos de biodegradación comprenden los procesos de descomposición de las sustancias orgánicas por la acción de organismos (Fernández López, 2000). El análisis de la biodegradación permite evaluar qué modificaciones se han producido en los restos como consecuencia de la muerte natural por enfermedad y catástrofes, la depredación y el carroñeo. Ya que se planteó la posibilidad de que la asociación de microvertebrados de Caleufú fue originada por el accionar de depredadores, se buscaron alteraciones producidas sobre los restos en el momento de la muerte de la presa.

Como característica general, las concentraciones generadas por depredadores, compuestas fundamentalmente de egagrópilas de rapaces y heces de carnívoros, presentan un grado alto de deterioro de los restos. Estos no son los únicos modos en que los depredadores pueden concentrar restos de microvertebrados; muchos esconden su comida realizando provisiones, otros trasladan el alimento a sus nidos o guaridas, pero en ambos casos la composición de restos es similar a la de egagrópilas y heces (Andrews y Evans, 1983).

Los depredadores producen modificaciones físicas (fracturas, que se analizan en otro ítem) y químicas. Las modificaciones químicas que sufren los elementos esqueléticos por efectos de la depredación están en función de la modalidad de ingestión y de la eficacia del proceso digestivo de cada depredador. Andrews (1990) dividió a los depredadores actuales en 3 grupos: aves nocturnas, aves diurnas y mamíferos carnívoros, basándose en sus métodos y capacidad de digestión. Durante la digestión, los mamíferos pequeños provocan más destrucción que las aves y a su vez las aves diurnas son más destructoras que las nocturnas (Andrews, 1990). Las primeras sujetan a sus presas con las patas y desgarran la carne con el pico para ingerirla, las nocturnas tragan a su presa entera. Los carnívoros, en cambio, mastican y muelen a sus presas, produciendo múltiples daños; la digestión de las presas es completa y la fuerte acidez de sus jugos gástricos es generalmente más destructiva que en el caso de las aves. Además, la masticación produce fracturas en los elementos esqueléticos, de 
modo tal que la acción de los jugos digestivos actúa también sobre las superficies expuestas de esas fracturas (Andrews, 1990).

Para el caso de los elementos postcraneales, Andrews (1990) sugirió evaluar el grado de digestión en los extremos proximales de fémures y distales de húmeros. De acuerdo a la intensidad de la digestión estableció las categorías ligera, moderada, fuerte y extrema (Tabla 4.1). La alteración por digestión actúa hacia el interior de los elementos esqueléticos, por lo que se redondean los extremos o áreas fracturadas.

\begin{tabular}{|l|l|}
\hline $\begin{array}{l}\text { Categoría de } \\
\text { digestión }\end{array}$ & \multicolumn{2}{|l|}{$\begin{array}{l}\text { Baja frecuencia de digestión, que afecta del } 6 \text { al } 20 \% \text { de los } \\
\text { especímenes. Estos en general están enteros, por lo que la } \\
\text { digestión se observa en las zonas articulares. }\end{array}$} \\
\hline LIGERA & $\begin{array}{l}\text { La frecuencia de elementos con evidencias de digestión varía } \\
\text { entre el } 25 \text { al } 50 \% \text { de los especímenes. Las zonas articulares de } \\
\text { los huesos largos están muy digeridas. }\end{array}$ \\
\hline FUERTE & $\begin{array}{l}\text { El grado de digestión es similar al anterior, pero afecta a más del } \\
60 \% \text { de los especímenes. En muchos casos se produce } \\
\text { agrietamiento. }\end{array}$ \\
\hline EXTREMA & $\begin{array}{l}\text { La alteración es muy fuerte. Los especimenes están muy } \\
\text { redondeados por la acción digestiva. La mayoría de los elementos } \\
\text { esqueléticos están rotos. }\end{array}$ \\
\hline
\end{tabular}

Tabla 4.1. Categorías de digestión para elementos esqueléticos postcraneales

Para el caso de los dientes (en particular para especímenes asignados a roedores) se diferencia la digestión en incisivos y molares (Tablas 4.2 y 4.3).

\begin{tabular}{|l|l|}
\hline $\begin{array}{l}\text { Categoría } \\
\text { digestión }\end{array}$ & \multicolumn{1}{|l|}{ de } \\
\hline LIGERA & $\begin{array}{l}\text { El esmalte presenta un ligero desgaste en forma homogénea y el } \\
\text { relieve de las cúspides aparece ligeramente atenuado. Afecta del } 0 \text { al } \\
3 \% \text { de los especímenes. }\end{array}$ \\
\hline MODERADA & $\begin{array}{l}\text { La superficie del esmalte aparece más desgastada que en el caso } \\
\text { anterior. El esmalte desaparece en los bordes y en las cúspides. } \\
\text { Afecta del } 4 \text { al } 6 \% \text { de los especimenes. }\end{array}$ \\
\hline FUERTE & $\begin{array}{l}\text { Hay áreas donde el esmalte ha desaparecido, pero no está afectada } \\
\text { la dentina. Las superficies desgastadas son más evidentes. Afecta del } \\
18 \text { al } 22 \% \text { de los especímenes. }\end{array}$ \\
\hline EXTREMA & $\begin{array}{l}\text { La alteración es muy fuerte. El esmalte ha desaparecido en gran parte } \\
\text { del diente. Afecta a más del } 50 \% \text { de los especímenes. }\end{array}$ \\
\hline
\end{tabular}

Tabla 4.2. Categorías de digestión para molares 
Los molares suelen ser menos afectados que los incisivos por efectos de la digestión y en estos casos la alteración varia con el taxón y la forma del diente. Para ambos tipos de dientes Andrews (1990) y Fernández Jalvo y Andrews (1992) establecieron 4 grados de digestión: ligera, moderada, fuerte y extrema.

\begin{tabular}{|l|l|}
\hline $\begin{array}{l}\text { Categoría } \\
\text { digestión }\end{array}$ & de \\
\hline LIGERA & $\begin{array}{l}\text { Afecta a toda la superficie del esmalte que presenta un ligero } \\
\text { desgaste. Puede estar concentrada en la parte extramandibular del } \\
\text { diente o afectarlo todo, de acuerdo a que este haya permanecido en } \\
\text { el alvéolo o no. Afecta del } 8 \text { al } 13 \% \text { de los especímenes. }\end{array}$ \\
\hline MODERADA & $\begin{array}{l}\text { El esmalte está más afectado y también la dentina que adquiere una } \\
\text { superficie ondulada. Afecta del } 20 \text { al } 30 \% \text { de los especímenes. }\end{array}$ \\
\hline FUERTE & $\begin{array}{l}\text { Hay evidencias de digestión en el esmalte, que aparece como } \\
\text { pequeños islotes y en la dentina que está muy ondulada. Afecta del } \\
60 \text { al } 80 \% \text { de los especímenes. }\end{array}$ \\
\hline EXTREMA & $\begin{array}{l}\text { La alteración es generalizada. El esmalte ha desaparecido en gran } \\
\text { parte del diente, puede quedar restringido a pequeños islotes. Afecta } \\
\text { a más del } 60 \% \text { de los especímenes. }\end{array}$ \\
\hline
\end{tabular}

Tabla 4.3. Categorías de digestión para incisivos

Considerando los tipos de modificaciones de las distintas partes esqueléticas, Andrews (1990) estableció una clasificación que incluye a varias especies de depredadores actuales de la fauna europea, africana y algunas especies de América del Norte (tanto rapaces diurnas y nocturnas como pequeños mamíferos carnívoros). Gómez (2000), al analizar los restos de mamíferos del Sitio Arqueológico Arroyo Seco 2 en la provincia de Buenos Aires, realizó experimentos sobre especies actuales de aves y mamíferos carnívoros de la Región Pampeana que fueron incorporadas en las categorías mencionadas.

Las evidencias de digestión son a veces difíciles de diferenciar de otros agentes ya que, sobreimpuestas a las modificaciones primarias antes descriptas aparecen modificaciones secundarias no relacionadas con la causa de muerte (Fernández Jalvo y Andrews, 1992). Entre ellas se pueden citar cambios a nivel molecular (Tuross et al., 1989), descomposición bacteriana (Korth, 1979) y acción de insectos (Dodson, 1973). A éstos se suman atributos relacionados con la exposición de los huesos sobre el sustrato, que pueden ser afectados por acción del agua y del viento (Korth, 1979), produciendo redondeamiento, que en general 
los afecta totalmente, característica que permite diferenciarlos de aquellos redondeados por efectos de digestión (Fernández Jalvo, 1995).

De acuerdo al modelo propuesto por Andrews (1990) se analizaron las modificaciones registradas en los especímenes recuperados en Caleufú. Por las características de esta asociación, las evidencias de digestión se buscaron por un lado en los especímenes que forman parte de la asociación de microvertebrados y por otro, en los coprolitos. Los restos fueron observados buscando identificar la presencia de atributos que indicaran la acción enzimática durante la digestión, ya que mediante esta línea de investigación se podrían encontrar evidencias que avalen la hipótesis sobre la acción de depredadores como formadores de esta concentración.

\section{Asociación de microvertebrados}

Con respecto a los elementos postcraneanos y siguiendo a Andrews (1990) y Fernández Jalvo y Andrews (1992), se buscaron evidencias de acción digestiva particularmente sobre fémures y húmeros, si bien también fueron observados los demás elementos esqueléticos. En muchos especímenes las modificaciones secundarias (fundamentalmente corrosiones) producidas sobre los restos una vez que estos se mineralizaron pueden ocultar los efectos ocasionados previamente por la digestión. Sin embargo, en algunos especímenes se identificaron caracteres propios de acción digestiva, como redondeamiento sin microestriaciones (Figuras 4.1 y 4.2), que pueden ser incluidas en la categoría de modificación ligera.

También se observaron ligeras evidencias de digestión en mandíbulas. Por ejemplo, para el caso de mandíbulas de roedores, algunos ejemplares presentan la cresta masetérica sin hueso compacto, de modo tal que el área más expuesta de la misma tiene sólo hueso esponjoso, la observación con MEB de esa zona no muestra microestriaciones ni otra evidencia de abrasión, por lo que el redondeamiento de la superficie se puede atribuir a digestión (Figura 4.3). 

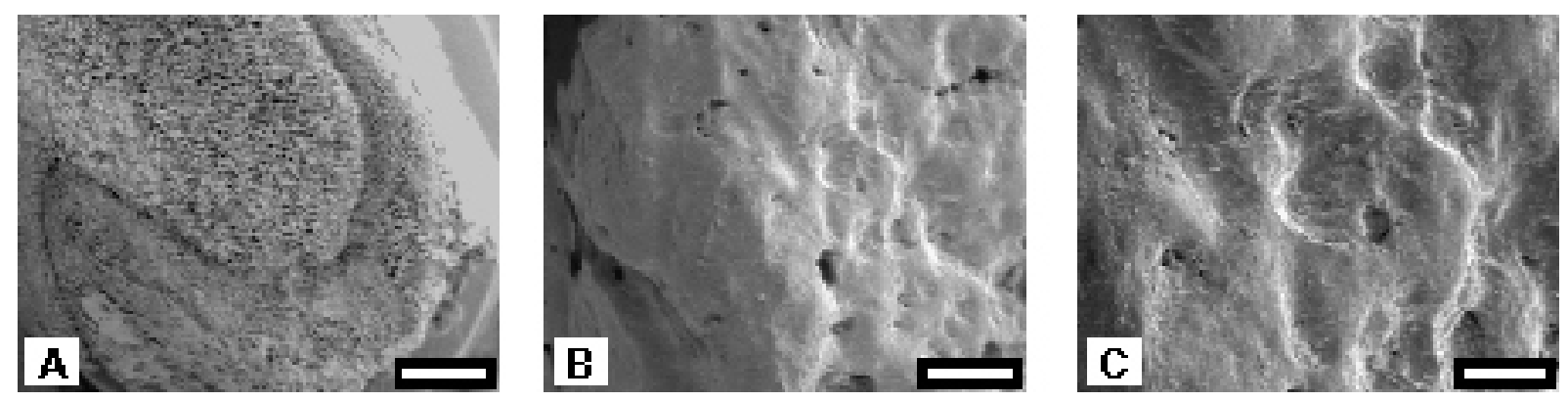

Figura 4.1. A. GHUNLPam 21564/54 fémur distal de un individuo juvenil, escala $1000 \mu$; B. mayor aumento del área con evidencias de digestión, escala $50 \mu$; C. mayor aumento del área con evidencias de digestión, escala $20 \mu$
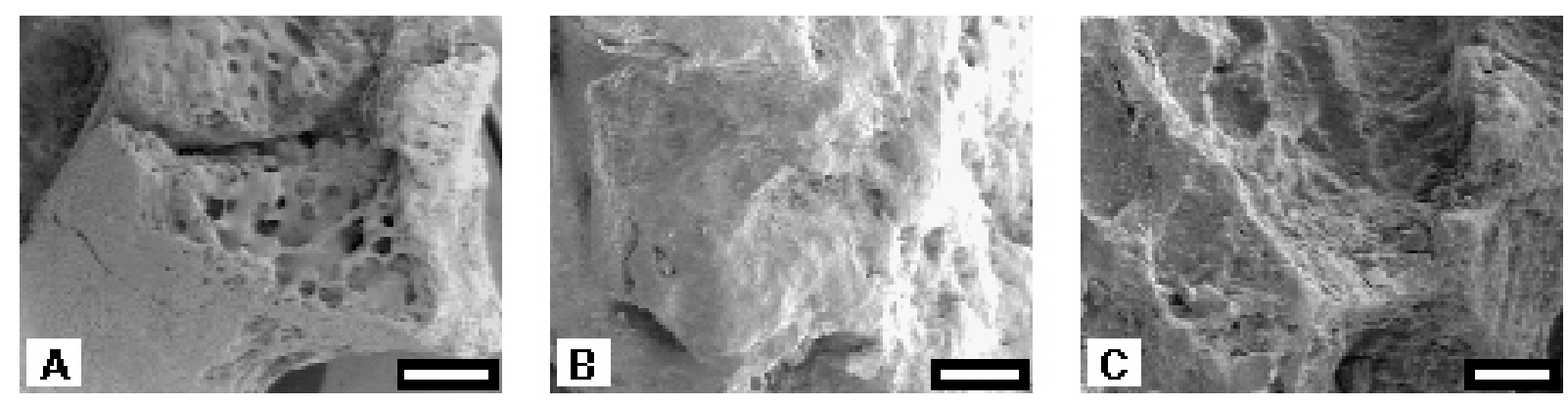

Figura 4.2. A. GHUNLPam 21564/29 húmero distal, escala $1000 \mu$; B. mayor aumento del área con evidencias de digestión, escala $50 \mu$; C. mayor aumento del área con evidencias de digestión, escala $20 \mu$
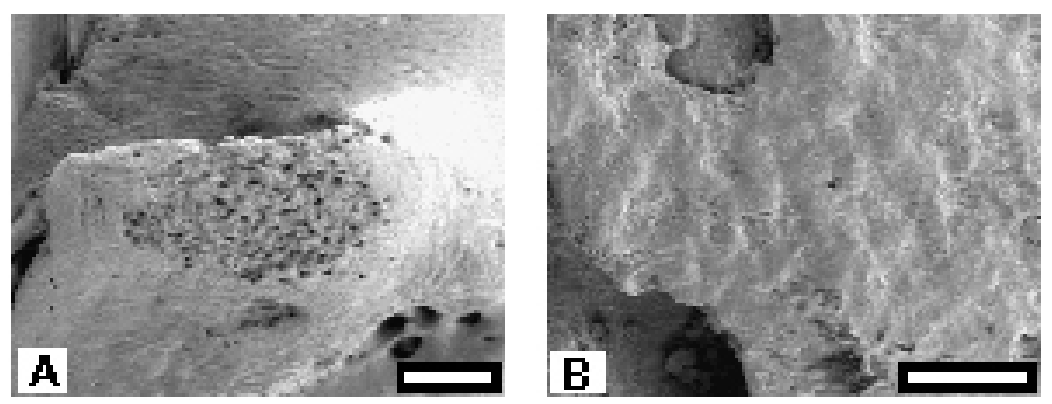

Figura 4.3. Digestión sobre mandíbula de Palaeocavia sp. (GHUNLPam 19534) A. área digerida de la cresta masetérica, escala $1000 \mu$; B. aumento del área con evidencias de digestión, escala $50 \mu$

La Figura 4.4 muestra una hemimandíbula con la cresta masetérica rota, pero muy pulida por acción de la digestión. 

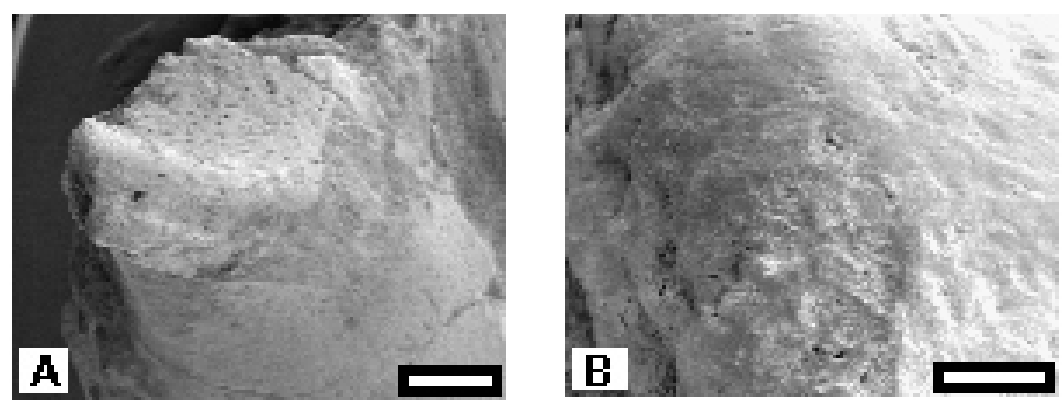

Figura 4.4. Digestión sobre mandíbula de un Octodontinae (GHUNLPam 21216) A. área digerida de la cresta masetérica, escala $1000 \mu$; B. aumento del área con evidencias de digestión, escala $100 \mu$

Las superficies de los elementos esqueléticos próximas a roturas presentan también en algunos casos redondeamiento sin microestriaciones (Figura 4.5).
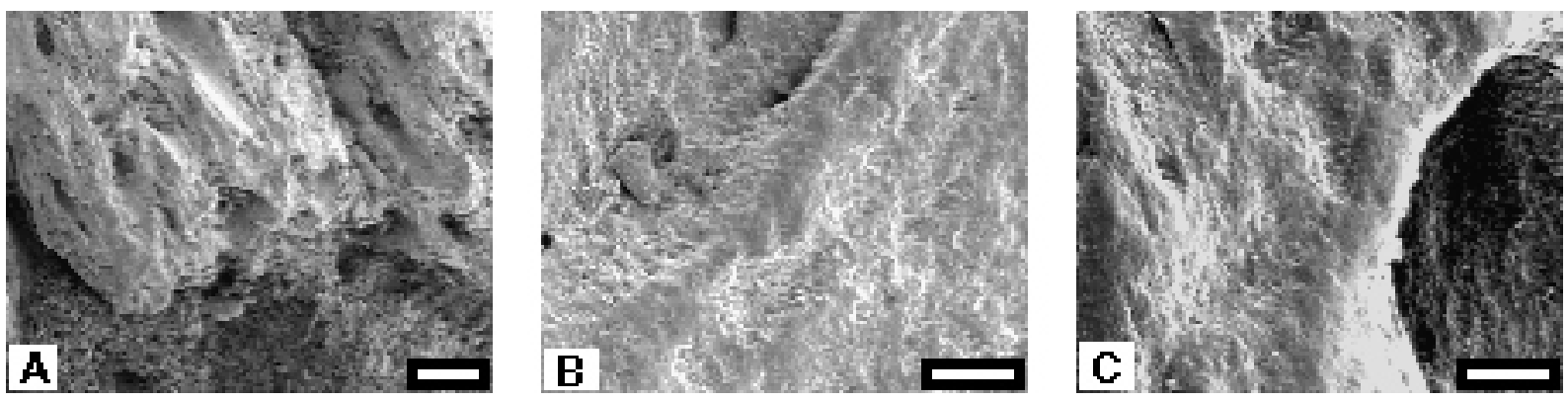

Figura 4.5. Digestión sobre borde mandibular roto de un individuo juvenil de Paedotherium minor (GHUNLPam 19300) A. borde mandibular, escala $100 \mu$; B y C mayor aumento del área digerida, escalas $20 \mu$

Muy pocos ejemplares presentan evidencias de digestión sobre dientes, tal como se pueden observar en asociaciones actuales formadas por depredadores. En estos elementos esqueléticos se acentúa la dificultad para diferenciar efectos de digestión u otro tipo de corrosiones. Como ejemplo de estas dificultades se puede citar el caso de cómo identificar modificaciones químicas sobre los dientes del notoungulado Paedotherium minor. Sus molariformes hipsodontes están cubiertos por una espesa capa de cemento que ocupa las caras interna y externa de cada diente. Ese cemento muchas veces está degradado, punteado, siendo más abundante la modificación cerca de la cara oclusal. Estas modificaciones podrían ser atribuidas a digestión, pero en general el esmalte, que es la estructura que clásicamente muestra los efectos de la digestión, está en buen estado y si presenta modificaciones, éstas también pueden ser atribuidas a procesos 
ocurridos más tardíamente (por ejemplo corrosiones producidas luego del enterramiento).

Entre los roedores se han encontrado molares in situ que muestran ligeras modificaciones por digestión. En los representantes de la Familia Octodontidae (Xenodontomys elongatus y Octodontinae indet.) la digestión se manifiesta como un ligero desgaste del esmalte cercano a la zona oclusal del diente, más evidente en las porciones ántero-labial y póstero-lingual, con redondeamiento de la dentina expuesta.

En el caso de los representantes de la Familia Caviidae, se observan en algunos casos las modificaciones expuestas para los octodóntidos, pero es más frecuente hallar efectos que podrían atribuirse a digestión sobre el cemento que cubre en forma de pequeños discos al esmalte (Figura 4.6 A).
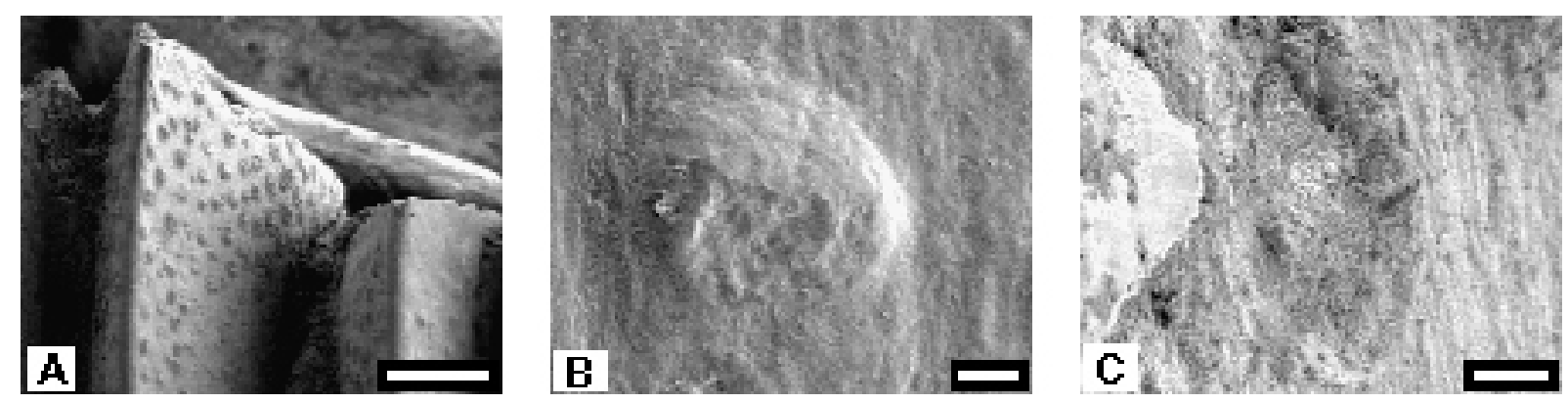

Figura 4.6. A. Molar de Palaeocavia sp. (GHUNLPam 19534) donde se observan los discos de cemento sobre el esmalte, escala $500 \mu$; B. imagen de un disco sin modificación; C. imagen de una cicatriz en la zona del disco; A y B. escalas $20 \mu$

El cemento es muy abundante en la zona interprismática de cada molariforme y continúa en forma de discos aplanados de distribución irregular sobre todo el esmalte (Figura 4.6 B). Cerca de la cara oclusal de cada diente, este cemento en general está alisado, seguramente por abrasión durante la masticación, lo mismo ocurre en las áreas de esmalte entre dos molares contiguos. En algunos casos, se observó que los discos de cemento han desaparecido en ciertas áreas de la zona expuesta del molariforme, dejando una cicatriz en el esmalte y eso podría atribuirse a efectos producidos por la digestión (Figura $4.6 \mathrm{C}$ ). En muchos especímenes se presenta corrosión diagenética en esas áreas, de modo tal que las cicatrices adquieren un color más claro que el resto del esmalte. 
Muchos molariformes, estén in situ o aislados, muestran modificaciones más marcadas en el esmalte e incluso en la dentina, pero en esos casos es difícil evaluar si son producto de la digestión o de otros procesos.

Los incisivos de roedores, ya se trate de los hallados aislados como los que están in situ, no presentan las modificaciones por efecto de digestión definidas previamente. Se han hallado pocos incisivos cuya punta está redondeada, y es la dentina la porción más afectada. Al ser observada con MEB, muestra una superficie ondulada, sin estriaciones, que podría atribuirse al efecto de la digestión, mientras que el esmalte no está tan afectado (Figura 4.7).
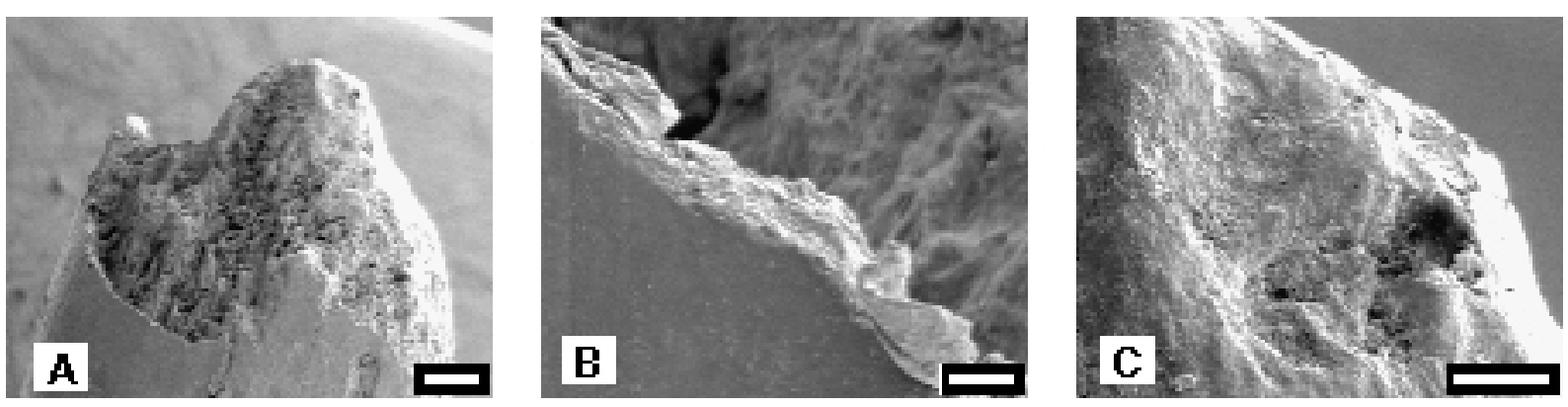

Figura 4.7. Digestión sobre incisivo de roedor (GHUNLPam 21123/6) A. imagen de la punta expuesta del incisivo, escala $200 \mu$; B. aumento del área de esmalte, escala $10 \mu$;

C. aumento del área de dentina con evidencias de digestión, escala $50 \mu$

De lo expuesto surge que solo se reconocieron ligeras modificaciones que pueden ser atribuidas a digestión, tanto en los elementos postcraneales como en los craneales (principalmente en hemimandíbulas y dientes). En todos los casos la proporción observada de restos con estas evidencias de digestión no alcanza los valores mínimos indicados en la categoría de modificación ligera, que incluye, de acuerdo a lo propuesto por Andrews (1990) a las aves nocturnas. Pero, como se mencionó previamente, las categorías establecidas por Andrews (1990) y Fernández Jalvo y Andrews (1992) han sido realizadas sobre la base del análisis de modificaciones producidas por depredadores actuales sobre micromamíferos, y en el caso particular de los dientes sólo se incluyen las modificaciones producidas sobre elementos de roedores e insectívoros. Esto dificulta mucho las comparaciones de los especímenes fósiles aquí estudiados, ya que no se conocen los efectos de la digestión producida por los depredadores extinguidos. 
$\underline{\text { Coprolitos }}$

Como se indicó, en la asociación de Caleufú se recuperaron 66 restos identificados como coprolitos (Hunt et al., 1994). Estos incluyen especímenes claramente identificables como coprolitos y también fragmentos de los mismos, cada uno con un número variable de restos con evidencias de fuerte digestión (Lámina 4.1). También se incluyeron en esta categoría elementos esqueléticos y fragmentos óseos asociados con muy fuerte grado de digestión que indicaría que estuvieron incluidos en un coprolito.

En los coprolitos fueron reconocidos los siguientes atributos: forma, medidas máximas, densidad ósea, tipo de material aglutinante, color, digestión, tipo de elemento esquelético incluido y orientación de los elementos óseos incluidos.

- Coprolitos enteros

Bajo esta categoría se incluyeron los siguientes especímenes: GHUNLPam 21002; 21003; 21219; 21516; 21557; 21912 (Figura 4.8); 21926; 21963; 22504; 22505; 22516 (Lámina 4.1. A y B); 22540 y 22563 (Figura 4.9).

La forma es en general cilíndrica, con los extremos aguzados, sus medidas oscilan entre 4,95 y $11,60 \mathrm{~mm}$ de diámetro $(\mathrm{N}=13$; promedio: $9,03 \mathrm{~mm}$ ) y entre 8,65 y $21,10 \mathrm{~mm}$ de largo ( $\mathrm{N}=13$; promedio: $14,08 \mathrm{~mm}$ ). Todos tienen una alta densidad de fragmentos óseos, el material aglutinante está conformado por granos dispersos de tamaño arena muy fina cementados por calcita, y en algunos especímenes hay también clastos de arcilla. En algunos coprolitos los fragmentos óseos tienen una fuerte impregnación de óxidos de manganeso (por ejemplo GHUNLPam 21516 Lámina 4.1 A y B). En todos los casos los elementos esqueléticos presentan un grado de digestión fuerte o extremo de acuerdo a las categorías de Andrews (1990), esta digestión se evidencia en un marcado redondeamiento de las porciones expuestas de cada pieza y además un adelgazamiento de la zona de hueso compacto. Si bien en los coprolitos la 
mayoría de los elementos esqueléticos incluidos no pueden ser identificados debido al alto grado de fragmentación, se han reconocido algunos: en GHUNLPam 21002 un trozo de vértebra y un fragmento de calcáneo; en GHUNLPam 21219 una porción de paladar con los premolares del Octodontinae indet.; en GHUNLPam 21557 un fragmento de escápula asociado a un húmero proximal; en GHUNLPam 21912 molariformes de Palaeocavia sp. bastante completos; en GHUNLPam 21963 un fragmento de arcada zigomática; en GHUNLPam 22504 un extremo de metápodo; en GHUNLPam 22505 un fragmento de vértebra y en GHUNLPam 22540 un fémur proximal y un fragmento de vértebra. En los casos de coprolitos que incluyen dientes, llama la atención que el esmalte no presenta modificación muy evidente por digestión. Los fragmentos óseos tienden a ubicarse de modo tal que el eje mayor de cada uno es perpendicular al eje mayor del coprolito.
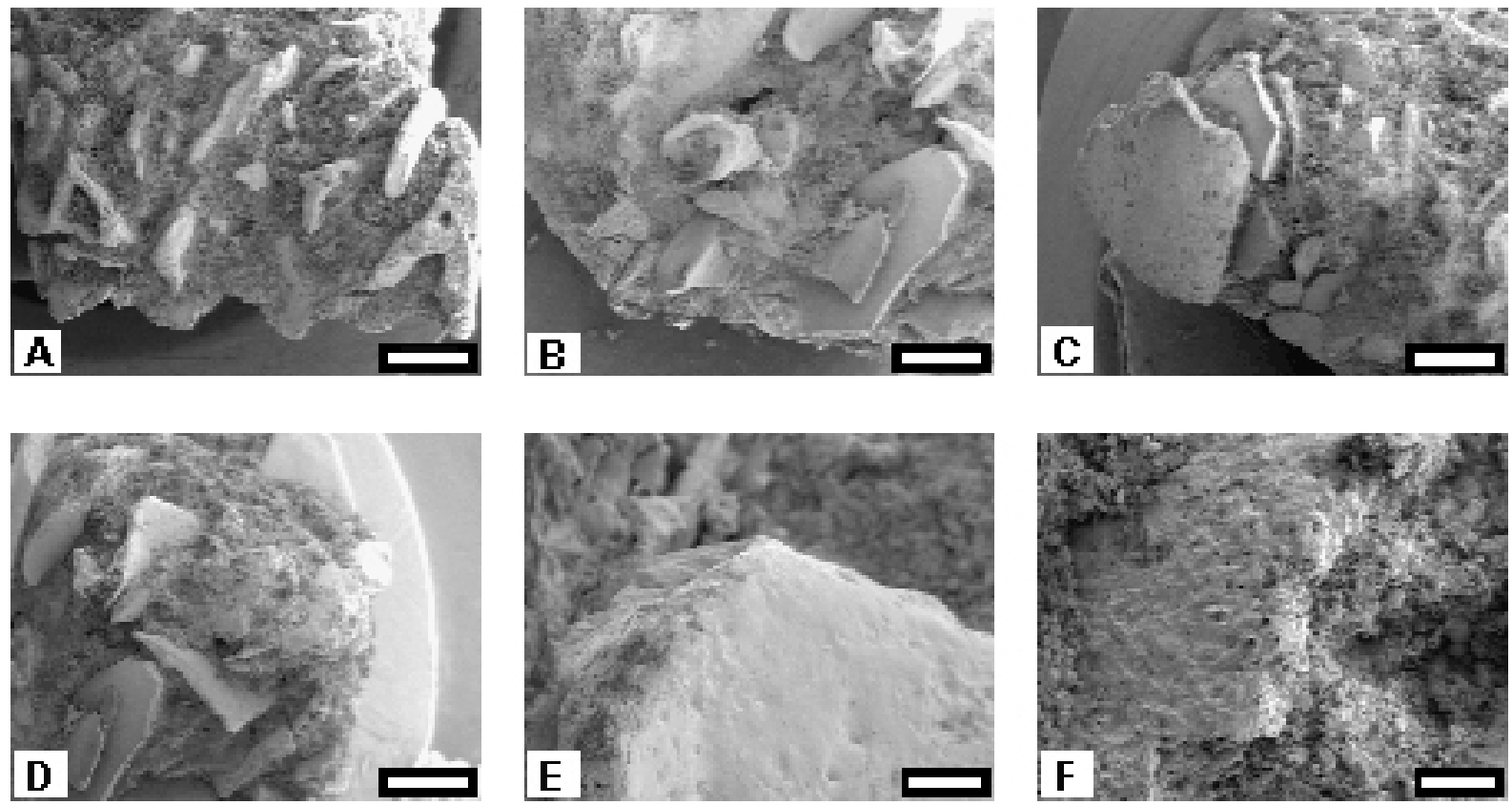

Figura 4.8. Coprolito (GHUNLPam 21912) A, B, C y D Vistas del coprolito, escalas 1000 $\mu$; E y F. mayor aumento de astillas óseas, escalas $100 \mu$ 

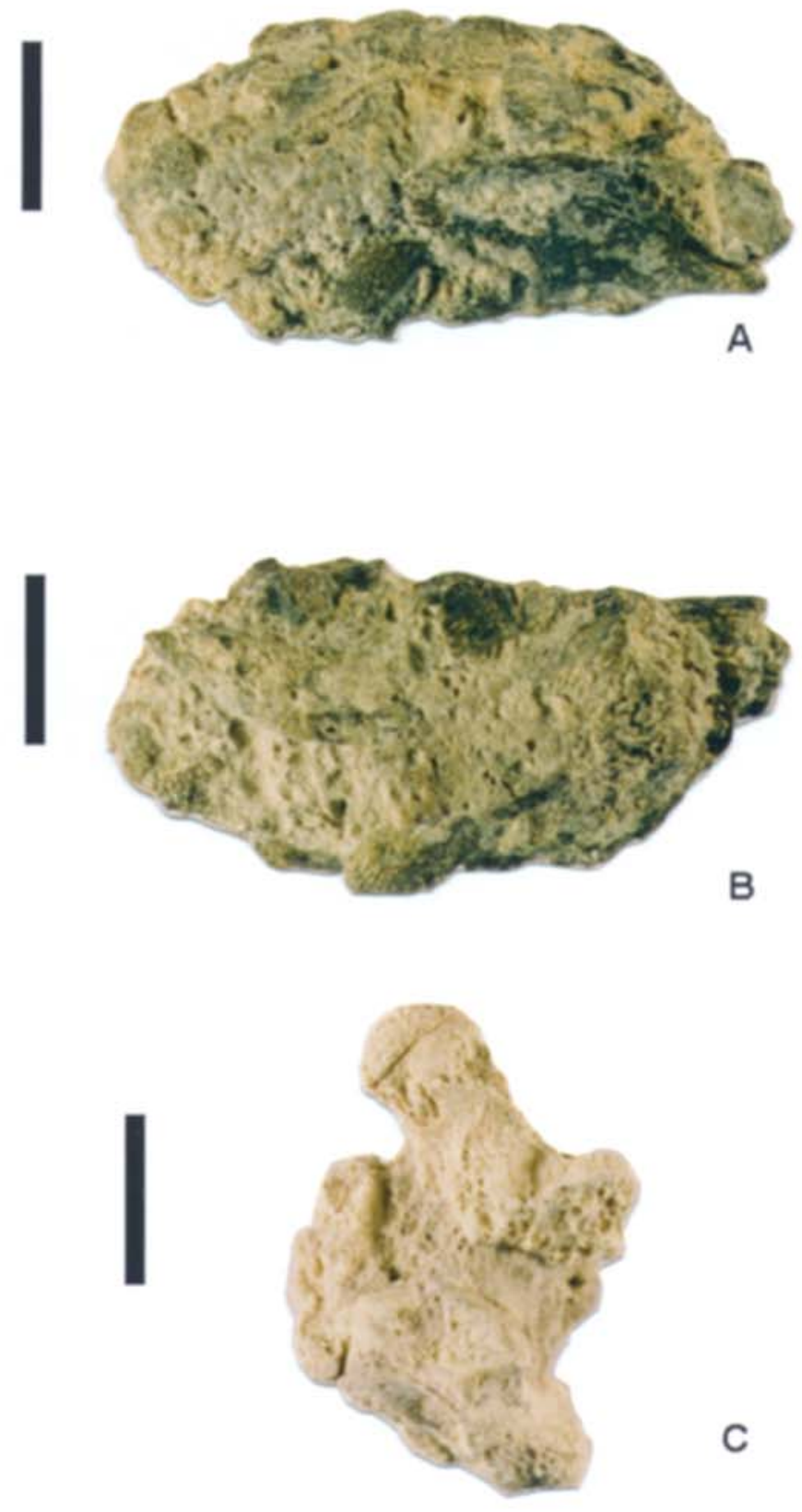

C

Lámina 4.1. Coprolitos. A y B. Vistas generales de GHUNLPam 21516; C. Vista general de GHUNLPam 22530, escalas $5 \mathrm{~mm}$. 
Paleobiología de la asociación faunística de Caleufú (La Pampa, Formación Cerro Azul, Mioceno superior - Plioceno inferior), a través de análisis tafonómicos

Lámina 4.1. Coprolitos. A y B. Vistas generales de GHUNLPam 21516; C. Vista general de GHUNLPam 22530, escalas $5 \mathrm{~mm}$. 

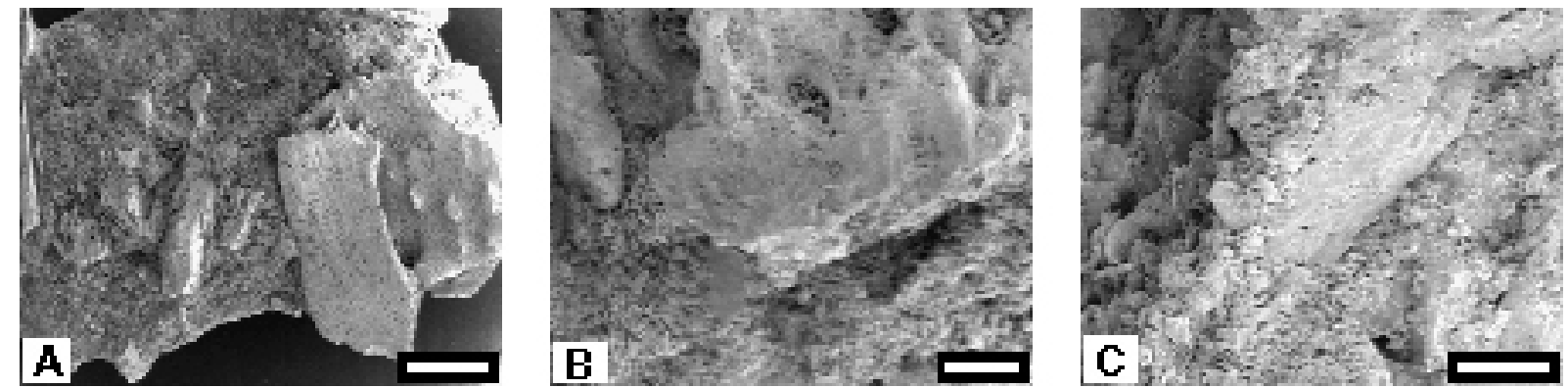

Figura 4.9. A. Coprolito (GHUNLPam 22563), escala $1000 \mu$.; B. aumento de una astilla ósea con evidencia de digestión, escala $100 \mu$; C. aumento de una astilla ósea con evidencia de digestión, escala $50 \mu$

- Fragmentos de coprolitos

Bajo esta categoría se incluyeron los siguientes especímenes: GHUNLPam 21074; 21091; 21521; 21593; 21923; 21924; 21925; 21927 (Figura 4.10); 21930; 21931; 22502; 22503; 22518; 22530 (Lámina 4.1. C); 22566; 22568; 22571 y 22578.
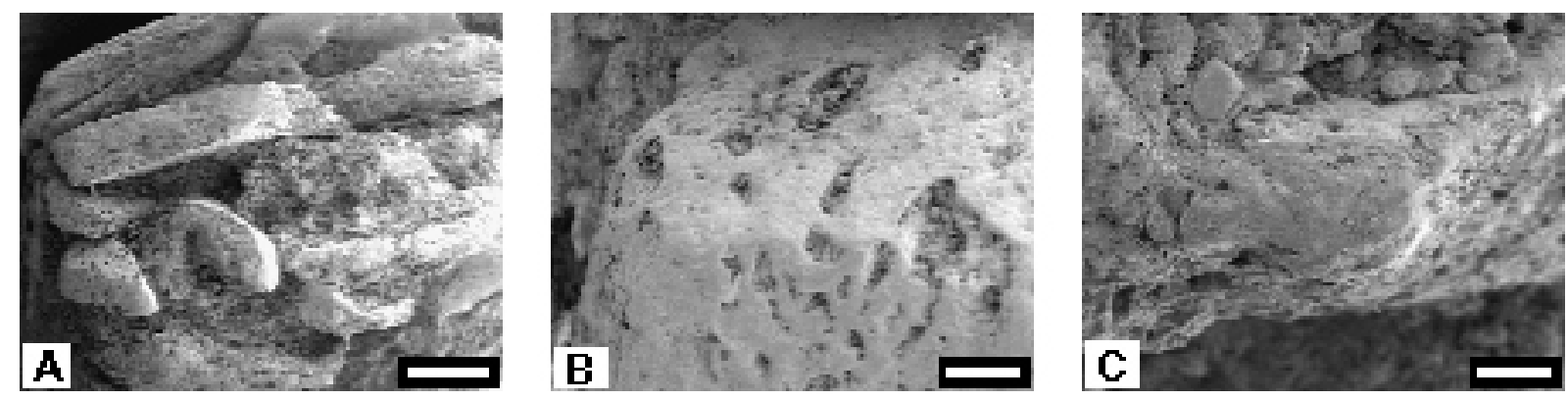

Figura 4.10. Coprolito (GHUNLPam 21927) A. fragmento de coprolito, escala $1000 \mu$; B y C. aumento de áreas óseas con evidencia de digestión, escalas $100 \mu$

La parte preservada de estos coprolitos indica que la forma era cilíndrica. El diámetro oscila entre 4,65 y $16,50 \mathrm{~mm}(\mathrm{~N}=9$; promedio: 10,39 mm). Los atributos que presentan estos especímenes son similares de los detallados para los coprolitos enteros. En cuanto a los elementos esqueléticos identificados, se pueden mencionar en GHUNLPam 21074 un fémur proximal roto; en GHUNLPam 21521 dos dientes de Paedotherium; en GHUNLPam 21539 un paladar de Palaeocavia sp. y un innominado; en GHUNLPam 21923 un pequeño metápodo; en GHUNLPam 22502 trozos de calcáneo y astrágalo asociados; en GHUNLPam 
22503 un fragmento de incisivo de roedor; en GHUNLPam 22530 un fémur proximal y en GHUNLPam 22566 una vértebra.

- Fragmentos óseos asociados con muy fuerte grado de digestión que indicaría que estuvieron incluidos en un coprolito

Esta categoría incluye los siguientes especímenes: GHUNLPam 21154/1; 21726; 21727/1-3; 21910; 21911; 21922; 21928; 21929; 21932; 21933; 21934; 21935; 21968; 22521; 22522; 22523; 22529; 22531; 22532; 22533; 22534; 22535; 22536; 22537; 22541; 22547; 22553; 22554; 22567; 22569; 22570; 22572 у 22577.

Estos especímenes están constituidos por fragmentos de elementos esqueléticos asociados y su característica más notable es el fuerte grado de digestión que presentan. En algunos casos se trata de astillas o porciones de huesos largos no reconocibles. Se han identificado en GHUNLPam 21154/1 una vértebra; en GHUNLPam 21727/1 una diáfisis que contiene varias astillas con digestión fuerte (Figura 4.11 A) en GHUNLPam 21727/2 un diente de Paedotherium incluido en la médula de una diáfisis (Figura $4.11 \mathrm{~B}$ ); en GHUNLPam 21726 una vértebra cervical con varias astillas óseas (Figura 4.12); en GHUNLPam 21910 un fémur proximal y un fragmento de vértebra; en GHUNLPam 21911 un fémur proximal y un fémur; en GHUNLPam 21929 un innominado; en GHUNLPam 21933 un incisivo superior de Paedotherium; en GHUNLPam 21968 un rostro de Paedotherium con una porción de incisivo; en GHUNLPam 22529 una vértebra y una porción de fémur proximal; en GHUNLPam 22531 un metápodo; en GHUNLPam 22534 una vértebra; en GHUNLPam 22542 dientes de Paedotherium; en GHUNLPam 22547 fragmentos de astrágalo, calcáneo y epífisis de tibia y en GHUNLPam 22569 un innominado. 

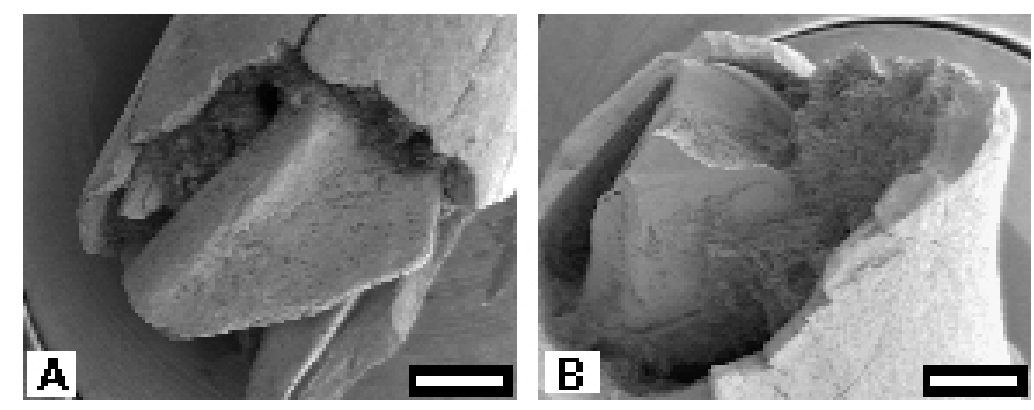

Figura 4.11. A. diáfisis con astillas óseas (GHUNLPam 21727/1); B. diáfisis con diente de Paedotherium (GHUNLPam 21727/2), escalas $1000 \mu$

Los especímenes analizados asignados a coprolitos, fragmentos de coprolitos y fragmentos óseos asociados con muy fuerte grado de digestión, se caracterizan por constituir una asociación homogénea en cuanto a su tamaño o tamaño estimado y por el grado de digestión y rotura de los elementos óseos incluidos en ellos, caracteres similares a los presentes en heces de mamíferos actuales (Andrews, 1990; Fernández Jalvo y Andrews, 1992; Stahl, 1996). Sin embargo, también algunas aves diurnas, como las águilas (Accipritiformes, Accipritidae) pueden producir egagrópilas que incluyen huesos con las mismas modificaciones (Hockett, 1996). Al respecto, Fernández Jalvo (1995) indicó que los mamíferos carnívoros producen algo de redondeamiento en los bordes de los elementos esqueléticos y se presentan marcas de dientes en elementos de algunas asociaciones formadas por cánidos y mustélidos. En este caso, se identificaron marcas de dientes sobre astillas en dos especímenes. La modificación observada en los restos incluidos en los coprolitos es siempre fuerte o extrema. Sin embargo, en los dientes incluidos en los coprolitos, el esmalte no manifiesta los efectos de ácidos digestivos tal como sería esperable en concordancia con la que presentan otros elementos esqueléticos. Como se verá más adelante, el grado de rotura de las piezas también coincide con este tipo de productor, sin embargo no se puede determinar la razón por la cual el esmalte de los dientes está afectado en menor medida que las superficies óseas de otros elementos esqueléticos. Como se mencionó antes, la capa de cemento que cubre a estos dientes podría haber actuado como estructura protectora del esmalte frente a la acción de los jugos digestivos. 


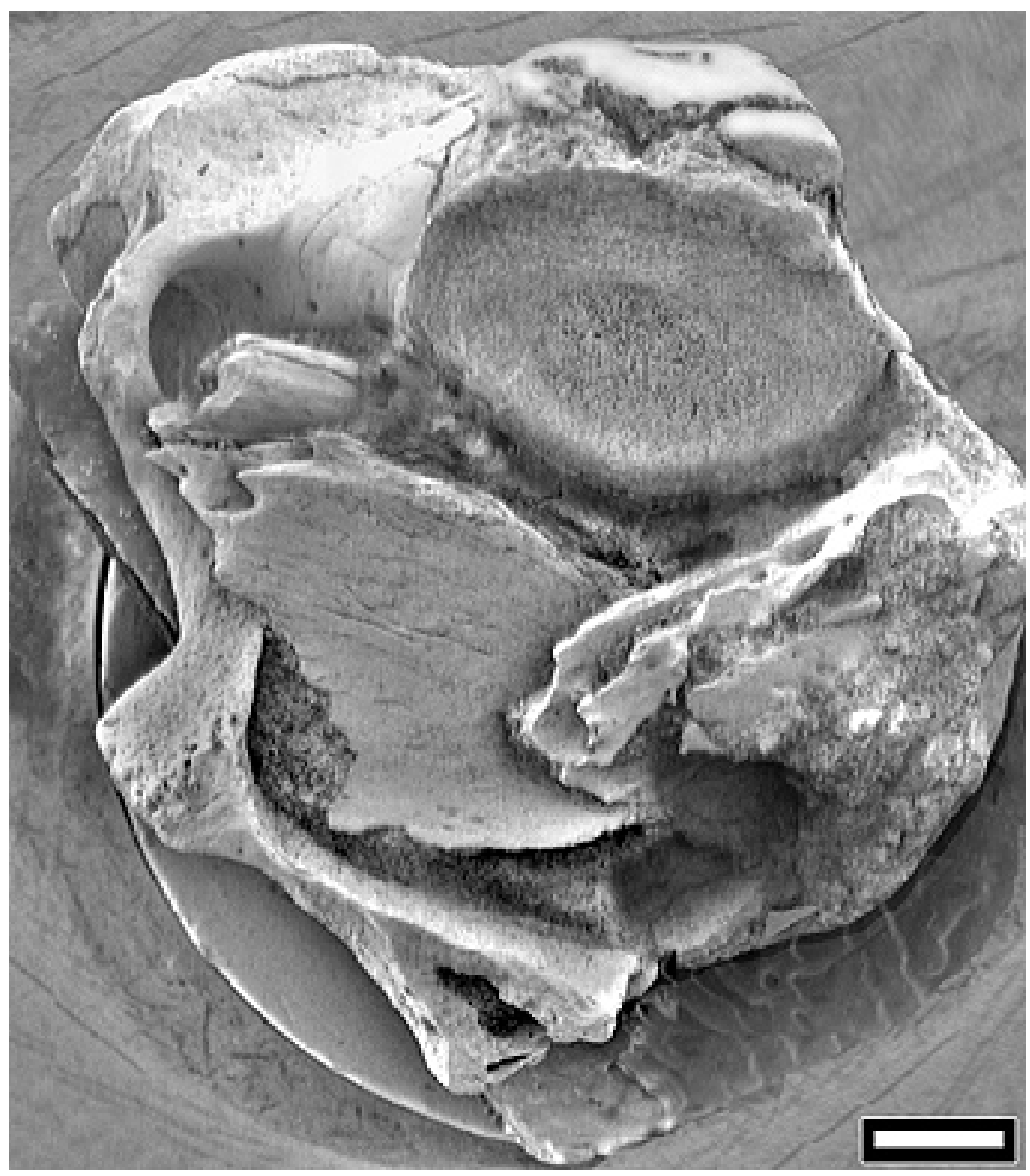

Figura 4.12. Fragmentos óseos asociados (GHUNLPam 21726), vértebra y astillas óseas con evidencias de digestión, escala $1000 \mu$

Los elementos esqueléticos reconocibles en los coprolitos, en particular los dientes que se han determinado taxonómicamente, corresponden a taxa incluidos en la asociación de microvertebrados. Esto podría avalar el sincronismo de la asociación de coprolitos y la de microvertebrados. Se plantea entonces la hipótesis que el productor de los coprolitos pueda ser también el productor de la concentración de microvertebrados. En este contexto ambas asociaciones constituirían una coprocenosis (Mellet, 1974), definida como la asociación de fósiles formada por reagrupamiento de restos defecados (Fernández López, 2000), pero debe tenerse en cuenta que ambas presentan restos con diferentes grados de digestión, característica que no sustenta aquella hipótesis. Otra 
posibilidad sería que el mismo productor hubiese generado las dos asociaciones y las diferencias mencionadas en el grado de digestión respondan a un comportamiento particular del depredador (un mamífero carnívoro), por ejemplo la regurgitación de masas con elementos no digeridos (Stahl, 1996). 


\section{GRADO DE BIOEROSIÓN}

La bioerosión es un mecanismo de alteración tafonómica y corresponde a la acción erosiva producida por organismos sobre un sustrato duro (Fernández López, 2000).

Se describen aquí dos grupos de atributos bioerosivos. Por un lado, aquellos relacionados con la actividad de los depredadores sobre los elementos esqueléticos en el momento de la muerte de la presa como marcas de dientes y arañazos que indican que los restos óseos fueron mordidos, masticados y manipulados. El otro grupo incluye a los atributos bioerosivos relacionados con la actividad de bacterias, hongos, líquenes, raíces de vegetales y ácidos del suelo, que se manifiestan como diferentes tipos de corrosión y que han ido afectando a los especímenes en distintos momentos de su historia tafonómica. También se identificaron algunos especímenes con marcas producidas por incisivos de roedores, atributo bioerosivo cuya edad de formación es incierta, ya que puede haber ocurrido antes o después del enterramiento de los restos.

La bioerosión es un atributo que se analizó sobre todos los restos recuperados de la asociación de Caleufú, incluyendo los fragmentos indeterminables y los especímenes asignados a coprolitos.

Atributos bioerosivos relacionados con la actividad de los depredadores sobre los elementos esqueléticos en el momento de la muerte de la presa

- Marcas de dientes

Fueron reconocidas marcas de dientes sobre 100 especímenes de la asociación de microvertebrados y en elementos óseos incluidos en algunos coprolitos. También se encontró este tipo de marcas en 18 fragmentos indeterminables. Estos valores indican que este atributo afecta a menos del $2 \%$ de los restos de la asociación de Caleufú y si bien es un valor bajo, es de gran importancia paleoecológica. 
Las marcas de dientes se manifiestan de dos maneras. El primer tipo corresponde a pequeñas marcas de presión producidas directamente por los dientes que generalmente son superficiales y afectan sólo al hueso compacto (Lámina 4.2. A y B). En el segundo tipo se incluyen las señales dejadas por el accionar de los dientes en el momento de la mordida. Estas marcas son de tamaño mayor que las primeras, más profundas e incompletas, ya que siempre se asocian a bordes óseos (Lámina 4.2. C, D y E).

Las marcas de dientes son generalmente subcirculares a ovaladas, en algunos casos están rellenas de cemento, presentan pequeñas fracturas en sus bordes y el fondo es generalmente plano y con múltiples fracturas en su superficie (Figura 4.13).
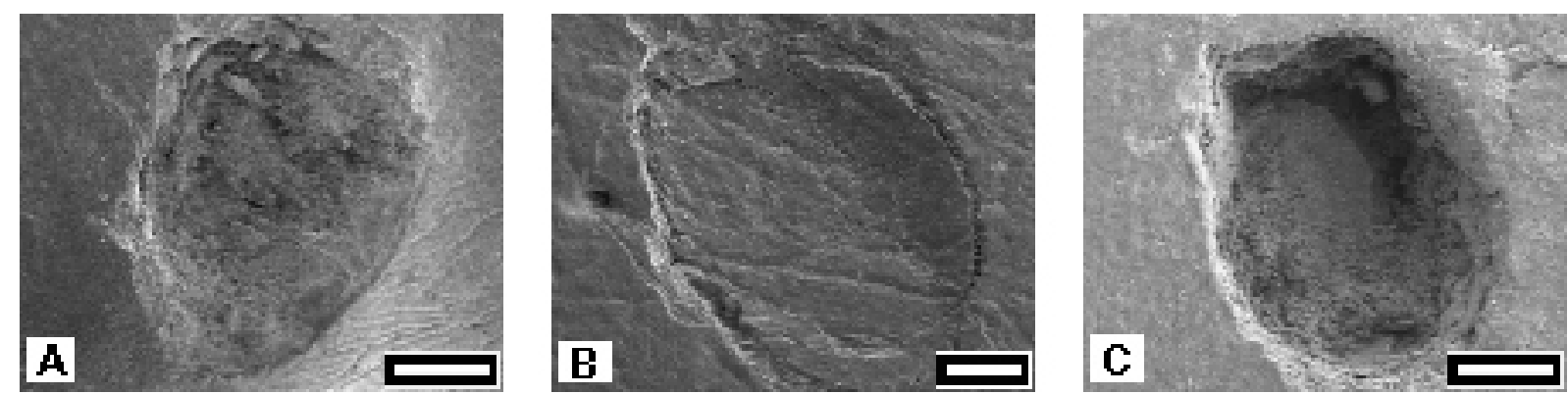

Figura 4.13. A. Marca de diente en una hemimandíbula de Xenodontomys elongatus (GHUNLPam 19669), escala $500 \mu$; B. marca de otro diente en la misma hemimandíbula; C. marca de diente en una hemimandíbula de Xenodontomys elongatus (GHUNLPam 19693), B y C escalas $500 \mu$

Estas marcas fueron identificadas en 53 restos de la asociación de microvertebrados, coprolitos y fragmentos indeterminables. El promedio de tamaño de cada marca es de 1,94 $\mathrm{mm}$ de largo (con valores máximos y mínimos de 3,90 y $0,45 \mathrm{~mm}$ ) y $1,54 \mathrm{~mm}$ de ancho (con valores máximos y mínimos de 3,00 y $0,30 \mathrm{~mm}$ ). Se presentan en forma individual (en 31 especímenes) o en grupos de 2 (18 especímenes), 3 (4 especímenes) o 4 (1 espécimen). Generalmente se las ha hallado en el mismo lado del elemento óseo (Lámina 4.2. A y B) y en algunos casos (3 especímenes) se presentan marcas en dos lados, indicando el accionar de dientes superiores e inferiores.

Se encontraron también marcas de dientes de mayor tamaño en 3 fragmentos indeterminables. En los tres casos se trata de 2 marcas en el mismo lado y el promedio de tamaño de las mismas es de 3,45 mm de largo (con valores 
máximos y mínimos de 4,20 y $1,35 \mathrm{~mm}$ ) y $2,75 \mathrm{~mm}$ de ancho (con valores máximos y mínimos de 3,75 y $0,77 \mathrm{~mm}$ ).

En 30 especímenes correspondientes a elementos postcraneanos de Mammalia indet. (escápulas, innominados, calcáneos, vértebras, fémures distales, tibias proximales y ulnas) hay marcas de dientes. En general se encuentran en la zona más robusta de los elementos esqueléticos. En 2 coprolitos se identificaron astillas óseas con marcas de dientes.

En la Tabla 4.4 se muestra la cantidad de especímenes identificados por taxón (NEIT=65) con marcas de dientes (exceptuando 3 especímenes de Rodentia indet.), señalando para cada taxón su NMI y el porcentaje de individuos con evidencias de acción de un depredador a través de estas marcas. Se observa que los taxa más afectados son los Caviidae Palaeocavia sp. y Neocavia cf. $\mathrm{N}$. Iozanoi. También son abundantes en el hegetoterino Paedotherium minor y el cávido Orthomyctera sp. Coincidentemente restos identificables de Palaeocavia sp. y Paedotherium minor fueron identificados en coprolitos.

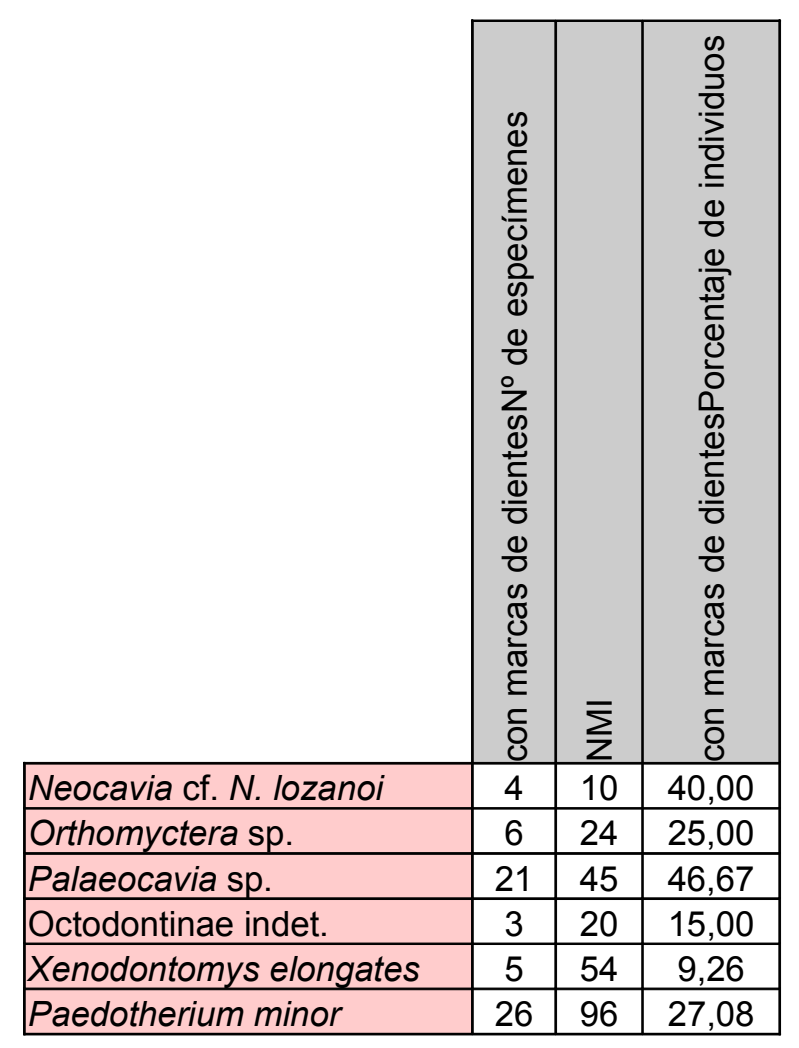

Tabla 4.4. Número de especímenes identificados por taxón con marcas de dientes, NMI y porcentaje de individuos por taxón con esas señales 


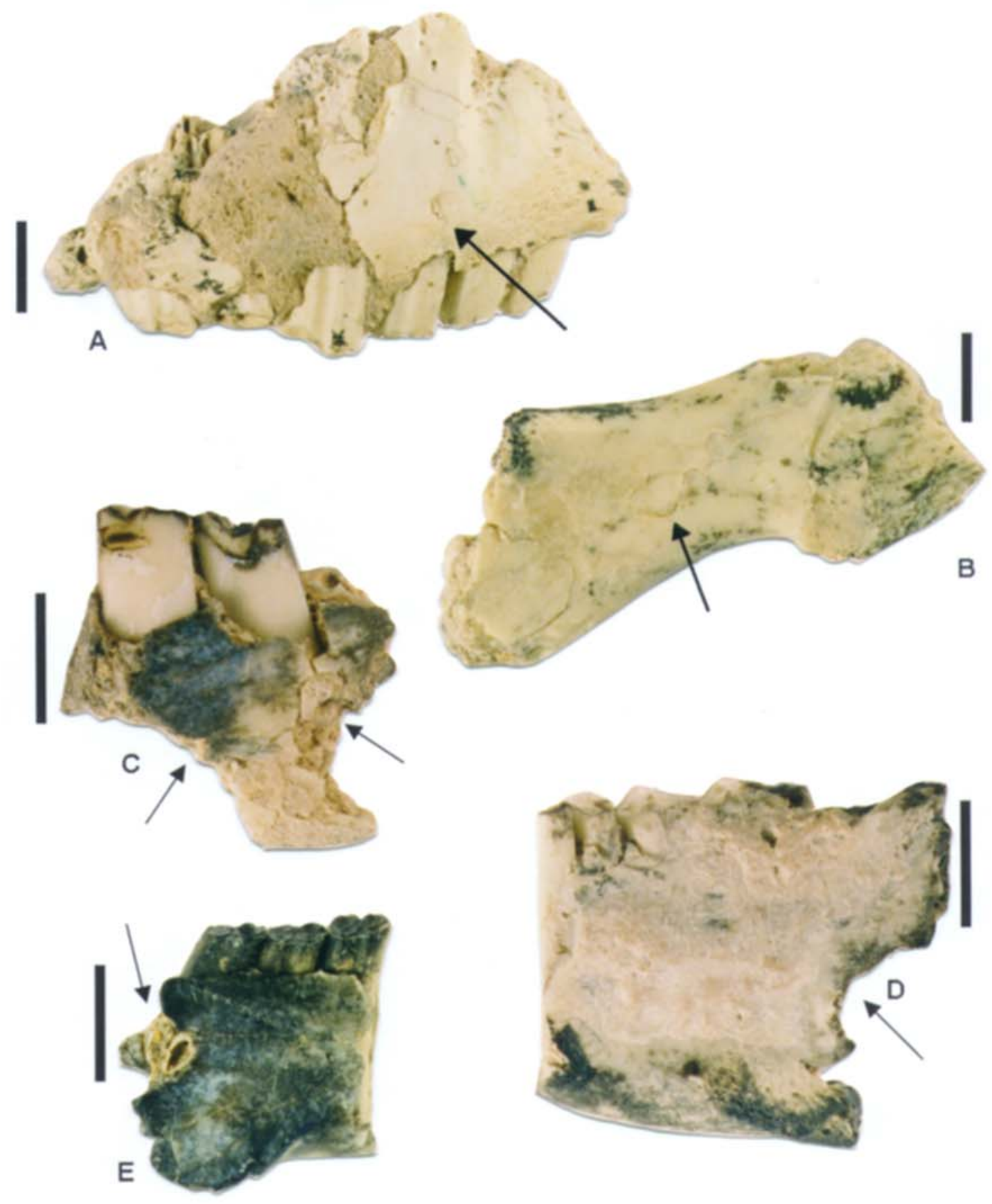

Lámina 4.2. Marcas de dientes. A. dos marcas sobre un paladar de Paedotherium minor (GHUNLPam 19209); B. tres marcas sobre un innominado (GHUNLPam 19865/66); C. marcas de mordida sobre hemimandibula de Paedotherium minor (GHUNLPam 19392);

D. marca de mordida sobre hemimandibula de Paedotherium minor (GHUNLPam 19421); E. marca de mordida sobre hemimandibula del Octodontinae gen.y sp. nov. (GHUNLPam 19818), escalas 5 mm 
Paleobiología de la asociación faunística de Caleufú (La Pampa, Formación Cerro Azul, Mioceno superior - Plioceno inferior), a través de análisis tafonómicos 
Lámina 4.2. Marcas de dientes. A. dos marcas sobre un paladar de Paedotherium minor (GHUNLPam 19209); B. tres marcas sobre un innominado (GHUNLPam 19865/66); C. marcas de mordida sobre hemimandíbula de Paedotherium minor (GHUNLPam 19392);

D. marca de mordida sobre hemimandíbula de Paedotherium minor (GHUNLPam 19421); E. marca de mordida sobre hemimandíbula del Octodontinae gen.y sp. nov. (GHUNLPam 19818); escalas $5 \mathrm{~mm}$ 
También es de destacar que las marcas de dientes son frecuentes sobre restos asignados a individuos juveniles. De los 65 especímenes identificados por taxón con marcas de dientes, el 32,31\% pertenece a ese grupo de individuos. En cuanto a los elementos postcraneanos (30), sólo el 16,66 \% corresponde a especímenes asignados a individuos juveniles.

Por otro lado, se han identificado señales dejadas por los dientes en el momento en que la mordida produjo la rotura del elemento esquelético (62 especímenes); aparecen por ejemplo en la zona posterior de las hemimandíbulas y se manifiestan como áreas en el borde del resto con múltiples fracturas (Lámina 4.2. B, C y D; Figura 4.14). En algunos especímenes, a estas señales se suman marcas longitudinales y paralelas, que se podrían atribuir al accionar de los dientes sobre el hueso.

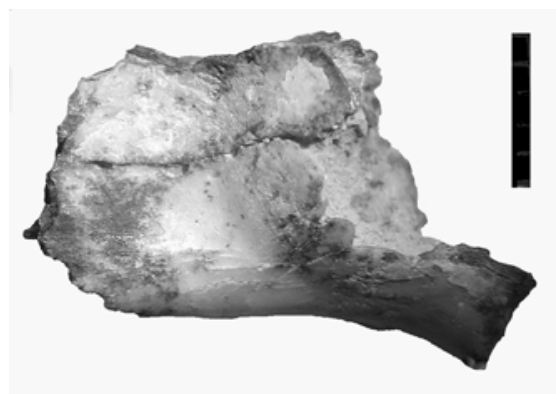

Figura 4.14. Fragmento indeterminable con borde mordido, escala $5 \mathrm{~mm}$.

En los casos en que ha sido posible inferir un diámetro máximo para estas señales, éste es similar al de las marcas de mayor tamaño antes mencionadas. La diferencia en el tamaño de las marcas podría indicar que más de un tipo de carnívoros sería responsable de estas señales, o bien que las marcas producidas por un sólo depredador difieren entre sí de acuerdo al área ósea donde se produce la mordida y/o a la presión ejercida durante la misma. Se ha señalado que hay un tamaño máximo límite en las marcas dejadas por pequeños carnívoros, de modo tal que estos no pueden producir marcas mayores a ese límite, pero los carnívoros de mayor tamaño pueden realizar marcas de varios tamaños (Andrews y Fernández-Jalvo, 1997).

Es de destacar que para asociaciones actuales Andrews y Evans (1983) y Andrews (1990) señalaron que las marcas de dientes son raras en los 
especímenes excepto en aquellas concentraciones producidas por cánidos y mustélidos.

- Marcas de arañazos y roído

Las marcas de arañazos y roído aparecen en los bordes del elemento esquelético. Estas marcas son más frecuentes entre los fragmentos indeterminables (98 restos con marcas), pero también se identificaron sobre 37 especímenes que incluyen principalmente hemimandíbulas de Paedotherium minor (13 especímenes), de diferentes taxa de roedores (10 especímenes) y de otros mamíferos (3 especímenes), en elementos postcraneanos de mamíferos indet. (11 especímenes) y en un fémur de ave.

En general se trata de varias perforaciones de diferente profundidad, con forma de "U" aplanada o de "V" (Figura 4.15). Por su forma pueden ser atribuidas a marcas dejadas por carnívoros.
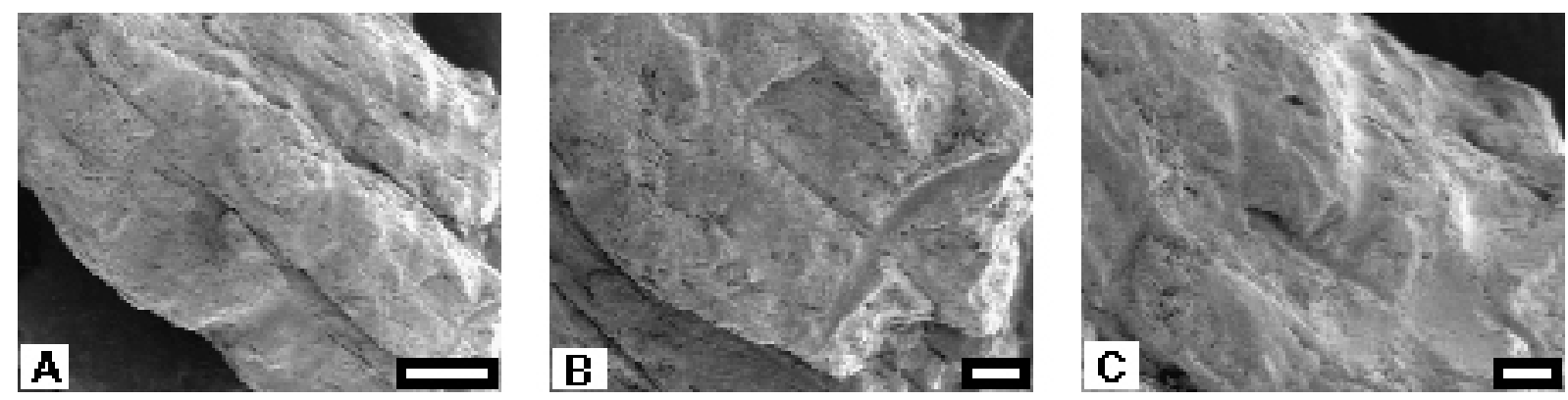

Figura 4.15. A. Marcas sobre un fragmento indeterminable, escala.1000 $\mu$; B. mayor aumento de ese mismo resto; $\mathrm{C}$. otra vista con mayor aumento del mismo resto; $\mathrm{B}$ y $\mathrm{C}$. escalas $200 \mu$

Algunos ejemplares presentan marcas producidas por los incisivos de roedores. Se trata de marcas paralelas (generalmente de a pares) de fondo plano y con una ligera elevación entre cada marca (Figura 4.16). Estas marcas han sido producidas sobre el resto una vez que éste se mineralizó. Esto último se evidencia bien en los especímenes con cierto grado de impregnación dendritiforme por óxidos de manganeso, ya que las líneas de avance de la impregnación están cortadas por la marca realizada, indicando la secuencia de los eventos tafonómicos (impregnación-marca de roído). 

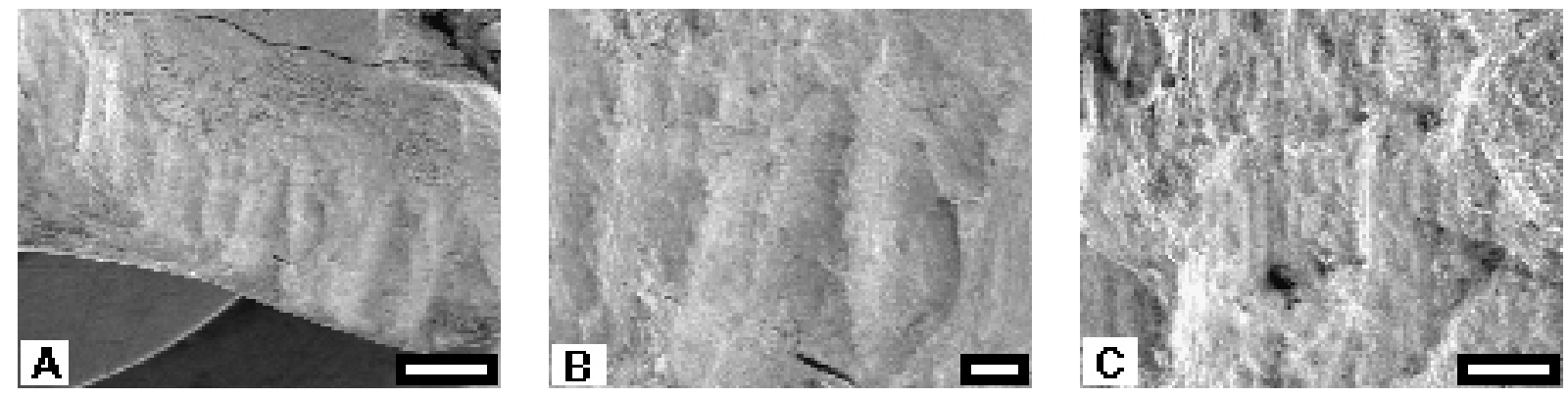

Figura 4.16. A. marcas de roído sobre una mandíbula de Paedotherium minor (GHUNLPam 19216), escala $1000 \mu$; B. mayor aumento de ese mismo espécimen, escala $200 \mu$; C. otra vista con mayor aumento del mismo espécimen, escala $100 \mu$

La ausencia de marcas de roído producidas sobre huesos secos sería un indicio del enterramiento rápido de estos elementos esqueléticos (Diez et al., 1999). Por otro lado, su presencia en restos mineralizados es una evidencia de reelaboración, es decir de una reexposición posterior al enterramiento inicial.

\section{Corrosión sobre los restos}

En la asociación de Caleufú el 10,19 \% de los restos presenta evidencia de corrosión bioerosiva (Figura 4.17). La misma afectó la superficie ósea y/o dentaria (se consideró evidencia cuando al menos la tercera parte de la superficie ósea está modificada). Muchos restos presentan pequeñas marcas de corrosión, áreas con cambio de color o punteaduras, que no fueron evaluadas en el conteo general por su tamaño reducido. Estos tipos de corrosiones bioerosivas se presentan en áreas localizadas de los elementos esqueléticos y se pueden diferenciar de la corrosión producida por digestión, ya que, en este último caso, la corrosión es homogénea en el elemento esquelético, a veces localizada en sus bordes (Fernández Jalvo, 1995). 


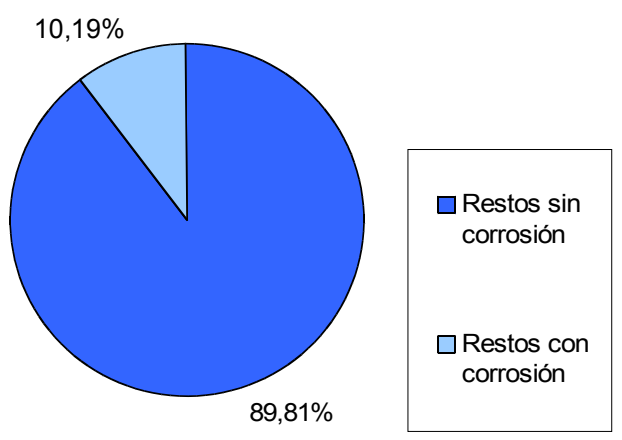

Figura 4.17. Porcentaje de restos con evidencias de corrosión

La corrosión se manifiesta como una alteración de áreas óseas o dentarias de contorno irregular, en muchas ocasiones excavadas y también como pequeñas cavidades y surcos, que en algunos casos tienen variación de color con respecto a otras áreas donde no hay corrosión.

En los restos de la asociación de Caleufú se identificaron varios tipos de marcas de corrosión:

- Señales producidas por el crecimiento de raíces

Estas señales de bioerosión corresponden a las marcas dejadas por el crecimiento de raíces en la interfase elemento esquelético-sedimento. Las marcas de raíces se desarrollan sobre la superficie de los elementos esqueléticos. Los hongos y bacterias asociadas a las raíces pueden causar corrosión sobre los restos (Fernández Jalvo, 1995). El desarrollo de las raíces sobre los elementos esqueléticos produjo dos tipos de trazas o estructuras biogénicas sobre los especímenes, que corresponden a las categorías sphenoichnia y corrosichnia descriptas por Mikulas (1999). Las mismas pueden haber sido sobreimpuestas en el resto esquelético en diferentes momentos de la historia tafonómica. Estos tipos de estructuras biogénicas fueron identificados previamente en especímenes recuperados de la asociación faunística de la Formación Cerro Azul en Telén (Montalvo, 2002 a).

Sphenoichnia y corrosichnia fueron observadas en el 3,81\% de los restos (Figura 4.18). 


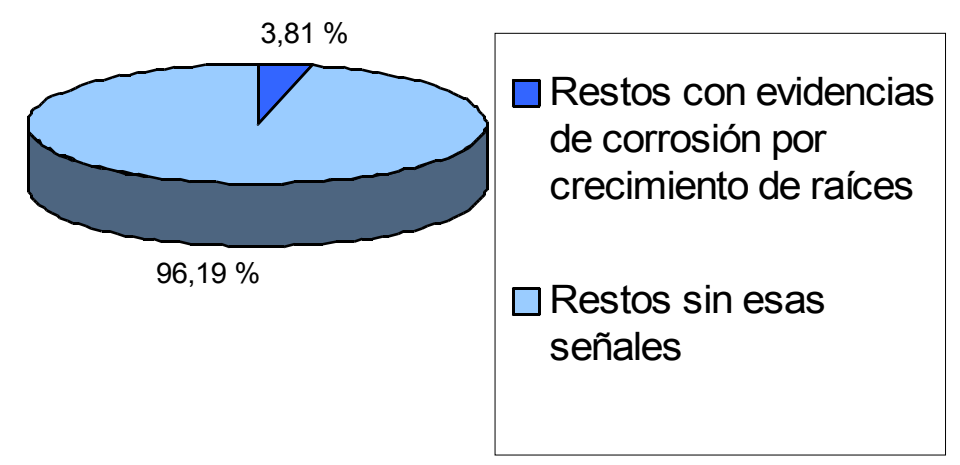

Figura 4.18. Porcentaje de restos con evidencias de corrosión por el accionar de raíces

Sphenoichnia está representada por pequeñas marcas dendríticas superficiales irregulares, con ejes principales y ramificaciones, que forman canales con márgenes nítidos (Figura 4.19). No hay cambio de color en el área afectada por esta traza, si bien se la ha encontrado tanto en restos poco impregnados por óxidos de manganeso, como en aquellos muy impregnados. Esta traza se ha observado en el $0,50 \%$ del total de restos.

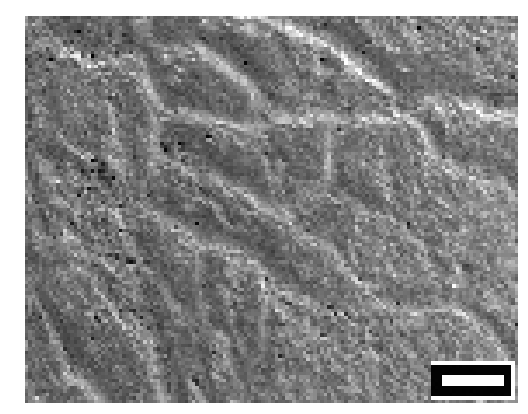

Figura 4.19. Sphenoichnia sobre un espécimen de Paedotherium minor (GHUNLPam 19844), escala $200 \mu$

Corrosichnia, es más abundante y fue observada en el 3,31 \% de los restos. Se trata de una marca de disolución superficial, de mayor espesor que la anterior, más profunda y con fondo en forma de "U" aplanada, en general sin bifurcaciones, pero puede tener pequeñas punteaduras asociadas a sus bordes (Lámina 4.3 y Figura 4.19). 


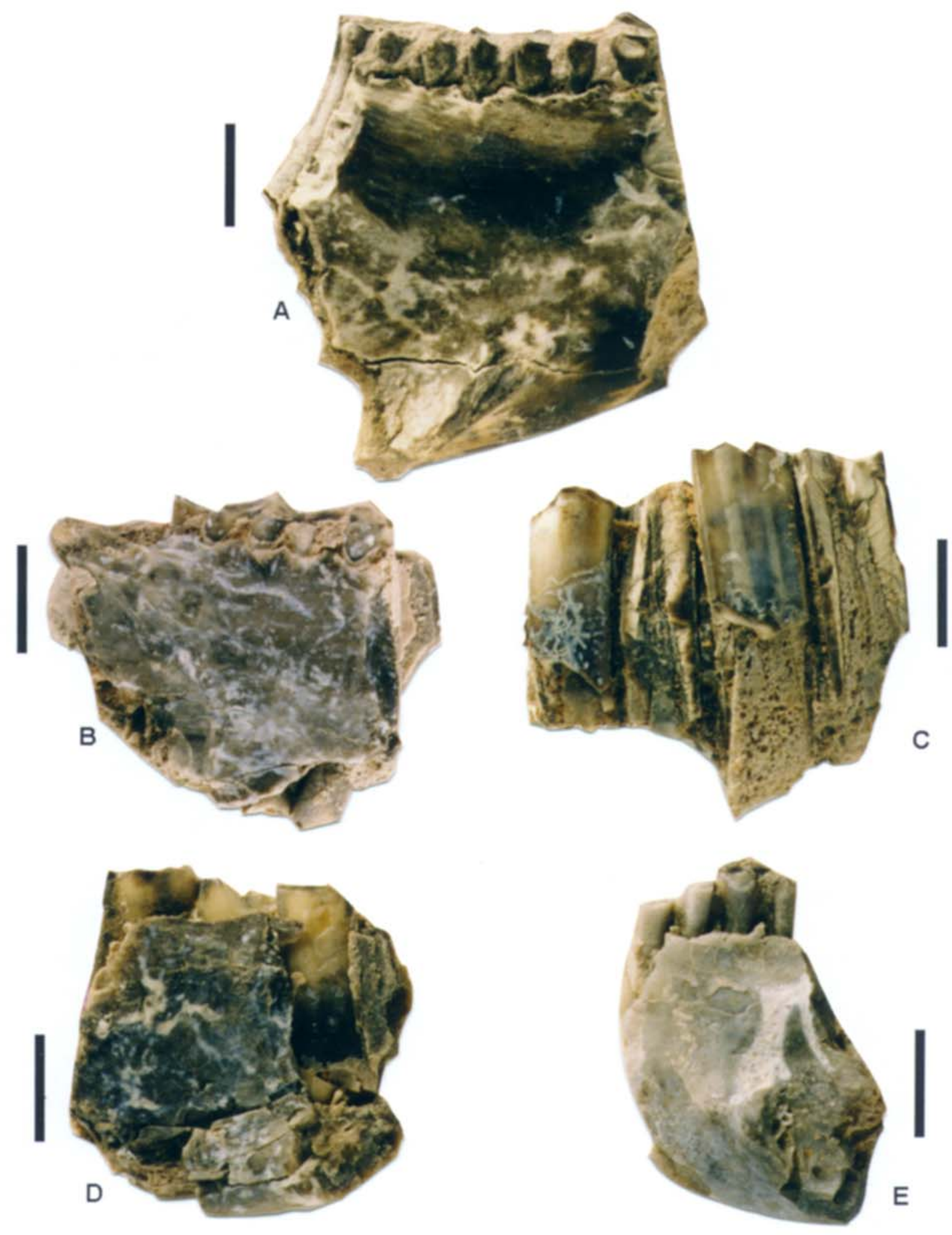

Lámina 4.3. Corrosichnia sobre mandibulas y molariformes de Paedotherium minor.

A. GHUNLPam 19428; B. GHUNLPam 19257; C. GHUNLPam 19229; D.

GHUNLPam 19244; E. GHUNLPam 19256, escalas 5 mm 
Lámina 4.3. Corrosichnia sobre mandíbulas y molariformes de Paedotherium minor.

A. GHUNLPam 19428; B. GHUNLPam 19257; C. GHUNLPam 19229; D. GHUNLPam 19244; E. GHUNLPam 19256, escalas 5 mm 

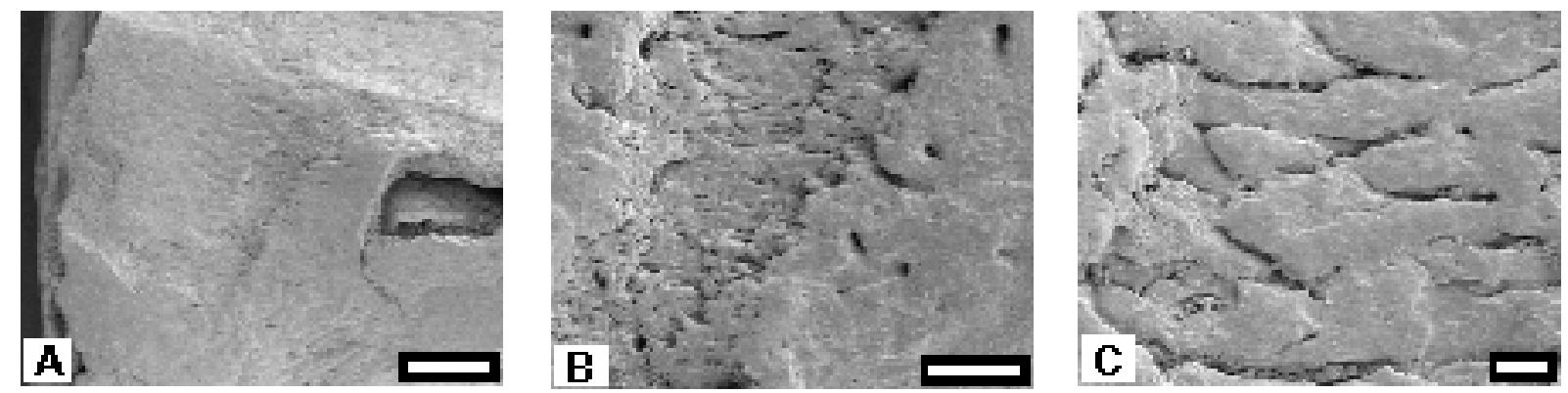

Figura 4.19. A. Corrosichnia sobre un espécimen de Paedotherium minor (GHUNLPam 19631), escala $1000 \mu$; B. mayor aumento del área con corrosichnia, escala $200 \mu$; C. mayor aumento del área con corrosichnia, escala $20 \mu$

Corrosichnia es muy notable en los restos que tienen mucha impregnación por óxidos de manganeso, ya que en esos casos la corrosión produjo un cambio de color en el área afectada (Lámina 4.3), pero también se observó, con las mismas características, en restos sin impregnación.

La traza sphenoichnia es similar a las marcas que, sobre elementos esqueléticos actuales y fósiles, fueron descriptas como producidas por raíces (Andrews, 1990; Lyman, 1994). Las características de esta traza y su presencia sin cambio de color en los restos impregnados por óxidos de manganeso indicarían que se produjo sobre los restos en las primeras fases posteriores al enterramiento, durante los primeros estadios diagenéticos (Montalvo, $2002 \mathrm{a}$ ).

En cambio corrosichnia se habría producido en cualquier momento posterior al enterramiento del resto, ya que afecta del mismo modo a los especímenes, pero en los muy impregnados provoca, además, cambio de color por efecto de la corrosión.

La baja proporción de restos con sphenoichnia podría estar relacionada con el desarrollo de un sustrato con escasa vegetación en el momento del enterramiento, o con la rápida formación de una cubierta calcárea sobre los restos, o con ambos procesos. La mayor proporción de restos con corrosichnia puede indicar que estos restos permanecieron en algún momento cercanos a la superficie expuesta. 
- Corrosiones provocadas por hongos, bacterias y ácidos propios del sustrato

Algunos restos presentan áreas corroídas de contorno irregular, que muestran cambio de color en los casos de los impregnados. Se presentan como grupos de pequeños círculos con degradación del material óseo y cambio de color, también como áreas deprimidas, surcos irregulares, disolución de sectores con contorno regular del elemento conservado o simplemente como grandes áreas con cambio de color (Lámina 4.4. A, B, C y D).

En algunos casos se presenta corrosión irregular en los dientes, afectando cemento, esmalte y dentina en los casos más severos. El cemento que rodea a los dientes en cávidos, octodóntidos y Paedotherium minor está comúnmente afectado por corrosión. Ésta se presenta como pequeñas áreas rugosas o directamente áreas con disolución total del cemento (Lámina 4.4. E). El esmalte también se modifica en algunos casos y la corrosión se manifiesta como marcas con cambio de color, irregulares y rugosas o directamente por su disolución en algunos sectores, dejando expuesta la dentina que es rápidamente corroída (Figura 4.20).

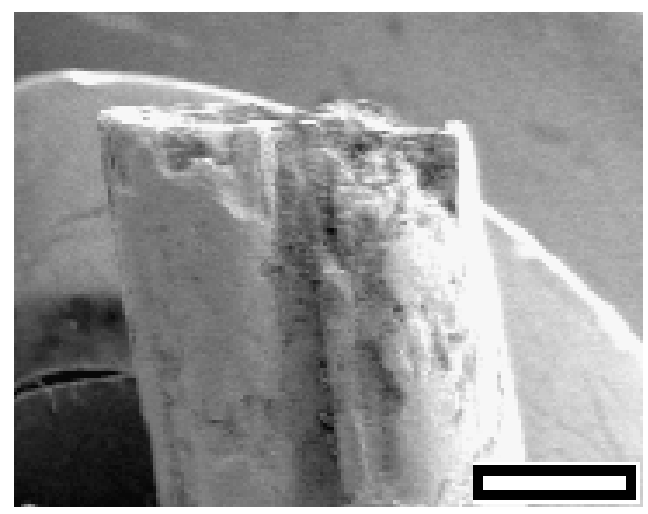

Figura 4.20. Diente del Octodontinae indet. GHUNLPam 19789, muy afectado por corrosión, escala $1000 \mu$

No fue posible identificar un patrón de comportamiento etológico para estas corrosiones; en este caso los restos podrían haber sido afectados por ácidos propios del sustrato, hongos o bacterias. 

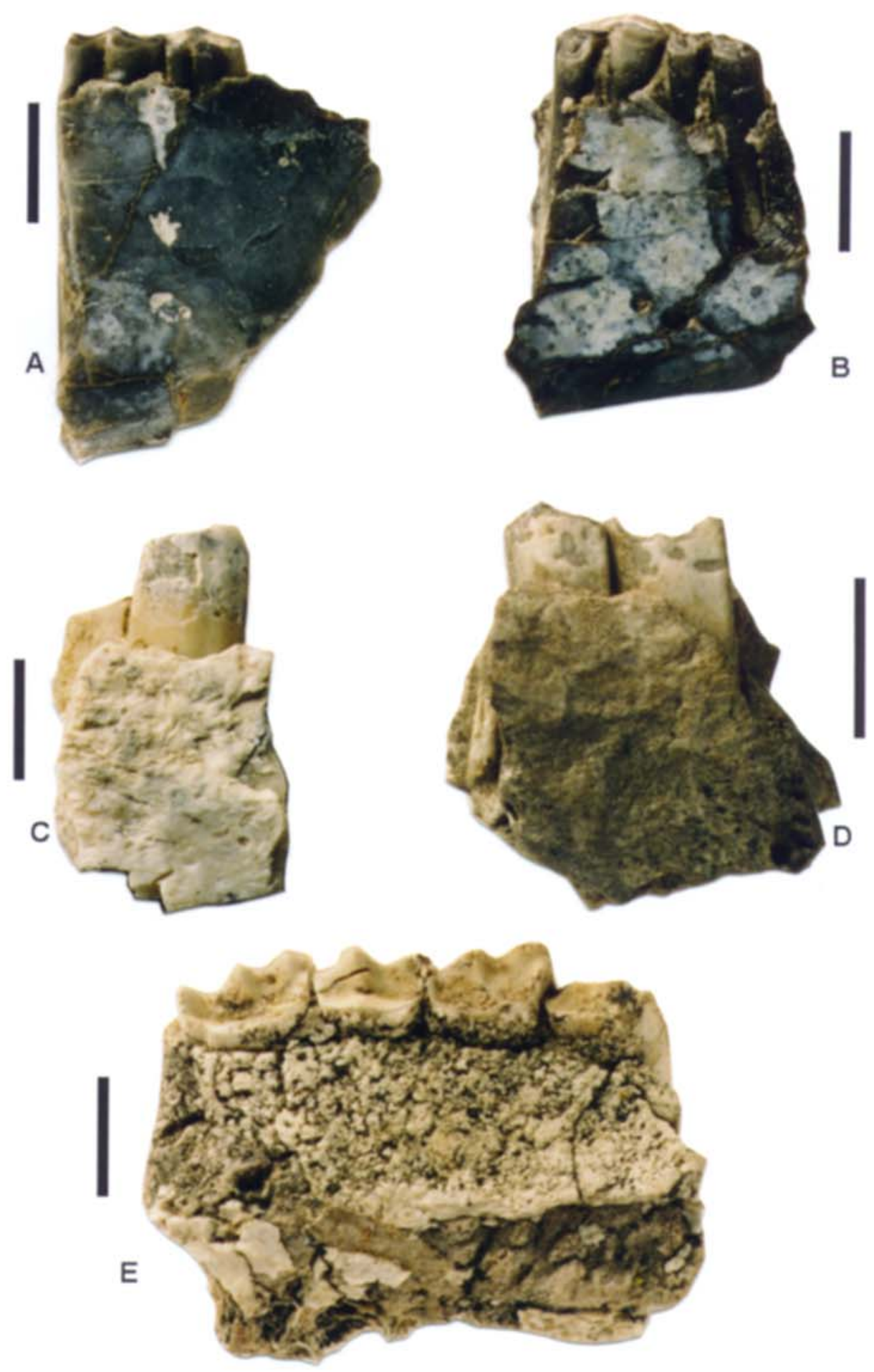

Lámina 4.4. Corrosión sobre hemimandibulas y paladares de Paedotherium minor. A. GHUNLPam 21419; B. GHUNLPam 19228; C. GHUNLPam 19437; D. GHUNLPam 19308; E. GHUNLPam 19269, escalas $5 \mathrm{~mm}$ 
Lámina 4.4. Corrosión sobre hemimandíbulas y paladares de Paedotherium minor. A. GHUNLPam 21419; B. GHUNLPam 19228; C. GHUNLPam 19437; D. GHUNLPam 19308; E. GHUNLPam 19269, escalas 5 mm 
En algunos dientes de roedores cávidos se observó un tipo particular de corrosión en la dentina de la superficie oclusal (Figura 4.21). En este caso la corrosión se manifiesta como pequeños agujeros de borde muy suavizado, formando una línea de orificios que en general coincide con la zona media de la cara oclusal del diente, donde la dentina es menos espesa. Este tipo de corrosión puede haber sido producida por ácidos propios del sustrato.
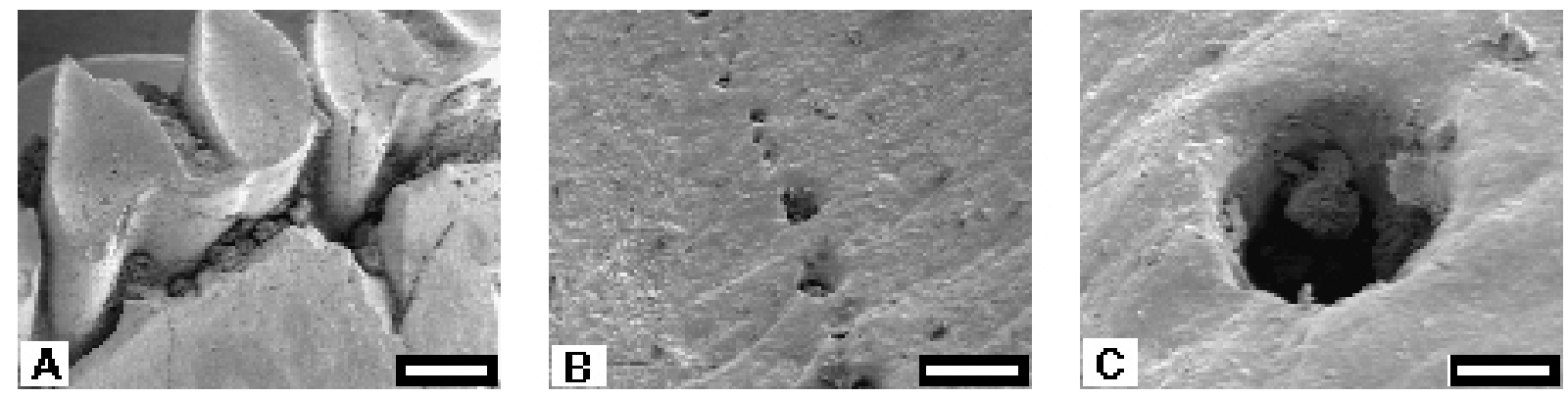

Figura 4.21. A. Hemimandíbula de Palaeocavia sp. (GHUNLPam 21043) con la dentina de los molariformes afectada por corrosión, escala $1000 \mu$; B y C. mayor aumento del mismo espécimen, B. escala $100 \mu$, C. escala $20 \mu$

La presencia de áreas irregulares degradadas sobre la superficie ósea y dentaria y de agujeros en la dentina, que podrían haber sido afectadas por ácidos propios del sustrato, hongos o bacterias del suelo provocando corrosiones sobre algunos restos, también es indicadora de que los mismos habrían permanecido en algún momento cercanos a la superficie.

En algunas hemimandíbulas y maxilares los efectos de corrosión se manifiestan directamente como disolución de sectores de la superficie ósea, de modo tal que quedan expuestas las bases de los dientes (Lámina 4.5). Se interpreta que este tipo de disolución se provocaría por acción de los ácidos propios del sustrato.

Fernández Jalvo y Sánchez Chillón (2000) indicaron que el esmalte es el primero que se afecta en ambientes ácidos, en tanto que en ambientes más básicos las modificaciones se evidencian en los huesos y en la dentina de los dientes. 

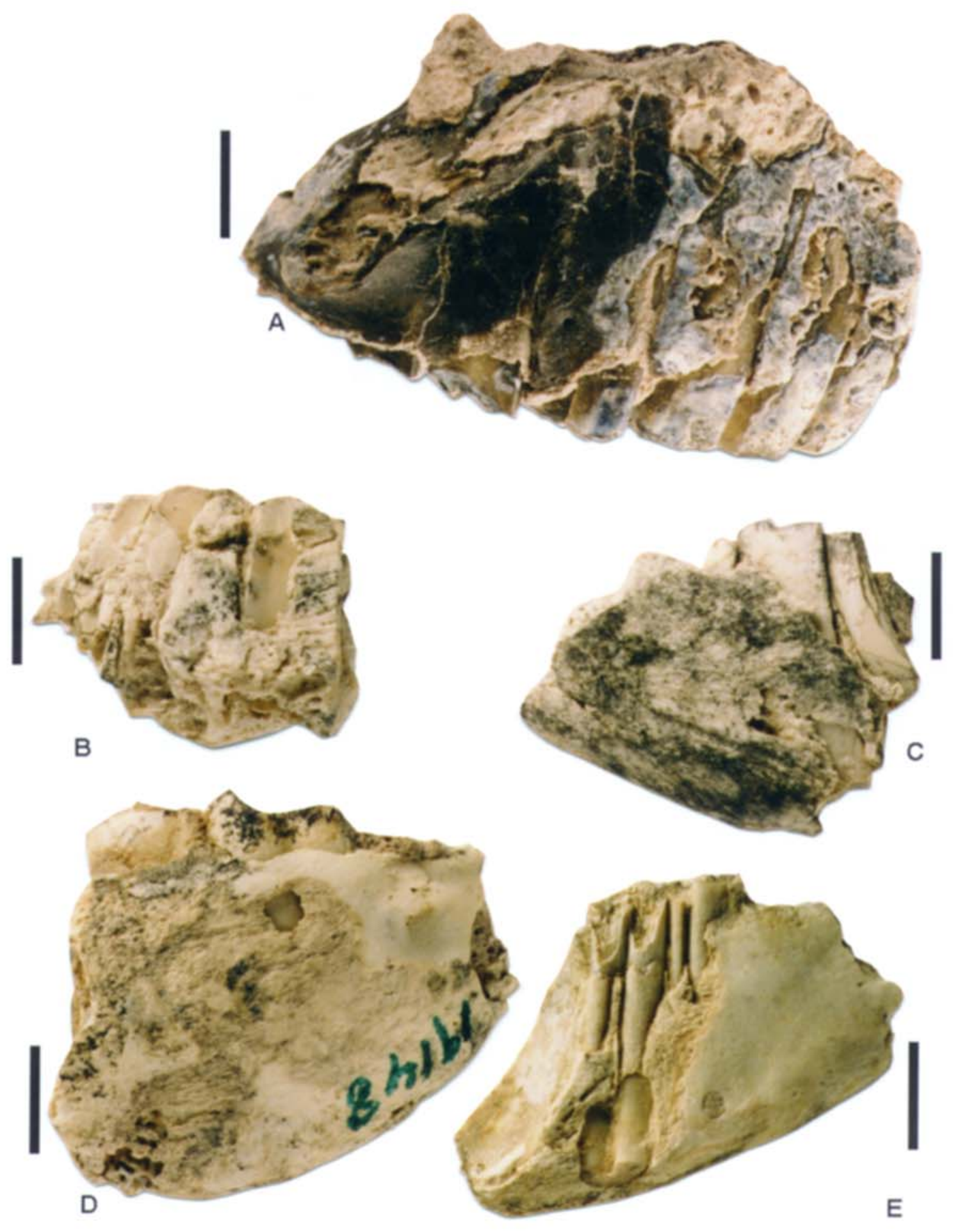

Lámina 4.5. Corrosión sobre hemimandibulas y paladares de Paedotherium minor. A. GHUNLPam 21382; B. GHUNLPam 19509; C. GHUNLPam 19432; D. GHUNLPam 19148; E. GHUNLPam 19187, escalas 5 mm 
Lámina 4.5. Corrosión sobre hemimandíbulas y paladares de Paedotherium minor. A. GHUNLPam 21382; B. GHUNLPam 19509; C. GHUNLPam 19432; D. GHUNLPam 19148; E. GHUNLPam 19187, escalas 5 mm 
El primer tipo de modificación fue encontrada en los dientes de algunos especímenes (Figura 4.22), y también ésta podría ser la interpretación de lo que le ocurrió a unos pocos ejemplares de Paedotherium minor, que presentan la superficie del hueso y el cemento de los dientes con fuertes modificaciones, rugosidades e irregularidades, en tanto el esmalte y la dentina no se ven afectados (Lámina 4.5 B, C y D).

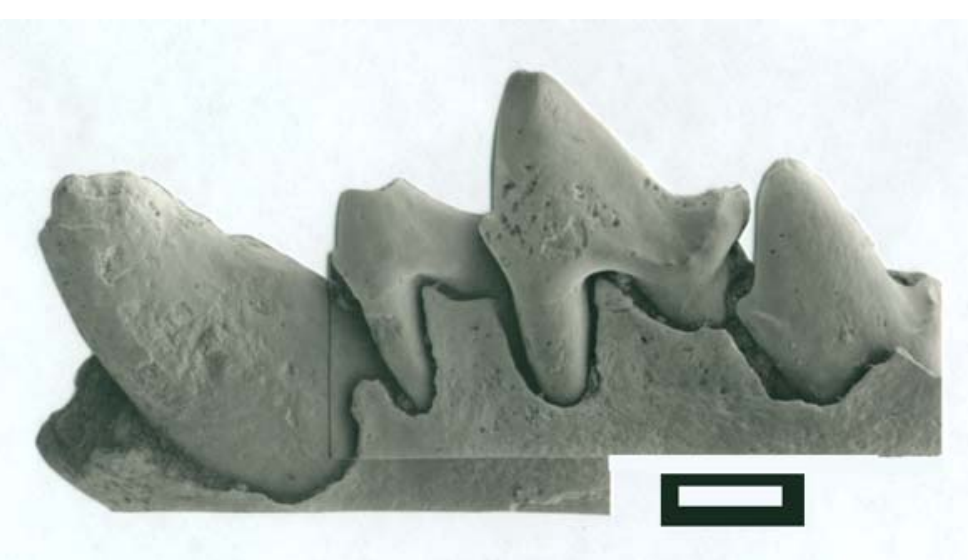

Figura 4.22. Hemimandíbula de Sparassocynus sp. (GHUNLPam 21228) con corrosión en los dientes; escala $1000 \mu$

- Corrosiones producidas por el desarrollo de líquenes sobre la superficie El 3,40 \% de los restos recuperados presenta corrosión producida por líquenes (Lámina 4.6 A y Figura 4.23). En este caso se observan áreas con corrosión y cambio de color, con un agrietamiento paralelo, bandeado, en el fondo de la zona afectada que aparece como pulverulento (Fernández Jalvo, com. pers.). La presencia de este tipo de corrosión, atribuida a líquenes es un factor importante a tener en cuenta al momento de evaluar la presencia de elementos reelaborados en la asociación. Los líquenes crecen sobre áreas expuestas a la intemperie y lo han hecho en estos casos sobre restos mineralizados, incluso impregnados por óxidos de manganeso. Eso significa que algunos elementos de la asociación fueron reexpuestos en algún momento de la historia tafonómica, colonizados por líquenes y luego nuevamente enterrados. 

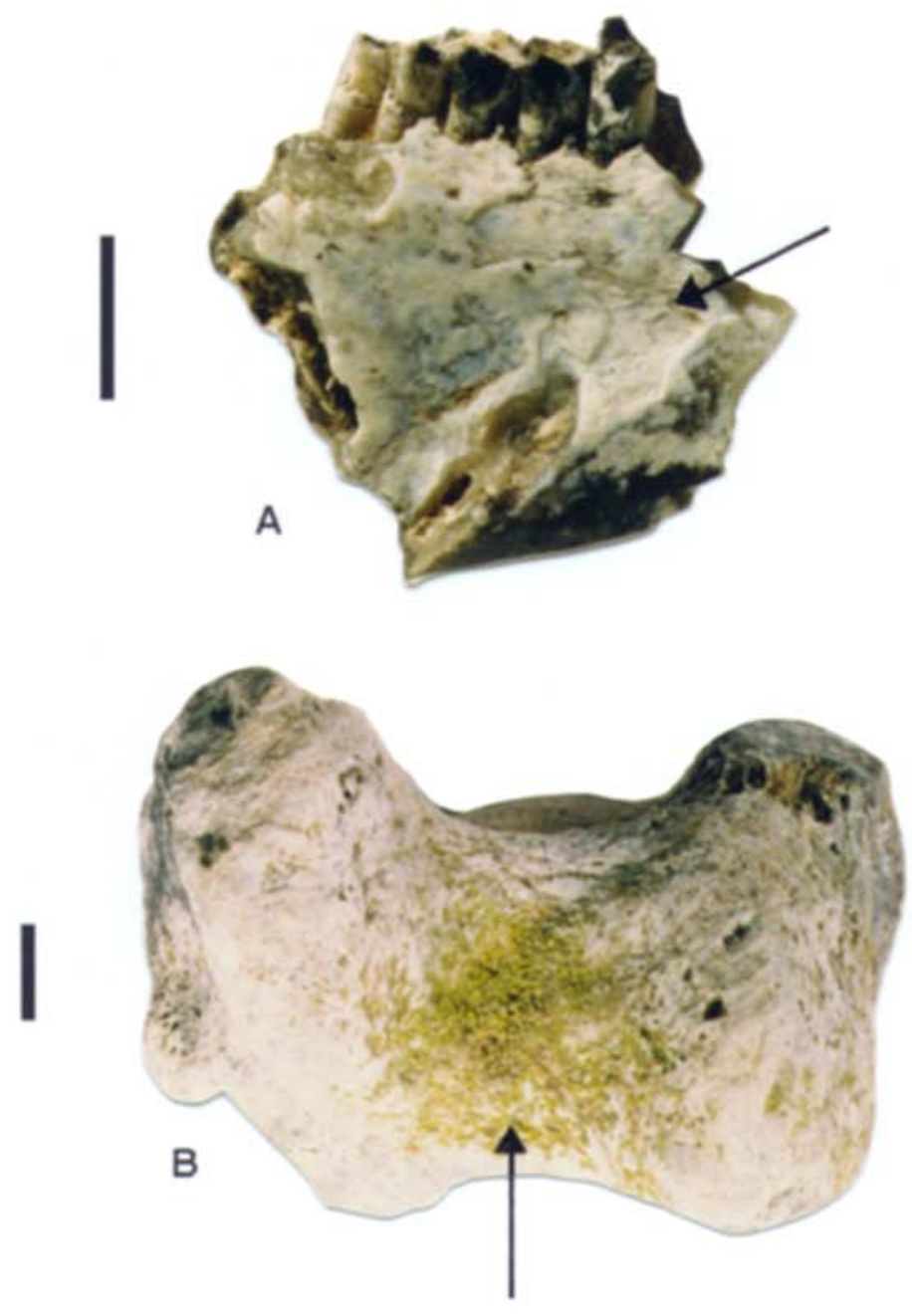

Lámina 4.6. Corrosión por liquenes. A. corrosión sobre una hemimandibula de Paedotherium minor, C. liquenes actuales sobre una epifisis de tibia proximal (GHUNLPam 19874/2), escala 5 mm 
Lámina 4.6. Corrosión por líquenes. A. corrosión sobre una hemimandíbula de Paedotherium minor; C. líquenes actuales sobre una epífisis de tibia proximal (GHUNLPam 19874/2), escala $5 \mathrm{~mm}$ 

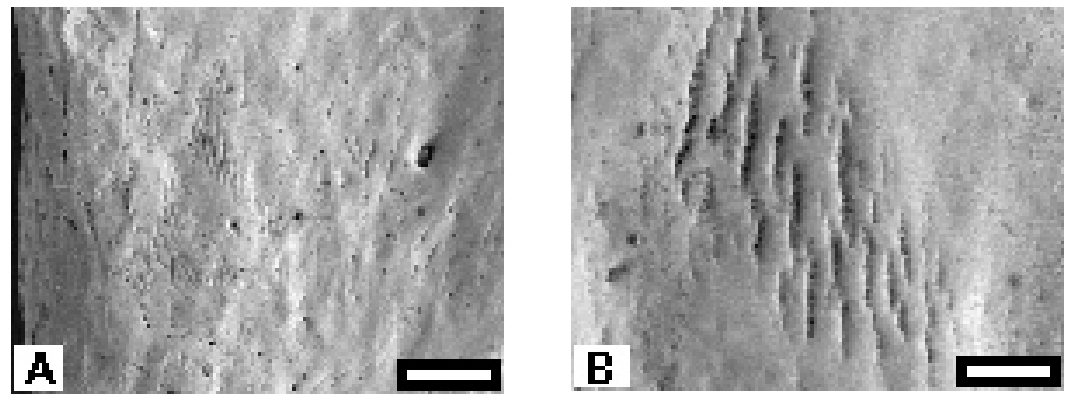

Figura 4.23. A. Corrosión producida por líquenes sobre un resto indeterminable, escala $1000 \mu$; B. mayor aumento del mismo ejemplar, escala $200 \mu$

El 0,73\% del total de restos de la asociación presenta líquenes actuales (Montalvo y Rosato, 2002). Se trata de dos especies del género Caloplaca (Ascomycotina, Fungi Lichenisati) C. citrina (Hoffm) Th. Fr. y C. americana Malme. Estos organismos ocupan las grietas y fracturas de los restos o directamente crecen sobre las áreas con concreción calcárea que rodea a algunos restos, es decir, las zonas donde se retienen la humedad y el agua de lluvia (Figura 4.24).
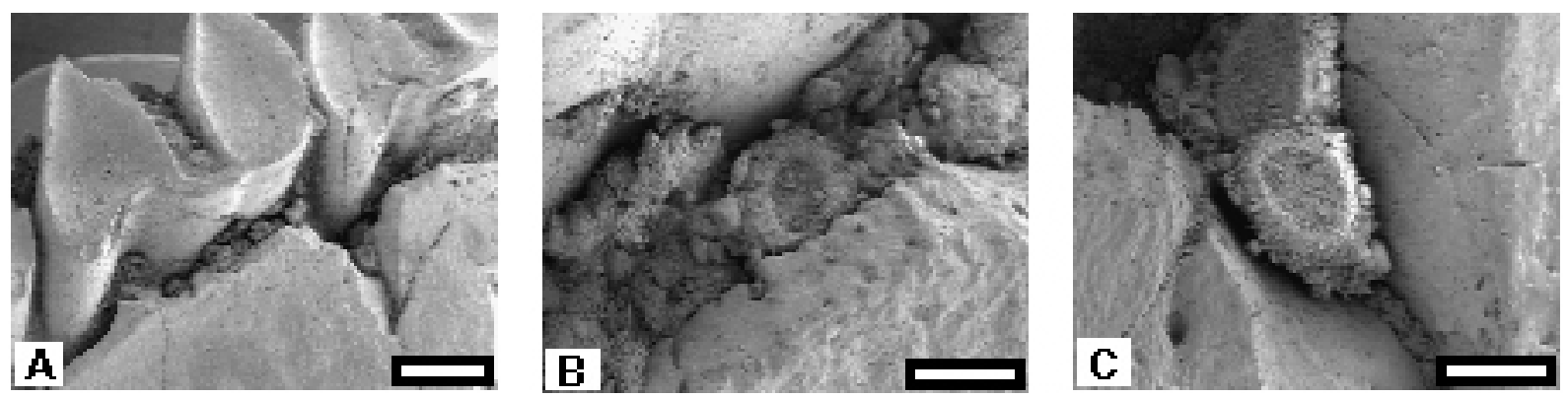

Figura 4.24. A. Líquenes actuales sobre una hemimandíbula de Palaeocavia sp. (GHUNLPam 21043), escala $1000 \mu$; B y C. mayor aumento del mismo espécimen, escalas $200 \mu$

Caloplaca citrina es una especie cosmopolita y muy difundida, crece sobre rocas, cemento y metales y produce ácido oxálico que forma complejos con las sales de calcio presentes en el sustrato; estas sustancias se disuelven y son arrastradas por el agua de lluvia, causando la pérdida del calcio (Traversa et al., 2000). Se ha observado que en el caso del cemento, las hifas perforan y penetran el sustrato hasta 1-1,5 mm (Rosato, 2001). Con respecto a Caloplaca americana se ignora cuál es su acción sobre el sustrato, pero vale destacar que fue citada en 
la provincia de Salta sobre huesos secos expuestos (Malme, 1926). De todos modos no se observó corrosión directa de estas especies sobre los restos.

El desarrollo de líquenes actuales sobre los restos indica un período de exposición previa a la recolección. Ese tiempo de exposición no es posible de evaluar con las especies de líquenes presentes, ya que estas tienen un crecimiento rápido y en forma difusa.

Como se indicó, la bioerosión provoca degradación de la superficie expuesta; en el caso de los especímenes recuperados en Caleufú, la alta proporción de restos con fuerte encostramiento calcáreo resulta ser un carácter que favoreció su preservación, ya que esta capa protegió su superficie. 


\section{GRADO DE DISTORSIÓN MECÁNICA}

La distorsión tafonómica comprende cualquier cambio de tamaño, forma, estructura y/o textura de un elemento conservado, debido a la acción de algún esfuerzo mecánico (Fernández López, 2000). Los efectos de la distorsión pueden ser continuos o discontinuos; entre los primeros se citan arrugas o pliegues, atributos que no se encontraron en ningún espécimen de la asociación analizada. Entre los discontinuos, se pueden mencionar las grietas, fisuras y fracturas producidas tanto antes como después del enterramiento de los restos. Se incluyen en esta categoría a los patrones particulares de rotura de los elementos esqueléticos que son interpretados como producidos en el momento de la muerte, a algunos atributos resultantes de la acción de agentes biológicos que alteraron los especímenes en la etapa bioestratinómica, como las fracturas producidas por pisoteo y también a los efectos de la meteorización por agentes atmosféricos sobre los elementos esqueléticos. Por último se analizaron los fragmentos indeterminables.

De lo expuesto surge que para el análisis de este ítem se tuvo en cuenta el tipo de rotura y el grado de meteorización que presentan los elementos esqueléticos, tomando como base las consideraciones que de ambos atributos realizó Alcalá (1994). Se buscó interpretar, a través del análisis de estas características, el momento de producción de la distorsión en cada elemento esquelético.

\section{Tipos de rotura y de fracturas}

Para el estudio del tipo de rotura se distinguieron las siguientes categorías: elemento entero y elemento con roturas.

Sobre los elementos esqueléticos rotos fueron analizados los diferentes tipos de fracturas presentes. En estado fresco, el hueso se comporta como un material dúctil, elástico y capaz de soportar grandes presiones y deformaciones antes de fracturarse. Una vez seco, se comporta de modo diferente, ya que tiene mayor porcentaje de sustancias inorgánicas, por lo que pierde elasticidad y se 
fractura más rápidamente, comenzando a romperse a partir de microfracturas (Lyman, 1994).

Para huesos largos de grandes mamíferos, Gifford-González (1989) propuso una clasificación general de las fracturas:

- fracturas perpendiculares o transversales: son las que forman un ángulo recto con el eje longitudinal del hueso; se producen cuando el hueso está seco, sin ningún componente orgánico.

- fracturas longitudinales: son paralelas al eje longitudinal del hueso; se producen principalmente cuando el hueso está seco. Haynes (1980) consideró que estas fracturas se producen como consecuencia de la contracción del tejido óseo por efecto de meteorización antes del enterramiento.

○ fracturas espirales: son fracturas curvadas, formando una espiral alrededor de la circunferencia de la diáfisis del hueso; se producen cuando el hueso está fresco.

Para describir la textura de la zona de la fractura esta misma autora utilizó las categorías lisa y escalonada.

En este trabajo, las diferentes categorías de esa clasificación se hicieron extensivas también a restos de vertebrados de la categoría I, ya que fácilmente fueron reconocidas sobre ellos.

Los modelos de fractura que se presentan en los elementos esqueléticos están relacionados con los diferentes procesos que afectaron a estos restos en distintos momentos de la historia tafonómica de la asociación.

\section{- Elementos esqueléticos enteros}

No se encontraron elementos craneanos enteros. Solo se recuperaron 124 elementos del postcráneo enteros, el 13,15 \% del total de estos elementos. Se trata de astrágalos, calcáneos, elementos del basipodio, metápodos y falanges, en general correspondientes a individuos de talla pequeña y atribuidos a la categoría I (Figura 4.25). Estos elementos esqueléticos tienen alta densidad, lo que seguramente favoreció que se preservaran completos. 


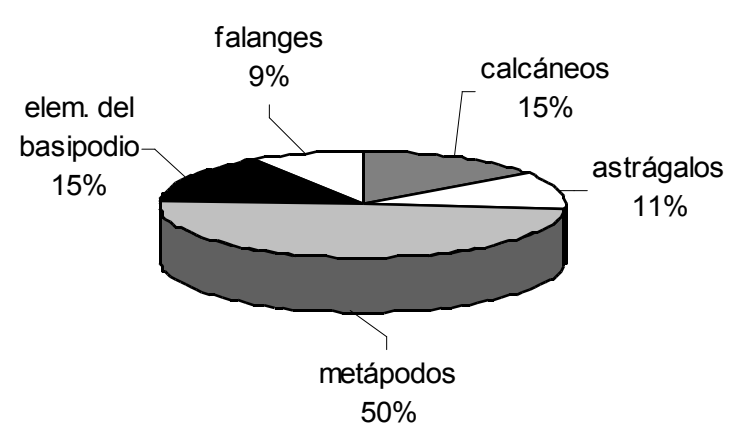

Figura 4.25. Distribución en porcentaje de los diferentes elementos esqueléticos del postcráneo recuperados enteros

- Elementos del postcráneo rotos

En la asociación de microvertebrados los elementos esqueléticos integrantes de la columna vertebral, cinturas, fémures, tibias, húmeros, ulnas y radios siempre presentan algún tipo de rotura. En cuanto a las vértebras generalmente se preservaron los cuerpos vertebrales, si bien hay especímenes que conservan alguna apófisis. De las cinturas se preservan porciones de escápulas, en particular el área de la fosa glenoidea y de los innominados se conserva la porción del acetábulo.

Se debe tener en cuenta que es común que estos elementos esqueléticos tengan fracturas transversales con bordes lisos, producidas en etapas posteriores al enterramiento. La presencia de elementos con ese tipo de fracturas impide evaluar con cierta precisión el real porcentaje de elementos preservados y enterrados enteros en la asociación.

Sin embargo, es también frecuente en los elementos correspondientes a huesos largos la rotura a nivel de epífisis o de diáfisis con fracturas de tipo espiral y escalonada (Lámina 4.7). Por otro lado, si bien son menos frecuentes, hay en esos elementos esqueléticos fracturas longitudinales. Estos patrones de fractura son comunes además en otros elementos del postcráneo.

La presencia de fracturas espirales es consistente con la hipótesis de roturas producidas en los elementos esqueléticos en el momento de la muerte de la presa por parte de los depredadores. También se las ha interpretado como producto de la rotura del elemento esquelético por acción de pisoteo (Alcalá, 


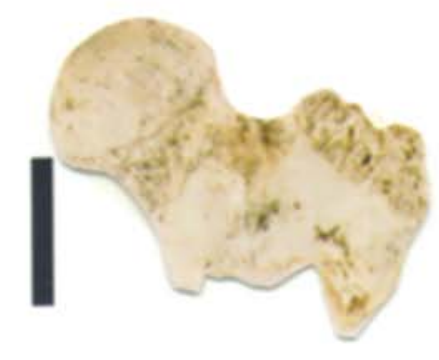

A

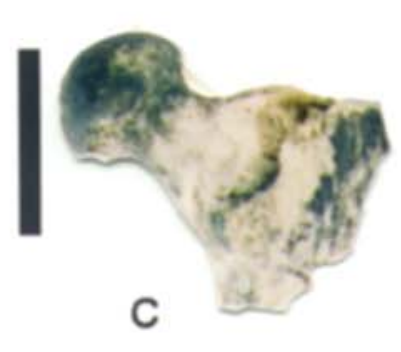

C

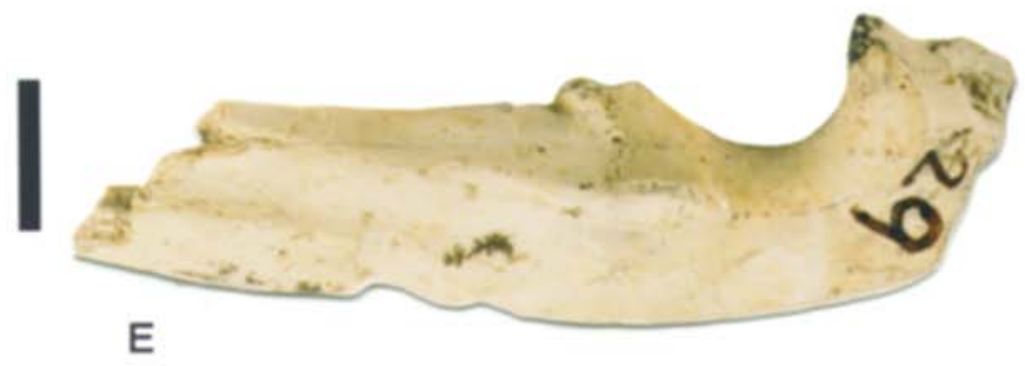

Lámina 4.7. Fracturas espirales. A. fémur proximal (GHUNLPam 19867/70); B. fémur proximal (GHUNLPam 19867/71); C. fémur proximal (GHUNLPam 19867/72); D. fémur proximal (GHUNLPam 21566/28); E. ulna (GHUNLPam 19874/29), escalas 5 mm 
Lámina 4.7. Fracturas espirales. A. fémur proximal (GHUNLPam 19867/70); B. fémur proximal (GHUNLPam 19867/71); C. fémur proximal (GHUNLPam 19867/72); D. fémur proximal (GHUNLPam 21566/28); E. ulna (GHUNLPam 19874/29), escalas 5 mm 
1994), pero en este caso hay especímenes que presentan marcas de dientes cercanas a la zona de fractura, lo que avalaría la primera hipótesis planteada.

Se mencionó que las fracturas transversales y longitudinales se produjeron sobre el resto seco, por este motivo es difícil evaluar en que momento de la historia tafonómica ocurrieron. En algunos especímenes, las fracturas longitudinales están asociadas a evidencias de meteorización previa al enterramiento, señalando que se pueden haber producido en ese momento.

En la asociación de mamíferos de más de $5 \mathrm{~kg}$ de masa corporal estimada los elementos postcraneanos son sumamente escasos (41 especímenes) y muy deteriorados (ver Tabla 3.22). En particular se han identificado algunos huesos largos que fueron interpretados en esta categoría, pero que corresponderían a mamíferos de talla mediana, sólo las vértebras y metápodos incluyen especímenes provenientes de mamíferos de talla grande.

Este grupo de mamíferos aporta un porcentaje muy abundante de restos indeterminables, característica de la asociación que se discute más adelante.

- Rotura de elementos postcraneanos en la asociación de microvertebrados Andrews (1990) al caracterizar a los depredadores actuales analizó las proporciones de elementos postcraneanos enteros y rotos. Tuvo en cuenta húmeros, ulnas, fémures y tibias, considerando en el caso de los rotos las siguientes zonas: epífisis proximal, diáfisis y epífisis distal para cada resto. En la asociación de micromamíferos de Caleufú no se halló entero ninguno de los elementos esqueléticos citados, y entre los elementos rotos predominan las epífisis, tanto distal como proximal, que por otro lado son las regiones más robustas de esas piezas esqueléticas (Tabla 4.5). 


\begin{tabular}{|c|l|c|r|}
\hline \multirow{4}{*}{ húmero } & & $\mathrm{N}$ & \multicolumn{1}{|c|}{$\%$} \\
\cline { 2 - 4 } & completo & 0 & 0 \\
\cline { 2 - 4 } & proximal & 8 & 36,36 \\
\cline { 2 - 4 } & diáfisis & 0 & 0 \\
\cline { 2 - 4 } & distal & 14 & 63,64 \\
\hline \multirow{5}{*}{ ulna } & completo & 0 & 0 \\
\cline { 2 - 4 } & proximal & 31 & 100 \\
\cline { 2 - 4 } fémur & diáfisis & 0 & 0 \\
\cline { 2 - 4 } & distal & 0 & 0 \\
\hline \multirow{4}{*}{ tibia } & completo & 0 & 0 \\
\cline { 2 - 4 } & proximal & 30 & 47,62 \\
\cline { 2 - 4 } & diáfisis & 0 & 0 \\
\cline { 2 - 4 } & distal & 33 & 52,38 \\
\cline { 2 - 4 } & distal & 0 & 0 \\
\cline { 2 - 4 } & prompleto & 20 & 45,45 \\
\cline { 2 - 4 } & diáfisis & 0 & 54,55 \\
\hline
\end{tabular}

Tabla 4.5. Registro de elementos postcraneanos preservados

La utilización en la asociación de micromamíferos del análisis propuesto por Andrews (1990) señala, en principio, que la ausencia de elementos completos indicaría ciertas similitudes con las asociaciones formadas por mamíferos carnívoros, en las que se verifica el mayor grado de rotura, pero debe tenerse en cuenta, como ya se destacó, que entre estos elementos esqueléticos hay fracturas transversales con bordes lisos producidas en etapas posteriores al enterramiento. La presencia de elementos con ese tipo de fracturas impide evaluar con precisión el porcentaje real de elementos preservados y enterrados enteros en la asociación y también realizar comparaciones de los valores obtenidos para cada porción de los elementos analizados, con datos surgidos a partir del análisis de depredadores actuales. Es probable además, que sobre los elementos del postcráneo, el alto grado de rotura y la propia fragilidad y tamaño de estos especímenes pueden haber facilitado la destrucción de muchos de ellos.

- Tipo de rotura en hemimandíbulas

Andrews (1990) indicó que la variación en tamaño y estructura de las hemimandíbulas preservadas en una asociación da información acerca de los procesos de alteración que sufrieron estos elementos. La rama ascendente constituye la zona mandibular que más rápidamente se pierde. De acuerdo al 
grado de rotura de las mandíbulas, Andrews (1990) distinguió 4 categorías de asociaciones formadas por depredadores actuales. Las asociaciones sin ninguna mandíbula entera constituyen la categoría de rotura extrema donde se incluye a los mamíferos carnívoros como depredadores.

En la asociación de micromamíferos no hay ninguna hemimandíbula completa. Si bien las mandíbulas preservadas presentan varios tipos de rotura, las de la zona posterior, que implica la pérdida de la rama ascendente (Lámina 4.8 A), son las de mayor interés. Esta rotura está asociada a fracturas escalonadas que indicarían que se produjo cuando el elemento esquelético estaba fresco. En algunos casos, en esa zona se registraron marcas de dientes, por lo que se infiere que este tipo de rotura está relacionada con el accionar de depredadores en el momento de la muerte de la presa.

Por otro lado, es interesante señalar que hay variación en la preservación de diferentes áreas mandibulares en los taxa presentes en esta asociación. Por ejemplo en las hemimandíbulas de Paedotherium minor es común la presencia de fracturas transversales de borde liso a nivel de la diastema o de los molariformes y también de fracturas longitudinales paralelas al borde inferior. En esta especie es muy alta la cantidad de roturas diagenéticas de los elementos mandibulares, y esto puede estar relacionado con la forma de las mismas, ya que son alargadas y estrechas, susceptibles de romperse ante cualquier fuerza. En la zona posterior, como ya se anticipó, la rotura es irregular, escalonada, y con evidencias de haberse producido cuando el hueso estaba fresco (Lámina $4.8 \mathrm{~B}$ ). Algo similar ocurre con las hemimandíbulas de los roedores y marsupiales, pero en estos casos hay menos roturas diagenéticas, lo que estaría relacionado en este grupo con que en la mayoría de los taxa, estos elementos esqueléticos son más robustos.

Andrews (1990) indicó que en los restos de roedores es común la rotura del borde inferior de la mandíbula facilitando la pérdida del incisivo. Esta característica se encontró en algunos especímenes, pero en general la zona sinfisaria está en buen estado y el borde inferior está entero. La integridad del borde inferior de las mandíbulas y de la zona sinfisaria parece estar más relacionada, también en este caso, con la morfología de esa zona en cada grupo 
taxonómico. Por ejemplo, en los representantes de la Familia Caviidae el alvéolo del incisivo es de ubicación lingual y ese diente falta en algunos casos por la rotura del hueso en esa zona (Lámina $4.8 \mathrm{C}$ ). En los representantes de la Familia Octodontidae, la base del incisivo termina por detrás y dorsalmente a los molariformes y las áreas linguales del hueso que aparecen rotas son de ubicación variable.

Es común la presencia de perforaciones en la base de los alvéolos de los molariformes inferiores, tanto en restos de roedores como de Paedotherium minor. Es probable que algunas de estas perforaciones hayan sido producidas por el accionar del depredador (Lámina 4.8 D) y que correspondan en estos casos a la alteración del borde inferior mandibular, ya que en estos taxa la capa de hueso en ese lugar es muy fina. Sin embargo, este último atributo es de difícil evaluación, ya que hay muchos ejemplares en los que el hueso de la base de los alvéolos de los molariformes se ha roto por el desarrollo del relleno sedimentario que ocupa el espacio entre el diente y el hueso, en cada una de las cavidades alveolares (Lámina $4.8 \mathrm{C}$ ). Los dos tipos de rotura descriptas se pueden identificar por las características que presenta el relleno sedimentario en cada caso. En el primero, la zona rota de la base del alvéolo presenta bordes netos, mientras que en el segundo tipo descripto el borde es irregular y en muchos casos hay pequeños fragmentos de hueso adheridos a la concreción que rellena el alvéolo.

Se destaca que en las hemimandíbulas de roedores la zona sinfisaria está generalmente en buen estado, indicando que la separación de las dos mandibulas no implicó rotura en esa zona; esa separación probablemente sea una evidencia de meteorización sobre estos elementos esqueléticos (Lámina $4.8 \mathrm{E}$ ). En Paedotherium minor la zona sinfisaria generalmente se encuentra completa y si esa zona mandibular aparece rota, aislada, es común que presente fracturas transversales diagenéticas.

Entre los macromamíferos de la asociación sólo se preservó en muy buen estado una hemimandíbula de Tetrastylus sp., GHUNLPam 19830 (ver Lámina 4.11 A). 


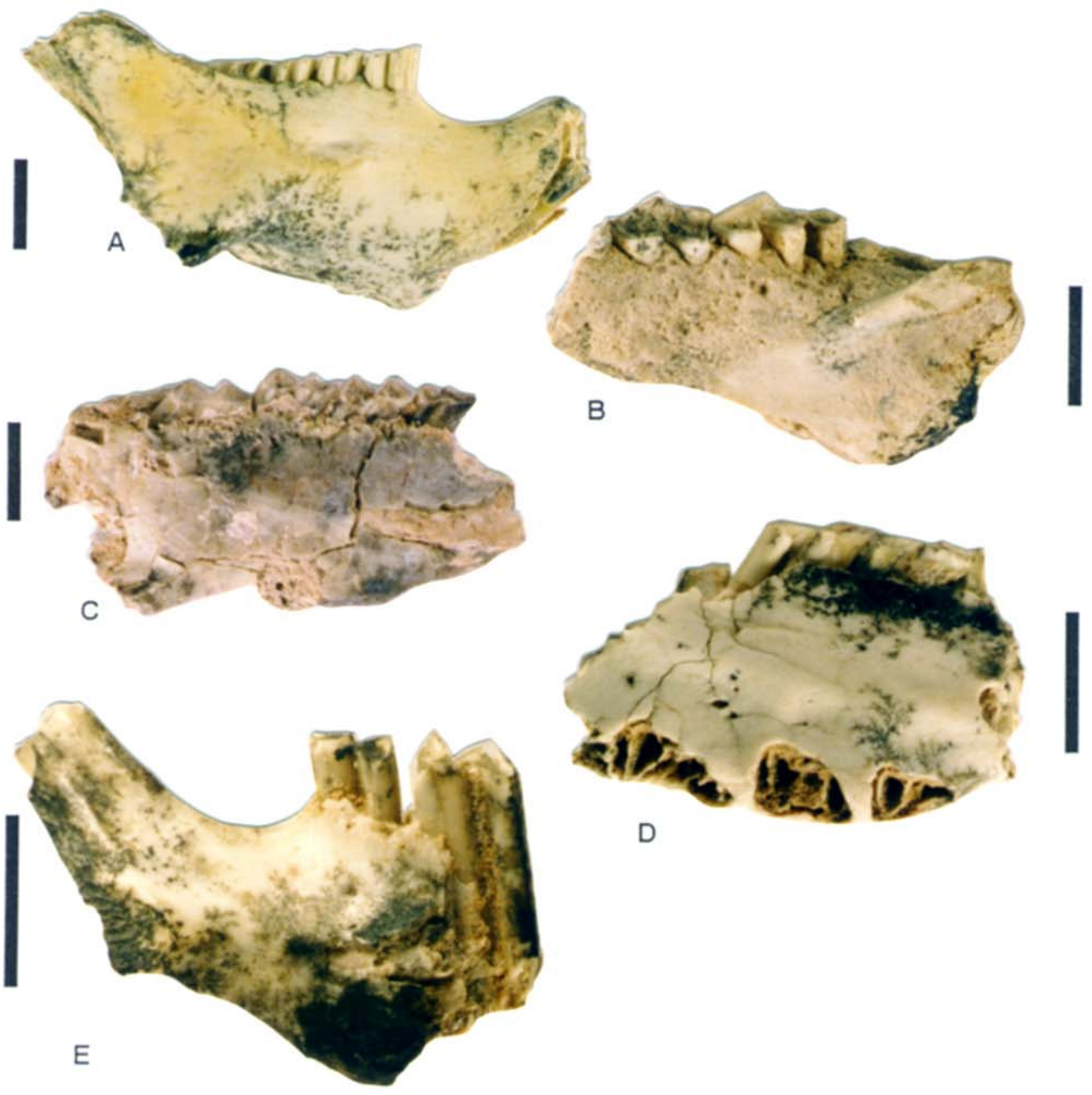

Lámina 4.8. Modificaciones sobre hemimandibulas. A. hemimandibula derecha del Octodontinae indet. (GHUNLPam 19820); B. hemimandibula izquierda de Paedotherium minor (GHUNLPam 19263); C. hemimandibula izquierda de Palaeocavia sp.

(GHUNLPam 21033); D. hemimandibula izquierda de Palaeocavia sp. (GHUNLPam 19536); E. hemimandibula derecha de Palaeocavia sp. (GHUNLPam 19543), escalas 5 $\mathrm{mm}$ 
Lámina 4.8. Modificaciones sobre hemimandíbulas. A. hemimandíbula derecha del Octodontinae indet. (GHUNLPam 19820); B. hemimandíbula izquierda de Paedotherium minor (GHUNLPam 19263); C. hemimandíbula izquierda de Palaeocavia sp.

(GHUNLPam 21033); D. hemimandíbula izquierda de Palaeocavia sp. (GHUNLPam 19536); E. hemimandíbula derecha de Palaeocavia sp. (GHUNLPam 19543), escalas 5 $\mathrm{mm}$ 
- Tipo de rotura de cráneos

En las asociaciones formadas por el accionar de depredadores raramente se encuentran cráneos enteros (se considera entero a aquel que preserva intacto el maxilar, los huesos frontales y al menos la mitad de la caja craneana). Es común la pérdida de toda la caja craneana, luego las arcadas zigomáticas y finalmente la separación de los maxilares (Andrews, 1990). Basándose en la integridad de los cráneos, Andrews (1990) propuso 4 categorías de asociaciones formadas por depredadores actuales. En la categoría de modificación extrema se ubican las asociaciones sin ningún cráneo entero, producidas por mamíferos carnívoros. La asociación de Caleufú se ubica en esta categoría.

Entre los microvertebrados unos pocos especímenes de Paedotherium minor y de algunos cávidos preservaron alguna porción del techo craneano, pero siempre falta la zona occipital (Lámina 4.9 A). Hay maxilares completos, pero es común que los especímenes correspondan a hemimaxilares con dientes; la separación de estos elementos esqueléticos se produjo en muchos casos a nivel de las suturas y esta zona se encuentra en buen estado (Lámina $4.9 \mathrm{~B}$ y C). En algunos casos se conserva la zona del rostro (Lámina 4.9 D), pero en muchos especímenes éste se ha separado justamente en la sutura premaxilar-maxilar. Algunos maxilares conservan una porción de las arcadas zigomáticas. Sin embargo en estos casos, ya que se presentan fracturas que indican que la rotura se produjo una vez que el resto estaba mineralizado, no queda claro cual es el verdadero grado de alteración producido en esa zona.

Entre los macromamíferos sólo se preservó relativamente completo parte de un hemimaxilar de Pseudotypotherium subinsigne (GHUNLPam 21137).

- Índice de fragmentación

El índice NEIT/NME permite analizar la tasa de fragmentación presente en una asociación y debe ser tomado sobre los elementos esqueléticos rotos (ver Lyman, 1994). A efectos de evaluar de qué modo la fragmentación de hemimandíbulas y maxilares se relacionan con las características intrínsecas de estos elementos esqueléticos en cada taxón, se calculó este índice sobre los valores de NEIT y NME obtenidos para los taxa más frecuentes en la asociación de 

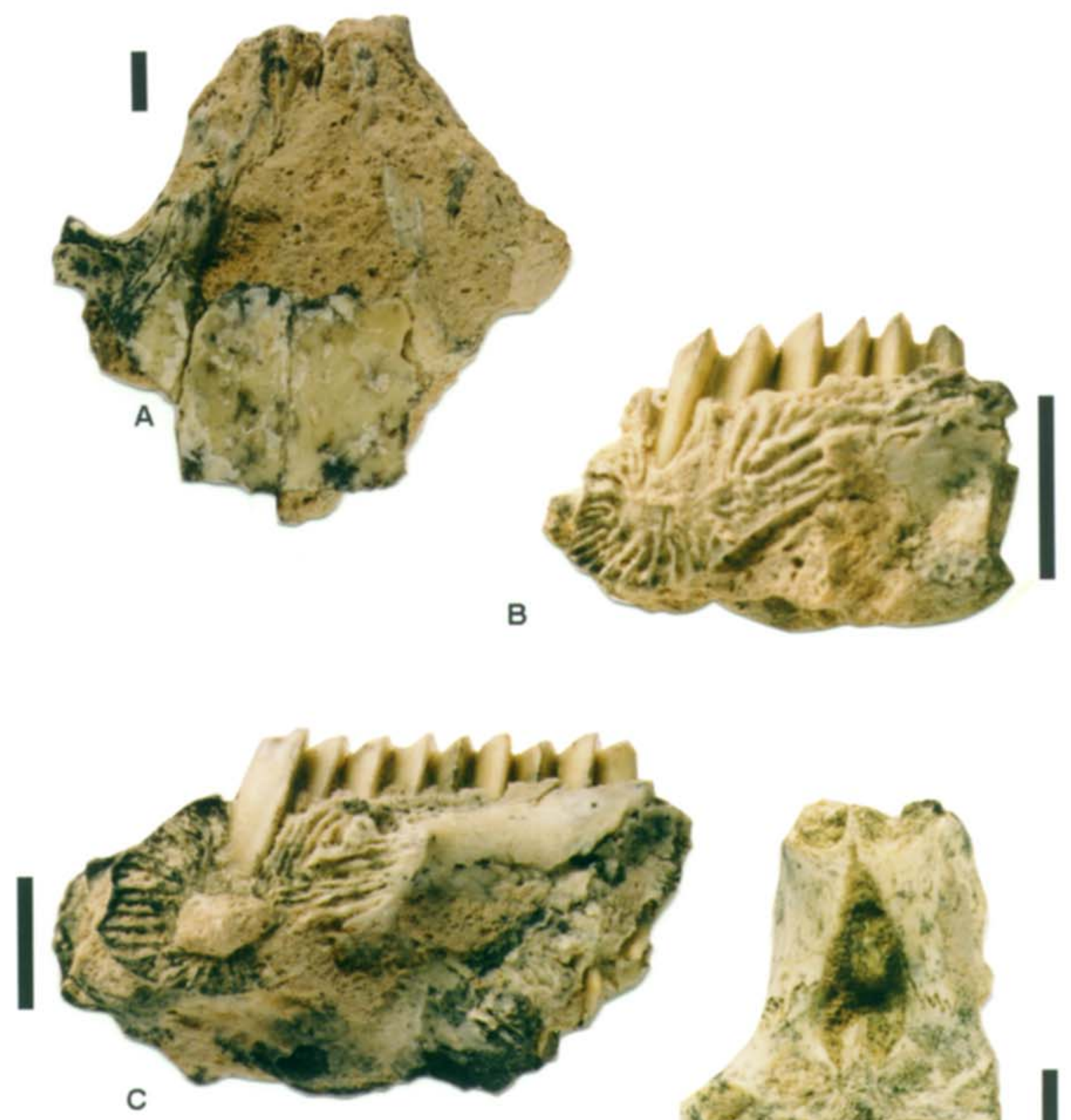

D

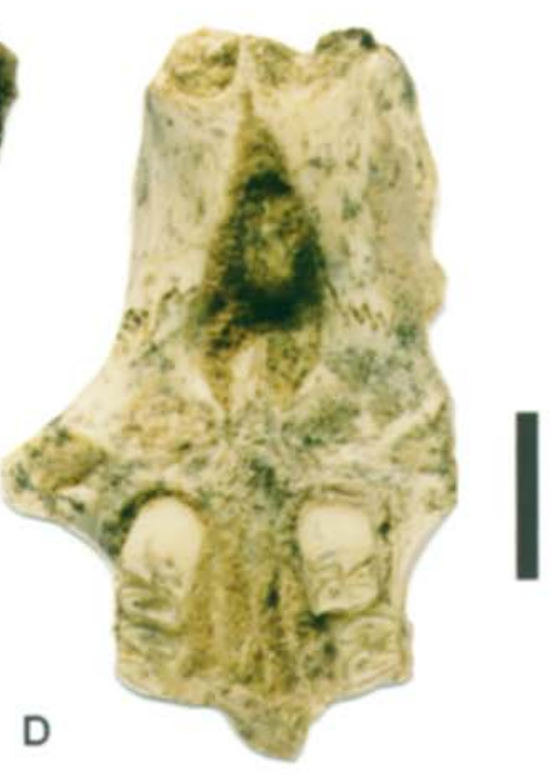

Lámina 4.9. Modificaciones sobre cráneos y paladares, A. vista dorsal de rostro y techo craneano de Paedotherium minor (GHUNLPam 19474); B. vista lateral interna de paladar de Palaeocavia sp. (GHUNLPam 19565); C. idem anterior de Orthomyctera sp. (GHUNLPam 19548); vista ventral de rostro y paladar del Octodontinae indet. (GHUNLPam 19872), escalas 5 mm 
Lámina 4.9. Modificaciones sobre cráneos y paladares, A. vista dorsal de rostro y techo craneano de Paedotherium minor (GHUNLPam 19474); B. vista lateral interna de paladar de Palaeocavia sp. (GHUNLPam 19565); C. ídem anterior de Orthomyctera sp.

(GHUNLPam 19548); vista ventral de rostro y paladar del Octodontinae indet.

(GHUNLPam 19872), escalas $5 \mathrm{~mm}$ 
microvertebrados (Tabla 4.6). Se observa en la Tabla 4.6 que sólo para el caso de los maxilares asignados a Neocavia cf. $N$. lozanoi el índice es 1 , lo que indica cierta integridad de estos elementos esqueléticos. El valor más alto de este índice se da para las hemimandíbulas de Paedotherium minor, que, como se señaló antes, presentan caracteres que seguramente han favorecido su rotura.

\begin{tabular}{|c|c|c|c|c|c|c|}
\hline & \multicolumn{3}{|c|}{ Mandíbulas } & \multicolumn{3}{|c|}{ Maxilares } \\
\hline Taxón & NEIT & NME & VEIT/NME & NEIT & NME & NEIT/NME \\
\hline Paedotherium minor & 412 & 148 & 2,78 & 182 & 101 & 1,80 \\
\hline Neocavia cf. N. Iozanoi & 18 & 10 & 1,80 & 11 & 11 & 1,00 \\
\hline Orthomyctera sp. & 43 & 29 & 1,48 & 30 & 18 & 1,67 \\
\hline Palaeocavia sp. & 108 & 58 & 1,86 & 49 & 44 & 1,11 \\
\hline Octodontinae indet. & 45 & 26 & 1,73 & 9 & 6 & 1,50 \\
\hline Xenodontomys elongatus & 127 & 94 & 1,35 & 53 & 44 & 1,20 \\
\hline
\end{tabular}

Tabla 4.6. Índice NEIT/NME para mandíbulas y maxilares de los taxa más frecuentes en la asociación de microvertebrados

Los taxa menos frecuentes en la asociación tienen valores de 1 o cercanos a 1 para hemimandíbulas y/o maxilares. Esto seguramente está relacionado con el bajo número de especímenes hallados en cada caso.

Para los elementos postcraneanos de la asociación de microvertebrados este índice se evaluó sobre húmeros, ulnas, fémures y tibias (Tabla 4.7), resultando los primeros los elementos más afectados por la fragmentación.

\begin{tabular}{|l|r|r|r|}
\hline Elemento esquelético & NEIT & NME & NEIT/NME \\
\hline Húmeros & 52 & 22 & 2,36 \\
\hline Ulnas & 62 & 31 & 2,00 \\
\hline Fémures & 142 & 63 & 2,25 \\
\hline Tibias & 62 & 44 & 1,41 \\
\hline
\end{tabular}

Tabla 4.7. Índice NEIT/NME para elementos postcraneanos en la asociación de microvertebrados

- Pérdida de dientes y dientes aislados

Son muy escasos los especímenes (hemimandíbulas y maxilares) en los que se verifica la pérdida de algún diente; en los pocos casos en que se ha producido esa pérdida, el alvéolo se encuentra relleno de sedimento. Debe recordarse aquí que entre los micromamíferos, excepto en algunos marsupiales y 
carnívoros, todos los demás órdenes tienen representantes con dientes protohipsodontes o hipsodontes, cuya base tiene implantación muy profunda, lo que seguramente facilitó la retención de cada diente en su alvéolo. Si bien es abundante la cantidad de dientes aislados de un determinado taxón en relación a los restos de hemimandíbulas y maxilares de ese taxón (Tabla 4.8), la baja proporción de especímenes sin dientes o con pérdida de algún diente, indicaría que los dientes aislados corresponden a aquéllos que se separaron en etapas posteriores a la mineralización. En ese caso la pérdida estaría relacionada con roturas diagenéticas de la porción de hemimandíbula o maxilar a la que perteneció.

\begin{tabular}{|l|r|r|}
\hline & NEIT & $\%$ dientes aislados \\
\hline Paedotherium minor & 737 & 19,40 \\
\hline Xenodontomys elongatus & 244 & 26,23 \\
\hline Octodontinae indet. & 66 & 18,18 \\
\hline Palaeocavia sp. & 164 & 4,27 \\
\hline Orthomyctera sp. & 79 & 7,59 \\
\hline
\end{tabular}

Tabla 4.8. Porcentaje de dientes aislados hallados en relación al NEIT total de cada taxón

En cuanto a los incisivos hallados aislados (78 especímenes) constituyen el $8,66 \%$ del total de restos asignados a roedores y muestran un patrón de pérdida similar al de los molares.

Entre los mamíferos de mayor talla es notorio el grado de rotura de los dientes, hasta fragmentos que impiden su determinación más que a nivel de orden o familia en algunos casos. Son abundantes las porciones de estos elementos esqueléticos entre los notoungulados (NEIT=34), litopternos (NEIT=8) y xenartros (NEIT=10).

- Coprolitos

Ya se indicaron los elementos esqueléticos que se reconocieron en los coprolitos (ver Grado de bioerosión). En cada coprolito, la densidad de restos es muy alta, pero también es muy alto el grado de rotura. Las características de fragmentación que presentan estos restos son similares a las descriptas para heces de mamíferos carnívoros actuales. 


\section{Grado de meteorización}

La meteorización fue definida por Behrensmeyer (1978) como el proceso por el cual los componentes originales de los huesos se separan entre sí y son destruidos por agentes físicos y químicos que actúan sobre el mismo, tanto en superficie como en el suelo. En el análisis se consideraron en este ítem solo a los atributos producidos por diferentes agentes atmosféricos sobre los huesos en superficie o sea antes del enterramiento. Los procesos que actúan sobre los elementos una vez que estos se enterraron son analizados en otros ítems (por ejemplo bioerosión producida por el crecimiento de raíces).

Para huesos actuales de macromamíferos, Behrensmeyer (1978) describió seis etapas diferentes del proceso de meteorización, pero recomendó el uso de tres para la descripción de material fósil: hueso intacto, hueso con pérdida de materia ósea superficial y hueso con pérdida de materia ósea profunda (Alcalá, 1994). La diferenciación entre la segunda y la tercera categoría se determina en función de la intensidad de la pérdida de materia ósea detectada, el límite entre ambas estaría dado por la exposición o no de la zona de hueso esponjoso. Behrensmeyer (1978) sugirió que los cambios térmicos y la humedad son los principales agentes de las alteraciones superficiales del material óseo expuesto en superficie, sin embargo también se considera que los rayos ultravioletas constituyen un factor importante como agentes meteorizantes (Tuross et al., 1989). Además, en el modelo propuesto por Behrensmeyer (1978) no se consideran otros factores que condicionan la meteorización, como la estructura misma del tejido óseo y la variabilidad de acuerdo a la especie de mamífero a la que corresponde.

Con respecto a los micromamíferos, diversos factores modifican su grado de meteorización ya que pueden iniciar su período de exposición a la intemperie protegidos por la propia estructura de egagrópilas o heces, pueden estar expuestos al transporte y a la rotura por pisoteo. Andrews (1990) propuso una serie de estados de meteorización para elementos esqueléticos de micromamíferos considerando como agentes meteorizantes a la luz del sol, viento, lluvia y cambios de temperatura (Tabla 4.9). De todos modos debe 
aclararse que sus experimentos fueron realizados con concentraciones de huesos en egagrópilas, las que protegieron a estos elementos durante un tiempo prolongado.

\begin{tabular}{|l|l|l|}
\hline Estadío & Micromamíferos & Años \\
\hline 0 & No hay modificación. & $0-2$ \\
\hline 1 & $\begin{array}{l}\text { Ligero resquebrajamiento paralelo a la estructura fibrosa. Dientes } \\
\text { flojos, dentina resquebrajada. }\end{array}$ & $1-5$ \\
\hline 2 & $\begin{array}{l}\text { Agrietamiento más extendido, pero poca exfoliación; astillamiento y y } \\
\text { agrietamiento de los dientes que lleva a la pérdida de casi toda la } \\
\text { corona. }\end{array}$ & $3-5+$ \\
\hline 3 & $\begin{array}{l}\text { Agrietamiento profundo y pérdida de algunos segmentos profundos } \\
\text { o escamas entre grietas. Agrietamiento extensivo a los dientes. }\end{array}$ & $4-5+$ \\
\hline
\end{tabular}

Tabla 4.9. Estados de meteorización para elementos esqueléticos de micromamíferos según Andrews (1990)

Es importante señalar aquí que en la asociación de Caleufú otros mecanismos distintos a la meteorización, por ejemplo bioerosiones y diferentes tipos de corrosión, provocaron la pérdida posterior de materia ósea superficial y dificultan la observación de evidencias de meteorización antes del enterramiento, pero en general se observó una gradación en los especímenes, de modo tal que todos los estados propuestos por Andrews (1990) están representados. Son abundantes los especímenes que preservaron el hueso intacto (estado 0) y sus dientes sin modificación (Lámina 4.10 A y B), pero también hay ejemplares con resquebrajamiento superficial (Figura 4.26), con descamación ósea superficial (Lámina $4.10 \mathrm{C}$ y D) y otros con diferentes grados de modificación en la dentina de los molariformes (Lámina 4.10 E, F, G y H), que va desde un agrietamiento de su superficie hasta la rotura y pérdida de parte de la misma en la zona expuesta del diente. 


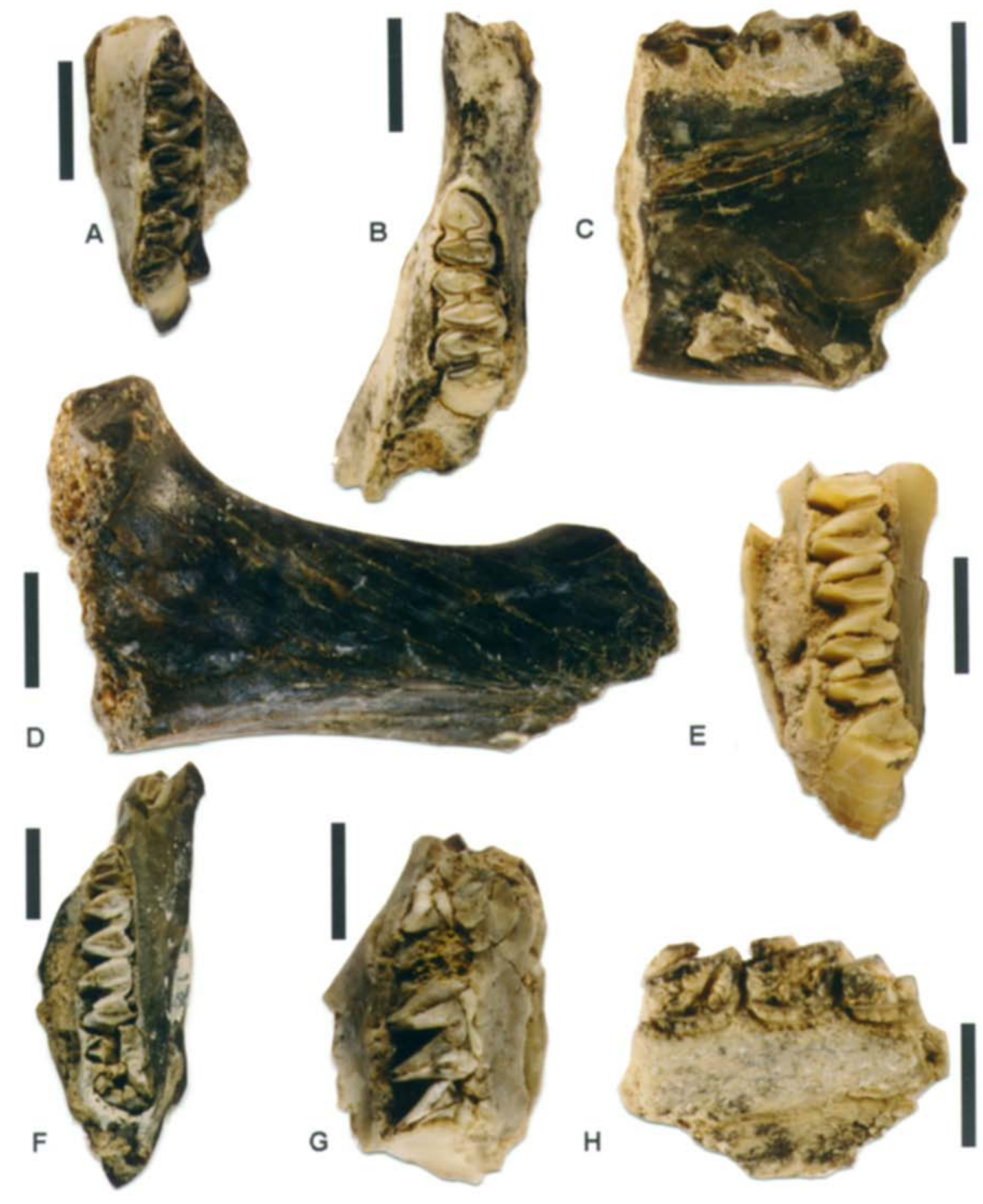

Lámina 4.10. Meteorización. A. hemimandibula derecha de Neocavia cf. N. Iozanoi (GHUNLPam 21288); B. hemimandibula izquierda del Octodontinae indet. (GHUNLPam 19824); C. hemimandibula izquierda de Paedotherium minor (GHUNLPam 19535); D. ulna (GHUNLPam 19865/67); E. hemimandibula izquierda de Palaeocavia sp.(GHUNLPam 21311); F. idem anterior (GHUNLPam 21307); G. idem anterior de Orthomyctera sp. (GHUNLPam 19535); H. paladar de Paedotherium minor (GHUNLPam 19569), escalas $5 \mathrm{~mm}$ 
Lámina 4.10. Meteorización. A. hemimandíbula derecha de Neocavia cf. N. lozanoi (GHUNLPam 21288); B. hemimandíbula izquierda del Octodontinae indet. (GHUNLPam 19824); C. hemimandíbula izquierda de Paedotherium minor (GHUNLPam 19535); D.

ulna (GHUNLPam 19865/67); E. hemimandíbula izquierda de Palaeocavia sp.

(GHUNLPam 21311); F. ídem anterior (GHUNLPam 21307); G. ídem anterior de Orthomyctera sp. (GHUNLPam 19535); H. paladar de Paedotherium minor (GHUNLPam 19569), escalas $5 \mathrm{~mm}$ 


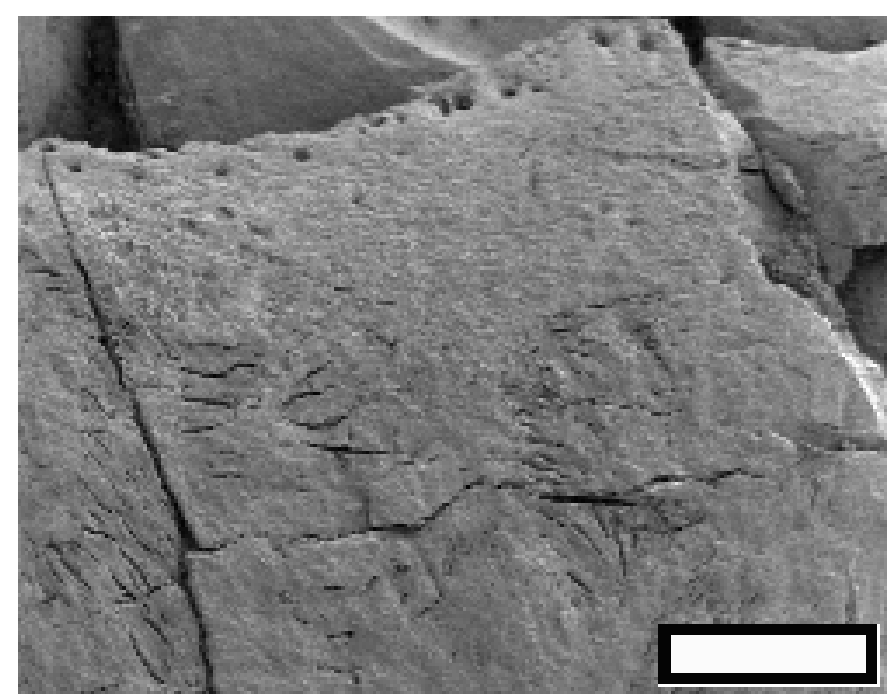

Figura 4.26. Hemimandíbula de Paedotherium minor con resquebrajamiento superficial y fracturas posteriores escala $1000 \mu$

Es de destacar que los pocos elementos conservados asignados a Aves, si bien son muy fragmentarios presentan un grado bajo de meteorización. Al respecto Behrensmeyer et al. (2003) señalaron que la mayoría de los huesos de aves recuperados en asociaciones actuales en Amboseli (Kenya) muestran el estado 1 de meteorización de la escala propuesta por Behrensmeyer (1978) para restos de mamíferos. Indicaron que luego de este estado, los huesos de aves se desintegran rápidamente, ya que sus paredes son muy delgadas y porosas.

Compararon, además, esos huesos con los de mamíferos juveniles, y concluyeron que éstos también son afectados antes por procesos meteorizantes que los de mamíferos adultos, por lo que no observan especímenes con otros estados de meteorización (Behrensmeyer et al., 2003). Es de destacar que los especímenes asignados a juveniles en la asociación de micromamíferos de Caleufú se encuentran en buen estado, prácticamente sin modificaciones en su estructura ósea superficial.

De todos modos, las diferencias señaladas en el estado de meteorización en los especímenes de la asociación de microvertebrados, se pueden relacionar con una incorporación paulatina de los elementos esqueléticos en el suelo, característica que se describirá más adelante. 
En la asociación de mamíferos de más de $5 \mathrm{~kg}$ de masa corporal estimada, la meteorización es un proceso muy importante que afectó a los restos de manera muy marcada. Pocos especímenes conservan el hueso intacto (Lámina 4.11 A), aunque es común la presencia de numerosas fracturas (Lámina 4.11 B). En general se presenta un evidente deterioro del hueso compacto superficial y muchos muestran directamente el hueso esponjoso.

Esta diferencia en el grado de meteorización entre los dos grupos de especímenes se puede atribuir a diferentes momentos en el enterramiento de los elementos. Los restos de microvertebrados se habrían enterrado más rápidamente, mientras que los elementos producidos por mamíferos de mayor tamaño habrían permanecido expuestos en la superficie, sometidos a diferentes agentes meteorizantes durante mucho más tiempo.

Por otro lado, en esta asociación se observaron marcadas diferencias en el grado de meteorización relacionadas con la asignación taxonómica de los elementos conservados. Esto es evidente por ejemplo en las placas de la coraza de representantes de las familias Dasypodidae y Glyptodontidae (Xenarthra). Las de los primeros se encuentran en mejor estado, con escasa pérdida de materia ósea superficial, que puede haber borrado caracteres diagnósticos, pero que no deja expuesto el hueso esponjoso. Las placas asignadas a gliptodontes, en cambio, están siempre mucho más deterioradas y eso se debe a que en esta familia las placas son mucho menos densas que las de los dasipódidos (Hoffstetter, 1958), por lo que pueden ser modificadas más rápidamente por los agentes meteorizantes (Lámina 4.12). 
Paleobiologia de la asociación faunistica de Caleufú (La Pampa, Formación Cerro Azul, Mioceno superior - Plioceno inferior), a través de análisis tafonómicos
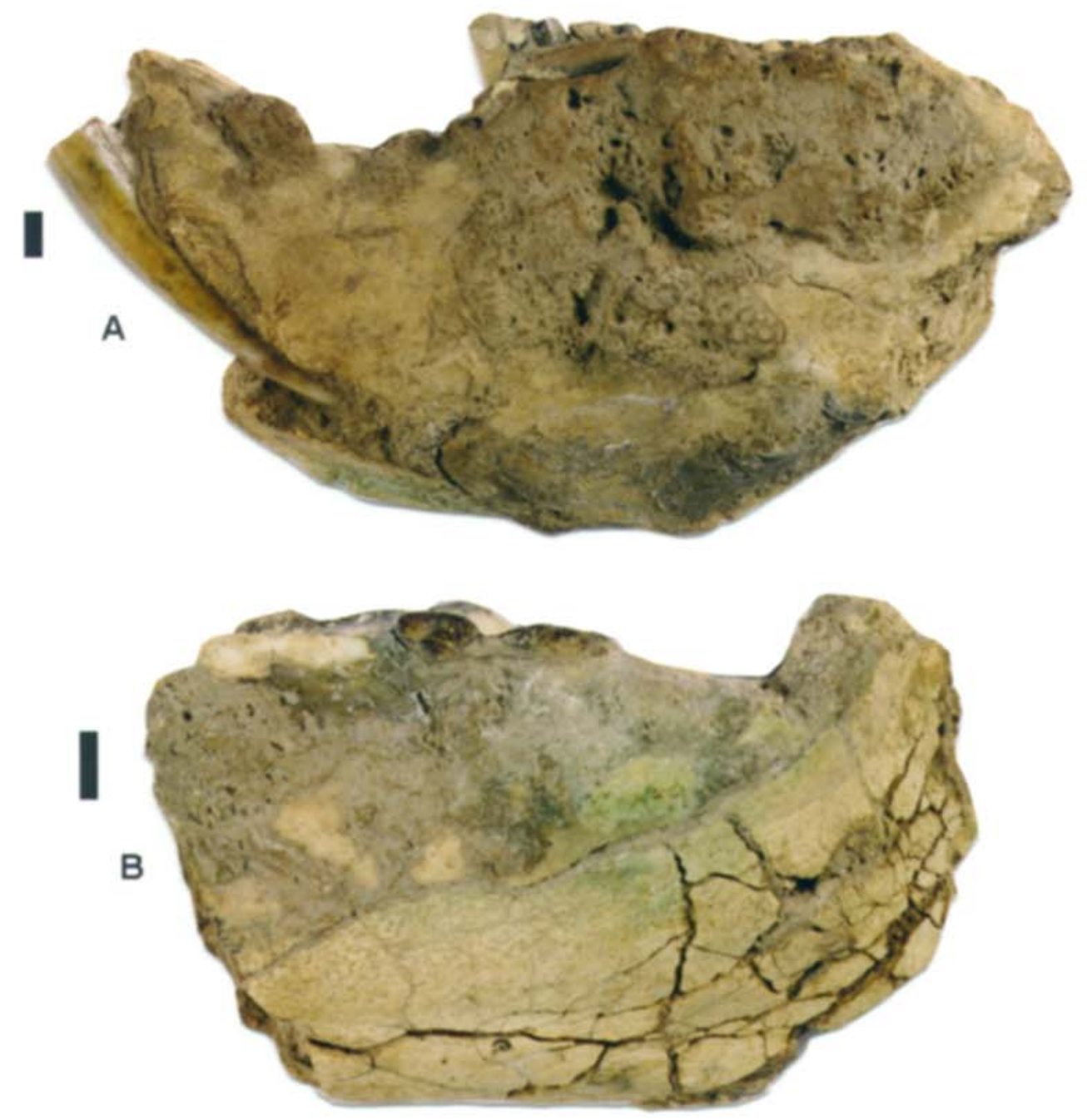

Lámina 4.11. A. Vista lateral de la hemimandibula izquierda de Tetrastylus sp. (GHUNLPam 19830); B. vista lateral lingual de la hemimandibula derecha del Proterotheriidae indet. (GHUNLPam 19826), escalas $5 \mathrm{~mm}$ 
Lámina 4.11. A. Vista lateral de la hemimandíbula izquierda de Tetrastylus sp.

(GHUNLPam 19830); B. vista lateral lingual de la hemimandíbula derecha del

Proterotheriidae indet. (GHUNLPam 19826), escalas $5 \mathrm{~mm}$ 

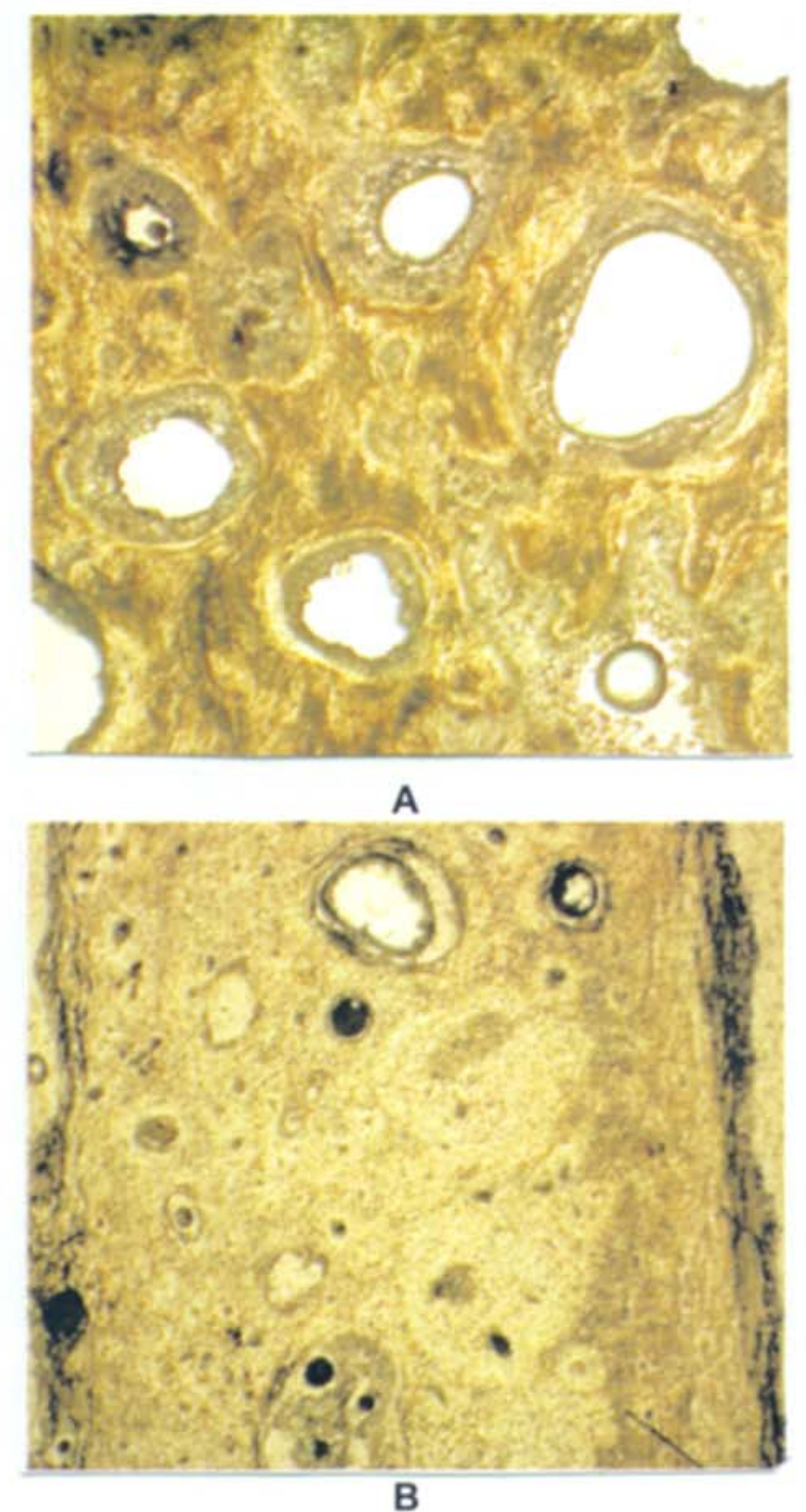

Lámina 4.12. Cortes delgados de placas de la coraza de Xenarthra. A. placa de Glyptodontidae indet. (GHUNLPam 21905/1), B. placa de Dasypodidae indet. (GHUNLPam 21900/2), X 4 
Lámina 4.12. Cortes delgados de placas de la coraza de Xenarthra. A. placa de Glyptodontidae indet. (GHUNLPam 21905/1), B. placa de Dasypodidae indet. (GHUNLPam 21900/2), X 4 


\section{Fragmentos indeterminables}

En el afloramiento de Caleufú fueron recolectados 3.250 fragmentos indeterminables. Estos restos fueron incorporados en el análisis de la distorsión mecánica, ya que el alto grado de rotura, fragmentación y meteorización que presentan está directamente relacionado con la historia tafonómica de la asociación faunística. De ese total se tomó al azar una muestra de 913 restos (el $28,09 \%$ del total), los que fueron primeramente clasificados de acuerdo a su probable productor en restos provenientes de microvertebrados (275 restos, el $30,12 \%$ ) y restos provenientes de macromamíferos (638 restos, el 69,88 \%), usando para ello su tamaño y características. Para ambos tipos de restos se tomaron las siguientes medidas: largo máximo (D1), ancho máximo (D2), y espesor máximo (D3). Los rangos de estas medidas en cada caso y los promedios se muestran en las Tablas 4.10 y 4.11 .

\begin{tabular}{|l|c|c|c|}
\hline \multicolumn{4}{|c|}{ Restos provenientes de macromamíferos } \\
\hline & Largo máx. & Ancho máx. & Espesor máx. \\
\hline Rango & $0,80-6,78$ & $0,55-5,22$ & $0,20-3,38$ \\
\hline Promedio & 2,25 & 1,58 & 0,99 \\
\hline
\end{tabular}

Tabla 4.10. Promedio y rango de tamaño de las medidas $(e n \mathrm{~cm})$ de los fragmentos indeterminables asignados a macromamíferos

\begin{tabular}{|l|c|c|c|}
\hline \multicolumn{4}{|c|}{ Restos provenientes de microvertebrados } \\
\hline & Largo máx. & Ancho máx. & Espesor máx. \\
\hline Rango & $0,64-2,30$ & $0,35-1,66$ & $0,19-1,30$ \\
\hline Promedio & 1,28 & 0,79 & 0,48 \\
\hline
\end{tabular}

Tabla 4.11. Promedio y rango de tamaño de las medidas $(e n \mathrm{~cm})$ de los fragmentos indeterminables asignados a microvertebrados

En la Tabla 4.10 se muestran las dimensiones máximas obtenidas. Estos valores muestran un sesgo en el tamaño de los restos, ya que no hay fragmentos de tamaño grande que serían esperables de acuerdo a la talla estimada de los posibles productores, por ejemplo elementos esqueléticos de mesoterinos, toxodontes y xenartros entre los macromamíferos. Debe acotarse que en la asociación de macromamíferos hay muy pocos especímenes identificados que 
superan el tamaño máximo de los restos indeterminables, ya que la mayoría se encuentran en el rango de tamaño indicado para aquellos fragmentos.

La mitad de los fragmentos indeterminables tiene alguna rotura longitudinal y/o transversal de borde liso, interpretada como producida sobre el hueso mineralizado y relleno de sedimento. Estas roturas, producidas en cualquier momento luego del enterramiento y hasta su reexposición, sesgan las medidas de estos restos hacia un tamaño menor, por lo que el carácter tamaño es difícil de evaluar, pero de todos modos se evidencia una tendencia a la disminución general del tamaño del resto. La otra mitad presenta evidencias de haberse fragmentado y roto cuando el elemento esquelético estaba fresco y en muchos casos hay una importante pérdida de hueso compacto, caracteres que se pueden relacionar con la acción de procesos meteorizantes previos al enterramiento.

Se puede postular que en el ambiente abierto donde se desarrollaba esta fauna, sobre un suelo de llanura en constante formación, los agentes meteorizantes (luz, cambios de temperatura, viento, precipitaciones) sumados a posibles agentes bioturbadores y quizá también algo de transporte lateral por efecto de pequeñas corrientes de agua y sedimento en los momentos de mayor precipitación, actuaron sobre los esqueletos promoviendo la rotura de cada elemento esquelético hasta un tamaño apto como para ser enterrado en un ambiente con baja tasa de sedimentación. La fragmentación y rotura se podrían relacionar directamente con extendidos lapsos de exposición previos al enterramiento. Se puede estimar que esta exposición fue mayor para los elementos esqueléticos de tamaño grande que para el de los producidos por microvertebrados. Pero además, se desconoce cuanto tiempo han permanecido estos fragmentos en superficie en diferentes momentos de la historia tafonómica; debe recordarse que hay restos indeterminables que muestran corrosión por líquenes $(2,77 \%)$ que evidencia su exposición en superficie. Esto indicaría que los mismos factores mencionados pueden haber actuado sobre fragmentos ya fosilizados.

Por otro lado, la caracterización de la forma de los restos indeterminables se realizó con un diagrama que describe morfologías, comparando las 3 dimensiones tomadas en cada caso: D1/D2 frente a D2/D3, siendo D1 $\geq D 2 \geq D 3$ 
(Flinn, 1978; Alcalá, 1994). Se realizaron dos gráficos (Figura 4.27 y 4.28), uno para cada grupo de restos formado, que permiten visualizar los contrastes entre los restos de forma alargada y estrecha (valores altos de D1/D2 y bajos de D2/D3) y los de forma aplanada (valores bajos de D1/D2 y altos de D2/D3). La mayor o menor disparidad entre estos 2 índices permite apreciar el grado de diversidad de formas. En ambas muestras hay una tendencia al predomino de las formas cúbicas, que son las que más se aproximan al punto $(1,1)$ de la bisectriz del ángulo que forman los 2 ejes de coordenadas.

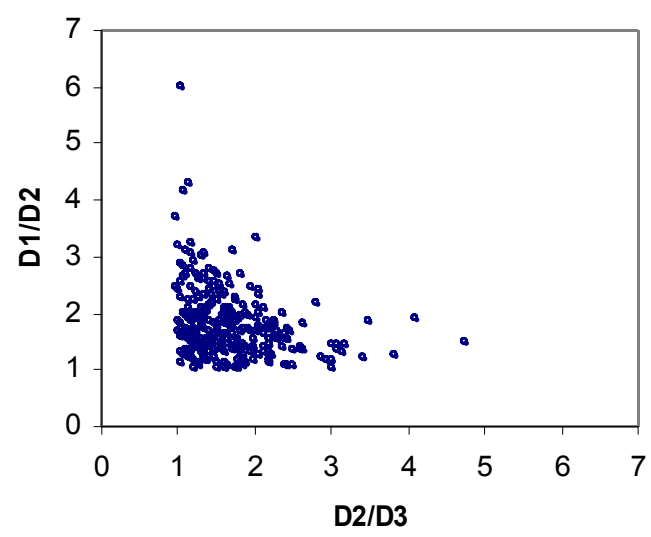

Figura 4.27. Diagrama de Flinn de la forma geométrica de los fragmentos indeterminables atribuibles a microvertebrados

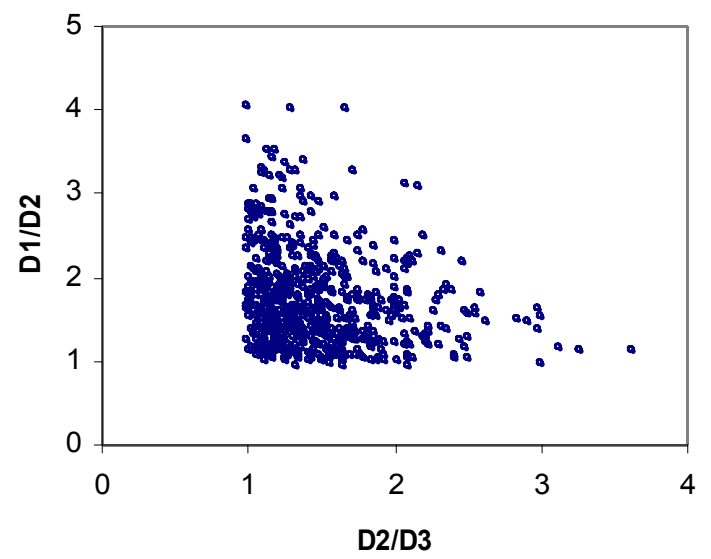

Figura 4.28. Diagrama de Flinn de la forma geométrica de los fragmentos indeterminables atribuibles a macromamíferos 
En la muestra de restos atribuibles a macromamíferos (Figura 4.28), la dispersión es mayor que en la otra muestra, lo que indica una gama más amplia de formas.

La mayor diversidad de formas fue relacionada por Alcalá (1994) con una menor intensidad de los procesos de selección en la etapa previa al enterramiento, ya que la forma condiciona el movimiento. Sin embargo, en el afloramiento de Caleufú, como ya se indicó, hubo algún tipo de selección sobre los restos, relacionada con la meteorización y el enterramiento, que favoreció la preservación de fragmentos de tamaño bastante uniforme y con tendencia a la forma cúbica.

\section{Señales de pisoteo}

El pisoteo constituye un importante factor de dispersión y rotura de los elementos esqueléticos (Andrews, 1990).

Sobre huesos frescos de mamíferos grandes, los efectos del pisoteo producen fracturas y daño de la superficie que pueden tener características similares a las producidas por carnívoros durante la masticación. En sustratos de grano fino el pisoteo puede producir pulido y alisado de la superficie. Sobre huesos secos puede provocar astillamiento y fracturas longitudinales (Behrensmeyer et al., 1989).

Fernández Jalvo (1996) señaló tres características que le permitieron identificar los efectos producidos en el proceso de pisoteo sobre huesos de micromamíferos:

- Predominancia de elementos esqueléticos de pequeño tamaño, especialmente los más robustos (astrágalos, calcáneos, molares). Ausencia de escápulas y escasez de mandíbulas, maxilas e innominados.

- Alto porcentaje de elementos esqueléticos rotos, hay gran destrucción de mandíbulas y el índice de dientes aislados es alto.

- Los especímenes muestran estriación superficial producida seguramente por fricción con el sedimento. 
El análisis de estas características en la asociación de microvertebrados indica que predominan los elementos esqueléticos de tamaño pequeño, con un muy alto porcentaje de elementos rotos, hay algunas escápulas e innominados, pero son muy abundantes las mandíbulas y maxilares. El porcentaje de dientes aislados es bajo y la pérdida de los mismos se atribuyó a procesos diagenéticos. No se observaron marcas o rayas sin orientación, o multidireccionales, sobre la superficie ósea que puedan ser asignadas a pisoteo. Si bien algunos especímenes presentan estriación superficial no es claro que se pueda asignar este carácter a pisoteo o a fricciones ocurridas más tardíamente.

De lo expuesto surge que pudo existir algo de acción de pisoteo sobre los restos, ya que los especímenes presentan algunos atributos característicos, pero procesos ocurridos más tardíamente, los protegieron. Entre éstos se pueden citar la cementación rápida del sedimento que rellenó los espacios libres en el hueso poroso, en los alvéolos de mandíbulas y maxilares y en las diáfisis de huesos largos favoreciendo su integridad.

En la asociación de Caleufú, sólo el 0,46 \% de los especímenes presenta marcas de presión con características diferentes a las producidas por dientes. En su mayoría se encuentran en especímenes de la asociación de microvertebrados y consisten en pequeñas roturas del hueso compacto con fragmentos óseos rotos y asociados en la zona (Figura 4.29). Estas marcas pueden ser asignadas a presión por pisoteo.

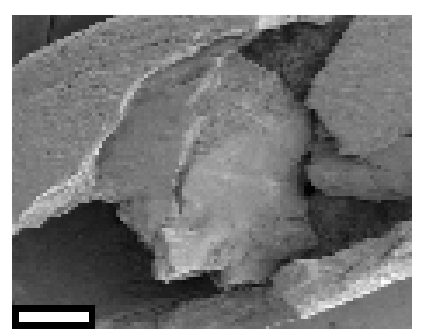

Figura 4.29. Marca atribuida a la presión por pisoteo sobre una diáfisis; escala $1000 \mu$

El bajo porcentaje de restos con estas señales se atribuye a la escasa posibilidad de que estén presentes en elementos esqueléticos de tamaño pequeño. En esos casos, es más esperable una rotura que una marca. En ese 
sentido ya se mencionó que algunas fracturas espirales se pueden atribuir a pisoteo.

De lo expuesto surge que en la asociación de microvertebrados hay escasas evidencias de pisoteo; sin embargo, este proceso, que puede haber favorecido la rotura de los elementos, también puede haber contribuido a la movilidad tanto horizontal como vertical de los elementos conservados en el sustrato, además de favorecer la rotura de los elementos esqueléticos (Olsen y Shipman, 1988). 


\section{GRADO DE DESARTICULACIÓN}

Bajo el atributo desarticulación se analizan los patrones de desconexión y separación de los elementos esqueléticos (Fernández López, 2000). En la asociación faunística de Caleufú, el grado de articulación es muy bajo, ya que sólo el 2,72 \% de los especímenes corresponden a dos o más fragmentos de elementos esqueléticos articulados o hallados asociados.

Entre los especímenes de la asociación de microvertebrados determinados taxonómicamente se recuperaron mandíbulas conectadas con paladares de Paedotherium minor (NEIT=4) y del Octodontinae indet. (NEIT=1). Considerando los cráneos, es común la presencia de especímenes con separación de los elementos óseos a nivel de las suturas, por ejemplo desconexiones a nivel de la sutura premaxilar - maxilar y entre hemimaxilares entre sí. Este carácter es común en asociaciones producidas por aves nocturnas (Korth, 1979), sin embargo también puede deberse a una exposición prolongada a agentes atmosféricos.

Entre los elementos postcraneanos, 15 especímenes corresponden a dos o más placas de la coraza de xenartros articuladas o halladas asociadas, 20 especímenes a vértebras articuladas y el resto $(\mathrm{NEIT=47)}$ fundamentalmente a elementos del basipodio articulados. La articulación de los elementos esqueléticos sugiere que algo de tejido conectivo se encontraba presente al momento del enterramiento. Dado que el tiempo necesario para eliminar tejidos frescos es muy corto en el caso de micromamíferos (Korth, 1979), se puede plantear que hubo un enterramiento muy rápido de esos especímenes.

El bajo grado de articulación entre los especímenes de la asociación de microvertebrados se puede relacionar directamente con la modalidad de formación de la concentración ósea, atribuible al accionar de depredadores. Debe tenerse en cuenta que los factores meteorizantes en la superficie y los procesos pedogenéticos que actuaron antes y después del enterramiento, pueden haber provocado mayor desconexión entre elementos esqueléticos dificultando la evaluación de este atributo. Sin embargo, la escasa evidencia disponible indica que las únicas conexiones registradas están representadas por elementos craneanos (mandíbulas y maxilares) y por elementos distales de los miembros. 
Esto podría estar directamente relacionado con un comportamiento particular de manipulación por parte del depredador, comportamiento que se discute más adelante.

Con respecto a los taxa asignados a mamíferos de más de $5 \mathrm{~kg}$ de masa corporal estimada todos están representados por especímenes aislados o incluso porciones de especímenes, por lo que no es posible realizar ningún tipo de evaluación sobre su desarticulación. Entre los xenartros, las placas que constituyen la coraza aparecen como elementos esqueléticos aislados, con un porcentaje muy bajo de grupos de pocas placas. En general la separación de estos elementos se produjo a nivel de las suturas. Evidentemente en estos casos hubo también factores ambientales, actuando durante un tiempo prolongado, que favorecieron la desarticulación de los elementos esqueléticos. Coincidentemente con otros atributos analizados, la total desconexión entre elementos esqueléticos correspondientes a macromamíferos es una evidencia más de que el período de exposición al que estuvieron sometidos antes del enterramiento fue prolongado. 


\section{GRADO DE ABRASIÓN}

La abrasión de los especímenes es una consecuencia del impacto que sobre los mismos ejercen las partículas transportadas por el agua o el viento. Como resultado de este proceso, la superficie externa suele ser pulida y sus relieves positivos llegan a ser desgastados o incluso obliterados (Fernández López, 2000). En la asociación no se han encontrado evidencias que indiquen la acción abrasiva sobre los elementos antes de su mineralización y relleno sedimentario, lo que sería un indicio de transporte previo al enterramiento. Sin embargo, se han identificado especímenes que muestran señales de abrasión post-enterramiento, evidenciada por desgastes que afectan algunos sectores del fósil incluyendo el relleno sedimentario. En muchos fragmentos indeterminables se observa un pulido intenso de la superficie ósea, que llega a exponer la zona del hueso esponjoso. En algunos fragmentos de tamaño grande esta abrasión ha pulido solo una cara del mismo, lo que podría deberse a la acción eólica. De todos modos, no fue posible establecer ningún patrón de desgaste.

Se encontraron algunos especímenes de micromamíferos que presentan pequeñas marcas circulares, de desgaste concéntrico que podrían atribuirse a golpes producidos sobre el resto mineralizado. 


\section{ATRIBUTOS RELACIONADOS CON EL DESARROLLO Y EVOLUCIÓN DEL PALEOSUELO}

La preservación diferencial de fósiles puede ser explicada en función del $\mathrm{pH}$ y el Eh del suelo, si bien se considera que está más controlada por el pH; en términos de estas variables, es posible visualizar qué clases de fósiles se pueden preservar en los diferentes paleosuelos, de modo tal que la preservación se produce por un equilibrio químico con el suelo (Retallack, 1990). Los huesos y dientes, compuestos por minerales fosfáticos, normalmente se disuelven en suelos ácidos, y en particular primero se afecta el esmalte de los dientes (Fernández Jalvo y Sánchez Chillón, 2000). Sin embargo, los dientes son persistentes en estos ambientes por su mayor densidad y menor porosidad y además presentan una superficie menor a disolver (Shipman, 1981). Ya que los huesos pequeños tienen una mayor relación superficie-volumen que los de gran tamaño están más expuestos a la disolución en ambientes ácidos (Retallack, 1990). Esta es una razón por la que en los paleosuelos los huesos de pequeños animales y de individuos juveniles son raros, comparados con aquellos de mayor tamaño y de adultos. En particular el pH del suelo está relacionado directamente con la preservación de especímenes correspondientes a individuos juveniles (Gordon y Buikstra, 1981), que se preservan mejor si el ambiente de depositación es más básico.

Numerosos procesos afectan a los restos óseos a partir del momento en que son enterrados. Entre ellos se pueden citar el pisoteo producido por animales en la superficie y la compactación producida por la expansión de las arcillas al humedecerse que pueden fracturar, desconectar o distorsionar los restos enterrados; la descomposición microbiana y la alteración química que producen corrosiones sobre las superficies expuestas $y$, la reexposición de fósiles en superficie que puede provocar nuevas roturas y desconexión. Estos procesos pueden ser considerados filtros en el sentido que pueden colaborar en la determinación de qué especímenes se preservarán en los suelos (Retallack, 1990). Sin embargo, con una visión diferente, el análisis de atributos tafonómicos presentes en los especímenes constituyen evidencias de la acción de diferentes 
procesos que actuaron sobre los mismos y ofrecen importante información acerca de la historia tafonómica de la asociación y también de sus niveles hospedantes.

Wood y Johnson (1978) indicaron que los suelos no son cuerpos estáticos, son sistemas abiertos, dinámicos, en los que diferentes procesos operan para perturbar los perfiles y producen movimientos verticales y horizontales de sus materiales y también de los objetos que en ellos se encuentran; estos pueden hundirse en el suelo, concentrarse en capas profundas, ser reorientados dentro del suelo, volver a la superficie o moverse horizontalmente de acuerdo a los planos de inclinación. En el caso de la asociación de Caleufú, estos procesos pueden haber afectado a los elementos óseos que se encontraban enterrados en el suelo. El perfil estratigráfico tiene evidencias que indican que el suelo era de tipo básico, incrustante. Este carácter hizo que muchos de los restos óseos fueran rápidamente protegidos por una cubierta calcárea, incluidos en una concreción calcárea o mineralizados y esto impidió que aquellos procesos los afectaran de modo importante.

En este ítem se analizan varios atributos de los elementos recuperados que están directamente relacionados con el desarrollo y evolución del suelo en el que fueron enterrados, se incluyen aquí a los grados de encostramiento, desarrollo de concreciones calcáreas y relleno sedimentario por un lado y a la impregnación por óxidos de manganeso por otro. Ya fueron analizados previamente ciertos atributos bioerosivos, como algunos tipos de corrosiones, que se produjeron como consecuencia de la relación entre los elementos enterrados y el nivel hospedador.

Grados de encostramiento, desarrollo de concreciones calcáreas y relleno sedimentario

Al describir las características de las sedimentitas de la Formación Cerro Azul en Caleufú, se indicó la presencia de abundantes concreciones calcáreas alargadas y dispersas en la capa inferior, niveles que contienen la asociación faunística analizada. Estas concreciones calcáreas se forman por la cementación, reemplazo e introducción de $\mathrm{CO}_{3} \mathrm{Ca}$ en el perfil del suelo, en áreas donde la zona vadosa y el agua de la capa freática se saturan de $\mathrm{CO}_{3} \mathrm{Ca}$ (Wright y Tucker, 
1991). Estos autores indicaron que estas acumulaciones aparecen en áreas climáticas donde ocurre déficit estacional de humedad, lo que facilita la acumulación del $\mathrm{CO}_{3} \mathrm{Ca}$. Pueden formar horizontes del suelo que aparecen comúnmente en aridisoles, vertisoles y molisoles (Soil Survey Staff, 1975). Si bien los caracteres del perfil de Caleufú no son suficientes como para ubicar el paleosuelo en alguna de las categorías de la clasificación utilizada, el afloramiento de la Formación Cerro Azul en Telén, que presenta algunas características similares a éste fue clasificado como vertisol (Melchor et al., 2000). Se reconocen varios mecanismos que explican la precipitación de carbonatos; éstos incluyen fundamentalmente la evaporación y la evapotranspiración que remueven el agua. Este último mecanismo es visto como el de mayor importancia en la formación de concreciones en regiones semiáridas y también probablemente la mayor causa de formación de rizoconcreciones. También se reconoce la importancia de la pérdida de $\mathrm{CO}_{2}$ en el suelo y la acción de procesos producidos por microorganismos del suelo (Wright y Tucker, 1991). Ya se señaló que en el afloramiento de Caleufú, la precipitación de los carbonatos se efectuó durante las sucesivas variaciones verticales de la capa freática, característica de climas con alternancia entre períodos de mayor y menor humedad. En estos casos la cementación normalmente ocurre en los sectores más altos de perfil facilitando la liberación de $\mathrm{CO}_{2}$, la evaporación y la evapotranspiración. Esto permite inferir que, al menos en el momento en que se formaron las concreciones, el nivel que las contiene debía estar cerca de la superficie expuesta.

Las características expuestas del perfil pueden relacionarse con ciertas características que presentan los elementos conservados, ya que estos presentan encostramiento superficial o están incluidos total o parcialmente en una concreción calcárea y además el relleno sedimentario que contienen está cementado por $\mathrm{CO}_{3} \mathrm{Ca}$.

Se define al encostramiento como el revestimiento de los elementos conservados en la asociación formando costras superficiales que pueden ser o no de origen biogénico (Fernández López, 2000).

En el caso de los especímenes de la asociación de Caleufú, sobre todo los de la asociación de microvertebrados, es común la presencia de una capa fina de 
calcita cristalina de tamaño subesparita a esparita, formando un encostramiento, de desarrollo variable, que puede aparecer en algunos sectores de los especímenes (Lamina 4.13) o cubrir totalmente al resto. En los especímenes que incluyen dientes, la capa los puede cubrir tanto en la zona del esmalte como en la dentina de la cara oclusal de los molariformes.

No fue posible determinar si esta película es de origen biológico; sin embargo, la formación del encostramiento calcáreo estaría relacionada con procesos que ocurrieron en el nivel del sustrato que contenía estos especímenes.

En muchos casos, la distribución y morfología de esta película calcárea ha ayudado a evaluar en qué momento se produjeron algunas roturas, ya que este revestimiento se puede presentar cubriendo los bordes del espécimen, indicando una rotura muy temprana del resto o bien la rotura puede afectar también al encostramiento calcáreo, señalando en este caso que se produjo tardíamente.

En unos pocos especímenes se ha observado una tinción de la capa calcárea por óxidos de manganeso, pero en general esta película no está afectada por nuevas impregnaciones. Sin embargo, esta capa no impidió el pasaje de estos óxidos, de modo tal que en algunos casos se pueden observar en la superficie ósea debajo del encostramiento las marcas dendríticas oscuras típicas del avance de los mismos. En las zonas cercanas a fracturas o roturas la impregnación es más fuerte y por lo tanto la coloración en esa zona es más oscura.

Se interpreta que este encostramiento se produjo tempranamente luego del enterramiento, actuando como una capa protectora para los especímenes, evitando que estos fueran afectados por otros procesos de origen pedológico, como las impregnaciones por óxidos de manganeso mencionadas y corrosiones.

Por otro lado, son muy abundantes los restos que están incluidos total o parcialmente en una concreción calcárea (Lámina 4.14). Estas concreciones son de calcita microcristalina de tamaño micrita con alto contenido de arcilla. En varios de los especímenes analizados la arcilla se presenta formando clastos redondeados, si bien aparecen también clastos aislados cuya litología corresponde a limo grueso y algunos clastos que pueden corresponder a minerales ferruginosos. En general, el aspecto de estas concreciones es similar al 


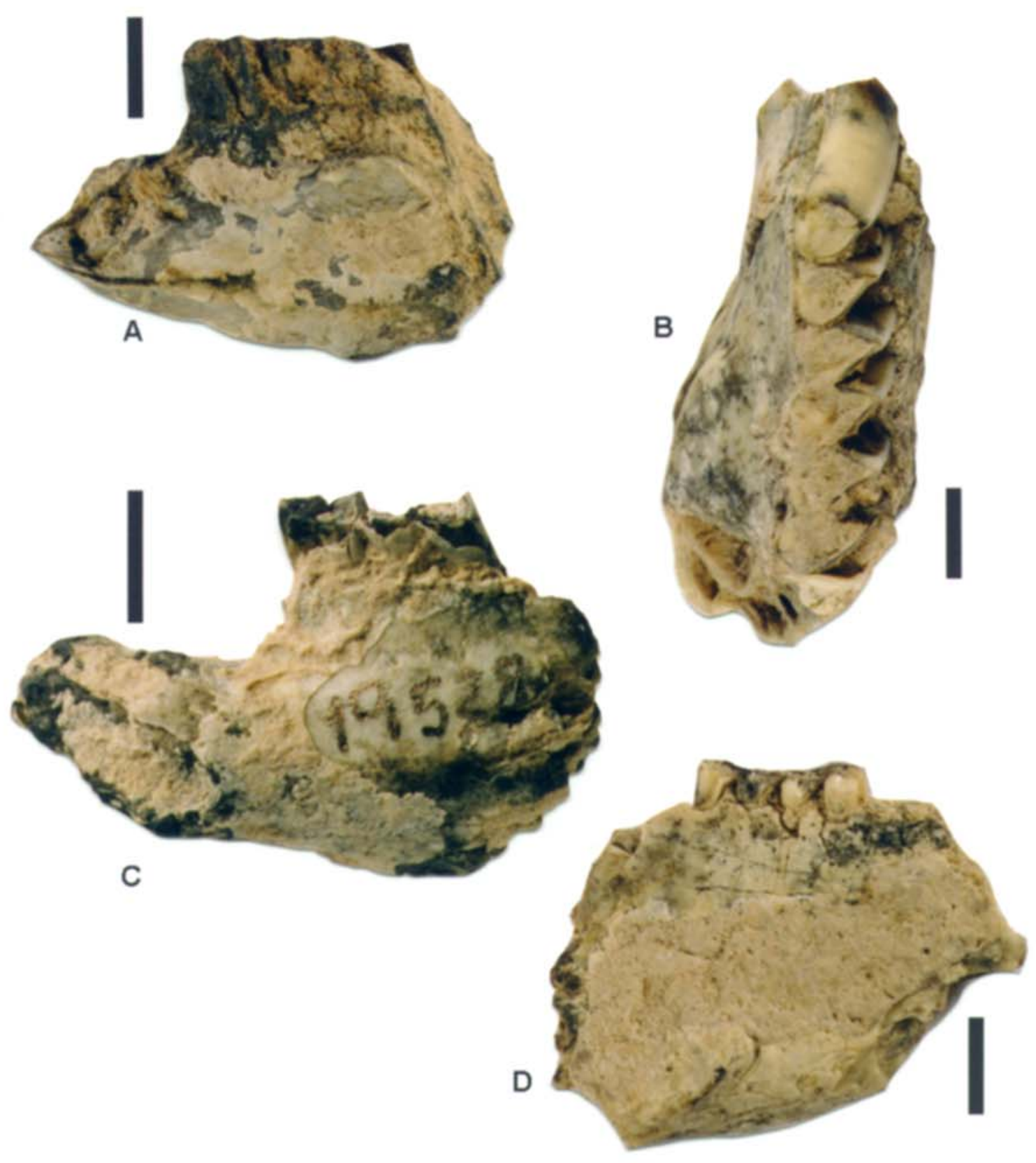

Lámina 4.13. Encostramiento. A. Hemimandibula izquierda de Orthomyctera sp. (GHUNLPam 21873); B. hemimandibula derecha de Orthomyctera sp. (GHUNLPam 21029); C. idem anterior (GHUNLPam 19528); D. idem anterior de Paedotherium minor (GHUNLPam 19242), escalas $5 \mathrm{~mm}$ 
Lámina 4.13. Encostramiento. A. Hemimandíbula izquierda de Orthomyctera sp. (GHUNLPam 21873); B. hemimandíbula derecha de Orthomyctera sp. (GHUNLPam 21029); C. ídem anterior (GHUNLPam 19528); D. ídem anterior de Paedotherium minor (GHUNLPam 19242), escalas $5 \mathrm{~mm}$ 


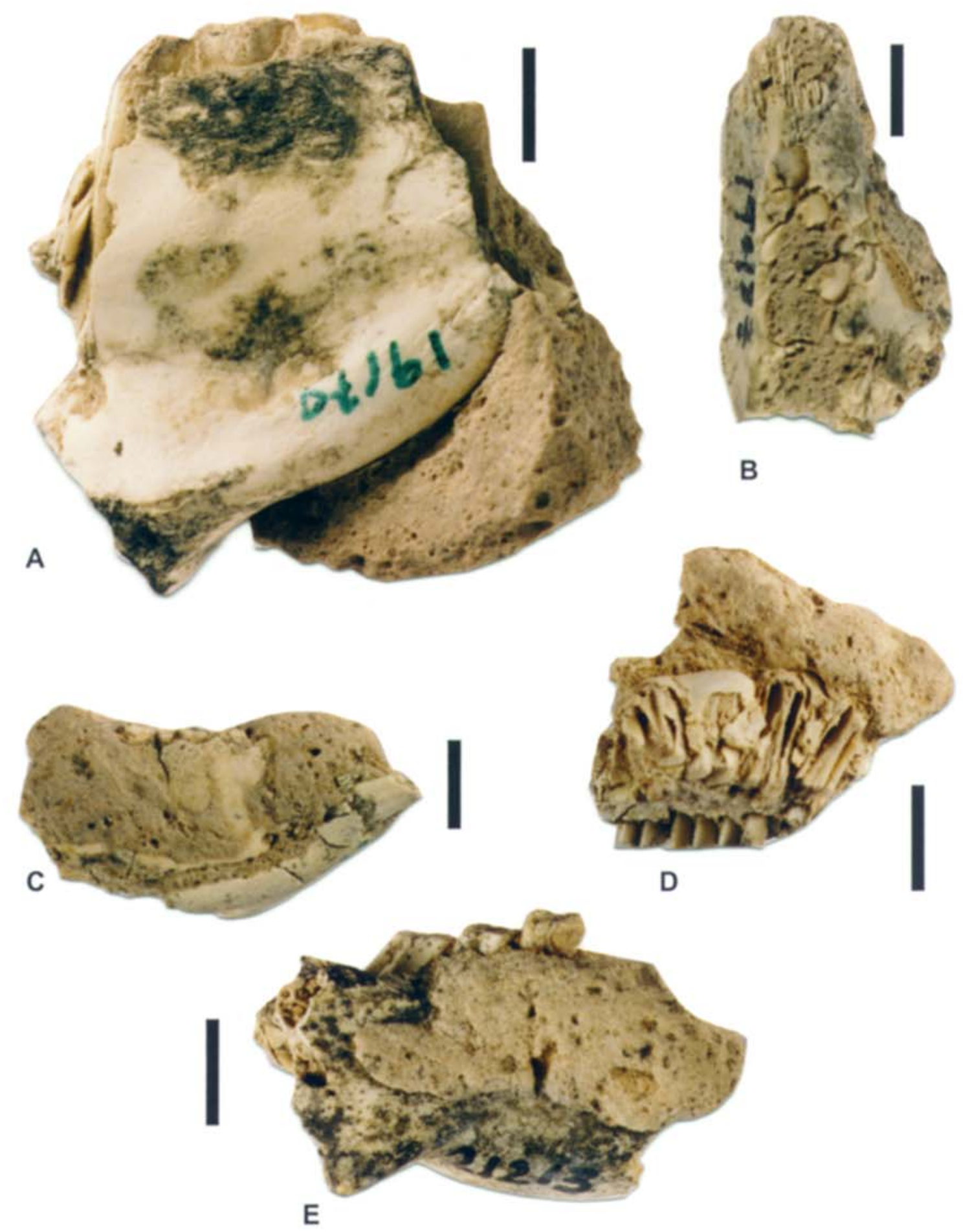

Lámina 4.14. Inclusión en concreciones calcáreas. A. Hemimandibula derecha de Paedotherium minor (GHUNLPam 19170); B. paladar de Paedotherium minor (GHUNLPam 19487); C. sinfisis de Paedotherium minor (GHUNLPam 19260); D. paladar de Neocavia cf. N. Iozanoi (GHUNLPam 21346); E. hemimandibula derecha del Octodontinae indet. (GHUNLPam 21213), escalas 5 mm 
Lámina 4.14. Inclusión en concreciones calcáreas. A. Hemimandíbula derecha de Paedotherium minor (GHUNLPam 19170); B. paladar de Paedotherium minor (GHUNLPam 19487); C. sínfisis de Paedotherium minor (GHUNLPam 19260); D. paladar de Neocavia cf. N. Iozanoi (GHUNLPam 21346); E. hemimandíbula derecha del Octodontinae indet. (GHUNLPam 21213), escalas $5 \mathrm{~mm}$ 
observado en los cortes de las concreciones asociadas al paleosuelo, por lo que se infiere un origen similar para ambos tipos de concreciones. En la asociación de Caleufú, los sectores de los especímenes o directamente los especímenes que no están protegidos por concreción son muy afectados por los distintos tipos de corrosiones, por lo que se infiere que estas concreciones también favorecieron la preservación de restos.

Las concreciones permitieron la preservación de algunos elementos esqueléticos articulados, que si bien son pocos, señalan que mecanismos bioturbadores propios del suelo no lograron desarticularlos, seguramente debido a la formación temprana de la concreción que los protegió.

Todos los restos de la asociación están permineralizados, es decir con sus cavidades rellenas por sustancias minerales cristalinas (Figuras 4.30 y 4.31). De acuerdo a la descripción de Downing y Park (1998) de este proceso, la fosilización incluyó la infiltración de los poros presentes en el hueso por $\mathrm{CO}_{3} \mathrm{Ca}$, movilizado en solución desde las aguas subterráneas, a medida que la materia orgánica original se fue removiendo. Los especímenes sobre los que se realizaron cortes delgados, muestran que se ha retenido la estructura histológica original, tanto en los individuos adultos (Figura 4.30) como en los juveniles (Figura 4.31). Los elementos microestructurales que se observan en el corte correspondiente a la hemimandíbula de un individuo adulto corresponderían a los osteoplastos (cavidades donde se ubicaban los osteocitos) y a restos de la matriz ósea extracelular mineralizada. También se observan los canalículos calcóforos, que son las numerosas y finas prolongaciones de la cavidad, por donde se extendían las prolongaciones citoplasmáticas del osteocito. En el corte correspondiente a la hemimandíbula que había sido asignada por sus características macroscópicas a un individuo juvenil, se observa tejido óseo no laminar o primario (Fawcett, 1995; Cuezva y Élez, 2000), constituido por la matriz ósea mineralizada y los osteoplastos sin aparente organización. Este tipo de organización caracteriza al hueso en sus estadíos juveniles, lo que permitió confirmar que eran correctas las asignaciones, en base a las características de la superficie ósea, de los especímenes a la edad juvenil. 


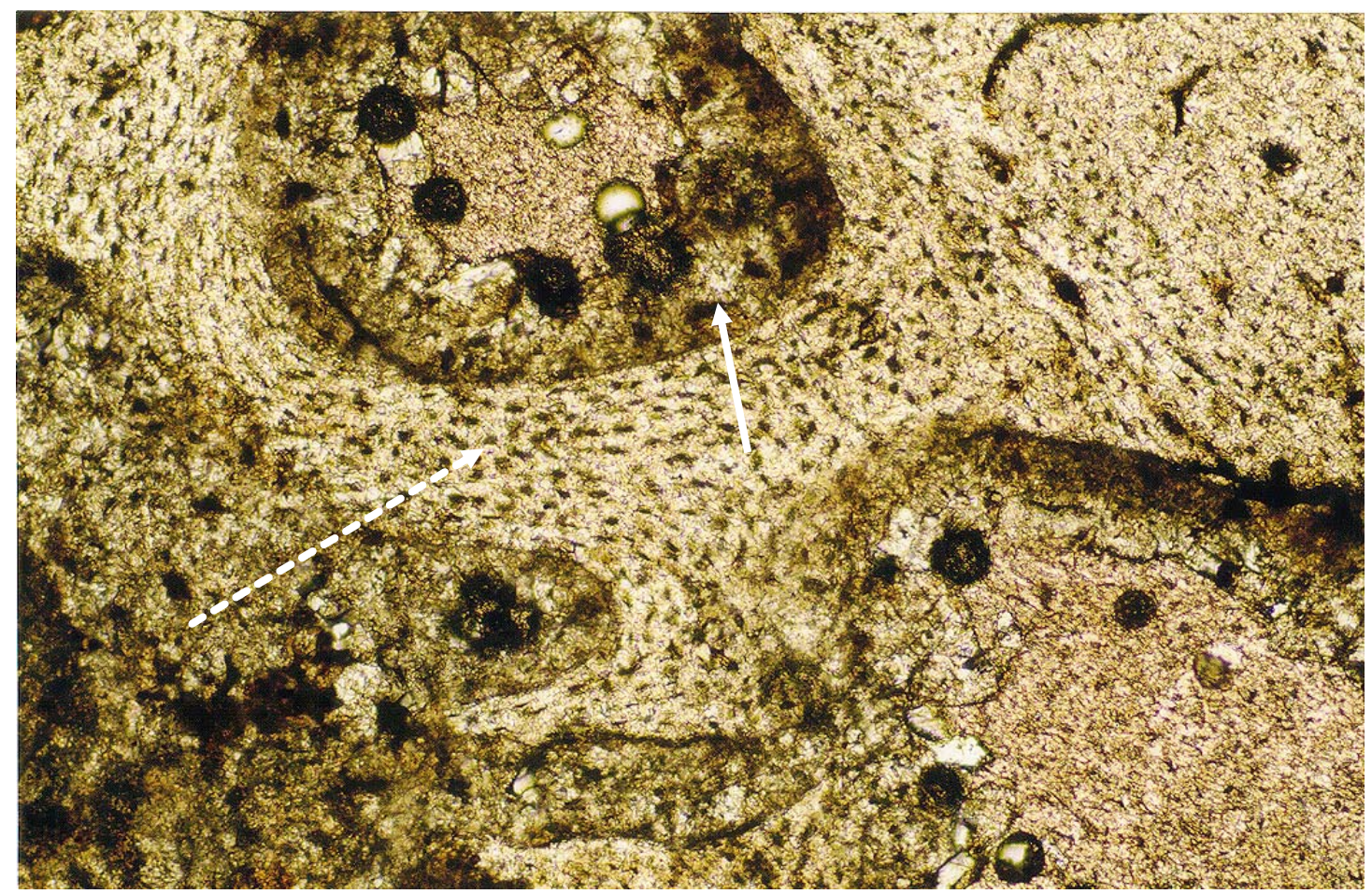

Figura 4.30. Corte delgado de una hemimandíbula de un individuo adulto de

Paedotherium minor (GHUNLPam 19221), donde se observa la microestructura histológica original (flecha con puntos) y las cavidades con pequeños cristales de calcita (flecha); X10, luz natural

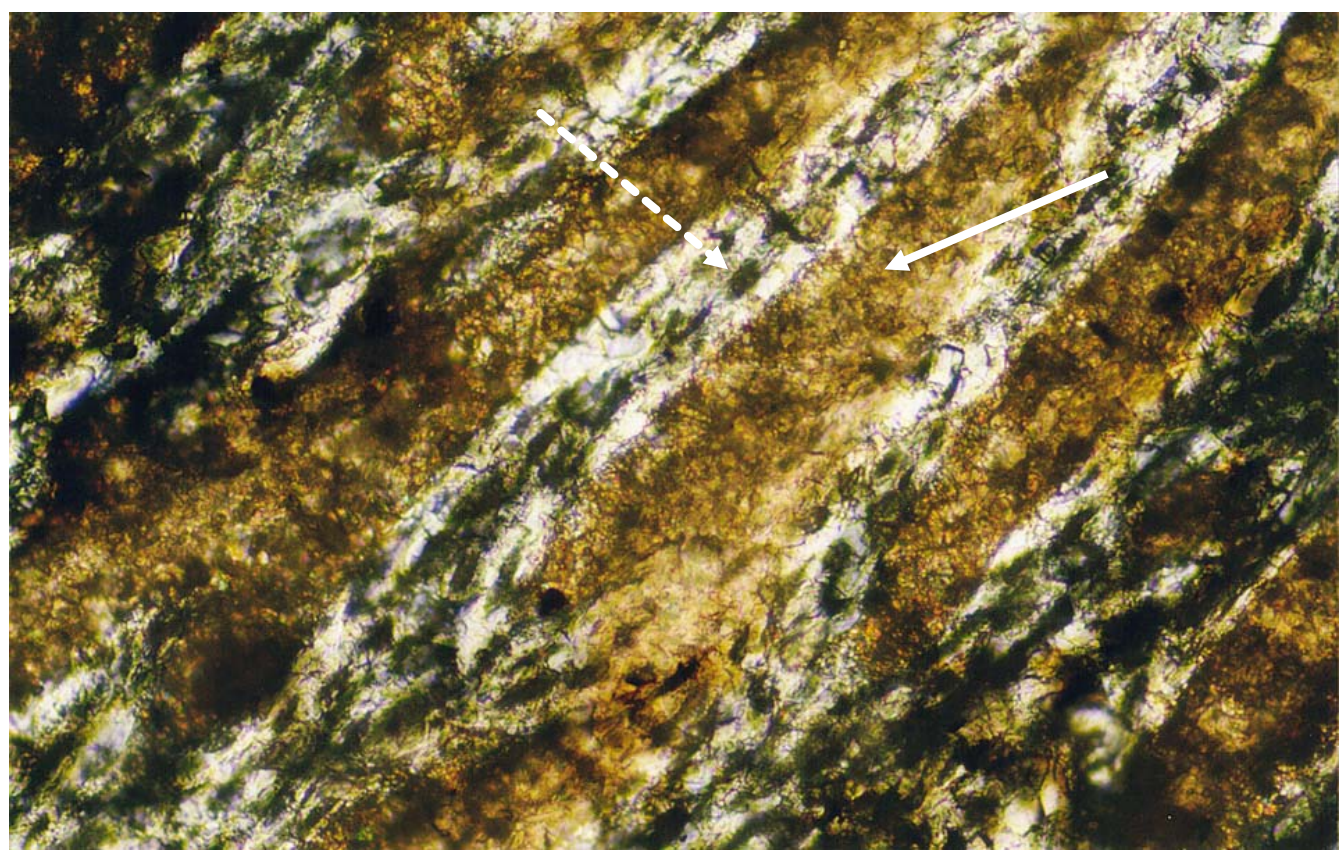

Figura 4.31. Corte delgado de una hemimandíbula de un juvenil de Paedotherium minor (GHUNLPam 19365), donde se observa la microestructura histológica original (flecha con puntos) y las cavidades rellenas con calcita (flecha); X20, nicoles cruzados 
El relleno sedimentario que ocupa las cavidades y poros de los especímenes está cementado por $\mathrm{CO}_{3} \mathrm{Ca}$ y es similar desde el punto de vista granulométrico y textural al de las concreciones mencionadas. El relleno de cavidades produjo, en muchos casos, la rotura del hueso en las áreas donde éste es más fino, por ejemplo en la base de los alvéolos de molares en los taxa con dientes hipsodontes, en sectores de la caja craneana, de las bulas auditivas y también de algunos paladares. El desarrollo de este relleno sedimentario provocó microfracturas en los elementos esqueléticos, que pueden haber favorecido la infiltración por óxidos de manganeso.

Hay especímenes que presentan sus cavidades totalmente rellenas. Este carácter fue utilizado al evaluar el tipo de rotura, ya que si la cavidad (por ejemplo, la zona médular de huesos largos) está totalmente rellena, se puede inferir que el espécimen estaba roto al momento de su relleno y cementación. Muchos de los especímenes con fracturas de borde liso, diagenéticas, no presentan sus cavidades rellenas de sedimento cementado. En estos casos, se observó que las cavidades (incluyendo las cavidades pulpares de los molares hipsodontes) presentan pequeños cristales de calcita en sus paredes internas. El desarrollo de estos cristales sugiere la precipitación del carbonato se produjo en un período húmedo, al que siguieron condiciones graduales más secas (Fernández Jalvo, 1995). El tamaño similar de los cristales entre sí, señala uniformidad en las condiciones ambientales y es indicador de la acción de aguas subterráneas movilizando el $\mathrm{CO}_{3} \mathrm{Ca}$ (James y Choquette, 1990).

Sobre algunos especímenes se desarrollaron concreciones calcáreas con forma de cilindros huecos, de diámetro bastante regular, que se interpretan como rizolitos (Lámina 4.15). Los rizolitos se definen como estructuras sedimentarias de origen orgánico que incluyen acumulación de sedimento y/o cementación alrededor de las raíces (Klappa, 1980). De acuerdo a la clasificación de los rizolitos que propuso Klappa (1980), los que se presentan en los especímenes de Caleufú corresponderían a cilindros cementados alrededor de raíces. La cementación de la rizósfera se puede haber producido tanto durante la vida como durante la descomposición de las raíces ("root tubules"). Los rizolitos proveen información acerca de la colonización del suelo por plantas (Klappa, 1980) e 

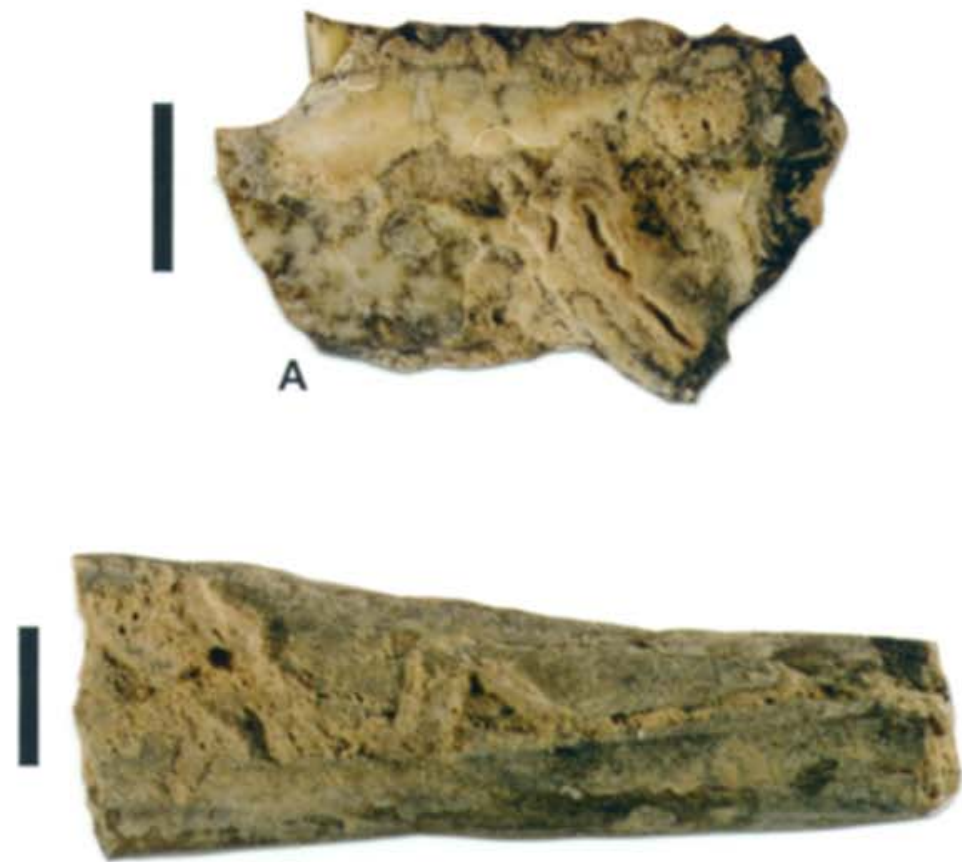

B

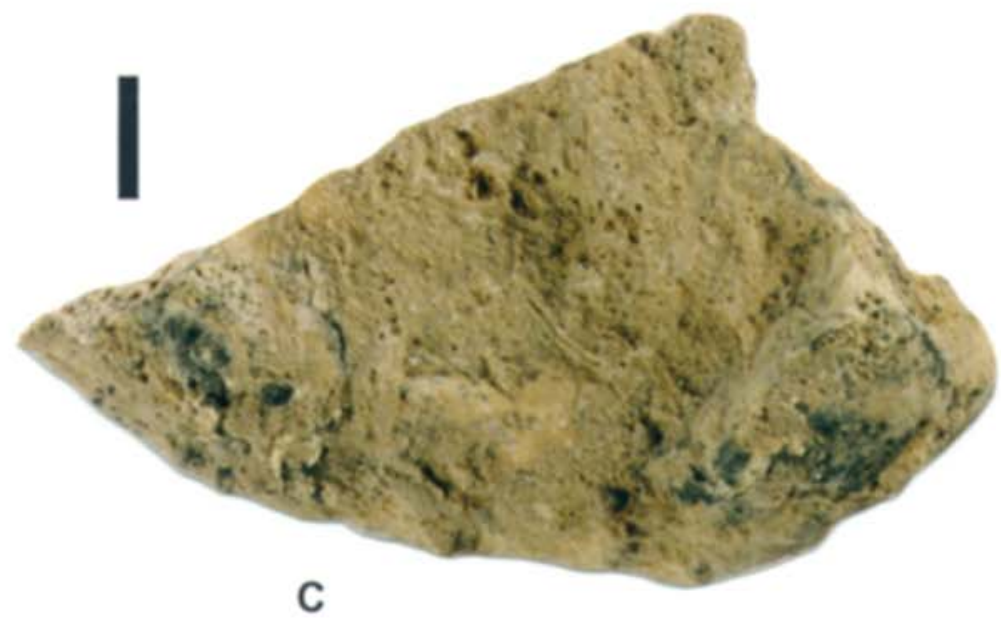

Lámina 4.15. Rizolitos. A. Hemimandibula izquierda del Octodontinae indet. (GHUNLPam 19823); B y C. fragmentos indeterminables, escalas $5 \mathrm{~mm}$ 
Paleobiología de la asociación faunística de Caleufú (La Pampa, Formación Cerro Azul, Mioceno superior - Plioceno inferior), a través de análisis tafonómicos

Lámina 4.15. Rizolitos. A. Hemimandíbula izquierda del Octodontinae indet. (GHUNLPam 19823); B y C. fragmentos indeterminables, escalas $5 \mathrm{~mm}$ 
indican, además, que los elementos sobre los que se desarrollaron debían estar cerca de la superficie expuesta, en los horizontes A o B del suelo, zona donde se desarrollan las raíces.

En este sentido, es interesante señalar que en el perfil de Caleufú se identificaron escasos rizolitos en la capa media, interpretada como un horizonte Bt. La escasez de estas estructuras (menos del $2 \%$ en la capa media del perfil y menos del $1 \%$ adheridos a los especímenes fósiles) puede ser interpretada de dos maneras. En primer lugar, si se plantea que este paleosuelo corresponde a un suelo de llanura sobre el que se desarrollaba una vegetación herbácea abundante, ya que soportaba una importante fauna de mamíferos herbívoros, podría ser que estas estructuras fueran destruidas por procesos ocurridos posteriormente, como por ejemplo bioturbación o pisoteo. Por otro lado, puede ser que realmente la escasez de rizolitos se deba a que ésta era un área con poca vegetación; el escenario de un cubil o madriguera de mamíferos es coherente con esta última interpretación, ya que el pisoteo y los ácidos eliminados por estos animales impiden un desarrollo favorable de la vegetación.

\section{Impregnaciones por óxidos de manganeso}

Todos los especímenes de la asociación de microvertebrados y de la de coprolitos están afectados en mayor o menor medida por impregnaciones oscuras de óxidos de manganeso. Algunos están totalmente impregnados, de modo tal que el espécimen es muy oscuro (N8), mientras que otros muestran una gradación en la intensidad de la impregnación que va desde especímenes muy poco afectados a otros muy modificados (Lámina 4.16). La presencia de estas impregnaciones es un indicador de ambientes húmedos (Diez et al., 1999).

Se ha postulado que el mayor aporte de agua en el nivel hospedante de los especímenes proviene de la capa freática y que ésta sufrió variaciones verticales de acuerdo a los períodos climáticos de mayor o menor humedad. En ese contexto, se puede plantear que, de acuerdo a la ubicación estratigráfica de cada espécimen en el perfil, pudo haber recibido un aporte mayor o menor de agua que 
facilitó la impregnación por los óxidos de manganeso y esto dio como resultado las diferencias registradas en los especímenes con respecto a este atributo.

Ya se indicó que los especímenes con encostramiento y/o los incluidos en concreciones calcáreas están menos afectados por las impregnaciones, lo que sugiere que este atributo fue adquirido más tardíamente en la historia tafonómica de los restos. 


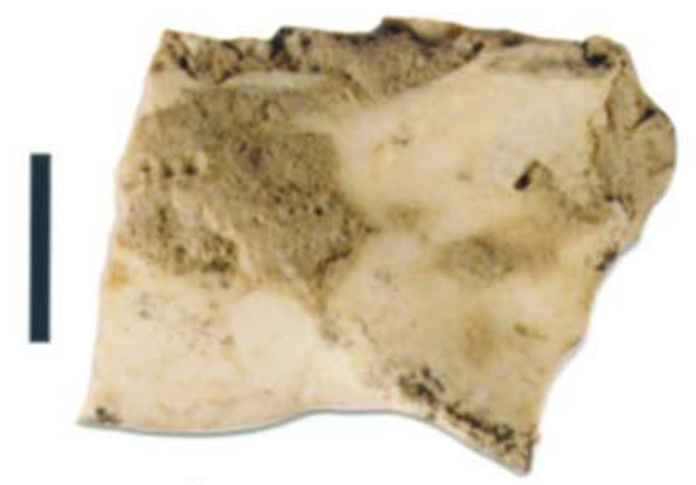

A
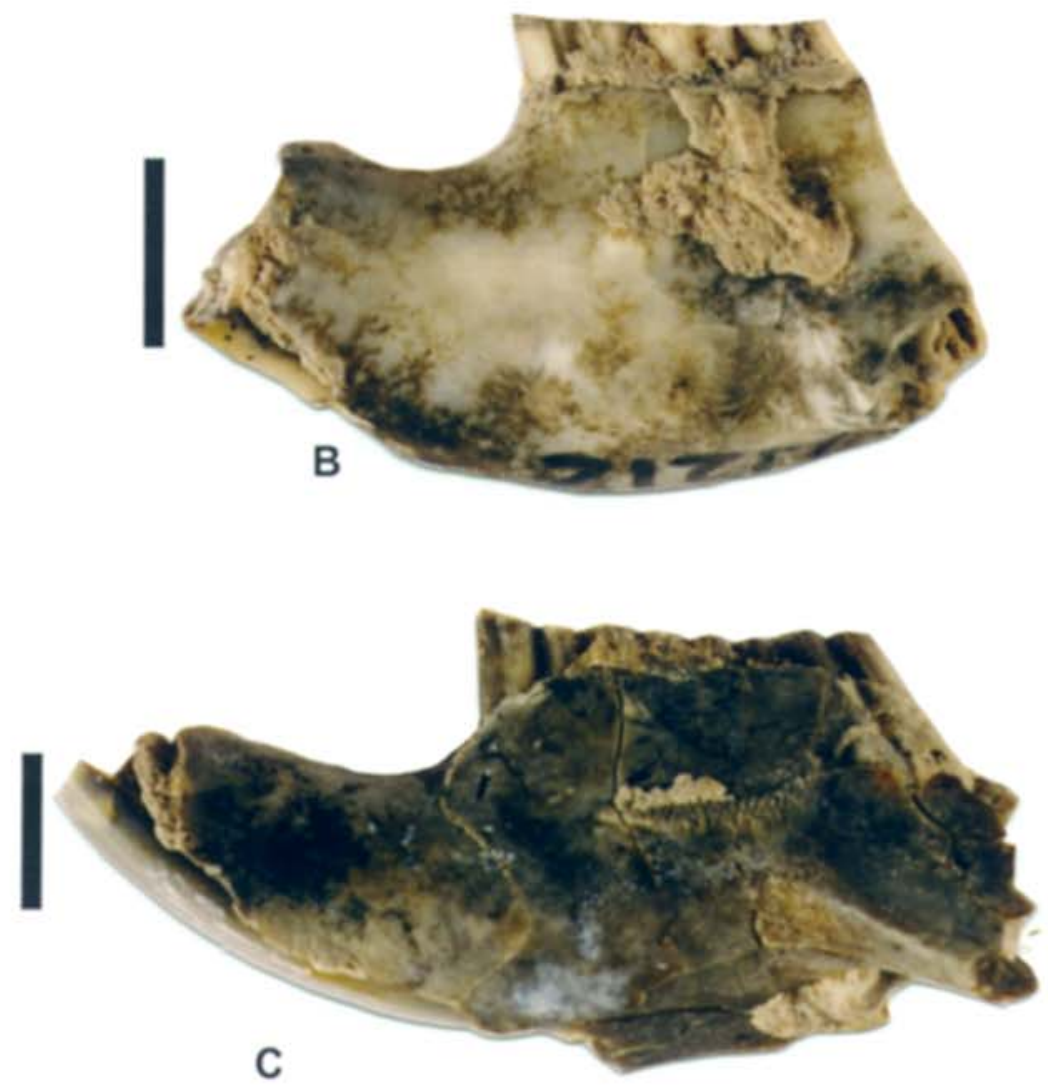

Lámina 4.16. Impregnación por óxidos de manganeso sobre hemimandibulas izquierdas del Octodontinae indet. A. GHUNLPam 19817; B. GHUNLPam 21212; C. GHUNLPam 19782, escalas $5 \mathrm{~mm}$ 
Paleobiología de la asociación faunística de Caleufú (La Pampa, Formación Cerro Azul, Mioceno superior - Plioceno inferior), a través de análisis tafonómicos

Lámina 4.16. Impregnación por óxidos de manganeso sobre hemimandíbulas izquierdas del Octodontinae indet. A. GHUNLPam 19817; B. GHUNLPam 21212; C. GHUNLPam 19782, escalas $5 \mathrm{~mm}$ 


\section{GRADO DE DISPERSIÓN}

Bajo el ítem grado de dispersión tafonómica, Fernández López (2000) propuso analizar la separación y diseminación de los elementos, que implica un desplazamiento de los mismos. Por otro lado, para estudios de tipo paleobiogeográficos y paleoecológicos se debe distinguir entre taxa démicos (aquellos registrados donde vivieron) y taxa adémicos (los que se registran en lugares o áreas diferentes a las que vivieron). Finalmente, se deben diferenciar los conceptos de fósiles in situ y ex situ. Un fósil esta in situ cuando se encuentra en su posición estratigráfica original, mientras que se considera ex situ o rodado, cuando ha sido desplazado a una nueva posición estratigráfica.

De acuerdo a estas definiciones, los elementos que constituyen la asociación de Caleufú se encuentran en su posición estratigráfica original, in situ y se pueden considerar autóctonos y démicos. Varios criterios permiten interpretar el carácter autóctono y démico de estos fósiles.

- La distribución de frecuencias de tamaño sin evidencias de selección constituye un carácter propio de asociaciones autóctonas. El análisis de las frecuencias de tamaño de los elementos en la asociación de microvertebrados de Caleufú muestra evidencias de selección, pero esta se debe fundamentalmente a la acción de depredadores. A esta misma acción se atribuyen también las diferencias en los estadíos del desarrollo ontogenético de varios taxa de esa asociación. Hay coherencia ecológica entre los taxa más abundantes de la asociación de micromamíferos, lo que sugeriría un área reducida de acción del depredador. En cuanto a los restos atribuidos a mamíferos de talla mayor, hay una selección por tamaño de los elementos preservados que estaría relacionada con procesos ocurridos antes del enterramiento. La prolongada exposición a agentes meteorizantes habría provocado roturas. De este modo, solo algunas porciones de los elementos esqueléticos llegaron a enterrarse y por lo tanto tuvieron mayor probabilidad de preservación.

- La coexistencia de restos y señales de actividad biológica confirman el carácter démico de una asociación. En Caleufú coexisten la asociación de 
microvertebrados con la de coprolitos. Más adelante se discutirá el sincronismo de ambas asociaciones y sus posibles productores.

- Hay compatibilidad ecológica entre los componentes de toda la asociación. Este carácter avala la autoctonía de la asociación. En todos los casos se trata de vertebrados terrestres. Los restos de la asociación de microvertebrados y los coprolitos representan concentraciones formadas en un lapso breve, mientras que los de la asociación de mamíferos de mayor tamaño pueden haber sido producidos por entidades paleobiológicas históricamente sucesivas y que por lo tanto, representan un lapso mayor que las anteriores, pero en todos los casos se pueden considerar como autóctonos.

- Hay compatibilidad ambiental entre los fósiles y la roca que los contiene. El ambiente de formación de la roca, en este caso niveles con paleosuelos, es compatible con los fósiles que se han preservado y, por lo tanto, se puede inferir que sobre estos suelos se desarrollaron las comunidades que finalmente produjeron la asociación estudiada. 


\section{GRADO DE REAGRUPAMIENTO}

Durante la fosilización, los elementos conservados pueden ser reagrupados, y de ese modo se pueden encontrar distribuidos de distintas maneras. Pueden formar agrupamientos, estar uniformemente dispersos 0 dispersos al azar y esto permite definir diferentes tipos de distribución de los fósiles: agrupada, uniforme o al azar respectivamente (Fernández López, 2000).

A escala regional, la distribución de toda la asociación de Caleufú es agrupada, ya que se encontraron concentrados en un área de $1.590 \mathrm{~m}^{2}$. En esa superficie, sin embargo, los especímenes y todos los fragmentos indeterminables se encontraron distribuidos al azar. Un modo de analizar el empaquetamiento que presentan los fósiles en esta asociación es analizar su densidad, considerada como el número de restos (NR) sobre el área ocupada, cuyo valor es 4,1 restos por $\mathrm{m}^{2}$.

Se considera que factores biológicos produjeron el patrón de agrupamiento de la asociación de microvertebrados, ya que los depredadores han contribuido a la recolección y reagrupamiento de los restos. Para el caso de restos asignados a mamíferos de mayor tamaño, el patrón de agrupamiento puede estar relacionado con factores que actuaron previo al enterramiento, sobre el sustrato, facilitando el enterramiento de restos de determinado tamaño; estos factores pueden haber sido biológicos y no biológicos (v.g. pisoteo, actividad de animales fosoriales o semifosoriales, meteorización y tasa de sedimentación).

En ese contexto, se puede analizar si la asociación de Caleufú es una asociación mezclada o condensada, entendiendo como mezclada a la formada por elementos que corresponden a entidades biológicas de ambientes diferentes. Una asociación condensada está constituida por elementos que corresponden a entidades biológicas sucesivas, que no fueron coexistentes (Fernández López, 2000).

Se considera que todos los taxa presentes en la asociación de Caleufú, son ecológicamente compatibles con ambientes terrestres, por lo que se descarta la posibilidad que se trate de una asociación mezclada.

Behrensmeyer y Chapman (1993) indicaron que las asociaciones faunísticas formadas por depredadores se acumulan en lapsos muy breves. Es 
probable que la asociación de microvertebrados, generada por el accionar de depredadores, haya sido formada en un intervalo temporal breve y su duración dependió exclusivamente de la actividad desarrollada en el área por los depredadores. En cuanto a los elementos de la asociación de mamíferos de mayor tamaño representarían un lapso más extenso, cuya duración estaría directamente relacionada con el desarrollo del paleosuelo que fue albergando los restos.

De lo expuesto surge que se puede considerar a la asociación de Caleufú, en su conjunto, como una asociación condensada. 


\section{GRADO DE REMOCIÓN}

Una vez que los restos se han acumulado, algunos pueden ser desplazados por el sustrato y a este mecanismo de alteración tafonómica, Fernández López $(1984,2000)$ lo denominó remoción tafonómica. La remoción comprende dos procesos, la resedimentación y la reelaboración. Se entiende por resedimentación al desplazamiento sobre el sustrato de elementos previamente acumulados. Este desplazamiento ocurre antes del enterramiento, por lo tanto es un proceso bioestratinómico. La reelaboración consiste en la reexposición y desplazamiento de los restos ya mineralizados y es considerado un proceso fósil diagenético, ya que ocurre después del enterramiento. La acumulación es un proceso único para cualquier resto o señal, pero la resedimentación y la reelaboración pueden ser procesos iterativos.

La asociación de Caleufú, en su conjunto, puede considerarse reelaborada; de hecho los especímenes y los fragmentos indeterminables recuperados fueron hallados en la superficie, desenterrados, con evidencias de crecimiento de líquenes actuales que indicaría un tiempo de reexposición suficiente, como para favorecer su desarrollo. Hay otras señales de reelaboración (por ejemplo corrosiones producidas por líquenes y marcas de roído) que muestran que algunos especímenes fueron desenterrados en otras oportunidades. 


\section{Capítulo 5 \\ DISCUSIÓN}




\section{ASOCIACIÓN DE MICROVERTEBRADOS}

El análisis de la asociación de microvertebrados incluyó las modificaciones que ocurrieron en los diferentes momentos de la historia bioestratinómica de los especímenes.

Ya que se planteó que esta concentración pudo haber sido formada por la acción de depredadores, se evaluaron los caracteres que están relacionados con la muerte del animal.

Fueron mencionadas antes las evidencias que avalan la posible selección de las presas. Hay 3 taxa abundantes, que constituyen el $68 \%$ del total de individuos asignados a la asociación de microvertebrados. Se trata del hegetoterino Paedotherium minor, la especie más abundante, seguida por los roedores Xenodontomys elongatus y Palaeocavia sp. La masa corporal estimada de los taxa más abundantes no supera $1 \mathrm{~kg}$. Se verificó, además, la presencia de un alto porcentaje de especímenes que se pueden asignar a individuos muy jóvenes y juveniles (el $30 \%$ del total de individuos de la asociación de micromamíferos).

Se tuvieron en cuenta otras categorías de información, entre ellas el análisis de la abundancia relativa de los elementos esqueléticos de la asociación de micromamíferos y los índices calculados sobre la base de la representación de elementos craneales y postcraneales. Estos datos indican que la representación de hemimandíbulas y de maxilares es alta, mientras que los demás elementos esqueléticos tienen una representatividad muy baja. La evaluación de las proporciones de elementos postcraneanos enteros y rotos, particularmente húmeros, ulnas, fémures y tibias, mostró, por un lado, la ausencia de elementos completos y por otro, el predominio de las epífisis, tanto distal como proximal, que son las regiones más robustas de esas piezas esqueléticas. La ausencia de elementos completos indicaría ciertas similitudes con las asociaciones formadas por mamíferos carnívoros, en las que se verifica el mayor grado de rotura. Sin embargo, la presencia de fracturas transversales con bordes lisos producidas en etapas posteriores al enterramiento, impide evaluar con cierta precisión el porcentaje real de elementos preservados y enterrados enteros en la asociación y 
comparar esos valores con datos surgidos a partir del análisis de depredadores actuales. Ya se mencionó que en esta asociación no se halló ningún cráneo entero y a todas las mandíbulas les falta la parte posterior. La presencia de fracturas espirales en elementos del postcráneo y también en la parte posterior de las hemimandíbulas, en muchos especímenes asociadas a marcas de mordida y de dientes, son caracteres que avalan la hipótesis de un mamífero carnívoro como formador de la concentración de micromamíferos.

Por otro lado, tanto los elementos craneanos, incluyendo dientes, como los del postcráneo de la asociación de micromamíferos muestran solo ligeras evidencias de digestión. Algunas mandíbulas presentan señales de acción digestiva, pero éstas son más marcadas en la zona del borde posterior o en áreas salientes, como por ejemplo la cresta masetérica. En cuanto a los dientes, ya se mencionó que la presencia de cemento externo en los molariformes de muchos taxa pudo haber protegido a estos elementos. Las escasas evidencias de digestión halladas son semejantes a las descriptas para aves nocturnas, pero los incisivos prácticamente no presentan las señales típicas producidas por ese grupo.

Fueron descriptas las marcas de dientes y de mordida que se encontraron sobre un $2 \%$ de los especímenes de la asociación de micromamíferos y de los elementos esqueléticos incluidos en los coprolitos. Como se mencionó, las marcas de dientes son semicirculares y no superan los 3,90 mm de largo y $3 \mathrm{~mm}$ de ancho; en general se presentan en forma individual, si bien hay algunos especímenes con 2, 3 y 4 marcas. Afectan fundamentalmente a los taxa más frecuentes de la asociación de micromamíferos, siendo más abundantes sobre Paedotherium minor y Palaeocavia sp. Más del $30 \%$ de estas marcas aparecen en especímenes asignados a individuos juveniles.

Las marcas de mordida aparecen en los bordes de las hemimandíbulas, en áreas con roturas, que son comunes tanto en el borde posterior como en el inferior de las mismas y en general se asocian a pequeñas fracturas múltiples.

Finalmente, las marcas asignadas a arañazos que se han descripto, son comunes en fragmentos indeterminables, pero también en hemimandíbulas de Paedotherium minor y de varios taxa de roedores. 
Todas estas marcas pueden ser atribuidas al manipuleo provocado por mamíferos carnívoros sobre los elementos esqueléticos.

Las evidencias de digestión halladas en los especímenes de la asociación de microvertebrados contrastan con las señales de acción digestiva hallada en los restos incluidos en los coprolitos. Estos se caracterizan por contener una alta densidad de fragmentos óseos indeterminados con fuerte grado de digestión y rotura. Como se mencionó, son homogéneos en cuanto a su tamaño, oscilando entre 4,95 y 16,50 mm de diámetro. Por el grado de digestión y las marcas de dientes en los restos incluidos en ellos, estos coprolitos se pueden asignar a mamíferos de pequeño tamaño.

\section{$\underline{\text { Consideraciones acerca de los depredadores }}$}

Con los datos expuestos y de acuerdo a los criterios analizados hasta el momento se realizó una aproximación a la caracterización de los posibles depredadores de esta asociación (Tabla 5.1), utilizando para ello el modelo propuesto por Andrews (1990). Este modelo ubica a los depredadores actuales en 5 categorías de modificación de los elementos esqueléticos, desde aquellos que presentan muy poca modificación (categoría 1) a los que presentan modificación extrema (categoría 5).

\begin{tabular}{|c|c|c|}
\hline & Categoría 1 & \begin{tabular}{|l|l|l|l|} 
Categoría 2 & Categoría 3 & Categoría 4 & Categoría 5 \\
\end{tabular} \\
\hline \multicolumn{3}{|l|}{ Abundancia relativa } \\
\hline \multicolumn{3}{|l|}{$\mathrm{pc} / \mathrm{c}$} \\
\hline \multicolumn{3}{|l|}{$\mathrm{F}+\mathrm{h} / \mathrm{md}+\mathrm{mx}$} \\
\hline \multicolumn{3}{|l|}{$\mathrm{T}+\mathrm{r} / \mathrm{f}+\mathrm{h}$} \\
\hline \multicolumn{3}{|l|}{ Fractura postcraneal } \\
\hline maxilar con arco zigomático & \multicolumn{2}{|r|}{ No es posible evaluar este carácter } \\
\hline Pérdida de dientes del maxilar & & No se verificaron pérdidas importantes de dientes \\
\hline \multicolumn{3}{|l|}{ Fractura mandibular } \\
\hline Pérdida de dientes de mandíbula & & No se verificaron pérdidas importantes de dientes \\
\hline \multicolumn{3}{|l|}{ Dientes aislados } \\
\hline \multicolumn{3}{|l|}{ Dientes fracturados } \\
\hline \multicolumn{3}{|l|}{ Molares con digestión } \\
\hline Incisivos con digestión & & \\
\hline postcraneal con digestión & & \\
\hline
\end{tabular}

Tabla 5.1. Ubicación de los diferentes atributos analizados en las categorías de modificación de los elementos esqueléticos propuestas por Andrews (1990) 
Como se observa en la Tabla 5.1, la mayor parte de los atributos encontrados se ubican en la categoría 1 de modificación, pero debe tenerse presente que esos atributos involucran caracteres descriptos fundamentalmente sobre elementos del cráneo, en tanto que otros atributos que incorporan caracteres de los elementos del postcráneo constituyen otro grupo, en los cuales las modificaciones son desde moderadas a extremas. Con respecto a esta consideración debe recordarse que son estos últimos elementos esqueléticos los que muestran mayores evidencias de roturas producidas en etapas postpredación. Además, las modificaciones halladas sobre estos restos pueden haberse producido por pisoteo de los mismos depredadores o bien pueden ser el resultado de la acción del propio depredador en el momento de matar o ingerir a la presa. En definitiva, estas modificaciones afectan la abundancia relativa y todos los índices analizados. La Figura 5.1 muestra un resumen de los resultados obtenidos que permitirían ubicar en las categorías de depredadores actuales al productor de esta asociación.

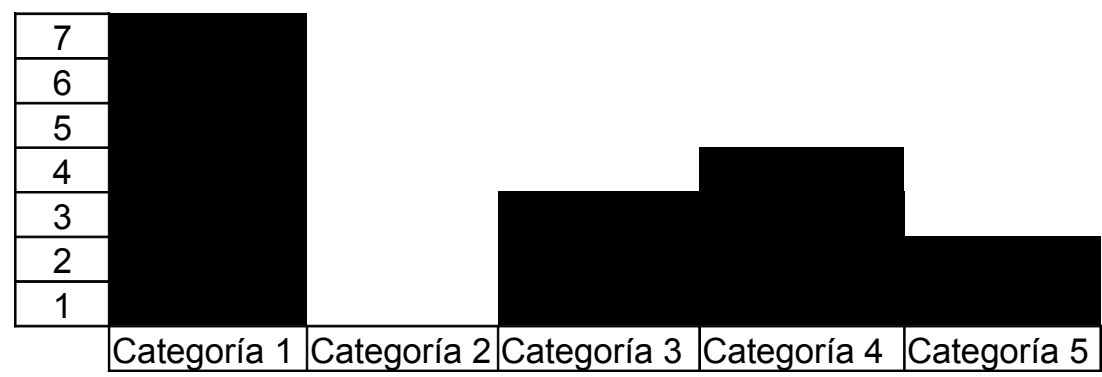

Figura 5.1. Histograma que muestra la sumatoria de atributos incorporados en cada categoría de modificación de los elementos esqueléticos

De acuerdo a lo expuesto, este gráfico puede ser interpretado de varias maneras:

1.- Una interpretación involucraría a dos depredadores formando la asociación de micromamíferos, uno de los cuales actuaría de modo similar a las aves nocturnas, produciendo una sumatoria de caracteres que señalan escasa modificación sobre los elementos esqueléticos y, otro depredador, que produciría mayor modificación, desde moderada a extrema, similar a la que producen las aves diurnas o los mamíferos carnívoros. Esta interpretación es difícil de sostener si se analiza la 
asociación en su conjunto, ya que hay caracteres en común a todos los especímenes, como por ejemplo marcas de dientes, grados de digestión, fracturas y roturas. Debe recordarse, además, que se presentan señales de mordidas y marcas de dientes en especímenes con escasa o nula evidencia de digestión. Tampoco se encontraron diferencias en las modificaciones analizadas que puedan relacionarse con alguno de los taxa presentes, que podrían avalar una selección taxonómica de las presas por diferentes depredadores tal como describen, por ejemplo, Fernández Jalvo et al. (1998) para el nivel FLKN 4 de Olduvai.

2.- El tamaño de las presas, su distribución por edad, el tipo de rotura de los elementos del cráneo y el bajo grado de digestión podrían ser indicadores de la acción de un ave nocturna formando la concentración de restos de microvertebrados. Estos datos son coincidentes con la sumatoria de atributos ubicados en la categoría I de modificación propuesta por Andrews (1990). Si se acepta esta interpretación, los valores obtenidos de abundancia relativa, tipos de fractura en elementos postcraneales e índices de proporciones entre elementos esqueléticos, que se ubican en las categorías de mayor modificación en esa clasificación, estarían sesgados por procesos ocurridos posteriormente a la captura de la presa, su ingestión y digestión. Pero, en el marco de este planteo es difícil explicar las marcas de dientes, mordidas y rasguños, así como la presencia de coprolitos que contienen elementos esqueléticos con marcas similares. Se podría plantear la acción de un mamífero carroñero sobre los restos. Pero, el pequeño tamaño de la mayoría de los individuos de la asociación de microvertebrados indica que estos no podrían ser aprovechados por mamíferos carroñeros (Fernández Jalvo, 1995).

3.- Una última interpretación incluiría un solo depredador, un mamífero. En ese contexto, Korth (1979) indicó ciertos caracteres de las asociaciones que permiten identificar a una coprocenosis en el sentido de Mellet (1974), definida como una asociación en la que el material craneal está roto, presenta desarticulación por las zonas de suturas y fracturas similares a las descriptas para heces de carnívoros y además muestran corrosión por ácidos digestivos similar a la de las aves diurnas. Los elementos de los miembros de pequeños animales están rotos, mientras que 
los de animales más grandes están siempre muy fragmentados y pueden presentar marcas de dientes.

La interpretación de un solo depredador formando la concentración se puede explicar si ese depredador presentaba un comportamiento selectivo en cuanto a las piezas esqueléticas que ingería. A favor de esta última hipótesis se han mencionado reiteradas evidencias que indicarían que un mamífero carnívoro podría haber sido el productor de esta asociación. El comportamiento particular del depredador implicaría la selección y manipulación de la presa, de tal modo que optaba por ingerir determinadas zonas del cuerpo de la presa, que incluiría aquellos elementos esqueléticos cuya abundancia relativa es menor en la asociación (zona postcraneana, excepto metápodos y falanges que representarían zonas no aprovechadas). Con respecto a los elementos del cráneo, si bien son muy abundantes, el patrón de rotura muestra que habría un aprovechamiento del encéfalo (rotura de la zona occipital en todos los casos y del techo y base craneanos en muchos), y también de la lengua (rotura de la parte posterior de las hemimandíbulas, como consecuencia de su separación del cráneo).

Por otro lado, ya fueron descriptas y analizadas las evidencias de digestión y grados de rotura en los restos incluidos en los coprolitos, lo que permitió asignarlos a un mamífero carnívoro. La evidencia taxonómica de algunos restos incluidos en los coprolitos avalaría la idea de que la asociación de coprolitos podría ser coetánea con la de micromamíferos. Se planteó entonces que los productores de los coprolitos y los de la asociación de micromamíferos fueran los mismos.

Con esa intención se analizó el porcentaje de los elementos esqueléticos que se identificaron y contabilizaron en los coprolitos y estos se compararon con los valores porcentuales de cada uno de esos especímenes de la asociación de micromamíferos (Figura 5.2), en ambos casos calculados sobre la base de la sumatoria de los NMEs de cada uno de esos elementos esqueléticos (NME=39 para los coprolitos y NME=1.042 para la asociación de micromamíferos). Se debe recordar al evaluar estos datos que los restos incluidos en los coprolitos están sumamente fragmentados, lo que dificultó su determinación anatómica. 


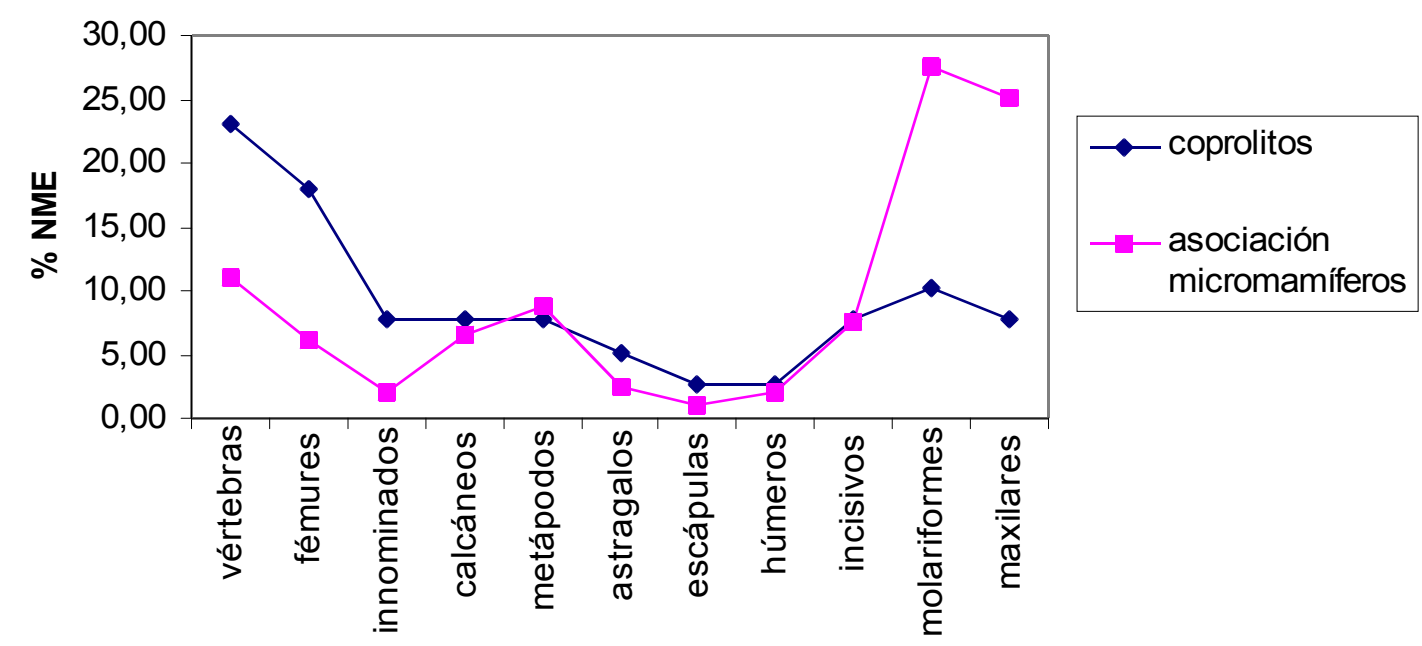

Figura 5.2. Proporción de los elementos esqueléticos reconocidos en los coprolitos y su comparación con los mismos elementos en la asociación de micromamíferos

En la Figura 5.2 se observa que si bien las proporciones de los elementos esqueléticos son similares, hay diferencias en los porcentajes obtenidos para elementos craneanos, que son altos para la asociación de micromamíferos. Por otro lado, excepto los metápodos, todos los elementos del postcráneo se encuentran en una proporción menor en la asociación de micromamíferos que en la de los coprolitos. Por lo tanto, las proporciones de elementos esqueléticos en ambas asociaciones, avalaría un comportamiento particular de ingestión de diferentes partes del cuerpo de la presa. Como resultado de este comportamiento, restos muy abundantes correspondientes a la parte del animal utilizada solo parcialmente constituirían la asociación de micromamíferos y restos con digestión fuerte y extrema, correspondientes a las partes del cuerpo más aprovechadas, forman la asociación incluida en los coprolitos.

Los grados de digestión y rotura serían los atributos que diferencian ambas asociaciones. Ya se indicó que por el grado de digestión de los restos incluidos en los coprolitos, éstos se asignan a mamíferos carnívoros. En cuanto a la representación anatómica, la escasez de elementos craneanos en los coprolitos también es un carácter que se asocia a este tipo de depredadores. Este comportamiento del depredador, sería entonces el responsable del sesgo en la asociación evidenciado por la mayor representación en la abundancia relativa de los elementos craneanos. 
Teniendo en cuenta estas observaciones, se puede plantear entonces que la asociación de microvertebrados fue formada como consecuencia de la acumulación de restos utilizados solo parcialmente por un depredador mamífero, probablemente actuando en un área pequeña, que podría ser un cubil o guarida, lo que favoreció la concentración de restos. A esta concentración se sumarían algunas heces propias del mismo depredador.

\section{Mamíferos candidatos a ocupar el papel de depredador}

La abundancia de Paedotherium minor y en menor proporción de los roedores octodóntidos y cávidos sobre un diverso espectro de otros taxa con una frecuencia baja de individuos, muestra un sesgo en la selección de las presas por parte del depredador. Además, esta selección está orientada a individuos cuya masa corporal estimada se encuentra en el rango de $300 \mathrm{~g} \mathrm{a} 1 \mathrm{~kg}$ con alta proporción de individuos muy jóvenes y juveniles. Una vez capturada la presa, hubo una segunda selección y manipulación relacionada con la parte del cuerpo ingerida. El depredador optaba por ingerir determinadas zonas del cuerpo de la presa, que incluiría aquellos elementos esqueléticos cuya abundancia relativa es menor en la asociación. Como resultado de este comportamiento, restos muy abundantes correspondientes a la parte del animal utilizada solo parcialmente constituirían la asociación de micromamíferos. Las marcas de dientes y los tipos particulares de rotura constituirían evidencias de ese accionar sobre los restos. Por otro lado, restos con digestión fuerte y extrema, correspondientes a las partes del cuerpo más aprovechadas, forman la asociación incluida en los coprolitos.

Aceptando que la depredación fue la causa principal de formación de la concentración de restos de microvertebrados y coprolitos en Caleufú, y en función de la caracterización del mismo, se intentó buscar en el listado faunístico que taxón podría ser candidato a actuar como depredador.

Entre los taxa de la asociación atribuidos a la categoría II de masa corporal estimada, se encuentran representantes de litopternos, toxodóntidos, mesoterinos, gliptodontes, milodontes, dasipódidos y roedores. Todos estos grupos son considerados herbívoros, excepto algunos dasipódidos, entre los que, 
actualmente, se encuentran formas desde insectívoras a omnívoras (Redford y Eisenberg, 1992). Recientemente, Vizcaíno y De luliis (2003) propusieron que el dasipódido Macroeuphractus outesi Ameghino, 1908, del Plioceno superior, presenta caracteres craneanos, mandibulares y dentarios que permiten sugerir que este taxón era carnívoro-omnívoro, ya que estaba en condiciones de capturar y matar vertebrados, de tamaño pequeño a mediano; además su morfología postcraneal, con adaptaciones para cavar, le permitiría tener fácil acceso a cuevas de taxa frecuentes en ese momento, Paedotherium y Lagostomus (Lagostomopsis), que podrían ser sus presas. De todos modos, la masa corporal estimada para Macroeuphractus outesi es de alrededor de 100 kg (Vizcaíno y Fariña, 1997), por lo que sería esperable un rango de presas de mayor tamaño que las presentes en la asociación de microvertebrados de Caleufú. Si bien Macroeuphractus outesi no está presente en la asociación de Caleufú, se encuentra otra especie del mismo género (M. morenoi).

Por otro lado, entre los mamíferos de la asociación de microvertebrados, los marsupiales argirolágidos, todos los roedores y los hegetoterinos, eran herbívoros; en tanto los representantes de las familias Didelphidae y Sparassocynidae, eran carnívoros. Las comadrejas actuales, Lutreolina crassicaudata (Desmarest, 1804) y Lestodelphys halli (Thomas, 1921), presentan similares hábitos de ingesta de la presa. Lutreolina crassicaudata se alimenta de pequeños vertebrados, peces e insectos (Redford y Eisenberg, 1992). Captura a los mamíferos con una primera mordida, generalmente los toma por el lomo, al sólo objeto de atraparla, luego la manipula con los miembros anteriores para acercar la cabeza de la presa a su boca. Finalmente rompe el cráneo con una mordida unilateral (generalmente por los parietales, aunque también puede destruir los occipitales y frontales) para matarla. Luego empieza a desollar la piel de la presa a medida que se la come; esto es, primero rompe la piel del cráneo y luego, con las manos, la va desollando como se saca un guante. Empieza comiendo el cerebro y el resto del cráneo (huesos, cerebro, dientes), sigue con el resto del cuerpo (músculos, intestinos, vísceras, vértebras) casi hasta la cola. En definitiva, se comen todo excepto, generalmente, cola, manos y pies (Goin, com. pers.). Lutreolina, un didélfido carnívoro de mediano tamaño, fue considerada el 
grupo hermano de Hyperdidelphys por Goin y Pardiñas (1996), por lo que se puede postular un comportamiento de depredación y de ingesta similar para el taxón extinto y quizá también para los Sparassocynidae.

Finalmente, dos restos muy incompletos de esa asociación se asignaron a Carnivora indet. Para el Mioceno superior los representantes de ese orden presentes en las asociaciones registradas en la Formación Cerro Azul corresponden a la Familia Procyonidae, de hábitos omnívoros. Sin embargo, ya se mencionó que los pocos caracteres preservados en esos dos especímenes no coinciden con los esperables para representantes de la Familia Procyonidae. Con los datos disponibles no es posible discutir la pertenencia del probable depredador a este orden.

De lo expuesto surge que, si el productor de la concentración forma parte del listado faunístico elaborado para la asociación de Caleufú, este debería ubicarse entre los marsupiales didélfidos y esparasocínidos o el carnívoro indeterminado o entre alguno de los dasipódidos (en particular Macroeuphractus). Poco se puede agregar sobre los dos últimos, con respecto a los didélfidos; al menos Didelphis, produce asociaciones muy diferentes a la de Caleufú.

\section{Otros atributos de la etapa bioestratinómica}

Las concentraciones formadas por depredadores constituyen asociaciones que representan lapsos breves (Behrensmeyer y Chapman, 1993), días o años, dependiendo del comportamiento del depredador (Mellet, 1974; Brain, 1980; Andrews, 1990). En ese sentido, la asociación de micromamíferos de Caleufú se caracteriza porque los elementos que la constituyen presentan atributos que indican homogeneidad en las condiciones previas al enterramiento, rasgo que también avalaría su sincronismo. Ya se analizaron los atributos adquiridos en el momento de la muerte del animal. Se considerarán ahora los caracteres relacionados con la etapa previa al enterramiento.

En el marco de un ambiente abierto, de llanura, una vez que los restos fueron acumulados por acción del depredador, quedaron sujetos a agentes que actuaron sobre ellos en la superficie del suelo. 
Ciertos atributos que presentan los elementos esqueléticos, que podrían estar ligados con procesos posteriores a la predación, ya fueron considerados entre las características producidas por el accionar de depredadores. Entre estos atributos, se incluyen algunos tipos de roturas con fracturas espirales, que podrían ser asignadas a pisoteo, pero que también son típicas del accionar de un mamífero carnívoro en el momento de la captura e ingestión de la presa. En cuanto al grado de desarticulación, ya se mencionó que en esta asociación la desconexión de los especímenes también se atribuye a la misma causa y se pueden descartar otros posibles mecanismos de desconexión de los elementos esqueléticos. Al analizar el grado de desarticulación, se indicó que sólo se mantuvieron conectados algunos tipos particulares de elementos esqueléticos: maxilares con mandíbulas y elementos del basipodio. Si bien el sesgo incorporado en la conexión preservada se puede relacionar con el comportamiento del depredador, esa articulación pudo ser mantenida debido a que el tiempo de exposición a los agentes atmosféricos debió haber sido muy breve, ya que mantenían tejidos blandos que los conectaban en el momento en que se enterraron.

Otros atributos, en cambio, fueron producidos sobre los especímenes antes que estos fueran enterrados, como los diferentes estados de meteorización descriptos, las fracturas, las marcas producidas por pisoteo y algo de transporte lateral de los especímenes en el área.

El grado de meteorización es un carácter que puede ser utilizado para evaluar el tiempo de exposición a los diferentes agentes atmosféricos y por lo tanto el tiempo en que los especímenes estuvieron sobre el sustrato, luego de su producción y hasta su enterramiento. Se indicó al analizar este atributo, que entre los especímenes de la asociación de microvertebrados, predominan los restos que presentan escasa modificación producida por agentes meteorizantes, señalada por los estadíos 0 y 1 de la categorización de Andrews (1990). Se señaló, además, que los especímenes correspondientes a juveniles, también se presentan en buen estado general, sin modificaciones en su estructura ósea superficial. Estos caracteres, sumados al tamaño reducido de los especímenes, con una relación superficie-volumen que avalaría su destrucción rápida, las 
escasas evidencias de pisoteo y de fracturas producidas en esa instancia, permiten postular un enterramiento rápido. Asimismo, se mencionó previamente que algunos especímenes de la asociación de microvertebrados presentan estadíos más avanzados de meteorización, que afecta sobre todo a la dentina de los molariformes. Entonces, la presencia de todos los estadíos de meteorización, tal como los describió Andrews (1990), implicaría diferentes lapsos de exposición para los distintos constituyentes en la asociación de microvertebrados y eso se puede explicar si se plantea una incorporación paulatina de los restos al suelo. 


\section{ASOCIACIÓN DE MAMÍFEROS DE MAYOR TALLA CORPORAL}

Los especímenes asignados a mamíferos de más de $5 \mathrm{~kg}$ de masa corporal estimada (NEIT=541) se caracterizan por su alto grado de rotura (NME=36 y 50 elementos postcraneanos asignados a Mammalia indet.). Solo es importante el NEIT asignado a los xenartros acorazados (488 especímenes), pero, como se mencionó, en ese caso el número de especímenes es alto debido a que se contabilizaron las placas de las corazas y estas han sufrido una alta desarticulación y desconexión. Sin embargo, es en este grupo en el que se han hallado algunos elementos asociados, grupos de placas de la coraza conectadas o encontradas en asociación, que indicarían que estos especímenes fueron hallados in situ. Se interpretó para esta asociación un MNI de 26 individuos, con al menos 17 taxa, de los cuales 11 corresponden a Xenarthra, lo que indica una diversidad alta para los representantes de esta categoría corporal.

Debe recordarse que muchos de los taxa que constituyen esta asociación están representados exclusivamente por fragmentos de molares, con una rotura tan extrema que no permitió asignaciones taxonómicas precisas (v.g. Toxodontidae indet., Notoungulata indet., Mammalia indet.). Sólo unos pocos especímenes correspondientes a dientes aislados se han preservado en buen estado. Exceptuando 4 metápodos, 3 falanges y 6 elementos del basipodio, no se han hallado elementos esqueléticos enteros y los asignados a algún elemento esquelético en particular están en realidad muy fragmentados. Justamente los elementos preservados enteros se caracterizan por su alta densidad, lo que probablemente facilitó su conservación. Solo se han preservado en mejor estado una hemimandíbula de Tetrastylus sp. y una de Proterotheriidae, así como un fragmento de maxilar de Pseudotypotherium subinsigne.

Se analizaron los fragmentos indeterminables atribuidos por su tamaño a restos de elementos esqueléticos de individuos integrantes de esta categoría de masa corporal estimada, los que mostraron un sesgo hacia un tamaño máximo de fragmento que no supera los 6,78; 5,22 y 3,38 cm para largo, ancho y espesor respectivamente. Estos valores indican una selección a un tamaño máximo de resto. Ya se planteó que los elementos esqueléticos se fracturaron y rompieron 
hasta llegar a un tamaño apto para su enterramiento. Este proceso habría afectado a todos los restos y explicaría, la escasez de elementos esqueléticos que superan las dimensiones máximas de los fragmentos indeterminables.

Solo unos pocos especímenes preservan el hueso intacto, entre ellos se pueden mencionar algunas placas de dasipódidos, la hemimandíbula de Tetrastylus sp. y el fragmento de maxilar de Pseudotypotherium subinsigne. Estos últimos ejemplares, coincidentemente, están bastante completos. Ambas características podrían indicar un enterramiento rápido para esos restos. En los demás especímenes atribuidos a esta categoría corporal, están representados todos los estados de meteorización descriptos por Behrensmeyer (1978) para macromamíferos. La prolongada exposición de los elementos esqueléticos a los factores ambientales, propios de un ambiente abierto de llanura, sería en parte el factor responsable de los atributos ocurridos antes del enterramiento. Sin embargo, debe tenerse presente que, ya que hay elementos reelaborados, pudieron existir varios momentos de reexposición $\mathrm{y}$, esa reexposición pudo implicar fracturación y rotura. El alto grado de rotura, por otro lado, aumentó la posibilidad de que los especímenes fueran afectados por corrosiones y otras modificaciones ocurridas cuando se encontraban enterrados.

Los especímenes de esta asociación presentan escasas evidencias de abrasión y cuando este atributo está presente sus características indican que se produjo sobre el resto ya mineralizado y con relleno sedimentario, por lo que se estima que la abrasión los afectó durante alguna reexposición.

Es de destacar que el sesgo más importante de la asociación de macromamíferos es su diversidad alta, sobre todo en lo que respecta a Xenarthra acorazados, pero con un número bajo de elementos asignado a cada taxón. Sin embargo, los grados de rotura, desarticulación y fractura son también altos, y los especímenes muestran evidencias de una meteorización muy marcada, indicando una prolongada exposición previa al enterramiento. Además se ha señalado la ausencia de evidencias de abrasión o cualquier otro tipo de señales que indiquen una movilidad importante de los mismos.

En el marco de una asociación que fue recuperada de un área bastante reducida $\left(1.590 \mathrm{~m}^{2}\right)$, todos estos atributos pueden ser explicados si se plantea 
que los especímenes de esta asociación surgieron como resultado de la acumulación de elementos esqueléticos de diferentes animales que fueron muriendo en el área analizada durante un lapso prolongado, cuya duración corresponde justamente al tiempo en el que se desarrolló el suelo que los sustentaba. La diversidad encontrada, no sería entonces más que el resultado de una condensación temporal de restos provenientes de animales de comunidades sucesivas. Este planteo también permite explicar la meteorización, fracturas y rotura de los elementos de esta asociación y la ausencia de evidencias de transporte. 


\section{DESARROLLO DEL SUELO E INTERPRETACIÓN DE LOS ATRIBUTOS ADQUIRIDOS DESPUÉS DEL ENTERRAMIENTO}

Se planteó que los especímenes de las asociaciones de microvertebrados y de coprolitos, acumulados por el propio accionar de los depredadores, fueron ingresando paulatinamente al suelo en el que se produjo la concentración, en un lapso que no debió ser muy extenso, ya que muestran escasa evidencia de meteorización. En cuanto a la formación de la acumulación de macromamíferos, la incorporación de los restos al suelo fue también paulatina, pero implicó un lapso de exposición de los elementos a los agentes meteorizantes mucho más prolongado.

A gran escala se puede postular que los especímenes recuperados en la asociación de Caleufú fueron enterrados en un ambiente básico, de tipo incrustante, pero a escala menor el microambiente que rodeó a algunos especímenes en el suelo pudo haber tenido, en diferentes momentos, un $\mathrm{pH}$ menor, ya que los restos muestran marcadas evidencias de corrosión por diferentes agentes propios del suelo.

El enterramiento en un ambiente incrustante provocó el encostramiento, la inclusión en concreciones calcáreas y el relleno sedimentario cementado por $\mathrm{CO}_{3} \mathrm{Ca}$ en los especímenes recuperados en Caleufú, principalmente a los de las asociaciones de microvertebrados y de coprolitos. Por otro lado, en la asociación de mamíferos de más de $5 \mathrm{~kg}$ de masa corporal estimada los especímenes con encostramiento y desarrollo de concreciones calcáreas son más escasos, pero cuando se presentan estos atributos, sus características son similares a los de la asociación de microvertebrados.

Se postuló que, al menos los especímenes de las asociaciones de microvertebrados y de coprolitos fueron rápidamente encostrados, cementados e incluidos en concreciones calcáreas una vez que se enterraron en el suelo y, de ese modo, la posibilidad de que se preservaran aumentó. Estas características evitaron que los especímenes fueran afectados por agentes destructivos que actuaban en el suelo en el que estaban enterrados y también permiten explicar la preservación de un porcentaje muy elevado de elementos de la asociación de 
microvertebrados asignados a muy jóvenes y juveniles de tamaño muy pequeño que, de otro modo, sin estas estructuras protectoras, deberían haber sido destruidos en el ambiente en el que se encontraban enterrados. La precipitación de los carbonatos en relación con los especímenes se produjo durante variaciones verticales de la capa freática, al alternarse períodos de mayor y menor humedad. Los atributos mencionados se habrían producido sobre los especímenes que se encontraban en las capas más altas del perfil y en un momento cercano al del enterramiento de los elementos esqueléticos.

Los especímenes de la asociación de Caleufú, muestran diferentes grados de impregnación por óxidos de manganeso, y estas impregnaciones también se pueden haber producido por variaciones verticales de la capa freática. De todos modos, ya que los especímenes más protegidos por las estructuras calcáreas mencionadas no fueron afectados por estas impregnaciones, se interpretó que su producción fue más tardía y puede haber ocurrido en diferentes momentos de la historia tafonómica de la asociación.

Un importante número de especímenes y fragmentos indeterminables muestran señales de corrosión bioerosiva producidas por el crecimiento de raíces, hongos, bacterias y ácidos propios del sustrato. Se trata, en general, de corrosiones que afectan áreas de cada espécimen en mayor o menor grado, motivo por el que se les atribuye ese origen. Si esas corrosiones fueran un indicio del $\mathrm{pH}$ del suelo en el que estaban enterrados los restos, sería esperable que toda su superficie fuera afectada. Estos últimos atributos son muy evidentes en los especímenes que preservan el hueso compacto, mientras que en aquellos muy meteorizados en los que la superficie está constituida por hueso esponjoso son más difusos y difíciles de identificar. Cualquier tipo de corrosión es más evidente si el resto ha sido impregnado previamente por óxidos de manganeso. De todos modos, ya que todos los tipos de corrosiones afectan tanto a los especímenes más impregnados como a los que tienen bajo grado de impregnación, no es posible establecer una secuencia de eventos con respecto a esos atributos, por lo que es probable que las corrosiones afectaran a los especímenes desde el momento de su enterramiento. Las trazas bioerosivas producidas por el crecimiento de raíces sobre algunos restos, sólo se pueden 
haber formado si el espécimen se encontraba en las capas más altas del perfil, y eso puede haber ocurrido en momentos cercanos al enterramiento o cercanos a alguna reexposición.

Las corrosiones producidas por el desarrollo de líquenes sobre la superficie de algunos fósiles, constituyen un indicio de que los mismos estuvieron reexpuestos en superficie en algún momento de su historia tafonómica e indica además que en esos momentos el nivel que contenía los restos estaba suficientemente cerca de la superficie, como para reexponer algunos.

Muchos procesos pedoturbadores han actuado en el suelo de Caleufú y son de fácil reconocimiento, ya que han dejado caracteres en los elementos conservados. Como ejemplo, ya se citó el desarrollo de estructuras calcáreas que protegieron a los especímenes, el crecimiento de raíces evidenciado a través de la presencia de rizolitos y de trazas bioerosivas, y la movilidad de agua proveniente de la capa freática que facilitó, por un lado, el desarrollo de nuevos cristales en las cavidades de los elementos esqueléticos y además movilizó los óxidos de manganeso provocando la impregnación de los especímenes. Otros procesos han facilitado la movilidad de los especímenes en el perfil del suelo y pueden ser inferidos a partir del conocimiento de las comunidades que ese suelo sustentaba, como por ejemplo la acción excavadora de animales fosoriales y semifosoriales, de diferentes tallas corporales, que pueden haber movilizado importantes cantidades de sedimento y también los elementos esqueléticos o fósiles que éste albergaba. También hay procesos de más difícil reconocimiento, como la posibilidad de que la expansión y contracción de las arcillas propias de este tipo de suelos haya provocado fracturas y rotura de especímenes. Además, la acción de la fauna propia del suelo contribuyó seguramente a movilizar especímenes de tamaño pequeño (Wood y Johnson, 1978). Si bien el análisis sedimentológico del perfil de Caleufú muestra que es la capa media la que tiene mayores rasgos pedológicos, los procesos pedoturbadores mencionados pueden ser los responsables de la abundancia de restos en la capa inferior. 


\section{HISTORIA TAFONÓMICA DE LA ASOCIACIÓN FAUNÍSTICA DE CALEUFÚ}

Sobre la base del análisis realizado se puede postular que la concentración de especímenes en la asociación de Caleufú se formó por la acumulación de restos surgidos a partir de diferentes procesos.

De acuerdo a lo expuesto, el análisis de la asociación de microvertebrados basado en la posible selección de las presas, teniendo en cuenta la información aportada por la representación taxonómica, la masa corporal estimada de los taxa representados, el espectro de edad de las presas y sus hábitos de vida, la abundancia relativa de los elementos esqueléticos y los índices que surgen de esos datos, el tipo de rotura de elementos craneales y postcraneales, la digestión y las marcas de dientes, mordidas y arañazos, permite sugerir que esa asociación se formó como resultado de la actividad de depredadores. Se planteó que la asociación de microvertebrados fue formada como consecuencia de la acumulación de restos utilizados solo parcialmente por un depredador, probablemente un mamífero actuando en un área pequeña, que podría ser un cubil o guarida, lo que favoreció su concentración. A esta concentración se sumarían algunas heces propias del mismo depredador que constituirían la asociación de coprolitos. Los restos así acumulados fueron ingresando paulatinamente al suelo, si bien su tamaño reducido favoreció el enterramiento rápido.

Por otro lado, la presencia de restos de macromamíferos se produjo como resultado de la mortalidad natural de individuos en un ambiente abierto durante el lapso de formación y desarrollo del suelo, sobre el que se desarrollaban comunidades sucesivas. Los esqueletos de los animales integrantes de esas comunidades quedaban expuestos a los agentes meteorizantes durante un lapso prolongado, a juzgar por el alto grado de meteorización y desarticulación que presentan. Este último factor sería el responsable del sesgo relativo al bajo número mínimo de elementos recuperados para esa asociación. De este modo, seguramente solo algunos restos fueron enterrados y de ellos solo algunos se habrían preservado. 
El orden en que están expuestos aquí los dos tipos de acumulación no significa una secuencia temporal. Seguramente en algún momento, durante el desarrollo del suelo y la consiguiente acumulación de restos, hubo un período en el que el área fue utilizada por los depredadores y ese fue el momento en que se concentraron los restos de la asociación de microvertebrados y de coprolitos.

Restos de las tres asociaciones así acumuladas fueron ingresando paulatinamente al sistema que constituye el paleosuelo. Las asociaciones de microvertebrados y de coprolitos representan la acumulación producida en un lapso muy breve, solo el que tardaron los depredadores en acumularla. Por otro lado, la asociación de mamíferos de mayor talla corporal representa un lapso mayor, que estaría en relación con el tiempo en el cual se formó y desarrolló el suelo que los alberga.

Las diferencias en el grado de meteorización de los especímenes de la asociación de microvertebrados y en mayor medida los de la asociación de mamíferos de mayor talla corporal, así como la desconexión producida sobre los elementos óseos incluidos en los coprolitos se pueden atribuir a procesos previos al enterramiento. Estas diferencias se produjeron ya que en ambos casos, el ingreso de los elementos acumulados al suelo fue gradual.

La incorporación de los restos de la asociación de macromamíferos fue un proceso relacionado con el lapso de estabilidad que permitió la formación del suelo, con la tasa de sedimentación y con la actividad de organismos en los niveles más expuestos del mismo. No se verificó la presencia de otras fuerzas externas que hayan contribuido a su enterramiento.

La acumulación, destrucción y eventualmente la preservación de los especímenes en un suelo requiere tiempo. Estos procesos no son constantes y dependen de muchos factores, pero el desarrollo de un suelo y la sucesión ecológica de las comunidades que soporta evolucionan juntos. La preservación diferencial de los elementos esqueléticos puede relacionarse con el momento en el cual se formó el suelo (Retallack, 1990) de acuerdo a las características del propio suelo y a los procesos que en él ocurren. En las asociaciones fósiles recuperadas de paleosuelos hay condensación temporal con respecto a los grupos más abundantes de las comunidades que vivieron durante la formación del 
suelo (Shipman, 1981). Bown y Kraus (1981) señalaron que los paleosuelos y las concentraciones de fósiles en ellos, constituyen unidades bioestratigráficas que pueden proveer una muestra grande de la biota de vertebrados de un lapso breve.

Finalmente, una vez que los restos se encontraban en el suelo quedaban sujetos a las características y procesos propios del suelo. Algunas características de los niveles hospedantes favorecieron la conservación de los elementos, por ejemplo el pH del suelo, el encostramiento calcáreo y la inclusión en concreciones calcáreas. Ciertos procesos propios del suelo favorecieron la dispersión de los elementos; entre estos la actividad de organismos habría producido la movilidad horizontal y vertical de los mismos en el área. Este proceso puede ser el responsable de parte de la reelaboración observada, verificada mediante la presencia de marcas de líquenes y de roído. También este proceso de movilidad podría relacionarse con las diferencias encontradas en los tipos y grados de corrosión bioerosiva. 


\section{Capítulo 6 CONCLUSIONES}


$\checkmark$ La asociación faunística recuperada de niveles de la Formación Cerro Azul en Caleufú ( $35^{\circ} 41^{\prime} 37^{\prime \prime} \mathrm{S}, 64^{\circ} 40^{\prime} 8^{\prime \prime}$ O) fue elegida para este estudio ya que fue prospectada desde su hallazgo utilizando la metodología tafonómica.

$\checkmark$ Los niveles portadores correspondientes a la Formación Cerro Azul, son limolitas loessoides cementadas por carbonatos, en los que se diferencian tres capas. La inferior (portadora de los fósiles) y la superior, tienen una potencia de 80 y $50 \mathrm{~cm}$, respectivamente; ambas son de color rojo anaranjado pálido (5 YR 7/2) y presentan abundantes concreciones calcáreas dispersas y generalmente amorfas. La capa media, del mismo color que las anteriores tiene $50 \mathrm{~cm}$ de espesor y es más arcillosa. Presenta "peds" de hábito cúbico y concreciones calcáreas cilíndricas, alargadas verticalmente. Estas últimas son interpretadas como rizolitos. Estos depósitos eólicos habrían sufrido con posterioridad procesos pedogenéticos y diagenéticos. La presencia de "peds" y rizolitos indican edafización, mientras que la cementación carbonática y la concentración de concreciones calcáreas indican una diagénesis importante de las capas inferior y superior.

$\checkmark$ La asociación faunística de Caleufú está constituida por Reptiles de la Familia Teiidae y la Superfamilia Colubroidea, Aves indeterminadas y Mamíferos de los órdenes Xenarthra (Dasypodidae, Glyptodontidae y Mylodontidae), Didelphimorphia (Didelphidae, Sparassocynidae), Orden indet. (Argyrolagidae), Rodentia (Echimyidae, Octodontidae, Chinchillidae, Dinomyidae, Caviidae y Muridae Sigmodontinae), Notoungulata (Hegetotheriidae, Mesotheriidae), Litopterna (Proterotheriidae) y Carnivora.

$\checkmark$ Los Dasypodidae son diversos, representados por Macroeuphractus sp., Macroeuphractus morenoi, Proeuphractus sp., Chorobates villosissimus, Chasicotatus sp., Chasicotatus ameghinoi, Doellotatus inornatus, Doellotatus chapadmalensis y Ringueletia simpsoni.

$\checkmark$ Los marsupiales están representados por un Marmosinae y un Didelphinae indet., Hyperdidelphys sp., Sparassocynus sp. y Argyrolagus sp. Estos tres últimos representarían nuevas especies. 
$\checkmark$ Pampamys emmonsae es el único roedor Echimyidae registrado. La escasez de representantes de esta familia en la asociación puede obedecer a la declinación que esta familia experimentó en el límite MioPlioceno en la región sur de la Pampasia.

$\checkmark$ La Familia Octodontidae está representada por las subfamilias Ctenomyinae y Octodontinae. Para la primera se registra un nuevo cronomorfo de Neophanomys, con caracteres derivados con respecto a los de los especímenes de $N$. biplicatus presentes en otros afloramientos de la Formación Cerro Azul. Otra especie nueva de Ctenomyinae es Xenodontomys elongatus que representa el cronomorfo más derivado del género Xenodontomys. Los Octodontinae están representados por Phtoramys aff. $P$. homogenidens y el Octodontinae indet. con molares euhipsodontes.

$\checkmark$ Neophanomys sp., Xenodontomys elongatus, Phtoramys aff. $P$. homogenidens y el Octodontinae indet. avalan una menor antigüedad para la asociación de Caleufú con respecto a otras conocidas de la Formación Cerro Azul.

$\checkmark$ Las familias Chinchillidae y Dinomyidae están representadas por Lagostomus (Lagostomopsis) sp. y Tetrastylus sp. respectivamente.

$\checkmark$ Los roedores cávidos están representados por 3 taxa: Neocavia cf. $N$. lozanoi, Palaeocavia sp. y Orthomyctera sp. La primera se citó por primera vez para la Formación Cerro Azul en esta asociación.

$\checkmark$ Se halló un Muridae (Sigmodontinae) que constituye un género y especie nuevos. Esta familia se registra por primera vez para la Formación Cerro Azul en este afloramiento. La presencia de múridos asociados a taxa de estirpe huayqueriense junto con otros un poco más modernos indicaría que se trata del registro más antiguo de esta familia en América del Sur.

$\checkmark$ Los notoungulados incluyen al Hegetotheriidae Paedotherium minor. Los promedios de medidas dentarias de los especímenes asignados a esta especie son apenas mayores que los esperados para esta especie. El incremento en el tamaño de los especímenes puede deberse a la gradación descripta entre las especies de Paedotherium desde el 
Chasiquense al Montehermosense y podría ser otro indicador de una mayor modernidad de esta fauna.

$\checkmark$ Los notoungulados mesoterinos están representados por especímenes en mal estado de preservación que sólo pueden ser asignados a ese nivel y por un solo ejemplar de Pseudotypotherium subinsigne.

$\checkmark$ Los especímenes de notoungulados toxodóntidos están muy fragmentados y sólo se asignan a ese nivel.

$\checkmark$ La Familia Proterotheriidae es la única representante del Orden Litopterna.

$\checkmark$ Se asignaron al Orden Carnivora dos especímenes muy incompletos. Por el tamaño y las características que presentan, ambos podrían corresponder al mismo taxón. Los caracteres que presentan no coinciden con los esperables en un representante de la Familia Procyonidae, única registrada hasta el momento en la Formación Cerro Azul, pero el material es muy incompleto como para asignarlo con mayor precisión.

$\checkmark$ De lo expuesto surge que la asociación faunística de Caleufú presenta 11 taxa atribuibles a la Edad mamífero Huayqueriense y 6 taxa más modernos, pero no exclusivos de la Edad mamífero Montehermosense, por lo que puede ser ubicada en el Mioceno tardío - Plioceno temprano. Estos registros avalan la propuesta previa de que esta asociación podría corresponder a la parte final del Mioceno tardío, cercana, pero algo más antigua que la Edad mamífero Montehermosense.

$\checkmark$ La posibilidad de resolución en la identificación fue baja, el NR de la asociación es de 6.516 restos, de los cuales el 49,88 \% no pudo ser determinado ni anatómica ni taxonómicamente.

$\checkmark$ El análisis de la representación taxonómica se realizó sobre la base de 3.200 especímenes identificados taxonómicamente. Se identificaron, además, 66 especímenes correspondientes a coprolitos.

$\checkmark$ Se recuperaron 943 elementos postcraneanos $(29,47 \%)$ que sólo pueden ser asignados a mamíferos indeterminables.

$\checkmark$ EI NEIT total de la asociación es de 2.257 especímenes. De estos, 59 corresponden a reptiles y aves; el resto a mamíferos. El Orden Rodentia es el de mayor frecuencia de hallazgos, con 11 especies, seguido por el 
Orden Notoungulata, con menor diversidad (3 especies). En esta asociación, a diferencia de lo que ocurre en otras localidades de la Formación Cerro Azul, es baja la proporción de especímenes asignados a xenartros; sin embargo su diversidad es alta (11 especies). Las proporciones obtenidas para especímenes asignados a litopternos, marsupiales y carnívoros son bajas como ocurre en otras asociaciones de esta formación.

$\checkmark$ EI NME total de la asociación es de 1.733 especímenes, con mayor proporción de hemimandíbulas, maxilares y dientes aislados. Los elementos postcraneanos son escasos, con valores relativamente altos para vértebras y metápodos. El NME para los taxa presentes es de 1.089 especímenes.

$\checkmark$ El NMI total en la asociación es de 315 individuos. Los taxa más abundantes son Paedotherium minor, (NMI=96); Xenodontomys elongatus (NMI=54); Palaeocavia sp. (MMl=45); Orthomyctera sp. (NMI=24); Octodontinae indet. (NMI=20) y Neocavia cf. $N$. lozanoi $(\mathrm{NMI}=10)$. El resto de los taxa tiene un NMI menor a 10.

$\checkmark$ Los taxa de la asociación fueron agrupados de acuerdo a su masa corporal estimada y otras características tafonómicas en 2 categorías. Así se formaron dos grupos, el de microvertebrados y el de mamíferos de más de $5 \mathrm{~kg}$ de masa corporal estimada. El NME de la asociación de microvertebrados es de 1.647 especímenes y su NMI de 289 individuos. El NME de la asociación de mamíferos de talla mayor es de 86 especímenes y su NMI de 26 individuos.

$\checkmark$ El promedio de abundancia relativa de los elementos esqueléticos (basado en elementos craneanos) de todos los taxa de mamíferos presentes en la asociación es de 36,35 \%, valor que indica la escasa representatividad de elementos del esqueleto.

$\checkmark$ En la asociación de microvertebrados, los taxa Paedotherium minor, Xenodontomys elongatus y Palaeocavia sp. son los más abundantes y sus masas corporales estimadas que no superan $1 \mathrm{~kg}$. 
$\checkmark$ El $11,07 \%$ de los individuos de la asociación de micromamíferos corresponde a la categoría muy jóvenes en tanto el 17,99 \% a juveniles y el $70,93 \%$ a adultos. Por otro lado, el 91,77 \% de los individuos muy jóvenes y juveniles se encuentran entre los seis taxa más frecuentes de la asociación.

$\checkmark$ El análisis de la abundancia relativa de los elementos esqueléticos en la asociación de micromamíferos muestra una representatividad alta de hemimandíbulas seguida por los maxilares. El resto de los elementos esqueléticos tiene una representatividad muy baja. Los índices calculados muestran también la abundancia de material craneal sobre el postcraneal y entre estos últimos es mayor la pérdida de elementos distales de los miembros con respecto a los proximales.

$\checkmark$ La información aportada por la representación taxonómica, la masa corporal estimada y el espectro de edad de los taxa más frecuentes sugiere que la acción de depredadores habría formado la acumulación de restos de microvertebrados.

$\checkmark$ En la asociación de microvertebrados se observaron ligeras modificaciones que pueden ser atribuidas a digestión, tanto en los elementos postcraneales como en hemimandíbulas y dientes, similar, pero no igual, a la producida por aves nocturnas.

$\checkmark$ En Caleufú se recuperaron 66 restos identificados como coprolitos. Constituyen una asociación homogénea en cuanto a su tamaño o tamaño estimado y el grado de digestión de los elementos óseos incluidos. De acuerdo a las categorías antes definidas, el tipo de digestión encontrada en las astillas y elementos esqueléticos de los coprolitos, habría sido producida por mamíferos carnívoros. Los elementos incluidos en los coprolitos que han podido ser determinados taxonómicamente corresponden a taxa que forman parte de la asociación de microvertebrados, por lo que se considera que ambas asociaciones podrían ser coetáneas.

$\checkmark$ Fueron reconocidas marcas de dientes sobre 100 especímenes de la asociación de microvertebrados y en elementos óseos incluidos en algunos 
coprolitos. También se encontró este tipo de marcas en 18 fragmentos indeterminables. Estos valores indican que este atributo afecta a menos del $2 \%$ de los restos de la asociación de Caleufú y si bien es un valor bajo, es de gran importancia paleoecológica.

$\checkmark$ Las marcas de dientes se manifiestan de dos maneras; en primer lugar como pequeñas marcas de presión subcirculares a ovaladas, que pueden estar rellenas de cemento, con pequeñas fracturas en sus bordes, con el fondo plano y múltiples fracturas en su superficie. Por otro lado, se observaron señales dejadas por los dientes en el momento en que la mordida produjo rotura del elemento esquelético. Los taxa más afectados por marcas de dientes son el hegetoterino Paedotherium minor y los Caviidae Palaeocavia sp., Orthomyctera sp. y Neocavia cf. N. Iozanoi. El $32,31 \%$ de los especímenes identificados por taxón y el 16,66 \% de los elementos postcraneanos con marcas de dientes corresponden a individuos juveniles.

$\checkmark$ Las marcas de rasguños y roído aparecen en los bordes de algunos elementos esqueléticos. Fueron identificadas sobre 135 restos. En general se trata de varias perforaciones de diferente profundidad, con forma de " $U$ " aplanada o de "V". Se pueden atribuir a marcas dejadas por carnívoros. También aparecen marcas de incisivos de roedores. Se trata de marcas paralelas (generalmente de a pares) de fondo plano y con una ligera elevación entre ambas. Estas marcas han sido producidas sobre restos mineralizados.

$\checkmark$ El 10,19 \% de los restos presenta evidencia de corrosión bioerosiva que afectó la superficie ósea y/o dentaria.

$\checkmark$ El desarrollo de las raíces en la interfase elemento esquelético-sedimento produjo dos tipos de trazas o estructuras biogénicas sobre el $3,81 \%$ de los especímenes. Se identificaron como sphenoichnia y corrosichnia. La primera está representada por pequeñas marcas dendríticas superficiales irregulares, con ejes principales y ramificaciones, que forman canales con márgenes nítidos. Las características de esta traza y su presencia sin cambio de color en los restos impregnados por óxidos de manganeso, 
indicarían que esta traza se produjo luego del enterramiento, durante los primeros estadios diagenéticos. Corrosichnia, una marca de disolución superficial, es más abundante que la anterior, de mayor espesor y más profunda que sphenoichnia; tiene la forma de "U" aplanada, en general sin bifurcaciones, pero puede tener pequeñas punteaduras asociadas a sus bordes. Esta traza se habría producido en cualquier momento posterior al enterramiento del resto, ya que afecta a todos los especímenes, pero sobre los muy impregnados provoca cambio de color por efecto de la corrosión. La mayor proporción de restos con corrosichnia indicaría que éstos permanecieron en algún momento cercanos a la superficie.

$\checkmark$ Algunos restos presentan pequeñas áreas corroídas, de contorno irregular o como grupos de pequeños círculos. No ha sido posible identificar un patrón de comportamiento etológico para estas corrosiones, en este caso los restos podrían haber sido afectados por ácidos propios del sustrato, hongos o bacterias. La misma génesis puede haber tenido la corrosión de la dentina de la cara oclusal de algunos molares de roedores. Ésta se manifiesta como pequeños agujeros de borde muy suavizado, formando una línea de orificios que en general coincide con la zona media de la cara oclusal del diente. Estos tipos de corrosión son también indicadores de que los restos habrían permanecido en algún momento cercanos a la superficie.

$\checkmark$ El 3,40 \% de los restos presenta corrosión producida por líquenes, se observan áreas con cambio de color y pérdida irregular de la superficie, con un agrietamiento paralelo, bandeado, en el fondo de la zona afectada.

$\checkmark$ El $0,73 \%$ del total de los restos de la asociación presenta líquenes actuales del género Caloplaca (Ascomycotina, Fungi Lichenisati) C. citrina y C. americana. El desarrollo de líquenes actuales sobre los restos indica un período de exposición previa a la recolección que no es posible de evaluar con las especies de líquenes presentes.

$\checkmark$ Se recuperaron 124 elementos postcraneanos enteros: astrágalos, calcáneos, elementos del basipodio, metápodos y falanges, correspondientes, en su mayoría, a individuos de talla pequeña. 
$\checkmark$ En la asociación de microvertebrados, las vértebras, escápulas, innominados, fémures, tibias, húmeros, ulnas y radios siempre presentan algún tipo de rotura. La presencia de elementos con fracturas transversales y longitudinales impide evaluar el real porcentaje de elementos preservados y enterrados completos en la asociación. Es frecuente en esas piezas esqueléticas la rotura a nivel de epífisis y diáfisis con fracturas de tipo espiral y escalonada, probablemente producidas en el momento de la muerte de la presa por parte de los depredadores. En la asociación de mamíferos de más de $5 \mathrm{~kg}$ de masa corporal estimada los elementos postcraneanos son sumamente escasos.

$\checkmark$ En la asociación de micromamíferos no hay ninguna hemimandíbula completa. Las mandíbulas preservadas presentan varios tipos de roturas diagenéticas, pero las que afectan la zona posterior, que implica la pérdida de la rama ascendente, están asociadas a fracturas escalonadas que indicarían que se produjeron cuando el elemento esquelético estaba fresco. La integridad del borde inferior de las mandíbulas y de la zona sinfisaria estaría más relacionada con la morfología de esas zonas en cada grupo taxonómico. Es común la presencia de perforaciones en la base de los alvéolos de los molariformes inferiores, es probable que algunas de estas perforaciones hayan sido producidas por el accionar del depredador, pero hay muchos ejemplares en los que el hueso de la base de los alvéolos de los molariformes se ha roto por el desarrollo del relleno sedimentario. Tampoco hay ningún cráneo entero. Hay maxilares completos, pero es común que los especímenes correspondan a hemimaxilares con dientes. En algunos casos se conserva la zona del rostro. Para asociaciones actuales, en la categoría de modificación extrema se ubican las asociaciones sin ningún cráneo entero, producidas por mamíferos carnívoros.

$\checkmark$ Para analizar la tasa de fragmentación se utilizó el índice NEIT/NME. El valor más alto se da para las hemimandíbulas de Paedotherium minor, que presentan caracteres que seguramente han favorecido su rotura (son alargadas y estrechas). Para los elementos postcraneanos de la asociación 
de microvertebrados el valor más alto de este índice se da para húmeros, que son los elementos más afectados por la fragmentación.

$\checkmark$ Son muy escasos los especímenes en los que se verifica la pérdida de algún diente; en los pocos casos en que se ha producido esa pérdida, el alvéolo se encuentra relleno de sedimento. La pérdida de dientes se relaciona con roturas diagenéticas de la porción de hemimandíbula o maxilar en la que estaban. Entre los mamíferos de mayor talla es marcado el grado de rotura de los dientes, produciéndose fragmentos que impiden su determinación más que a nivel de Orden o Familia en algunos casos.

$\checkmark$ Se observó una gradación en la meteorización de los especímenes de microvertebrados. Son muy abundantes los que preservaron el hueso intacto y sus dientes sin modificación, pero también hay ejemplares con descamación ósea superficial y diferentes grados de modificación en la dentina de los molariformes. Esta gradación se puede relacionar con una incorporación paulatina de los elementos esqueléticos al suelo. En la asociación de mamíferos de más de $5 \mathrm{~kg}$ de masa corporal estimada, la meteorización es un proceso muy importante que afectó los restos de manera muy marcada. Pocos especímenes conservan el hueso intacto; en general se presenta un evidente deterioro del hueso compacto superficial y muchos muestran directamente el hueso esponjoso.

$\checkmark$ Fueron recolectados 3.250 fragmentos indeterminables. De ese total se tomó al azar una muestra de 913 restos, los que fueron clasificados, de acuerdo a su probable productor, en restos provenientes de microvertebrados y restos provenientes de macromamíferos. Estos restos evidencian un sesgo hacia un tamaño máximo de cada una de las medidas de los mismos, ya que no hay fragmentos de tamaño grande que serían esperables de acuerdo a la talla estimada de los posibles productores. La mitad de los fragmentos tiene alguna rotura longitudinal y/o transversal de borde liso, interpretada como producida sobre el hueso mineralizado y relleno de sedimento. Estas roturas sesgan las medidas de estos restos hacia un tamaño menor. La otra mitad presenta evidencias de haberse roto cuando el elemento esquelético estaba fresco y en muchos casos hay una 
importante pérdida de hueso compacto, caracteres que se pueden relacionar con la acción de procesos meteorizantes previos al enterramiento. La rotura se podría relacionar directamente con extendidos lapsos de exposición previos al enterramiento. Se analizó la forma de los restos indeterminables, mediante dos gráficos que permiten visualizar los contrastes entre los restos de forma alargada y estrecha y los de forma aplanada. En ambas muestras hay una tendencia al predominio de las formas cúbicas, aunque en la muestra de restos atribuibles a macromamíferos la dispersión es mayor, lo que indica una gama más amplia de formas. Esta mayor dispersión puede relacionarse con una menor intensidad de los procesos de selección en la etapa previa al enterramiento.

$\checkmark$ En la asociación hay escasas evidencias de pisoteo, sin embargo este proceso puede haber favorecido la rotura de los elementos y la movilidad tanto horizontal como vertical de los elementos conservados.

$\checkmark$ Sólo el 2,72 \% de los especímenes corresponden a dos o más fragmentos de elementos esqueléticos articulados o hallados asociados, por lo que el grado de articulación es muy bajo.

$\checkmark$ En la asociación de microvertebrados, las conexiones registradas están representadas por elementos craneanos (mandíbulas y maxilares) y por elementos distales de los miembros. Esto podría estar directamente relacionado con un comportamiento particular de manipulación por parte del depredador y un enterramiento muy rápido.

$\checkmark$ Los taxa asignados a mamíferos de más de $5 \mathrm{~kg}$ de masa corporal estimada están representados por especímenes aislados. La total desconexión entre los elementos esqueléticos de este grupo es una evidencia de que el período de exposición al que estuvieron sometidos antes del enterramiento fue prolongado.

$\checkmark$ No se encontraron evidencias que indiquen la acción abrasiva sobre los elementos antes de su mineralización y relleno sedimentario.

$\checkmark$ Algunos especímenes muestran señales de abrasión posterior al enterramiento. 
$\checkmark$ Todos los restos de la asociación están permineralizados, es decir con sus cavidades rellenas por sustancias minerales cristalinas y se preservó la microestructura ósea.

$\checkmark$ Las características del perfil de Caleufú pueden relacionarse con ciertas características que presentan los elementos conservados, ya que todos tienen encostramiento superficial o están incluidos total o parcialmente en una concreción calcárea y además el relleno sedimentario que contienen está cementado por $\mathrm{CO}_{3} \mathrm{Ca}$.

$\checkmark$ Los elementos que constituyen la asociación de Caleufú se pueden considerar in situ, autóctonos y démicos.

$\checkmark$ A escala regional, la distribución de toda la asociación de Caleufú es agrupada, ya que se encontraron concentrados en un área de $1.590 \mathrm{~m}^{2}$. En esa superficie, sin embargo, los especímenes y todos los fragmentos indeterminables se encontraron distribuidos al azar.

$\checkmark$ La asociación de Caleufú, en su conjunto, se considera como una asociación condensada y reelaborada.

$\checkmark$ La asociación de microvertebrados habría sido acumulada, en un lapso breve, por la acción de depredadores que actuaban en un área reducida, lo que favoreció la concentración de restos. La abundancia de Paedotherium minor y en menor proporción de los roedores octodóntidos y cávidos sobre un diverso espectro de otros taxa con una frecuencia baja de individuos, muestra un sesgo en la selección de las presas, orientada además a individuos cuya masa corporal estimada se encuentra en el rango de $300 \mathrm{~g}$ a $1 \mathrm{~kg}$ con alta proporción de individuos muy jóvenes y juveniles.

$\checkmark$ Las evidencias tafonómicas (marcas de dientes, mordidas y rasguños; tipos de roturas y fracturas) sugieren que los depredadores serían mamíferos carnívoros, con un comportamiento particular de manipulación de la presa, que implicaría la selección de las partes del cuerpo a ingerir. Los coprolitos recuperados habrían sido producidos por el mismo depredador.

$\checkmark$ Los restos de microvertebrados acumulados tuvieron una corta exposición a los agentes atmosféricos antes de su enterramiento, pero este fue 
gradual, de acuerdo a la evidencia aportada por el análisis del grado de meteorización.

$\checkmark$ Los especímenes asignados a mamíferos de más de $5 \mathrm{~kg}$ de masa corporal estimada indican para este grupo una diversidad taxonómica alta, pero con los números mínimos de individuos y de elementos esqueléticos por taxón muy bajos. De acuerdo a ciertos atributos tafonómicos (grados de meteorización, rotura, fractura y desarticulación) se puede sugerir que estos restos estuvieron expuestos durante un tiempo prolongado a los agentes atmosféricos. Esta asociación se habría formado como resultado de la acumulación de restos de animales de comunidades sucesivas que murieron en el área analizada durante el lapso de desarrollo del suelo que los sustentaba.

$\checkmark$ Todos los especímenes fueron enterrados en un ambiente básico, de tipo incrustante. A escala menor, el microambiente del suelo que rodeó a algunos especímenes pudo haber tenido, en diferentes momentos, un $\mathrm{pH}$ más bajo, ya que hay evidencias de corrosión por diferentes agentes propios del suelo.

$\checkmark$ Al menos los especímenes de las asociaciones de microvertebrados y de coprolitos fueron rápidamente encostrados, cementados e incluidos en concreciones calcáreas una vez que se enterraron en el suelo. Estas características evitaron que los especímenes fueran afectados por agentes destructivos que actuaban en el suelo. Permiten explicar, también, la preservación de un porcentaje muy elevado de elementos asignados a muy jóvenes y juveniles de tamaño muy pequeño que, de otro modo, sin estas estructuras protectoras, deberían haber sido destruidos en el ambiente en el que se encontraban enterrados.

$\checkmark$ Ciertos procesos pedoturbadores pueden haber favorecido la movilidad horizontal y vertical de los fósiles en el área. Este proceso puede ser el responsable de parte de la reelaboración observada, verificada mediante la presencia de marcas de líquenes y de roído. 


\section{BIBLIOGRAFÍA}

Abello, A., Montalvo, C.I. y Goin, F.J., 2002. Marsupiales del Mioceno superior de Caleufú (La Pampa, Argentina). Ameghiniana 39 (4): 433-442.

Albino, A.M. y Montalvo, C.I., 2003. Primer registro de escamosos en la provincia de La Pampa (Argentina). XIX Jornadas Argentinas de Paleontología de Vertebrados, resúmenes: 5-6.

Alcalá Martínez, L., 1994. Macromamíferos neógenos de la fosa de Alfambra-Teruel. Museo Nacional de Ciencias Naturales. Madrid. 554 pp.

Ameghino, F., 1904. Nuevas especies de mamíferos cretáceos y terciarios de la República Argentina. Anales de la Sociedad Científica Argentina.

Andrews, P., 1990. Owls, caves and fossils. Predation, preservation, and accumulation of small mammal bones in caves, with the analysis of the Pleistocene cave faunas from Westbury-sub-Mendip, Somerset, UK. The University of Chicago Press. 231 pp.

Andrews, P. y Evans E.M., 1983. Small mammal bone accumulations produced by mammalian carnivores. Paleobiology 9 (3): 289-307.

Andrews, P. y Fernández Jalvo, Y., 1997. Surface modifications of the Sima de los Huesos fossil humans. Journal of Human Evolution 33: 191-217.

Badgley, C., 1986. Counting individuals in mammalian fossil assemblages from fluvial environments. Palaios 1: 328-338.

Behrensmeyer, A.K., 1978. Taphonomic and ecologic information from bone weathering. Palaeobiology 4: 150-162.

Behrensmeyer, A.K., 1991. Terrestrial Vertebrate accumulations. En Allison y Briggs (eds.). Taphonomy: Realising the data locked in the fossil record. Topics in Geobiology. Plenum Press, New York, 9: 291-335.

Behrensmeyer, A.K. y Chapman, R., 1993. Models and simulations of time-averaging in terrestrial vertebrate accumulations. En Kidwell y Behrensmeyer (eds.). Taphonomic approaches to time resolution in fossil assemblages. Short courses in paleontology 6: 125149.

Behrensmeyer, A.K., Gordon, K. y Yanagi, G., 1989. Nonhuman bone modification in Miocene fossils from Pakistan. En Bonnichsen y Sorg (eds.). Bone modification, Peoples of the Americas Publications, Maine: 99-120.

Behrensmeyer, A.K., Stayton, C. y Chapman, R., 2003. Taphonomy and ecology of modern avifaunal remains from Amboseli Park, Kenya. Paleobiology 29 (19): 52-70.

Birkeland, P.W., 1984. Soils and geomorphology. Oxford University Press, New York, 372 pp. 
Blasco Sancho, M.F., 1992. Tafonomía y prehistoria. Métodos y procedimientos de investigación. Universidad de Zaragoza, 254 pp.

Blasco Sancho, M.F., 1995. Hombres, fieras y presas. Estudio arqueozoológico y tafonómico del yacimiento del Paleolítico medio de la Cueva de Gabasa 1 (Huesca). Universidad de Zaragoza. Monografías arqueozoológicas Nº 38. 205 pp.

Bond, M., Cerdeño, E. y López, G., 1995. Los ungulados nativos de América del Sur. En Alberti, Leoni y Tonni (eds). Evolución biológica y climática de la región pampeana durante los últimos cinco millones de años. Un ensayo de correlación con el Mediterráneo occidental. Monografías. Museo Nacional de Ciencias Naturales y Consejo Superior de Investigaciones Científicas: $257-275$.

Bondesio, P., Laza, J., Scillato Yané, G., Tonni, E. y Vucetich, M., 1980. Estado actual del conocimiento de los vertebrados de la Formación Arroyo Chasicó (Plioceno temprano) de la provincia de Buenos Aires. II Congreso Argentino de Paleontología y Bioestratigrafía, Actas y I Congreso Latinoamericano de Paleontología III: 101-127.

Bown, T. y Kraus, M., 1981. Vertebrate fossil-bearing paleosol units (Willwood Formation, Lower Eocene, Northwest Wyoming, U.S.A.): implications for taphonomy, biostratigraphy, and assemblage analysis. Palaeogeography, Palaeoclimatology, Palaeoecology 34: 31-56.

Bown, T. y Larriestra, C., 1990. Sedimentary paleoenvironments of fossil platyrrhine localities, Miocene Pinturas Formation, Santa Cruz Province, Argentina. Journal of Human Evolution 19: 87-119.

Brain, C.K.,1980. Some criteria for the recognition of bone collecting agencies in African Caves. En Behrensmeyer y Hill (eds.). Fossils in the making: vertebrate taphonomy and paleoecology, University of Chicago Press: 107-130.

Brewer, R., 1964. Fabric and mineral analysis of soils. Wiley and Sons, New York. 482 pp.

Cabrera, A., 1939. Sobre vertebrados fósiles del Plioceno de Adolfo Alsina. Revista del Museo de La Plata 2 (6):3-35.

Campbell, K. y Tonni, E., 1980. A new genus of teratorn from the Huayquerian of Argentina (Aves: Teratornithidae). Contributions in Sciences (330): 59-68.

Campbell, K. y Tonni, E., 1981. Preliminary observations on the paleobioloby and evolution of teratorns (Aves: Teratornithidae). Journal of Vertebrate Paleontology 1 (3-4): 265-272.

Cano, E., 1980. Inventario integrado de los recursos naturals de la provincia de La Pampa. Clima, geomorfología, suelo y vegetación. INTA, Provincia de La Pampa y UNLPam.

Cerdeño, E. y Bond, M., 1998. Taxonomic revision and phylogeny of Paedotherium and Tremacillus (Packyrukhinae, Hegetotheriidae, Notoungulata) from the Late Miocene to the Pleistocene of Argentina. Journal of Vertebrate Paleontology 18: 799-811. 
Cerdeño, E. y Montalvo, C.I., 2001. Los Mesotheriinae (Mesotheriidae, Notoungulata) del Mioceno superior de La Pampa, Argentina. Revista Española de Paleontología 16 (1): 63-75.

Cerdeño, E. y Montalvo, C.I., 2002. Los Hegetotheriinae (Hegetotheriidae, Notoungulata) del Mioceno superior de la provincia de La Pampa, Argentina. Revista del Museo Argentino de Ciencias Naturales, n. s. 4 (1): 35-43.

Contreras, J.R., 1964. Datos acerca de la variación intrapoblacional de la morfología de los molares de las entidades de los géneros Galea y Microcavia (Rodentia, Caviidae). Ameghiniana 3 (8): 235-255.

Cuezva, S. y Élez, J., 2000. Reconocimiento del estadio de desarrollo en la microestructura de los huesos fósiles de mamíferos. (Somosaguas y Layna). Coloquios de Paleontología (Universidad Complutense de Madrid) 51: 159-174.

Diez, J.C., Fernández Jalvo, Y., Rosell, J. y Cáceres, I., 1999. Zooarchaeology and taphonomy of Aurora Stratum (Gran Dolina, Sierra de Atapuerca, Spain). Journal of Human Evolution 37: 623- 652.

Doering, A., 1882. Geología. En: Informe oficial de la Comisión Científica agregada al Estado Mayor General de la expedición al Río Negro (Patagonia). III: 300-530. Buenos Aires.

Dodson, P., 1973. The significance of small bones in paleoecological interpretation. Contrib. Geol. Univ. Wyoming 12: 15-19.

Downing, K. y Park, L., 1998. Geochemistry and early diagenesis of mammal-bearing concretions from the Sucker Creek Formation (Miocene) of Southeastern Oregon. Palaios 13: 13-27.

Efremov, I., 1940. Taphonomy: a new branch of paleontology. Pan-American Geologist 74: 81-93.

Esteban, G., Nasif, N. y Montalvo, C.I., 1996. Nuevos registros de Dasypodidae (Edentata) del Terciario tardío (Huayqueriense) de la provincia de La Pampa. Ameghiniana 33 (4): 464.

Esteban, G., Nasif, G. y Montalvo, C.I., 2001. Nuevos registros de Dasypodidae (Xenarthra) del Mioceno tardío de la provincia de La Pampa, Argentina. Revista Española de Paleontología 16 (1): 77-87.

Esteban, G., Nasif, N.; Montalvo, C.I. y Visconti, G., 2003. Nuevos registros de Dasypodidae (Xenarthra) para la Formación Cerro Azul, Terciario tardío de la provincia de La Pampa, Argentina. Ameghiniana 40 (3): 495-499.

Fawcett, D.W., 1995. Tratado de Histología. Interamericana Mc Graw-Hill, Madrid. 1044 pp.

Fernández Jalvo, Y., 1995. Small mammal taphonomy at La Trinchera de Atapuerca (Burgos, Spain). A remarkable example of taphonomic criteria used for stratigraphic correlations and palaeoenvironment interpretations. Paleoegeography, Palaeoclimatology, Palaeoecology 114: 167-195. 
Fernández Jalvo, Y., 1996. Small mammal taphonomy and the middle Pleistocene environment of Dolina, Northern Spain. Quaternary International 33: 21-34.

Fernández Jalvo, Y. y Andrews, P., 1992. Small mammal taphonomy of Gran Dolina, Atapuerca (Burgos), Spain. Journal of Archaeological Science 19: 407-428.

Fernández Jalvo, Y., Denys, C., Andrews, P., Williams, T., Dauphin, Y y Humphrey, L., 1998. Taphonomy and palaeoecology of Olduvai Bed-I (Pleistocene, Tanzania). Journal of Human evolution 34: 137-172.

Fernández Jalvo, Y. y Sánchez Chillón, B., 2000. Experimental etching of human teeth in alkaline and acid environment. Taphonomy and diagenesis Newsletter, $N^{\circ} 7$, Special issue 9.

Fernández López, S., 1984. Criterios elementales de reelaboración tafonómica en amonites de la Cordillera Ibérica. Acta Geológica Hispánica 19 (2): 105-116.

Fernández López, S., 1988. La Tafonomía: un subsistema conceptual de la Paleontología. Coloquios de Paleontología (Universidad Complutense de Madrid): 41 (1986-87):9-13.

Fernández López, S., 1989. La materia fósil. Una concepción dinamicista de los fósiles. En Aguirre (ed.). Nuevas tendencias en Paleontología. CSIC, Madrid: 25-45.

Fernández López, S., 1991. Taphonomic concepts for a theoretical biochronology. Revista Española de Paleontología 6: 37-49.

Fernández López, S., 2000. Temas de Tafonomía. Departamento de Paleontología, Universidad Complutense de Madrid, $167 \mathrm{pp}$.

Fernández López, S. y Fernández Jalvo, Y., 2002. The limit between biostratinomy and fossildiagenesis. En De Renzi, Pardo Alonso, Belinchón, Peñalver, Montoya y MárquezArriaga (eds). Current Topics on Taphonomy and Fossilization, Valencia: 27-36.

Flinn, D., 1978. Construction and computation of three-dimensionals progessive deformations. Journal of Geological Society London 135: 291-305.

Genise, J.F., 1989. Las cuevas de Actenomys (Rodentia, Octodontidae) de la Formación Chapadmalal (Plioceno superior) de Mar del Plata y Miramar (provincia de Buenos Aires). Ameghiniana 26 (1-2): 33-42.

Giallombardo, A., Castro, P., Ortiz Jaureguizar, E. y Bond, M., 2002. Estimación de la masa corporal de los Pachirukhinae (Notoungulata, Hegetotheriidae) y análisis de su patrón a través del tiempo. VIII Congreso Argentino de Paleontología y Bioestratigrafía, Resúmenes: 100.

Gifford-Gonzalez, D., 1989. Ethnographic analogues for interpreting modified bones: some cases from East Africa. En Bonnichsen y Sorg (eds.). Bone modification, Peoples of the Americas Publications, Maine: 179-246. 
Goddard, E., Trask, P., De Ford, R., Rove, O., Singewald, J. y Overbeck, R., 1948. Rock Color Chart. Geological Society of America, Boulder.

Goin, F. y Montalvo, C.I., 1988. Revisión sistemática y reconocimiento de una nueva especie del género Thylatheridium Reig (Marsupialia, Didelphidae). Ameghiniana 25 (2): 161-167.

Goin, F., Montalvo, C.I. y Visconti, G., 1997. Los Marsupiales de la Formación Cerro Azul (Mioceno tardío), provincia de La Pampa, Argentina. Ameghiniana 34 (4): 536.

Goin, F., Montalvo, C. I. y Visconti, G., 2000. Los Marsupiales (Mammalia) del Mioceno Superior de la Formación Cerro Azul (provincia de La Pampa, Argentina). Estudios Geológicos 56 (1-2): 101-126.

Goin, F.J. y Pardiñas, U.F.J., 1996. Revisión de las especies del género Hyperdidelphys Ameghino, 1904 (Mammalia, Marsupialia, Didelphidae). Su significación filogenética, estratigráfica y adaptativa en el Neógeno del Cono Sur sudamericano. Estudios Geológicos 52: 327-359.

Gómez, G.N., 2000. Análisis tafonómico y paleoecológico de los micro y mesomamíferos del sitio arqueológico de Arroyo Seco 2 (Buenos Aires, Argentina) y su comparación con la fauna actual. Departamento de Biología Animal I. Facultad de Ciencias Biológicas. Universidad Complutense de Madrid. España. Tesis Doctoral Inédita.

Gordon, C. y Buikstra, J., 1981. Soil pH, bone preservation, and sampling bias at mortuary sites. Amarican Antiquity 46 (3): 566-570.

Haynes, G., 1980. Evidence of carnivore gnawing on Pleistocene and Recent mammalian bones. Paleobiology, 6 (3): 341-351.

Hershkovitz, P., 1990. Mice of the Akodon boliviensis size class (Sigmodontinae, Cricetidae), with the description of two species from Brasil. Fieldiana Zoology, new series 57: 1-35.

Hockett, B.S., 1996. Corroded, thinned and polished bones created by Golden Eagles (Aquila chryasetos): taphonomic implications for archaeological interpretations. Journal of Archaeological Science 23: 587-591.

Hoffstetter, R., 1958. Xenarthra. En Piveteau (ed). Traité de Paléontologie, Paris. 6 (2): 535-636.

Hunt, A., Chin, K. y Lockey, M. 1994. The paleobiology of vertebrate coprolites. En Donovan (ed.) The paleobiology of trace fossils: 221-240.

James, N.P. y Choquette, P.W., 1990. Limestones. The meteoric diagenetic environment. En Mc Ilreath y Morrow (eds.). Diagenesis. Geoscience Canada. Reprint Series 4: 35-73.

Klappa, C., 1980. Rhizoliths in terrestrial carbonates: classification, recognition, genesis and significance. Sedimentology 27: 613-629. 
Korth, W., 1979. Taphonomy of microvertebrate fossil assemblages. Annals of Carnegie Museum 48: 235-285.

Kraglievich, L., 1932. Diagnosis de nuevos géneros y especies de Roedores Cávidos y Eumegámidos fósiles en la República Argentina. Anales Sociedad Científica Argentina 114 (4): 155-181.

Kraglievich, L., 1934. La antigüedad pliocena de las faunas de Monte Hermoso y Chapadmalal, deducidas en comparación con las que le precedieron y sucedieron. El Siglo llustrado, Montevideo: 17-133.

Laza, J., 1982. Signos de actividad atribuíbles a Atta (Myrmicidae, Hymenoptera) en el Mioceno de la provincia de La Pampa, República Argentina. Significación paleozoogeográfica. Ameghiniana 19 (1-2): 109-124.

Linares, E., Llambías, E. y Latorre, C., 1980. Geología de la provincia de La Pampa, República Argentina y geocronología de sus rocas metamórficas y eruptivas. Revista de la Asociación Geológica Argentina. 35 (1): 87-146.

Lyman, R.L., 1994 Vertebrate Taphonomy. Cambridge manuals in archaeology. Cambridge University Press. Cambridge. 524 pp.

Lyman, R.L., Power, E. y Lyman, J., 2003. Quantification and sampling of faunal remains in owl pellets. Journal of Taphonomy 1 (1): 3-14.

Llambías, E., 1975. Geología de la provincia de La Pampa y su aspecto minero. Inf. inédito. Dirección de Minas de la provincia de La Pampa, Santa Rosa.

Malme, G.O.A., 1926. Lichenes blasteneiopori Herbario Regnelliano. Arkiv for Botanik. 20 (9): $1-51$.

Martin, R.A., 1993. Patterns of variation and speciation in Quaternary rodents. En Martin y Barnosky (eds.). Morphological change in Quaternary mammals of North America. Cambridge University Press, New York: 226-280.

Melchor, R., Visconti, G. y Montalvo, C.I., 2000. Late Miocene calcic vertisols from central La Pampa, Argentina. II Congreso Latinoamericano de Sedimentología y VII Reunión Argentina de Sedimentología: 119-120.

Mellet, J.S., 1974. Scatological origin of microvertebrate fossil accumulations. Science 185: 349-350.

Mikulas, R., 1999. Notes to the concept of plant trace fossils related to plant - generated sedimentary structures. Bulletin of the Czech Geological Survey 74 (1): 39-42.

Mones, A., 1986. Palaeovertebrata Sudamericana. Catálogo Sistemático de los Vertebrados Fósiles de América del Sur. Parte I. Lista preliminar y bibliografía. Cour. Forsch. Senckenberg Franckfurt a M., 82: 1-625. 
Montalvo, C.I., 2001. Evidencias de la acción de un depredador sobre restos recuperados de la Formación Cerro Azul en Caleufú, La Pampa, Argentina (Mioceno superior - Plioceno inferior). Ameghiniana 38 (4): 37R.

Montalvo, C.I., 2002 a. Root traces in fossil bones from the Huayquerian (Late Miocene) faunal assemblage of Telén, La Pampa, Argentina. Acta Geologica Hispanica 37 (1): $37-42$.

Montalvo, C.I., 2002 b. Taphonomic analysis of the Mio-Pliocene micromammal assemblage (Cerro Azul Formation), Caleufú, La Pampa, Argentina. En De Renzi, Pardo Alonso, Belinchón, Peñalver, Montoya y Márquez-Arriaga (eds.). Current Topics on Taphonomy and Fossilization, Valencia: 353- 359.

Montalvo, C.I. y Casadío, S., 1988. Presencia del género Palaeoctodon (Rodentia, Octodontidae) en el Huayqueriense (Mioceno tardío) de la Provincia de La Pampa. Ameghiniana 25 (2): 111-114.

Montalvo, C.I., Cardonatto, M.C., Visconti, G., Verzi, D.H. y Vucetich, M.G., 1996. Vertebrados de la Formación Cerro Azul (Mioceno tardío) del Valle de Quehué, provincia de La Pampa, Argentina. VI Jornadas Pampeanas de Ciencias Naturales: 159-165.

Montalvo, C. I. y Cerdeño, E., 2002. Estudio de los Hegetotheriinae (Hegetotheriidae, Notoungulata) del Mioceno Superior de La Pampa, Argentina. Ameghiniana 39 (4): 14R.

Montalvo, C. y Rocha, A., 2001. Presencia de Neocavia lozanoi Kraglievich (Rodentia, Caviidae) en el Mioceno superior - Plioceno inferior de La Pampa, Argentina. Ameghiniana 38 (4): $37 R$.

Montalvo, C.I. y Rocha, A., 2003. Presencia de Neocavia Kraglievich (Rodentia, Caviidae) en la formación Cerro Azul (Mioceno superior - Plioceno inferior?) de La Pampa, Argentina. Ameghiniana 40 (3): 501-504.

Montalvo, C.I. y Rosato, V., 2002. Corrosión sobre restos óseos de la asociación faunística del Mioceno tardío recuperada en Caleufú, La Pampa. VIII Jornadas Pampeanas de Ciencias Naturales: 151-153.

Montalvo, C.I. y Verzi, D.H., 2002. Un nuevo Neophanomys (Rodentia, Octodontidae) de la Formación Cerro Azul en Caleufú, La Pampa. VIII Jornadas Pampeanas de Ciencias Naturales: 155-156.

Montalvo, C.I., Verzi, D.H., Casadío, S., Tiranti, S. y Visconti, G., 2000 a. Hallazgo de novedosos roedores en la Formación Cerro Azul en el norte de La Pampa, Argentina. Implicancias bioestratigráficas. Ameghiniana 37 (4): 30R.

Montalvo, C.I., Verzi, D.H. y Tiranti, S., 2000 b. Un nuevo Xenodontomys (Rodentia, Octodontidae) de la Formación Cerro Azul en Caleufú (La Pampa, Argentina). Ameghiniana 37 (4): $75 R$. 
Montalvo, C.I., Verzi, D.H. y Vucetich, M.G., 1999. Nuevos datos sobre los pequeños Octodontidae (Rodentia, Caviomorpha) del Mioceno tardío de Argentina. Ameghiniana 36 (1): 106.

Montalvo, C.I., Verzi, D.H., Vucetich, M.G. y Visconti, G., 1998. Nuevos Eumysopinae (Rodentia, Echimyidae) de la Formación Cerro Azul (Mioceno tardío) de La Pampa, Argentina. Quintas Jornadas Geológicas y Geofísicas Bonaerenses 1: 57-64.

Montalvo, C.I., Visconti, G., Pugener, L. y Cardonatto, M.C., 1995. Mamíferos de Edad Huayqueriense (Mioceno tardío), Laguna Chillhué, provincia de La Pampa. IV Jornadas Geológicas y Geofísicas Bonaerenses 1: 73-79.

Montalvo, C.I. y Szelagowski, M., 1999. Vertebrados del Mioceno superior en la Colección Paleontológica de la Universidad Nacional de La Pampa. VII Jornadas Pampeanas de Ciencias Naturales: 233-242.

Morales, A., 1987. Problemas de interpretación de los datos faunísticos procedentes de los yacimientos. II Congreso de Arqueología Medieval Española: 34-45.

Olsen, S.L. y Shipman, P., 1988. Surface modification of bone: trampling versus butchery. Journal of Archaeological Science 15: 535-553.

Ortega Hinojosa, E., 1967. Descripción de los restos de un Scelidotheriinae (Edentata, Mylodontidae) de edad Huayqueriense. Algunas consideraciones en torno a la filogenia de los Scelidotheriinae. Ameghiniana 5 (3): 109-120.

Ortiz Jaureguizar, E., 1998. Paleoecología y evolución de la fauna de Mamíferos de América del Sur durante la "Edad de las Planicies Australes" (Mioceno Superior-Plioceno Superior). Estudios Geológicos 54: 161-169.

Palmqvist, P., Arribas, A. y Arrébola, R., 1999. La descodificación de la información tafonómica como un mecanismo para recuperar la información paleobiológica encriptada en el registro fósil: el ejemplo de Venta Micena. Temas Geológico-Mineros ITGE, 26: 284-289.

Palmqvist, P. y Arribas, A., 2001. Taphonomic decoding of the paleobiological information locked in a Lower Pleistocene assemblage of large mammals. Paleobiology 27 (3): 512-530.

Pardiñas, U.F.J., 1997. Un nuevo sigmodontino (Mammalia: Rodentia) del Plioceno de Argentina y consideraciones sobre el registro fósil de los Phyllotini. Revista Chilena de Historia Natural 70 (4): 543-555.

Pardiñas, U.F.J., D’Elía, G. y Ortiz, P.E., 2002. Sigmodontinos fósiles (Rodentia, Muroidea, Sigmodontinae) de América del Sur: estado actual de su conocimiento y prospectiva. Mastozoología Neotropical 9 (2): 209-252.

Pardiñas, U.F.J. y Tonni, E., 1998. Procedencia estratigráfica y edad de los más antiguos muroideos (Mammalia, Rodentia) de América del Sur. Ameghiniana 35 (4): 473-475. 
Pascual, R., 1961. Un nuevo Cardiomyinae (Rodentia, Caviidae) de la Formación Arroyo Chasicó (Plioceno inferior) de la Provincia de Buenos Aires. Ameghiniana 2 (4): 61-71.

Pascual, R. y Bocchino, A., 1963. Un nuevo Borhyaeninae (Marsupialia) del Plioceno medio de Hidalgo (La Pampa). Ameghiniana 3 (4): 97-107.

Pascual, R. y Bondesio, P., 1982. Un roedor Cardiatheriinae (Hydrochoeridae) de la Edad Huayqueriense (Mioceno tardío) de La Pampa. Sumario de los ambientes terrestres en la Argentina durante el Mioceno. Ameghiniana 19 (1-2): 19-35.

Pascual, R. y Ortiz Jaureguizar, E., 1990. Evolving climates and mammal faunas in Cenozoic South America. Journal of Human Evolution 19: 23-60.

Pascual, R., Ortiz Jaureguizar, E. y Prado, J., 1996. Land mammals: paradigm for Cenozoic South America geobiotic evolution. En Arratia (ed.). Contributions of Southern South America to Vertebrate Paleontology. Münchner Geowissenschattliche Abhandlungen 30: 265-319.

Pascual, R., Pisano, J. y Ortega, E., 1965. Un nuevo Octodontidae (Rodentia, Caviomorpha) de la Formación Epecuén (Plioceno medio) de Hidalgo (Provincia de La Pampa). Ameghiniana 4 (1): 19-30.

Peña, M.I.,1997. Tafonomía de restos óseos y condiciones ambientales del Plioceno tardío, Playa San Carlos (Partido de General Pueyrredón). Tesis de Grado de la Universidad de Mar del Plata. 37 pp. Inédito.

Quintana, C., 1996. Diversidad del roedor Microcavia (Caviomorpha, Caviidae) de América del Sur. Mastozoología Neotropical 3 (1): 63-86.

Redford, K.H. y Eisenberg, J.F., 1992. Mammals of the Neotropics. The Southern cone. Vol. 2. The University of Chicago Press. $430 \mathrm{pp}$.

Retallack, G., 1988. Down-to-earth approaches to Vertebrate paleontology. Palaios 3: 335344.

Retallack, G., 1990. Soils of the past. Han introduction to paleopedology. Unwin Hyman, Boston. 520 pp.

Rocha, A. M. y Montalvo, C.I., 1999. Variabilidad morfológica de los molariformes inferiores de Kiyutherium (Rodentia, Hydrochoeridae, Cardiatheriinae). VII Jornadas Pampeanas de Ciencias Naturales: 279-287.

Rosato, V.G., 2001. Degradación del hormigón por acción liquénica. XIV Reunión de la Asociación Argentina de Tecnología del Hormigón: 97-103.

Rovereto, C., 1914. Los estratos araucanos y sus fósiles. Anales del Museo Nacional de Historia Natural 25:1-247.

Rusconi, C., 1933. New Pliocene remains of diprotodont marsupials from Argentina. Journal of Mammalogy 14: 244-250. 
Rusconi, C., 1934. Algunos fósiles terciarios de la Gobernación de La Pampa, Argentina. Revista Chilena de Historia Natural 38: 104-107.

Salso, J.H., 1966. La cuenca de Macachín, provincia de La Pampa. Nota preliminar. Revista Asociación Geológica Argentina 21 (2): 107-117.

Scillato-Yané, G.J., 1982. Los Dasypodidae (Mammalia-Edentata) del Plioceno y Pleistoceno de Argentina. Facultad de Ciencias Naturales y Museo. Universidad Nacional de La Plata, Tesis Doctoral Inédita, 159 pp.

Shipman, P.L., 1981. Life history of a fossil: an introduction to taphonomy and paleoecology. Harvard University Press, Cambridge.

Simpson, G.G., 1970. Additions to knowledge of the Argyrolagidae (Mammalia, Marsupialia) from the late Cenozoic of Argentina. Breviora 361: 1-9.

Simpson, G.G., 1974. Notes on the Didelphidae (Mammalia, Marsupialia) from the Huayquerian (Pliocene) of Argentina. American Museum Novitates 2259: 1-15.

Soil Survey Staff, 1975. Soil Taxonomy. A basic system for making and interpreting soil surveys, United States Department of Agriculture handbook 436.

Soria, M., 2001. Los Proterotheriidae (Litopterna, Mammalia), sistemática, origen y filogenia. Monografías del Museo Argentino de Ciencias Naturales 1: 1-167.

Stahl, P., 1996. The recovery and interpretation of microvertebrate bone assemblages from archaeological contexts. Journal of Archaeological Method and Theory 3 (1): 31-75.

Stappenbeck, R., 1926. Geologie und Grundwasserkunde der Pampa. Stuttgart. Alemania.

Straccia, P.C., 2000. Hábitos nocturnos de Paedotherium (Mammalia, Notoungulata, Hegetotheriidae, Pachyrukhinae) de las unidades pliocenas de los acantilados de Chapadmalal, Buenos Aires, Argentina. Ameghiniana 37 (4): 79 R.

Tambussi, C., 1987. Catálogo crítico de los Tinamidae (Aves: Tinamiformes) fósiles de la República Argentina. Ameghinana 24 (3-4): 241-244.

Tauber, A.A., 1997 a. Paleoecología de la Formación Santa Cruz (Mioceno Inferior) en el extremo sudeste de la Patagonia. Ameghiniana 34 (4): 517-529.

Tauber, A.A., 1997 b. Bioestratigrafía de la Formación Santa Cruz (Mioceno Inferior) en el extremo sudeste de la Patagonia. Ameghiniana 34 (4): 413-426.

Traversa, L.P., Rosato, V.G. y Cabello, M.N., 2000. The action of Caloplaca citrina on concrete surfaces: a preliminary study. En Fascina (ed.) Proceedings of the 9th International Congress on the deterioration and concervation of stone. 
Tuross, N., Behrensmeyer, A.K., Eanes, E., Fisher, L. y Hare, P., 1989. Molecular preservation and crystallographic alterations in a weathering sequense of wildebest bones. Applied Geochemistry 4: 261-270.

Verzi, D.H., 1994. Origen y evolución de los Ctenomyinae (Rodentia, Octodontidae): un análisis de anatomía cráneo-dentaria. Facultad de Ciencias Naturales y Museo. Universidad Nacional de La Plata (Tesis Doctoral Inédita) Vol. I: 222 pp., Vol. II: 17 pp.

Verzi, D.H., 1999. The dental evidence on the differentiation of the ctenomyine rodents (Caviomorpha, Octodontidae, Ctenomyinae). Acta Theriologica 44 (3): 263-282. Bialowieza.

Verzi, D.H., 2002. Patrones de evolución morfológica en Ctenomyinae (Rodentia, Octodontidae). Mastozoología Neotropical 9 (2): 309-328.

Verzi, D.H., Montalvo, C.I. y Tiranti, S.I., 2003. Un nuevo Xenodontomys (Rodentia, Octodontidae) del Mioceno tardío de La Pampa, Argentina. Patrón evolutivo y bioestratigrafía. Ameghiniana 40 (2): 229-238.

Verzi, D., Montalvo, C.I. y Vucetich, M.G., 1990. La sistemática de los más antiguos Ctenomyinae (Rodentia, Octodontidae) del Mioceno superior. Ameghiniana 27 (3-4): 391.

Verzi, D.H., Montalvo, C.I. y Vucetich, M.G., 1991. Nuevos restos de Xenodontomys simpsoni Kraglievich y la sistemática de los más antiguos Ctenomyinae (Rodentia, Octodontidae). Ameghiniana 28 (3-4): 325-331.

Verzi, D.H., Montalvo, C.I. y Vucetich, M.G., 1996. Estado sistemático, afinidades y significado evolutivo del octodóntido Neophanomys biplicatus del Mioceno tardío-Plioceno temprano? de Argentina (Rodentia, Caviomorpha). Ameghiniana 33 (4): 472.

Verzi, D.H., Montalvo, C.I. y Vucetich, M.G., 1999 a. Afinidades y significado evolutivo de Neophanomys biplicatus (Rodentia, Octodontidae) del Mioceno tardío-Plioceno temprano de Argentina. Ameghiniana 36 (19): 83-90.

Verzi, D.H., Montalvo, C.I. y Vucetich, M.G., 1999 b. La morfología de Pampamys y la diferenciación del viviente Thrichomys (Rodentia, Echimyidae). Ameghiniana 36 (4): 23R.

Verzi, D.H.; Vieytes, E.C. y Montalvo, C.I., en prensa. Dental evolution in Xenodontomys and first notice on secondary acquisition of radial enamel in rodents (Rodentia, Caviomorpha, Octodontidae). Geobios.

Verzi, D.H., Vucetich, M.G. y Montalvo, C.I., 1993. Dos nuevos Eumysopinae (Rodentia, Echimyidae) de la Formación Cerro Azul (Mioceno tardío) de La Pampa y consideraciones acerca de la historia de la subfamilia. V Jornadas Pampeanas de Ciencias Naturales: 50.

Verzi, D., Vucetich, M.G. y Montalvo, C.I., 1994. Octodontid-like Echimyidae (Rodentia): an upper Miocene episode in the radiation of the family. Palaeovertebrata 23 (1-4): 199-210. 
Verzi, D.H., Vucetich, M.G. y Montalvo, C.I., 1995. Un nuevo Eumysopinae (Rodentia, Echimyidae) del Mioceno tardío de la provincia de La Pampa y consideraciones sobre la historia de la subfamilia. Ameghiniana 32 (2): 191-195.

Visconti, G., Montalvo, C.I., Cardonatto, M.C. y Pugener, L., 1996. Análisis sedimentológico e interpretación paleoambiental de la Formación Cerro Azul (Mioceno tardío) en el Valle Argentino, provincia de La Pampa. VI Jornadas Pampeanas de Ciencias Naturales: 86-88.

Vizcaíno, S.F. y De luliis, G., 2003. Evidence for advanced carnivory in fossil armadillos (Mammalia, Xenarthra, Dasypodidae). Paleobiology 29 (1): 123- 138.

Vizcaíno, S.F. y Fariña, R., 1997. Diet and locomotion of the armadillo Peltephilus: a new view. Lethaia 30: 79-86.

Vizcaíno, S.F. y Fariña, R., 1999. On the flight capabilities and distribution of the giant Miocene bird Argentavis magnificens (Teratornithidae). Lethaia 32: 271-278.

Vucetich, M.G. y Verzi, D.H., 1995. Los roedores Caviomorpha. En Alberti, Leoni y Tonni (eds). Evolución biológica y climática de la región pampeana durante los últimos cinco millones de años. Un ensayo de correlación con el Mediterráneo occidental. Monografías. Museo Nacional de Ciencias Naturales y Consejo Superior de Investigaciones Científicas: 213-215.

Vucetich, M.G. y Verzi, D.H., 1996. Un nuevo Eumysopinae (Rodentia, Echimyidae) de la "Formación" Irene (Chapadmalalense inferior?) y la diversidad de la subfamilia. IV Jornadas Geológicas y Geofísicas Bonaerenses 1: 15-22.

Wrigth, P. y Tucker, M., 1991. Calcretes. The International Association of Sedimentologist.

Wood, W.R. y Johnson, D.L., 1978. A survey of disturbance proceses in archaeological site formation. Advances in archaeological method and theory. 1: 315-381.

Zetti, J., 1967. Sobre la presencia del género Marmosa (Didelphidae, Marsupialia) en sedimentos de la Formación Epecuén (Plioceno medio). Ameghiniana 5 (5):169-173.

Zetti, J., 1972 a. Los mamíferos fósiles de Edad Huayqueriense (Plioceno medio) de la región pampeana. Facultad de Ciencias Naturales y Museo, Universidad Nacional de la Plata (Tesis Doctoral Inédita $n^{\circ} 304$ ).

Zetti, J., 1972 b. Un nuevo Paquiruquino de la región pampeana. Revista Museo Municipal de Ciencias Naturales de Mar del Plata 2 (2):41-56. 